\title{
Growth factors in myocardial ischemia : focus on FGF- 1 and IGF-1
}

Citation for published version (APA):

Palmen, M. (2003). Growth factors in myocardial ischemia : focus on FGF-1 and IGF-1. [Doctoral Thesis, Maastricht University]. Universiteit Maastricht. https://doi.org/10.26481/dis.20030207mp

Document status and date:

Published: 01/01/2003

DOI:

10.26481/dis.20030207mp

Document Version:

Publisher's PDF, also known as Version of record

\section{Please check the document version of this publication:}

- A submitted manuscript is the version of the article upon submission and before peer-review. There can be important differences between the submitted version and the official published version of record.

People interested in the research are advised to contact the author for the final version of the publication, or visit the DOI to the publisher's website.

- The final author version and the galley proof are versions of the publication after peer review.

- The final published version features the final layout of the paper including the volume, issue and page numbers.

Link to publication

\footnotetext{
General rights rights.

- You may freely distribute the URL identifying the publication in the public portal. please follow below link for the End User Agreement:

www.umlib.nl/taverne-license

Take down policy

If you believe that this document breaches copyright please contact us at:

repository@maastrichtuniversity.nl

providing details and we will investigate your claim.
}

Copyright and moral rights for the publications made accessible in the public portal are retained by the authors and/or other copyright owners and it is a condition of accessing publications that users recognise and abide by the legal requirements associated with these

- Users may download and print one copy of any publication from the public portal for the purpose of private study or research.

- You may not further distribute the material or use it for any profit-making activity or commercial gain

If the publication is distributed under the terms of Article $25 \mathrm{fa}$ of the Dutch Copyright Act, indicated by the "Taverne" license above, 


\section{Growth factors in myocardial ischemia; Focus on FGF-1 and IGF-1}





\section{Growth factors in myocardial ischemia Focus on FGF-1 and IGF-1}

\section{PROEFSCHRIFT}

ter verkrijging van de graad van doctor aan de Universiteit Maastricht, op gezag van de Rector Magnificus, Prof. dr. A.C. Nieuwenhuijzen Kruseman, volgens het besluit van het College van Decanen, in het openbaar te verdedigen

op vrijdag 7 februari 2003 om 12.00 uur

door

Meindert Palmen

Geboren op 25 juni 1976 te Heerlen 


\section{Promotones}

Prof. dr. MJ.A.P. Daemen

Prof. dr. H.J.J. Wellens

\section{Co-promotor}

Dr. P.A.F.M. Doevendans

\section{Beoordelingscommissie}

Prof. dr. B. Mochtar (voorzitter)

Prof. dr. M. Borgers

Prof. dr. A. van der Laarse (Leids Universitair Medisch Centrum)

Prof. dr. M. Post

Prof. dr. W. Schaper (Max Planck Institute, Bad Nauheim, Germany)

Financial support by the Netherlands Heart Foundation for the publication of this thesis is gratefully acknowledged.

Additional financial support for the publication of this thesis by, Stichting Rescar, TD Medical, Medtronic B.V, Pfizer, Sanofi-Synthelabo, Bristol-MyersSquibb, AB Medical, and Astra Zenica is also gratefully acknowledged

(c) Meindert Palmen, Maastricht 2003

ISBN $9016642-4$

Vormgeving: Geertian van Zonneveld, PgAV azM

Druk: Schrijen Huntjens, Voerendaal 
Want tussen droom en daad,

Staan wetten in de weg en praktische bezwaren, En ook weemoedigheid,

Die niemand kan verklaren,

En die des avonds komt,

Wanneer men slapen gaat.

(Willem Elsschot)

Waarnemen is het begin van alle verbazing (mijn vader) 



\section{Contents}

Chapter 1 Introduction 8

Chapter 2 Cardliac angiogenesis and growth factors.

Chapter 3 Cardiac remodeling after myocardial infarction is impaired in IGF-1 deficient mice.

Chapter 4 IGF-1 improves cardiac functional recovery and enhances cell survival during ischemia and reperfusion;

a PI-3K and PKC mediated mechanism.

Chapter 5 Cardiac-specific overexpression of hFGF-1 deteriorates cardiac function and alters remodeling following chronic myocardial infarction in mice.

Chapter 6 Fibroblast growth factor-1 improves cardiac functional recovery and enhancescell survival following ischemia and reperfusion; a FGF-R1, PKC and tyrosine kinase dependent mechanism.

Chapter 7 General discussion and future outlook.

Summary

Samenvatting

Dankwoord 


\section{Chapter 1 Introduction}




\section{Pathophysiology of myocardial infarction and failure}

\section{Etiology}

Despite all efforts, cardiovascular disease is still the leading cause of mortality and morbidity in the western world.' One of the most dramatic features is the occurrence of an acute myocardial infarction (MI). Rupture of an unstable atherosclerotic plaque causes local thrombus formation and occlusion of the coronary artery, blocking perfusion of the myocardial tissue previously nurtured by this vessel. The subsequent lack of oxygen and nutrients results in rapid death of cardiac tissue. Within several hours following occlusion of the vessel, the influx of inflammatory cells, like monocytes and neutrophils, commences. These cells importantly contribute to the wound healing process (cardiac remodeling) that is initiated after MI. In addition, acute myocardial ischemia is a stimulus for the production of peptide growth factors, modulaw ting various pathophysiological processes involved in ventricular remodeling following acute MI, including cardiac hypertrophy, angiogenesis, cell turnover and collagen deposition.

Due to progress made in clinical research, many patients presenting with acute MI can be successfully treated by rapid opening of the occluded vessel. This is a prerequisite to limit infarct size and to restore or to preserve cardiac function. "Time is muscle" is an adequate description of the situation. Thrombolysis, primary PTCA and acute coronary artery bypass surgery (CABG) are among the most frequently used strategies to achieve reperfusion.

Recently, it was recognized that reperfusion of ischemic tissue can cause additional damage to the myocardium, due to detrimental effects of oxygen free radicals and other toxic substances, released by ischemic tissues. ${ }^{2}$ For instance apoptosis, also called programmed cell death, is enhanced during reperfusion. Currently, several methods to reduce reperfusion damage are being investigated and tested in a pre-clinical and clinical setting.

Thanks to reperfusion therapy and other interventions to minimize infarct size and improve cardiac function, a vast number of patients survive the initial coronary event. However, these patients may be suffering from ongoing chronic (silent) myocardial ischemia and microinfarctions, caused by progression of atherosclerosis and/or micro-thromboembolisms. In addition, pathological hypertrophy of cardiomyocytes, compensating for the loss of contractile tissue, and reactive replacement fibrosis may contribute to an unfavorable cardiac architecture and impairment of systolic and diastolic function. As a result, cardiac function deteriorates further, eventually leading to overt cardiac 
failure. Cardiac failure is an intriguing syndrome with multiple causes and manifestations and can be defined as any condition in which the heart is not able to pump blood at the rate or volume required by the metabolizing tissues of the body (forward failure). Heart failure is characterized by depressed contractility of the (viable) myocardial tissue as a result of abnormal excitation- contraction coupling due to abnornal calcium-handling. In addition to symptoms of forward failure, stasis of blood in both lung-venous and systemic venous circulation result in pulmonary congestion and peripheral edema, respectively (backward failure). This is accompanied by the activation of neurohumoral compensatory mechanims, like the renin-angiotensin system and constitutive activity of the sympathetic nervous system, further deteriorating cardiac function.

Despite all research efforts, cardiac failure is still difficult to treat, probably because therapy is based mainly on symptomatology rather than the cause of this disease entity. While new drugs continue to be developed and used, mortality rates among heart failure patients are still very high, with an annual mortality rate of 15-40\% depending on the degree of cardiac failure."

\section{Growth Factors}

In the past few years, much attention has been paic to identification of genetic and neurohumoral factors, especially peptide growth factors, involved in the pathobiology of MI and heart failure. Understanding the role of these proteins in cardiovascular disease is essential to design future strategies for treatment.

In this thesis, attention is focused on two of these peptide growth factors, Insulin-like Growth Factor-1 (IGF-1) and Fibroblast Growth Factor-1 (FGF1). Their role in acute and chronic myocardial ischemia and infarction on cardiac functional and structural changes were investigated in transgenic and gene targeted murine models.

\section{Chronic myocardial infarction and scar formation.}

Thrombotic occlusion of a coronary artery results in ischemia of the area at risk. Longstanding ischemia finally results in death of the tissue. This is followed by the initiation of an acute local inflammatory response consisting of the influx of inflammatory cells, like neutrophils, lymphocytes and monocytes/macrophages. This can be seen as the start of the wound healing 
process. Initially, these migrating cells start to produce chemokines and cytokines, acting as chemotactic substances, attracting other cells like fibroblasts and monocytes within several days following the acute event. After the influx into the infarcted area, fibroblasts and endothelial cells start to proliferate. ${ }^{3,4}$ Fibroblasts are responsible for deposition of the collagen matrix that forms the structural backbone of the developing scar/granulation tissue. Monocytes and residing macrophages start the phagocytosis of necrotic cardiac cells and degradation of the extracellular matrix (ECM). This is associated with gradual dilatation of the ventricle and thinning of the ventricular wall, resulting, according to Laplace's law (wall stress $=$ pressure ${ }^{*}$ radius $/ 2^{*}$ wall thickness), in increased wall stress. All these changes are associated with a decreased cardiac function.

Early postnatally, myocardial cells lose the ability to undergo mitotis. In orcler to compensate for the loss of contractile ventricular tissue following $\mathrm{MI}$, cardiomyocytes have to increase in size, in order to maintain cardiac output. This increase in cell size in the absence of mitotic division is called hypertrophy. Furthermore, at this time the ingrowth of capillaries into the infarcted area is initiated (angiogenesis). Also in the non-infarcted area, new vessels are formed by sprouting to compensate for the increase in oxygen diffusion distance, resulting from myocyte hypertrophy. ${ }^{5}$

In response to ischemia or increased workload, the inflammatory cells that populate the granulation tissue start to produce growth factors. Also the viable myocytes in the remote myocardium produce peptide growth factors, in response to increased workload. ${ }^{6.9}$ These pepticles play a crucial role in the initiation and completion of scar formation and restoration of the architecture of the damaged ventricle. A vast number of peptide growth factors have been identified and classified in families according to structural or functional similarities. Important families of peptide growth factors are Insulin-like Growth factors (IGF-1 and IGF-2), Fibroblast Growth Factors (acidic FGF [FGF-1], and basic FGF [FGF-2]], as the most important members, and various unrelated peptide growth factors [Vascular endothelial growth factors [VEGF], Angiopoetin, Transforming Growth Factor [TGF- and] and Platelet-derived growth factor [PDGF]).

\section{Myocardial response to ischemia}

To better understand the nature of the acute myocardial response to ischemia and the intracellular signaling pathways involved, several pathological proces- 
ses and entities have to be clearly defined. Different pathological phenomena, like ischemia and reperfusion induced damage, myocardial stunning and hybernation and ischemic preconditioning of the myocardium, have been implicated in the hearts' response to ischemia.

\section{Reperfusion damage (apoptosis versus necrosis)}

While reperfusion is the primary goal of the treatment in acute MI, it is clear that also the process of reperfusion itself is detrimental in nature, causing additional damage to the area at risk. The harmful effects of formation of oxygen free radicals, complement activation and neutrophil accumulation have been well established..$^{10.12}$ While ischemia alone induces necrosis, reperfusion mainly induces apoptosis, a phenomenon also occurring in the ischemic reperfused myocardium. ${ }^{12-15}$

Stunning: The concept of "stunning" was first described by Heyndrickx et al. ${ }^{\text {t6 }}$ in 1975, who reported that the myocardium rendered ischemic, but not irreversibly damaged, exhibited prolonged depression of regional myocardial function, long after the complete return of blood flow and the resumption of a mormal electrocardiographic pattern. ${ }^{10,17}$. A decade later, Braunwald and Kloner's proposed the term "stunning" for this phenomenon.

Hibernation: The phenomenon of hibernation (hybernia means winter) was first described by Diamond et al. ${ }^{19}$ in 1978 as a state of persistently impaired myocardial and left ventricular function at rest due to reduced coronary blood flow that could be partially or completely restored to normal if the myocardial/oxygen supply relation was favorably altered, either by improving blood flow and/or by reducing demand. ${ }^{17,20}$

\section{Ischemic preconditioning: definitions and basic concepts}

Myocardial ischemic preconditioning (IP) is defined as the limitation or the delay of myocardial cell death following several brief cycles of coronary artery occlusion that precede an occlusion sufficiently long to produce near total necrosis of the area at risk. IP should be considered an endogenous protection against MI." "This phenomenon was first recognized by Murry and Reimer et al. ${ }^{21}$ in dogs in 1986. Since that discovery, intensive research has been performed to elucidate the mechanism of ischemic preconditioning and its effects on cardiac protection during $\mathrm{I} / \mathrm{R}$.

Ischemic preconditioning protects the heart in two separate time windows, referred to as "early" or "classic" preconditioning ${ }^{22}$ and "delayed" or "second window" of preconditioning. ${ }^{23.25}$ The early and powerful preconditioning phase 


\section{Ischemic preconditioning}

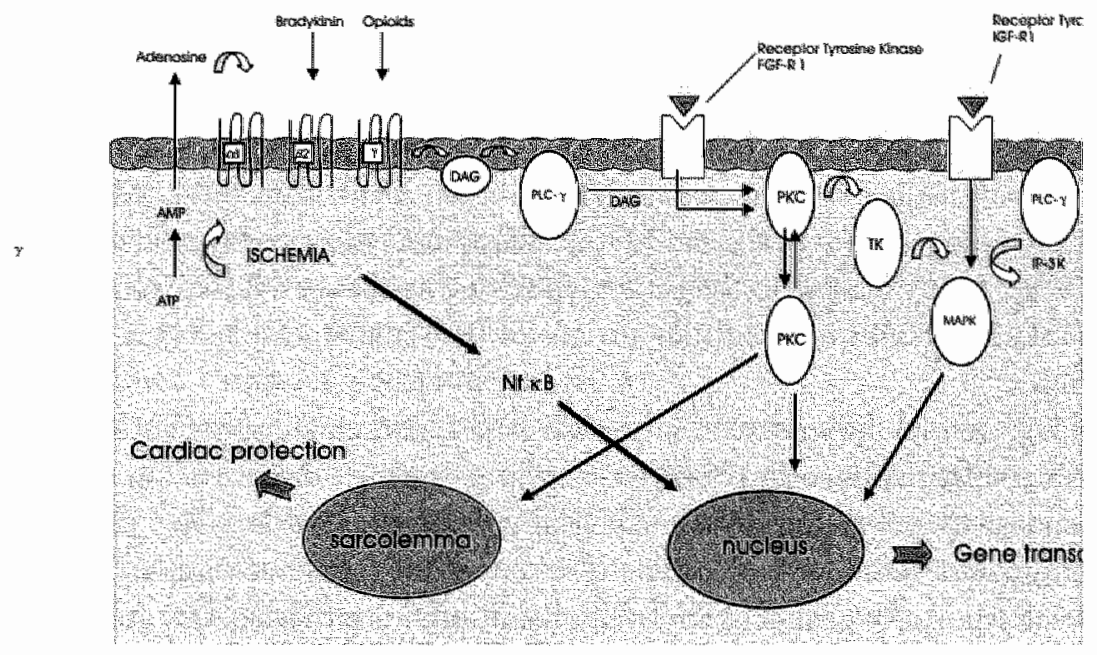

Figure 1 : ischemic preconditioning (bosic signaling pothwoys)

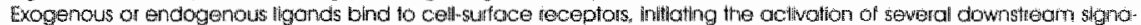

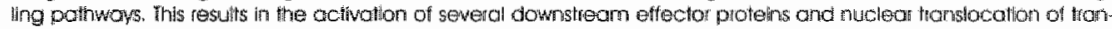
scripton lactors, inducing the ip etfect in lwo differentl time windows.

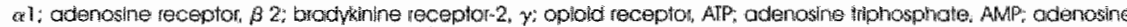

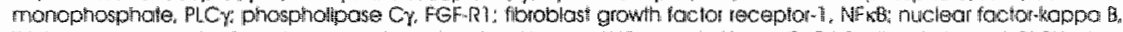

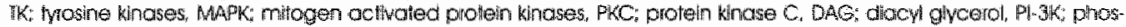

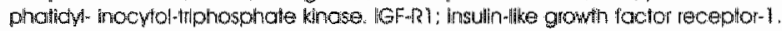

is induced within minutes and lasts 1-2 hours after the preconditioning stimulus. ${ }^{24}$ The second window of IP, which is believed to result from IP induced gene transcription, occurs 12-72 hours later and lasts for several days. ${ }^{26}$ During both windows, distinct intracellular signaling pathways may be activated.

Ischemic preconditioning results in limitation or attenuation of myocardial cell death following coronary artery acclusion. ${ }^{27.29}$ In addition to reduction of ische. mic cell death, also reperfusion or reoxygenation-induced apoptosis is attenuated when I/R is preceded by IP, both in vivo and in vitro. ${ }^{30,31}$ The mechanism of this anti-apoptotic effect of IP is, at least partially, relying on the upregulation of the anti-death gene $\mathrm{BCl}-2^{33}$

Cardiac functional recovery following ischemia and reperfusion is also enhanced when the heart is subjected to preconditioning. Cohen et al..$^{32}$ reported in a canine model of I/R that IP leads to enhanced recovery of the contractile function of the myocardial region at risk, in addition to decreased myocardial necrotic cell death and enzyme leakage. Also in rabbits ${ }^{33,34}$ and rats $\mathrm{s}^{35}$, preconditioning results in a Protein Kinase C (PKC)-dependent augmentation of cardiac functional recovery, potentially due to the preservation of mitochondrial function (figure 1 ). ${ }^{35}$

Later, when IP became generally accepted to be a receptor-mediated process, 
it was discovered that exogenous and endogenous agonists and inhibitors could mimic IP. Activation of such receptors like the opoid receptor ${ }^{35}$, bradykinin receptor, adenosine receptor ${ }^{33.35}$ and adrenergic receptors ( $\alpha 1$-adrenergic receptor ${ }^{6}$ by their respective natural ligands or pharmacological agonists mimick IP-like cardioprotection. Receptor activation subsequently results in activation of distinct intracellular signaling proteins involving several $\mathrm{PKC}$ isoforms, Tyrosine Kinases (TK), and Mitogen Activated Protein Kinases (MAPK's), finally leading to the activation of downstream effectors, translocation of these proteins to either the nucleus or the sarcolemma, and gene transcription.

Recently, attention has focused on tyrosine kinase growth factor receptors, which are able to induce an IP response after exogenous administration or after endogenous overexpression of their ligands in vitro and in vivo. Several years of intensive research demonstrated PKC, and most importantly the $\varepsilon$-isoform, is the pivotal upstream element, orchestrating a series of signaling events that result in the recruitment of many downstream factors involved in the establishment of cardioprotection. "To date, at least 11 PKC isoforms have been identified in vivo. These structurally and functionally related PKC isoforms are classified into 3 subfamilies: The "classical" or "conventional" PKC isoforms (PKC- $\alpha,-\beta,-\beta,-\gamma)$, requiring both calcium and lipids (Phorbol-12-myristate-13-acetate [PMA], Diacylglycerol [DAG], phosphatidylserine) for their activation. The "novel" PKC isoforms (PKC- $\delta,-\varepsilon,-\theta,-\eta)$, requiring lipds, but not calcium to become activated. And finally the atypical subfamily of PKC isoforms (PKC- $\zeta$, -1 and $-\lambda$ ), requiring neither calcium, nor diacylglycerol and/or PMA, but solely phosphatidylserine for activation. ${ }^{42,43}$ The protective effects of PKC activation were first hypothesized by Downey and Cohen ", who suggested that a wide variety of $\mathrm{G}$-coupled receptors could activate PKC isoforms through the activation of PLC- $\gamma$ (phospholipase C- $\gamma$ ). Actitivation of PKC isoforms subsequently results in the nuclear and sarcolemmal translocation of these proteins, where they influence gene transcription (most probably heat-shock proteins [HSP-70, HSP-27], anti-oxydant enzymes and intrinsic Nitric Oxide Synthase [iNOS] ${ }^{23,45}$ ) and phosphorylate substrate proteins at membrane targeted locations (sarcolemma), respectively. IP results in translocation of selective PKC isoforms from the cytosolic to the particulate fraction, without a subcellullar redistribution of total PKC activity. ${ }^{42}$ Phosphorylated (and thus activated) PKC isoforms, translocate to the particulate fraction, where they bind to so-called RACK proteins (receptor for activated kinases). ${ }^{46}$ This binding, mainly to RACK-2, is supposed to be crucial in exerting its protective function ${ }^{\mathrm{d} 7}$.

In rat, mouse, rabbit and humans, PKC isoforms are strongly involved in IP, 
although species-dependent differences are observed. In the rat PKC- $\delta^{\text {ta }}$ a and $\varepsilon^{49,50}$ are activated during IP, while in rabbits, mainly the epsilon isoform of

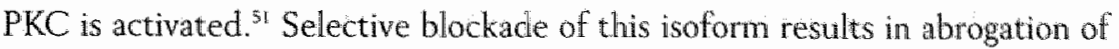
protection." In mice, allso PKC- $\varepsilon$ is supposed to be the pivotal isoform for the induction of $\mathrm{IP}^{\text {st }}$ although also the $\beta$-isoform of PKC proved to be involved in IP.33 A modest level of PKC- $\varepsilon$ overexpression resulted in increased cardiac functional recovery following global ischemia and reperfusion ${ }^{47}$, which could be completely abrogated with pre-ischemic administration of Chelerythrine (CHE, a global PKC inhibitor). ${ }^{33}$ However, a high level of PKC- $\varepsilon$ overexpression caused cardiac hypertrophy and failure. ${ }^{47}$

Bolli et al. ${ }^{52}$ hypothesized that PKC-induced gene transcription is responsible for the second window of preconditioning. Another potential pathway is through PKC-dependent activation of TK and subsequent downstream signaling as a requirement for early preconditioning. The second window of precon-

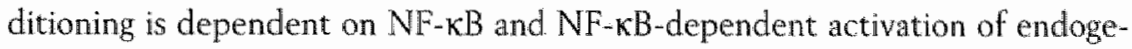
nous Nitric Oxide Synthase (eNOS) and subsequent Nirtic Oxide (NO) production. ${ }^{53}$

In addition to sarcolemmal and nuclear translocation, PKC isoforms also activate downstream $\mathrm{TK}_{y}$ like pp60-cSrc. ${ }^{5, .55}$ This in turn results in activation of the stress activated MAPK's $\mathrm{p} 38$ and p.JNK (c-Jun NH2-terminal kinase). ${ }^{56}$ Both TK and stress-activated MAPK's proved to be of critical importance for IP induction, since inhibition of these proteins results in attenuation of cardioprotection. Ping et al. demonstrated in a conscious rabbit model of preconditioning, that TKs Src and Lck are activated in a PKC-E dependent fashion. ${ }^{5.5}$ Inhibition of TK with Lavendustin-A resulted in complete abrogation of cardioprotection. CHE treatment resulted in the inhibition of $\mathrm{PKC}-\mathrm{E}_{i}$ but also the activation of both 'TK's was prevented, concomitant with abrogation of infarct size reduction. Baines et al. ${ }^{37}$ showed in a similar model that $\mathrm{PKC}$ is upstream from TK's in ischemic preconditioning's anti-infarct effect. Moreover, activation of MAPK's in the presence of CHE was protective, indicating that MAPK's are downstream of PKC in IP-induced cardioprotection. ${ }^{57}$ Also in a murine model of ischemic preconditioning, pERK- $1 / 2$ (p44/p42) and $\mathrm{pJNK}$ $1 / 2\left(p 54 / p^{46}\right)$ activation proved to be PKC- $\varepsilon$ dependent. ${ }^{56} \mathrm{Li}$ et all, showed that PKC- $\varepsilon$ activation also results in the pERK- $1 / 2$ and $p . J K-1 / 2$ dependent activation and translocation of $\mathrm{Nf}-\kappa \mathrm{B}$, while inhibition of $\mathrm{pERK}-1 / 2$ resulted in abrogation of $\mathrm{NF}-\mathrm{\kappa B}$ activation and nuclear translocation (figure 1 ). ${ }^{5.6}$ In general, PKC isoform activation is associated with cardioprotection, although deleterious effects of PKC and TK activation have also been described. In some studies, inhibition of PKC and TK attenuated cardiac swellinginduced amino-acid release in the isolated rat heart. ${ }^{58}$ 


\section{Downstream effectors for ischemic preconditioning}

From the above, it is evident that much is known about the upstream signaling events in IP. The downstream effector molecules which are responsible for cardioprotection are, however, largely unknown. Only recently, several of these downstream effectors have been identified.

One of these seems to be the ATP-sensitive potassium channels ( $K_{\text {w }}$ channels). It is hypothesized that PKC translocation results in the opening of $K_{w}$ channels, which are responsible for the short-term cardioprotection as observed in the early phase of preconditioning. ${ }^{\text {59.61 }}$ Pharmacological opening of these channels results in cardioprotection, to a similar degree as observed with repetitive cycles of ischemia and reperfusion. ${ }^{62-54}$ Conversely, IP-induced protection can be inhibited by $K_{*}$ channel-blockers. ${ }^{43,59,60,63,64}$. While it has been suggested that sarcolemmal $K_{\text {un }}$ channels were responsible for cardioprotection ${ }^{65}$, it has recently been shown that mitochondrial $K_{w i}$ channels are of critical importance for IP induction ${ }^{55,66,}$, while sarcolemmal $K_{\text {m }}$ channels being less important ${ }^{67}$ This concept was confirmed by Ping et al. " who showed that translocated PKC- $\varepsilon$ is confined to the inner mitochondrial membrane and cytoskeletal proteins, indicating previously unrecognized functions, like opening of mitochondrial Kai channels.

\section{Clinical aspects of preconditioning}

Also in man, IP has been suggested to be an important phenomenon. ${ }^{68.70}$ In isolated human ventricular myocytes and atrial appendages, IP induced similar protective effects as in animal myocytes. It was demonstrated that the same intracellular signaling pathways are involved in both humans and animals. Several groups demonstrated that adenosine, PKC and $K_{\text {ur }}$ channels are involved in the $I P$ phenomenon in human ${ }^{38,60,7,7,7}$

Also from a clinical point of view evidence is accumulating that IP is a relevant phenomenon. Patients complaining from angina pectoris before the occurrence of an acute $\mathrm{Ml}$ (preinfarction angina) have both better short$\operatorname{term}^{7374}$ and longterm ${ }^{75}$ survival, when compared to patients who did not have preinfarction angina pectoris. Moreover, human hearts subjected to repetitive cycles of ischemia and reperfusion induced by aortic cross clamping during cardiac surgery demonstrated an attenuation of myocardial cell damage ${ }^{2 \%}$, improvement of the recovery of cardiac contractility, ${ }^{\text {" }}$ and preservation of myocardial ATP levels ${ }^{78}$ However, contradicting results have been reported in patients undergoing cardiac surgery with cardioplegic arrest. Perrault et al. ${ }^{79}$ failed to show benificial effects of IP in this setting. Several other studies 
reported that even with optimal conventional protection (hypothermia and cardioplegia), some additional myocardial protection could be obtained using. an IP protocol preceding bypass surgery. ${ }^{77,80}$ It is now generally accepted that only patients with suboptimal myocardial protection during heart surgery might benefit from IP. ${ }^{8 !}$

In addition, in patients undergoing bypass surgery, optimal conventional protection with cardioplegia and hypothermia cannot prevent discrete necrosis to occur. These patients might benefit from pharmacological pretreatment. ${ }^{82}$ Another group of patients that might benefit from IP are cardiac transplant recipients. Some evidence emerged from experimental work that organ preservation for the purpose of transplantation can be improved with pharmacological pretreatment of explanted organs. ${ }^{83}$ In a rat model, Kevelaitis and coworkers ${ }^{62}$ demonstrated that preconditioning with diazoxide, a mitochondrial $K_{\text {mopener }}$ could improve the preservation of globally ischemic cold-stored. hearts used for transplantation. More recently, the same group reported that the combined treatment with a $\mathrm{Na}^{*} / \mathrm{H}^{+}$exchange inhibitor, in addition to classical ischemic preconditioning of the heart prior to cold storage, proved to be the optimal preventive treatment for cardiac performance and myocardial cell. integrity. ${ }^{84}$ Finding the optimal combination of classical ischemic preconditioning in combination with pharmacological preconditioning or preconditioning using different peptide growth factors might effectively contribute to improve donor heart preservation during cardiac transplantation. This might allow the extension of the "cold ischemic time", between harvesting and transplantation, enabling more careful matching of donor and recipient and better shorttime cardiac functional recovery following transplantation. ${ }^{70}$

Because of the nature of the IP phenomenon, pharmacological pretreatment should start before the potentially lethal coronary event occurs. In order to carefuliy identify the population at high risk for an acute coronary event, who might benefit from pharmacological preconditioning, criteria for risk stratification need to be developed. Most likely, this comprises the patient group suffering from unstable angina pectoris. ${ }^{30}$ However, it is important to realize that, although pharmacological preconditioning might be suitable to protect the heart from subsequent ischemic damage, it constitutes only a delay rather than prevention of the evolution of necrosis. Yellon et al. ${ }^{95}$ showed that IP could limit infarct size, when the ischemic period is of limited duration (30$90 \mathrm{~min}$.) When the ischemic period was extended to 3 hours, no protection of IP could be observed. Therefore, IP can be seen merely as a method to delay myocardial necrosis, prolonging the time window during which reperfusion therapy can be succesfully initiated.

In conclusion, IP is a potentially powerful tool with clinical relevance, media- 
ting short-term cardioprotection. One way to induce preconditioning is the direct pharmacological or gene-therapy induced activation of the downstream signaling nolecules and downstream effector molecules. However, these actwators are often highly toxic or carcinogenic or have major side effects while strong PKC overexpression induces cardiac hypertrophy and failure." Therefore, the fine-tuning of these treatments will be of great importance to be able to introduce these concepts into the clinic. Growth factor therapy might be one possible solution for these problems.

With the general pathobiology of acute and chronic myocardial ischemia described and all the definitions outlined, the remainder of this introduction will be dedicated to the description of the two growth factor families of interest for this thesis, namely the Insulin-like growth factor family and the Fibroblast Growth Factor family. Both growth factor families are involved in (patho-) physiologic processes in many different organs and systems. Attention will be focused on the role these growth factors play in cardiac development, physiology and pathophysiology.

\section{The Insulin-Like Growth factors in cardiac disease}

\section{IGF-1: family members and binding proteins}

The Insulin-like growth factor family was first described and characterized in 1978 by Rinderknecht and co-workers. The only two members of this family are IGF-1 (also called Somatomedin-C) and IGF-2. IGF-1 is a $7.6 \mathrm{kd}, 70$ amino-acid polypeptide protein with high structural and functional homology to insulin and functional characteristics of growth hormone (CH). IGF. I is produced in the liver in response to stimulation with $\mathrm{GH}$, derived from the hypothalamus. It serves as a general growth promoting peptide. GH overexpressing transgenic mice display increased circulating levels of $1 \mathrm{GF}-1^{8.7}$ and

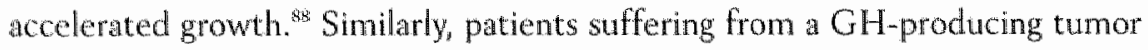
(acromegaly) have increased IGF-I serum levels. In contrast, GH insensitivity results in Laron-dwarfism which can be corrected by exogenous IGF-1 administration. ${ }^{90}$

After release into the circulation, $I G F-1$ is bound to one of $61 \mathrm{GF}-1$ binding proteins (IGFBP 1-6), mainly IGFBP-3, transporting IGF-1 through the bloodstream and modulating the interaction of $I G F-I$ with its cell membranebound receptors in distant target tissues. They regulate tissue compartment specific control and increase the half-life of the protein ${ }^{91.93}$. Likewise, in vitro administration of $1 G \mathrm{~F}-\mathrm{BP} 3$ inhibits IGF-I induced hypertrophy in neonatal rat cardiomyocytes, illustrative for its $I G F-1$ modulating function. ${ }^{4 ?}$ 


\section{IGF-receptors and signaling}

To date, at least 2, structurally unrelated, IGF receptors with different kinetic properties have been characterized. IGF-RI shows close resemblance to the insulin receptor and consists of a disulfide- linked heterotetrameric $(\alpha . \beta$ ) transmembrane glycoprotein, with an extracellular ligand-binding and multiple intracellular tyrosine kinase domains. ${ }^{3 * 4}$ IGF-RI preferentially binds $\llbracket G F-1$, but also IGF-2 and insulin act as a ligand for this receptor. ${ }^{95}$ Ligand binding to [GF-R] results in transactivation of the receptor and autophosphorylation of the intracellular domain on tyrosine kinase residues and other cytoplasmic substrates, including insulin receptor substrate (IRS)- 1 . This results in the subsequent activation of several distinct intracellular signaling cascades that ultimately lead to either gene transcription or non-genomic effects. ${ }^{3,960}$ Activation of the IRS-I results in the subsequent activation of PLC- $\gamma$ and Phosphatidyl-inocytol-triphosphate kinase (PI-3K), followed by the activation of MAPK's, ERK-I and ERK-2 (figure 2). ${ }^{12,97,98}$

The IGF-R2 consists of a single polypeptide chain and lacks intracellular tyrosine kinase domains. ${ }^{99}$ It only recognizes $I G F-2$, functioning as a scavenger for this peptide, and the question remains whether or not IGF-R2 takes part in signal transduction. Therefore, it is assumed that most, if not all, biological actions of IGF-1 and 2 are mediated through the IGF-R1 (figure 2).

\section{IGF-1 signaling}

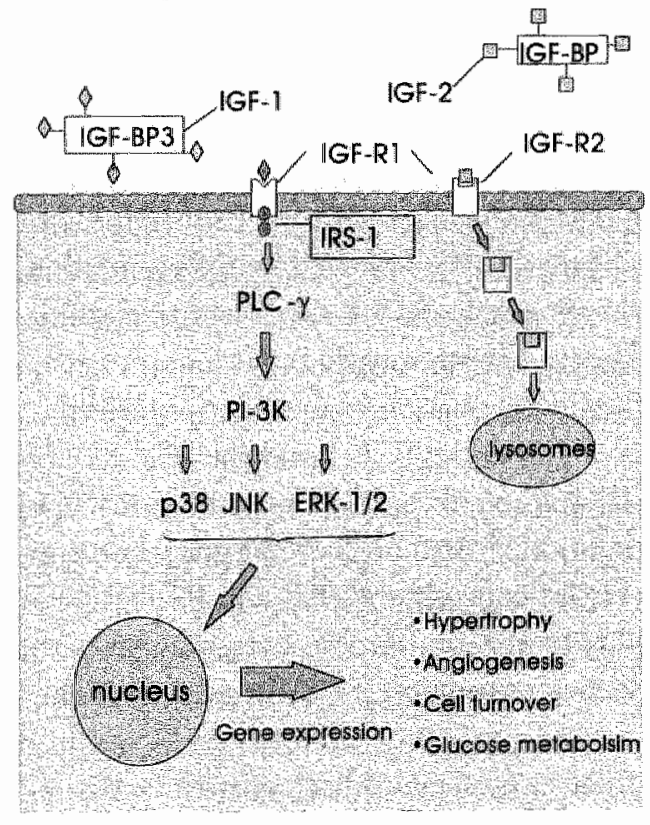

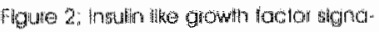
ling

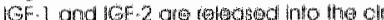

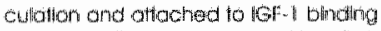
protens or they are producter locity in

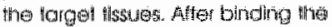

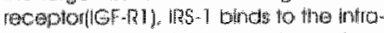
fellutar donalin of the maspton and becornes actwated this heads to the actlotion af downtream signoling mole.

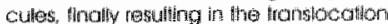

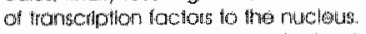

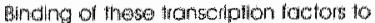
the ONA intlites gond tronchinglon and

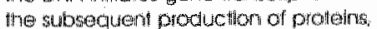

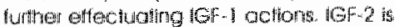

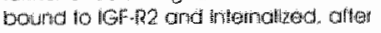
which it is ofegoded fromonos.

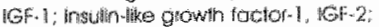

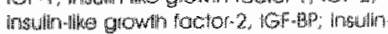

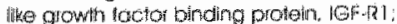

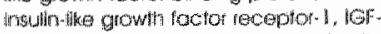

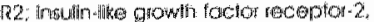

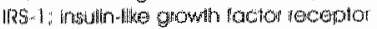

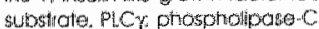

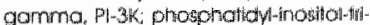

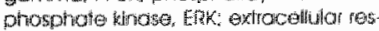

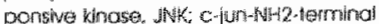
tringese: 


\section{The role of IGF-1 in development:}

IGF-1, as general growth promoting peptide, is indispensable for normal embryonic development, as mice bearing a null mutation for the IGF-1 gene show marked growth retardation and perinatal mortality rates of approximately $95 \%$, ${ }^{1000}, 10 \%$ Born IGF $-1-$ mice display a $40 \%$ reduction in body weight shortly after birth and an adult body weight of 8 grams, compared to $35-40$ grams in a normal adult mouse: Heterozygous IGF-1 deficiency results in a $40 \%$ reduction of circulating IGF- 1 plasma levels and a $10-20 \%$ decrease in both organ and body weight. Compared to the homozygous IGF-/- mice, IGFRI deficient mice show an even more severe growth retardation ( $45 \%$ normal size) and invariably die shortly after birth due to respiratory failure and generalized hypoplasia of several organ systems, including the heart and the central nervous system.

While IGF-2, a structurally related peptide consisting of 67 amino-acids, appears to play a minor role in post-natal life, it plays a pivotal role during embryogenesis. ${ }^{102,163}$ Double knockout embryo's for IGF-1 and IGF-2 displayed extreme growth retardation (70\% reduction in body weight) and perinatal death. ${ }^{104}$ Since IGF-R2 functions as a scavenger receptor mediating the transport of lysosomal hydrolases to lysosomes and the clearance of IGF-2, IGF-R2 deficient mice have very high circulating IGF-2 levels. ${ }^{105,106}$ These mice die perinatally due to cardiac failure. ${ }^{105}$

During embryogenesis, IGF-1/2 and their IGF-receptors are ubiquitously expressed throughout the developing organism. ${ }^{107}$ Initially, IGF-2 seems to be the most important and abundant factor for embryonic development, but from $\mathrm{I}^{13.5}$ (mouse), IGF-RI binds with high affinity to IGF-1 and its expression is increased.

The IGF-I system is of critical importance for cardiac development. IGF-1/2 and both $1 \mathrm{GF}$ - receptors regulate the development of avian precardiac mesoderm, by stimulation of proliferation of myoblasts, followed by differentiation into mature cardiomyocytes. ${ }^{109}$ In vitro exogenous IGF-1 administration stimulates myofibril development and decreases smooth muscle $\alpha$-actin expression, demonstrating the role of IGF-I in the differentiation of mesoderm-derived structures and cells. ${ }^{110}$ In the early neonatal period, IGF-1 and the IGF-RI are still expressed in the heart, where IGF-I is able to induce not only ventricular myocyte hypertrophy ${ }^{42}$ but also proliferation. "Also myocardial fibroblast proliferation during cardiac development is influenced by IGF-1 and IGF- R1."12 In addition, IGF-I modulates the ability of cardiac fibroblasts to interact with the surrounding collagen matrix and activates multiple PI-3K-regulated signaling pathways in these cells. ${ }^{113}$

In the first few weeks after birth, cardiac expression of both growth factors 
(IGF-1/2) and receptors (IGF-R1/2) gradually decreases. This occurs in conjunction with extracellular matrix deposition and capillary growth. ${ }^{11,45}$ In this same period, cardiomyocytes lose the ability to proliferate and enter into a post-mitotic state. Subsequently, cardiac growth can only occur by hypertrophy of the cardiomyocyte population. ${ }^{116-118}$ Concordantly, in the normal adult rat heart, IGF-1 and IGF-RI levels are low ${ }^{19}$ to undetectable. ${ }^{\text {th }}$ However isolation of adult rat cardiomyocytes results in expression of high levels of IGF$\mathrm{Rl}$ and reexpression of a number of fetal genes.

\section{The role of IGF-1 in adult life (physiology)}

During adult life, both receptor and ligand (IGF-1) have been reported to be active on several distinct cell types including vascular smooth muscle cells (VSMC) ${ }^{121}$, lymphocytes ${ }^{121}$, cardiomyocytes ${ }^{6,123122}$, endothelial cells ${ }^{123}$ and fibroblasts. ${ }^{11,121}$ Under physiological conditions, IGF-1 mediates the effects of growth hormone and acts as both a mitogen and a differentiation/survival factor for a variety of cell types. ${ }^{91,93,123}$ In addition, IGF.I increases protein synthesis in different cell types, including cardiomyocytes. ${ }^{124.126}$ A controversial issue is the ability of cardiomyocytes to reenter the cell cycle. Anversa and coworkers ${ }^{6,277,28}$ were able to demonstrate that IGF-1 enables adult cardiomyocytes to reenter the cell cycle. Transgenic overexpression of human IGF-1 in a murine model resulted in a $55 \%$ increase in myocyte numbers in IGF-1 transgenic hearts, in conjunction with a similar increase in heart weight, one year after birth. ${ }^{127.128}$ Interestingly, these mice did not show myocyte hypertrophy or altered myocardial function. So far, only one group reported postnatal myocyte division, and the general consensus is that myocyte division after the neonatal period is not possible or extremely rare.

Although IGF-1 might not be able to induce cardiomyocyte division, vast evidence is present that IGF-I acts as a hypertrophy inducing factor for cardiomyocytes both in vitro ${ }^{92,25}$ and in vitoo. ${ }^{129,130}$ Combined GH/IGF-1 treatment results in positive inotropic and hypertrophic effects without changing the expression of fetal gene markers of pathological hypertrophy, like ANF and skeletal actin. In addition, fibrosis was not enhanced after IGF-1 administration. ${ }^{129}$ These results indicate the induction of a physiologic or benificial type of hypertrophy.

In addition to its pro-hypertrophic characteristics, IGF-] also directly influences cardiac function. Ex vivo and in vitro administration of IGF- 1 to normal adult rat myocardium or myocytes, as well as IGF-1 overexpression in vitro ${ }^{131}$ result in an augmentation of contractility and overall cardiac performance. ${ }^{129,132}$ Similarly, in vivo administration of IGF-1 enhances cardiac function under 
physiological conditions. ${ }^{129.332 .33}$ Interestingly, Lembo et al. ${ }^{134}$ reported that IGF1 deficiency also resulted in augmentation of cardiac function, due to enhanced beta-adrenergic signaling.

In addition to the general growth promoting properties of IGF-I, it also possesses some insulin-like properties, as the name already indicates. IGF-I enhances glucose uptake by different cell types, especially adipose tissue. ${ }^{123,135}$ In addition, IGF-1 induces hypoglycemia in different cell types in fastened lambs. ${ }^{\text {is }}$

\section{Effects of IGF-1 under pathological conditions and chronic myocardial ischemia}

In addition to the systemic production of IGF-1 derived from the liver, this peptide is also produced locally in different tissues, in response to certain stimuli. In the heart, especially in cardiomyocytes, IGF-I and IGF-RI are upregulated in response to ischemia"or an increase in cardiac work load. "IG IGF-1 upregulation after acute $\mathrm{MI}$ is confined mainly to the viable borderzone of the infarcted area and gradually decreases after 24 hours. ${ }^{21}$ Also in heart failure patients, increased circulating IGF-I levels could be demonstrated which proved to be strongly correlated with preserved left ventricular function in these patients. ${ }^{13 y}$ In contrast, Osterziel and co-workers found decreased, rather than increased IGF-I levels in patients suffering from cardiac failure. ${ }^{138,139}$ Upregulation of the IGF-1 system is necessary for adequate cardiac remodeling in response to changes in tissue demand and local changes in wall stress or cardiac architecture. Administration of either [GF-] or GH during myocardial. ischemia, infarction or cardiac failure restores or improves cardiac architecture and function both in vivo and in vitro. ${ }^{140.143}$

IGI -1 overexpression leads to attenuation of left ventricular dilatation, myocyte necrosis and reactive replacement fibrosis. This results in augmentation of carcliac function both during gradual coronary artery narrowing ${ }^{143}$ and following acute MI. ${ }^{14}$ Other groups reported that administration of $\mathrm{GH}^{\mathrm{i} \text { 11 }}$ or IGF$1^{142,145}$ to rats suffering from overt cardiac failure after $\mathrm{MI}$, resulted in an enhanced hypertrophic response of the remote myocardium with similar positive effects on left ventricular dillatation and augmentation of cardiac function in vivo and $e x$ vivo $0^{1.1}$

Several groups reported the angiogenic potential of IGF-1 in different tissues. ${ }^{1.6 .149}$ Kluge et al. ${ }^{1.6}$ demonstrated IGF-1 mRNA upregulation colocalizing with the appearance of new capillaries in a porcine model of myocardial microembolization, suggesting that IGF-1 plays a role in cardiac angiogenesis. $I_{\text {IGF-1 stimulates procollagen formation }}{ }^{150}$, collagen deposition ${ }^{150}$ and the proli- 
feration of cardiac fibroblasts ${ }^{15.152}$ and therefore importantly contributes to scar formation following MI.

\section{IGF-1 during acute myocardial ischemia and reperfusion. Attenuation of apoptosis and augmentation of cardiac functional recovery.}

In addition to the effect on cardiac remodeling and scar formation following MI, it also acts as a survival factor decreasing apoptotic cell death induced by various pathologic stimuli. ${ }^{144,153-155}$ Wang et al. ${ }^{155}$ showed that IGF-1 enhanced cell survival and reduced DNA fragmentation in vitro after serum withdrawal and doxorubicin-induced apoptosis of isolated cardiomyocytes. This was associated with an attenuation in Bax induction and Caspase 3 activation. In addition, cardiac IGF- 1 overexpression leads to downregulation of the myocardial renin-angiotensin system (RAS), which is believed to induce apoptosis, through the upregulation of $\mathrm{Mdm} 2$ and its binding to $\mathrm{p} 53$, a known pro-apoptotic factor. ${ }^{153}$ Similarly, administration of IGF-1 to cultured isolated cardiac myocytes attenuates ethanol-induced apoptosis rates. ${ }^{154}$ Previously, it was reported that IGF-I administration in an in viwo rat heart model of regional ischemia and reperfusion attenuated both myocardial necrotic and apoptotic cell death and decreased neutrophil accumulation, 24 hours following the onset of reperfusion. ${ }^{15 \%}$

While IGF- 1 seems to be anti-apoptotic during acute ischemia and reperfusion, this might not be the case in chronic myocardial ischemia. Li et al. ${ }^{143}$ showed that IGF-I overexpression improved both cardiac architecture and function following non-occlusive coronary artery constriction, but they failed to show an attenuation in apoptosis, perhaps because of the low apoptosis rates that were observed in this study. In a murine model of MI, this group demonstrated that $I G F-1$ overexpression reduced cardiomyocyte apoptosis in the remaining viable myocardium and improved ventricular architecture by limiting ventricular dilation and loading and attenuating compensatory hypertrophy, one week after $M I^{144}$

In addition to anti-apoptotic effects, IGF-I also directly protects cardiac function and functional recovery during $I / R$. In an isolated rat heart model of acute regional ischemia and reperfusion, IGF- 1 administration enhanced cardiac functional recovery in a PI-3K dependent manner. ${ }^{157}$ This is underlined by the recent work of Friehs and co-workers ${ }^{158}$, who demonstrated in a rabbit model of aortic banding, that pre-ischemic IGF-1 administration augments functional recovery of the hypertrophied heart, and restores nyocardial glucow se uptake, after 30 minutes of normothermic ischemia, followed by reperfusion. These effects also proved to be PI-3K mediated. ${ }^{158}$ (figure 3 ) 
IGF-1 mediated cardioprofection

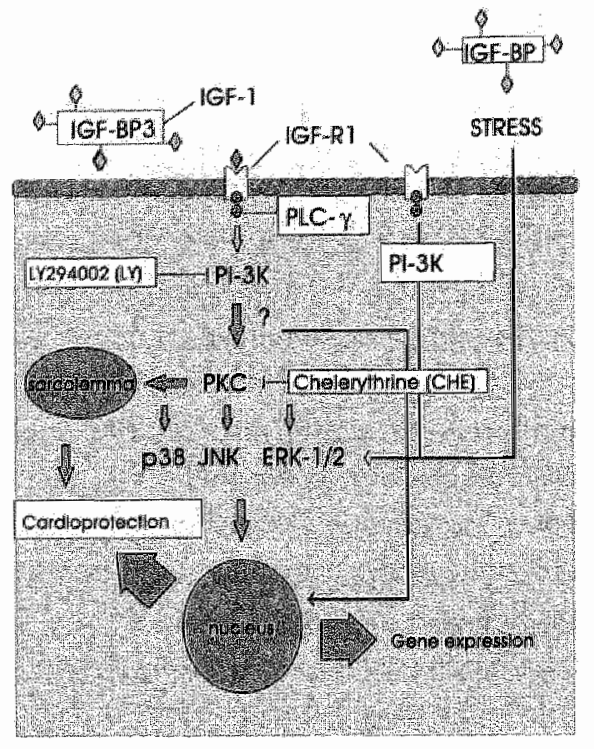

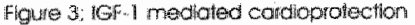

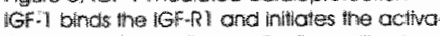
thon of signaling potthwoys; fing thy tesulth th cardac probetion and gene expression. IGF - I: insuln

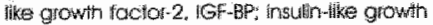

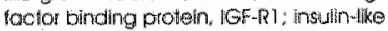

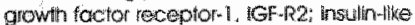

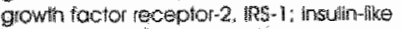
gowlin factor receper subshote, FLCr, phos-

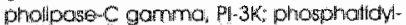
iriouta th lohosphote kricse; ERK; extrocellutor

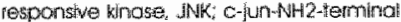
kinose:

\section{Clinical trials and clinical implications}

In recent years, encouraged by the promising results from animal studies, several clinical trials have been conducted. In patients suffering from the Laron syndrome (IGF-1 deficiency or primary GH resistance), GH and IGF-1 replacement therapy have been proven successful in restoring linear growth and diminishing other symptoms of this disease, like abnormal bone maturation. ${ }^{159,10^{160}}$ Also in GH-deficient adults, GH replacement therapy is successfull in alleviating symptoms and nomalizing IGF-1 plasma levels. ${ }^{\text {IG }}$ Either GH or IGF-I were administered to patients suffering from cardiac failure or chronic myocardial ischemia. Short-term administration of IGF-I or GH proved to be benificial to patients suffering from heart failure. Osterziel et al. ${ }^{139}$ demonstrated an acute improvement in cardiac function, after 4 days of $\mathrm{GH}$ treatment in heart failure patients with coronary artery disease. Furthermore, this group demonstrated in a larger, randomized, double-blind, placebo-controlled trial, that short-term recombinant human $\mathrm{GH}$ (thGH) treatment in heart failure patients was associated with an increase in left ventricular ejection fraction, which in turn, could be positively correlated to circulating IGF-] levels. ${ }^{139}$ Similarly, Donath et al. ${ }^{162}$ demonstrated in a randomized, double-blind, placebo-controlled study consisting of 8 patients, that 4 hours of i.v. treatment with rhIGF- 1 in patients suffering from chronic heart failure, was associated with improvement of cardiac index and stroke volume and decreased peripheral resistance and right atrial pressure, while heart rate, pul- 
monary artery wedge pressure, and pulmonary vascular resistance was simillar in treated and untreated control patients. One could therefore conclude that short term GH and IGF.I treatment in heart failure patients results in an acute improvement in cardiac performance.

In contrast to the benificial effects of short-term GH/IGF. I administration on cardiac performance in heart failure patients, long-term results in this patient group are less promising. Recently, two randomized, double blind, placebo-controlled studies did not show any significant GH-mediated improvement in cardiac performance, despite significant increases in plasma IGF-1 levels. ${ }^{163}$ The most important of the two is the report by Osterziel and co-workers $^{154}$, who administered rhGH for 12 weeks in a randomized placebo-controlled manner to patients suffering from dilated cardiomyopathy and failure. Although they showed an increase in left ventricular mass which was positively correlated with the increased IGF-I serum levels, they failed to demonstrate improvement of left ventricular wall stress, mean arterial blood pressure and systemic vascular resistance. In addition, NYHA functional class, left ventricular ejection fraction and results from tredmill testing were similar in rhGH treated patients and in the placebo control patients. This was underlined by Isgaard et al. ${ }^{165}$ who administered rhGH in a similar study design. They also demonstrated increased IGF-1 levels, but no differences in systolic and diastolic cardiac function, exercise capacity, functional class or dyspnoe grade were found between the treated and the placebo group. This failure to respond could be due to acquired GH resistance that is present in cardiac failure..$^{163}$

Thus far, the general consensus is that IGF-1 and GH therapy in chronic heart failure patients has become obsolete, since two well designed, randomized and placebo-controlled studies failed to show beneficial effects on cardiac performance in this patient group. Whether or not IGF-I can be implemented as a myocardial preconditioning treatment to reduce myocardial damage during ischemia and reperfusion, remains to be determined.

\section{The Fibroblast Growth Factor family in cardiac disease}

The Fibroblast Growth Factor family (FGF) represents a large family of heparin-binding growth factors which have been shown to be of crucial importance in (cardiac) development, growth and differentiation. Also in adult life, these peptides in conjunction with their cognate receptors (FGF- R's) modulate a myriad of functions, including angiogenesis, arteriogenesis, regulation of wound healing, cell turnover, and cell survival. In cardiovascular disease, the vast attention for FGF"s can be attributed mainly to their angiogenic potential. 
In response to the favorable results obtained from animal models of experimental myocardial infarction and failure, several (pre) clinical studies are conducted to evaluate the longterm effects of FGF's on the induction of therapeutic cardiac angiogenesis in patients suffering from chronic myocardial ischemia. Onlly recently it came to notice that FGF's might also mediate short-term cardioprotective effects on the myocardium.

Here, the angiogenic potential of FGF's will not be discussed in detail. Chapter 2 of this thesis focusses solely on the role of peptide growth factors in cardiac angiogenesis.

To date, the FGF family consists of at least 21 structurally and functionally related polypeptides. ${ }^{163,167}$ Already in 1974, Gospodarowicz and co-workers ${ }^{16 \%, 169}$ reported the identification of "Fibroblast Growth Factors". In 1986, the first two members of the FGF family, acidic FGF and basic FGF, were identified and sequenced by Jaye et al. ${ }^{170}$ and Abraham et al. ${ }^{17}$, and named after their potential to stimulate fibroblast proliferation. ${ }^{172,173}$ In the past twenty-five years, other members of the FGF growth factor family have been characterized and studied intensively. In 1991, at the Nomenclature Meeting Report and Recommendations of the New York Academy of Sciences, a new, less confusing nomenclature was proposed for the FGF family and the members are now named FGF's 1-21. ${ }^{\text {in }}$ However, one should reallize that the name "Fibroblast Growth Factor" is used for a historic reason and that not all FGF's possess the ability to stimulate fibroblast proliferation. In this chapter, attention will be focused on FGF-1 (acidic FGF) and FGF-2 (basic FGF), the most important and best characterized family members.

In humans, FGF-1 (or acidic FGF) is a 140 amino-acid protein derived from the FGF-1 gene, located on chromosome 5. FGF-2 (or basic FGF), is a 18 $25 \mathrm{kDa}$ protein, derived from the $\mathrm{FGF}-2$ gene. It is located on chromosome 4 and consists of three exons. The FGF-1 gene shares $55 \%$ homology with FGF2 and also consists of 3 exons. ${ }^{175}$ However, different splice variants are known, giving rise to several FGF proteins of different size. FGF-1 and 2 are produced by a myriad of cell types, including cardiomyocytes ${ }^{10.176 .178}$, endothelial cells ${ }^{116,126,178}$, macrophages ${ }^{176,17,1819}$ and fibroblasts. ${ }^{176}$ In each cell type, FGF's initiate distinct paracrine and autocrine functions.

While FGF- 1 and 2 lack a signaling peptide necessary to exteriorize the protein from the producing cell, the mechanism of release is still a point of discussion in literature. It is believed that FGF-1 and 2 originating from dying cells are released into the extracellular matrix (ECM) and are bound by heparan sulfates. These heparin proteoglycans protect FGF's from inactivation and degradation in vivo and in vitro. ${ }^{181,18 z}$ FGF's, by integrating into the $\mathrm{ECM}$, 
could act as a local growth regulator and induce the regeneration of these tissues following injury ${ }^{183}$ for instance after MI. Only recently, it was demonstrated that FGF"s can be released from cardiac myocytes due to contractions of myocytes. ${ }^{184,185}$

\section{FGF-receptors}

At least 4 distinct genes encoding for FGF receptors have been cloned, each with selective binding capacity, and thus specificity for different FGFs. In addition to these high-affinity receptors, ECM- bound heparan sulfates and heparan-sulfate-containing proteoglycans (HSPGs) also constitute low-alfinity receptors for FGFs and serve as a reservoir for FGFs localized extracellularly, thereby modulating FGF-activity. These HSPGs have been proven to be critical for interaction with the FGFRs.

During embryogenesis, the presence of FGFs and FGF-receptors in different organs is confined to a distinct pattern of up-and downregulation during specific time-frames. In the developing organism, the highest levels of FGF-receptors were detected in bones, in the brain and mesenchymal structures like skeletal, cardiac and smooth mucle. ${ }^{187}$

In the developing myocardium, FGF-R types 1, 2 and 3 are present, although FGF-Rl is by far the most abundant. ${ }^{155}$ The fetal isoform of FGF-RI, a product of the $f \lg$-gene, ${ }^{16,187}$ is present early in embryonic life and is downregulated during the neonatal period ${ }^{189}$, in concert with downregulation of FGF-1 and 2. ${ }^{190}$ This downregulation of fetal. FGF-R1 occurs at the same time that the myocardium transits from hyperplasia to hypertrophy, indicating that this fetal isoform might play an important role in the control of myocyte number and therefore myocardial architecture. ${ }^{116,11}$ ?

In the adult organism, FGF-receptors are detected mainiy in the adult brain and myocardium, but not in other organs, like the liver, kidneys, intestine, lung or stomach. ${ }^{19 !}$

In the adult heart, the most important FGF-R is FGF-RI ${ }^{188}$, although FGF -R4 is also present in small quantities. ${ }^{192}$ However, the FGF-R1 isoform present in adult myocardium proved to be smaller compared to the fetal isoform of FGF-RI. The fetal counterpart is virtually absent in adult myocardium. ${ }^{\text {ma }}$

\section{FGF-R signaling}

Binding of FGF's to the extracellular ligand-binding domain of FGF-RL is followed by transactivation of the intracellular domain of the FGF-RI and the subsequent dimerization of the receptor. ${ }^{194}$ This leads to autophosphorylation 
of intracellular tyrosine kinase residues, located at the intracellular domain of FGF-RI. ${ }^{\text {is }}$ These phosphorylated tyrosine residues serve as recruitment sites for so-called adaptor proteins, Src homology 2 [SH2]-containing signalling molecules, that subsequently activate a cascade of distinct intracellular substrates, which are eventually responsible for gene transcription among other

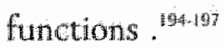

One of these $\mathrm{SH}-2$ containing proteins is Phospholipase C(PLC- $\gamma)$. Activation of PLCy leads to the formation of inositol $1,4,5$ triphosphate and

Diacylglycerol (DAG). Inositol $1,4,5$, triphosphate causes the release of calciuri from internal stores, while DAG activates different $\mathrm{PKC}$ isoforms. $\mathrm{PKC}$ in turn activates the Raf/MAPK pathway, responsible for cellular proliferation and growth. In addition, PKC activation might activate other signaling pathways involved in ischemic preconditioning, as was described above. ${ }^{194,195,198,199}$ Another family of $\mathrm{SH}-2$ containing proteins, binding to the intracellular domain of the FGF-R is the Src family of tyrosine kinases, proteins that are also involved in ischemic preconditioning, as was described earlier in this introduction. Also FGF receptor substrate-2 (FRS2), lacking an SH-2 domain, binds to the activated FGF-RI and finally activates the Ras/Raf/MAPK pathway. ${ }^{199,200} \mathrm{PI}-3 \mathrm{~K}$ activated $\mathrm{Akt}-1$ is strongly involved in insulin-receptor and IGF-R1 signaling, but not in FGF-RI related signaling. Therefore, the FGF-2 effects on apoptosis, cannot be regulated by the same pathway that is responsible for IGF-I mediated reduction of apoptosis. Other, for this thesis less important, adaptor proteins binding FGF-RI are Crk, Nck and Shb. ${ }^{i 99}$ FGF-RI binding of these different adaptor proteins and the subsequent activation of multiple divergating signaling pathways, finally result in multiple effects, like cell division, cell growth, cell migration and cell death.

In addition to their role in initiating FGF-mediated signaling by activation of several intracellular signaling pathways, FGF-Rx's may also play a role in the regulation of the extracellular pool of FGF growth factors. Binding of FGF's to FGF-R might lead to internalization of the FGF-FGF-R complex into the cytosol where it is degraded. ${ }^{201}$

The extracellular pool of FGFs is also influenced by the presence of soluble FGF-Rs (also called FGF-binding proteins), which are truncated isoforms of FGF-R1. By binding to circulating FGFs, these soluble FGF-receptors may play a role in the regulation of biological activity of FGF's. ${ }^{202}$

\section{The role of FGF's during embryogenesis:}

Fibroblast growth factors have been shown to be of critical importance for the development of mesenchymal structures, the nervous system and skele- 
ton. ${ }^{175.203 .205}$ In addition, FGFs might serve as a differentiation factor by instructing tissues destined to form ectodermal structures to differentiate into mesenchymal structures. ${ }^{178}$ During embryogenesis FGF-1 and FGF-2 share the ability to induce proliferation and differentiation of mesoderm-derived cells ${ }^{16,175,177,206-208}$, including myocytes ${ }^{116,177,205}$ and endothelial cells. ${ }^{198,209}$ The interplay between VEGF and FGF-2 is required for the effective formation of mature capillary tubes. ${ }^{210}$ Apart from its mitogenic and diffentiating properties, FGFs also act as survival factors for several cultured cells, including cardiac myocytes ${ }^{205}$, endothelial cellis ${ }^{2 ! 1}$ and neuronal cells. ${ }^{212}$

Deng et al..$^{212}$ demonstrated that FGF-RI is required for early postimplantation growth and axial organization. FGF-Rl deficient embryos displayed severe growth retardation both in vitro and in vivo and die prior to gastrulation. In addition, FGF-RI is required for in vivo cardiac myocyte proliferation at the early embryonic stages, while cardiomyocyte growth after the second week of embryogenesis is completely FGF-R1 independent. ${ }^{2 / 4}$

Surprisingly, FGF-2 deficient mice are viable and morphologically normal. However, they display decreased vascular smooth muscle cell contractility, low blood pressure, and thrombocytosis. ${ }^{2 i 5}$ In addition, FGF-2 deficient mice develop dilated cardiomyopathy. ${ }^{216}$ However, other FGF family members, like FGE-10, appear to be indispensable for normal embryogenesis and loss of this gene results in perinatal death."

\section{The role of FGF's in cardiovascular disease}

\section{Acute Myocardial Ischemia:}

When the heart is subjected to an ischemic stimulus, both FGF-1/2 and FGF$\mathrm{Rl}$ are upregulated in different cardiac cells, and act in an autocrine and paracrine fashion. ${ }^{218}$ In addition to enhanced ligand and receptor expression, tisstue damage causes the FGF-stores in the ECM to be released, thereby further enhancing the availability of FGFs in the ischemic tissues. Enhanced levels of both growth factor and receptor are indispensible for adequate remodeling of the infarcted ventricle and formation of bridging collaterals to ischemic tissue, even resulting in reduction of infarct size and enhanced cardiac function. ${ }^{219}$ When FGFs are freed from the surrounding ECM, they are also released into the bloodstream and pericardial fluid. Fujita et al. ${ }^{220}$ showed that FGF-2, but not VEGF levels, are elevated in the pericardial fluid of patients suffering from unstable angina pectoris, compared to patients with non- ischemic cardiac disease. Similarly, Cuevas et al. ${ }^{221}$ demonstrated enhanced serum levels of FGF-2 in patients suffering from an (sub)acute MI. Serum levels were signifi- 
cantly increased at 10 days post-infarction, but returned to baseline at 30 days post-MI. In contrast, Kawamoto et al "27z found enhanced VEGF, but not FGF2 levels in plasma of patients in the subacute phase of myocardial infarction (1 week post-MI). Finally, I wakura et al. ${ }^{223}$ demonstrated elevated levels of FGF1 in pericardial fluid of patients under conditions of both acute and chronic rnyocardial ischemia.

In addition to the more long-term effects of growth factors on cardiac remodeling and collateral formation in the infarcted ventricle, FGFs may also display acute effects on the ischemic myocardium. Buehler et al. ${ }^{224}$ recently demonstrated that FGF-1 overexpression delays infarct development in an in viwo model of regional myocardial ischemia and reperfusion. Expanding the time of ischemia increased infarct size. At 75 minutes of ischemia, no differences could be detected between FGF-1 transgenic mice and WT controls. This illustrates the temporary effect of FGF-1 on myocardial protection. In addition, it demonstrates that although this mouse strain develops more epicardial vessels and increased branching of epicardial coronary vessel $s^{225}$, collateral flow was not enhanced, since infarct size was similar in both genotypes. Furthermore, Cuevas et al. ${ }^{225}$ demonstrated in a rat model of cardiac ischemiareperfusion, that FGF-I administration during reperfusion alone was sufficient to reduce infarct size and to improve left ventricular function. This protection proved to be associated with the enhanced expression of iNOS. These results are in line with observations by Horrigan et al. ${ }^{227}$, who demonstrated an angiogenesis-independent reduction in infarct size after administration of FGF-2. They showed in a canine model of myocardial ischemia and reperfusion, that bolus administration of $\mathrm{FGF}-2$, both during the ischemic period and directly at reperfusion, significantly decreased infarct size one week after I/R. No effects on collateral formation and cardiac performance were reported. In an isolated rat heart model of $\pi / R$, Similarly, Cuevas et al. ${ }^{22 t}$ demonstrated in a rat model of myocardial ischemia (10 minutes) and reperfusion (24 h.) that FGF-2 administration during reperfusion, reduced myocardial necrotic cell death. In a similar study by the same group, it was demonstrated that FGF-1, administered during reperfusion, decreased the meutrophil accumulation in the infarcted ventricle. This might be one of the explanations for the attenuation of reperfusion induced damage by FGFs, since neutrophil extravasation is a critical step in neutrophil-induced myocardial reperfusion injury. ${ }^{229}$ In an isolated mouse heart model of $\mathrm{I} / \mathrm{R}, \mathrm{FGF}-2$ overexpression increased myocardial. cell viability with $45 \%$. Overexpression of FGF-2 was associated with a $20 \%$ increase in capillary density. In addition to decreasing necrotic cell death during $I / R$, also apoptotic cell death is attenuated by pre-ischemic FGF-l and 
FGF-2 administration. ${ }^{230,231}$ Finally; ischemia-induced cardiac arrhythmias can be prevented by FGF-I administration during reperfusion. ${ }^{232}$

The protective effects of FGFs under acute ischemic conditions, might be explained by the FGF-related induction of an ischemic pre-conditioning-like response and the activation of pathways that have been implicated in IPC. Htun et al. ${ }^{233}$ demonstrated that pre-ischemic administration of FGF-1 protects the myocardium from subsequent ischemic damage and mimics an ischemic preconditioning response. The FGF-1 induced protective effects could be completely abrogated by administration of a FGF-RI inhibitor, indicating that protection by FGF-] is FGF-R1 mediated. The hypothesis of FGF inducing IP is further underlined by the work of Sheikh et al. ${ }^{185}$, who showed that FGF-2 overexpression resulted in enhanced resistance to ischemia, which was associated with enhanced phosphorylation of JNK and enhanced cytosolic PKC- $\propto$ and $\varepsilon$ levels, proteins which are strongly involved in IP. ${ }^{234}$ Finally, Padua et al. ${ }^{235}$ demonstrated in an isolated rat heart model of $l / R$ that pre-ischemic administration of FGF-2 resulted in cardiac protection from subsequent ischemic damage. FGF-2 administration was associated with enhanced PKC- translocation and MAPK activation. Both PKC-E translocation and the FGF-2 mediated protection of myocardial cell death were completely abolished when PKC activation was pharmacologically inhibited. The notice that ${ }^{F} \mathrm{GF}-1$ administra-

\section{FGF-1 mediated cardioprotection}

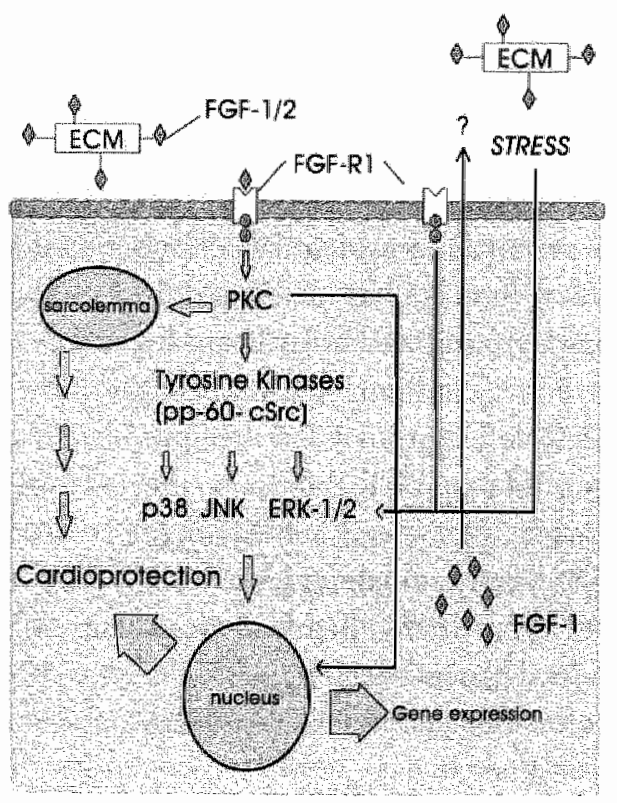

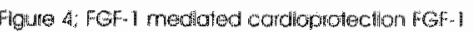
binds the FGF-R1. Which results in the astivation of stgnaling porthwass leoding io corbloprotection and gene expresston. ECH: extracestulan motrix, FGF i

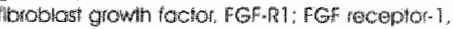

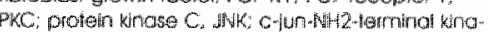
se. ER: extrow 
tion during reperfusion alone proved to be sufficient to reduce infarct formation and enhance cardiac functional recovery as soon as reperfusion therapy is initiated $^{2 x}$, might offer a new (adjuvant) treatment to attenuate reperfusion damage in patients suffering from acute MI, in addition to thrombolytic therapy. FGFs also directly influence cardiac function under non-ischemic circumstances. While IGF-1 improves cardiac function and cardiomyocte contractility, FGF-2 is negative inotropic, both in vitro ${ }^{236}$ and ex vivo ${ }^{235}$, probably due to alterations in intracellular calcium handling ${ }^{236,237}$ (Figure 4).

\section{Chronic Myocardial ischemia}

During chronic ischemia, FGFs modulate different processes involved in cardiac remodeling, like myocardial angiogenesis (chapter 2), induction of cardiac hypertrophy in vivo and in vitro, induction of cellular proliferation and repression of ischemia induced necrotic or apoptotic cell death and modulation of the ECM and scar formation.

In the past years, attention has focused on the angiogenic role of FGFs. While FGF-2 is mainly involved in angiogenesis $176,180,155.279,235.251, F G F-1$ is maily involved in arteriogenesis. $225,252-25$. . However, other studies also report angiogenic properties of FGF-1 ${ }^{230,233,255.235}$ The angiogenic potential of FGFs is described in more detail in chapter 2 of this thesis.

Fibroblast growth factors influence scar formation following chronic MI by modulating the deposition of ECM constituents, including collagen type I and III, as well as fibronectin and laminins. ${ }^{183.259}$ FGF-2 represses the production of collagen type-I and fibronectinn ${ }^{201,251}$ In addition, bFGF stimulates the breakdown of the ECM by induction of collagenases like matrix metalloproteases (MMP). ${ }^{26 x}$ Myocardial ischemia inevitably leads to the loss of contractile units, resulting in increased workload for the remaining cardiomyocyte population, in order to maintain cardiac output. In response to myocardial ischemia, FGF$1 / 2$ and $F G F-R I$ expression in the myocardium is enhanced. In addition, pulmonary hypertension", and increase in systemic afterload (primary hypertension, aortic stenosis, hypertrophic obstructive cardiomyopathy) result in the expression of FGFs and FGF-RI. ${ }^{9}$ FGF-2 deficient mice fail to show a hypertrophic response. ${ }^{216}$ Recently it was reported that FGF-1 and 2 are key players in pressure induced myocardial hypertrophy $y^{9,21,263,264}$ and in cardiomyocyte hypertrophy occurring in idiopathic dilated cardiomyopathy. ${ }^{263}$ Also in vitro, exogenous FGF-2 administration causes hypertrophy of cultured cardiomyocytes and the expression of a number of fetal genes, which are considered as molecular markers of hypertrophy, like $\alpha$-smooth muscle actin and Atrial Natriuretic Factor (ANF) ${ }^{266}$ 
Furthermore, FGFs play a role in cell turnover in the infarcted ventricle. In general, FGFs induce DNA synthesis and proliferation of non-myocytes ${ }^{\text {sin }}$, while attenuating apoptosis of cardiomyocytes and non-myoctes. ${ }^{20,23 !}$ In addition to effects on the myocardium, FGFs also display direct effects on the vasculature. Both FGF-1 and FGF-2 are capable of dilating arterioles and causing hypotension. ${ }^{26,769}$ However, FGF- 2 deficient mice displayed hypotension due to decreased vascular smooth muscle cell contractility. Therefore, it is concluded that FGF-2 plays an important role in control of the vascular tone. ${ }^{215}$

\section{Clinical trials and implications}

In recent years, several clinical trials have been conducted, mainly with IFGF-I and FGF-2. They were aimed at the induction of angiogenesis. Recently, Laham et al. ${ }^{270}$ conducted a randomized, placebo-controlled trial, in which patients undergoing bypass surgery were treated with a local perivascular delivery of FGF-2. Stress nuclear imaging demonstrated a significant decrease of the perfusion defect, compared to placebo treated patients. MRI assessment of the target ischemic zone, showed a trend toward reduction in the target ischemic area in the FGF-2 treated group. However, statistical significance was not reached, because of the small number of patients ( $n=24)$. Currently, the trial is continued to recruit more patients for this adjuvant therapy. In another phase- 1 clinical trial, Laham and co-workers ${ }^{2 \% !}$ administered a single intracoronary dose of FGF-2. Intracoronary administration of FGF-2 protein was associated with transient hypotension. At 6 months follow-up, there was an improvement in the quality of life and an improvement in exercise tolerance, in addition to increased regional wall thickening (assessed by MRI) and a reduction in the extent of the ischemic area. However, efficacy could not be assessed, since no placebo control group was included. To this end, a placebocontrolled, double blind follow-up phase-II trial (FGF Initiating RevaSculaization Trial [FIRST trial]) was conducted with intracoronary administration at 3 different dosages. After a three month follow-up, it was demonstrated that FGF-2 treated patients had less anginal complaints. However, this effect had disappeared at 6 months follow-up. In addition, no significant improvement in exercise tolerance or improvement in myocardial perfusion area could be demonstrated ${ }^{272}$ Subgroup analysis demonstrated that the "sicker" patients had more benefit from treatment. ${ }^{273}$ Sellke et al. ${ }^{274}$ administered FGF-2 to patients undergoing coronary artery bypass grafting. FGF-2 was impregnated in heparin-alginate beats and implanted in the epicardial fat in multiple regions of an area of the heart that could not be revascularized. All 
patients showed an improvement in angina functional class. However, because no placebo group was used and all patients underwent $C A B G$, the effect of FGF-2 treatment could not be properly assessed. Very recently, Grines et all. ${ }^{23}$ demonstrated in the placebo-controlled AGENT-trial (Angiogemic GENe Therapy triall that administration of an adenovirus encoding for human FGF-4 (AdS FGF4) to patients suffering from stable angina results in an improvement in exersize time compared to the placebo controls. Finaly, Schumacher et al ${ }^{258,276}$ administered $\mathrm{FGF}-1$ in patients with three-vessel coronary artery disease undergoing concomitant CABG. Recombinant human FGF -1 [rhFGF1) was injected intramyocardially close to the anastomosis of the left internal mammary artery to the native left anterior descending artery. Again, no placebo control group was studied and thFGF-1 therapy was not used as a sole therapy. After 3 months, several patients showed enhanced collateral formation close to the site of injection. All of these studies demonstrated that growth factors are well tolerated, can be safely administered and that side effects are minor, including the absence of tumor growth. ${ }^{207}$ However, none of these studies demonstrates major positive effects of growth factor treatment.

\section{Outline thesis and hypotheses}

The recent advent of transgenic mouse models, either overexpression models or knock-out murine models, enabled researchers to investigate the role of a single protein in vivo. Together with the development of the necessary tools to evaluate cardiac performance in these small rodents, the use of transgenic mouse models to study cardiac disease on basic cellular and subcellular level have exponentially increased in the past few years. In the following chapters, the role of $1 \mathrm{GF}-1$ and $\mathrm{FGF}-1$ during acute and chronic myocardial ischemia will be investigated using two trangenic mouse lines, a model of heterozygous IGF-I deficiency and a mouse strain with a cardiac-specific FGF-I overexpression. Alterations in cardiac function or functional recovery, cardiac architecture and composition and myocardial cell death have been compared to wild-type (WT) controls.

\section{Insulin-like growth factor-1 during chronic myocardial ischemia}

The general growth promoting and insulin-like effects were described several years ago, while more recently, attention focused on the role of $1 \mathrm{GF}-1$ in the pathobiology of different organ systems. In the myocardium, IGF-1 may have effects during acute myocardial ischemia and during the ventricular remodeling process following chronic MI. 
While the role of IGF-I in chronic myocardial ischemia and cardiac hypertrophy have been described extensively in literature, the effects of reduced IGF. I plasma levels or IGF-1 deficiency on the development of a MI have not been investigated. This is in part due to the fact that homozygous IGF-I deficient animals are, if viable, extremely small and weak. Since IGF-1 might alter the remodeling response and therefore might influence cardiac function we propose the following hypothesis.

Hypothesis:IGF-1 deficiency impairs cardiac remodeling and function following chronic MI in mice.

In order to study the effects of reduced IGF-1 plasma levels on cardiac remodeling and function during chronic myocardial ischemia, we used an heterozygous [GF-] deficient mouse strain and surgically induced a MI by ligation of the left coronary artery. One week after induction of the MI, cardiac function measurements were performed. Subsequently, the heart was excised and several parameters of cardiac architecture, composition and cell population were investigated, using different (immuno-) histological staining techniques. The results of this study will be described in chapter 3 .

\section{Insulin-like growth factors during myocardial ischemia and reperfusion}

The role of IGF-I in reduction of apoptosis during acute ischemia and reperfusion has been deliniated on a (sub)cellular level in literature, the effects of IGF-I on cardiac functional recovery and necrotic cell death during myocardial ischemia and reperfusion have not been studied intensively. Therefore, the mechanism of IGF-1 mediated protection is not known. From the data in literature, demonstrating the IGF-I and insulin-mediated PI-3K and PKC mediated protective effects during acute ischemia, we formulated the following hypothesis

\section{Hypothesis:IGF-1 protects the myocardium from ischemia and reperfu- sion induced damage through a PKC and PI-3K mediated pathway}

In chapter 4 , we report our fndings on the protective effects of $\left|G^{F}-\right|$ during myocardial ischemia and reperfusion in a murine model of IGF-I deficiency and try to further delineate the intracellular signaling pathways involved in IGF-1 mediated protection. To this end, we used an isolated ejecting murine heart model of ischemia and reperfusion ${ }^{278}$ (Figure 5). In addition to the assessment of alterations in tolerance to ischemia due to IGF-I deficiency, we 


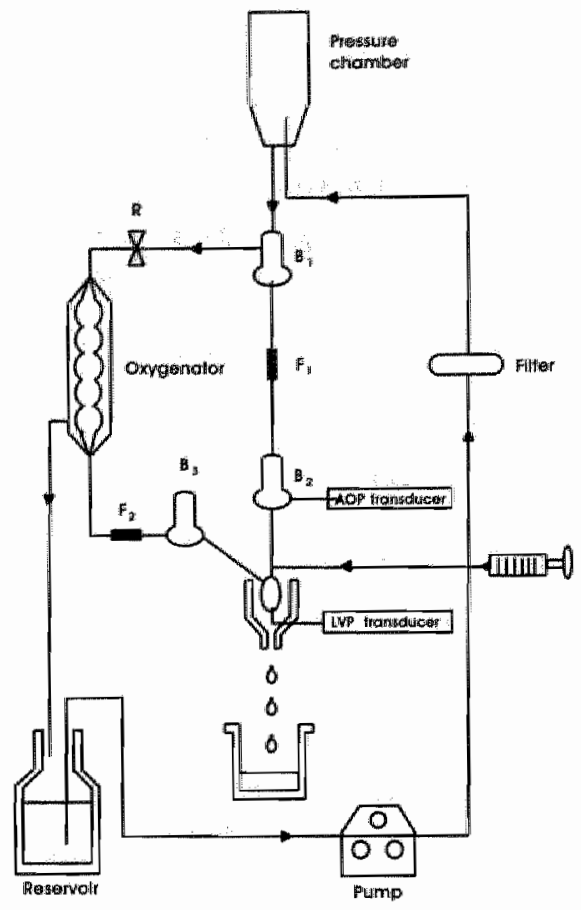

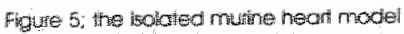
Cilstollow wiffer is pumped them a reserwar

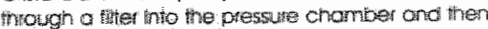

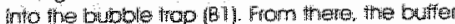

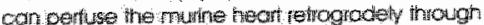

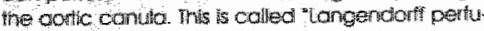

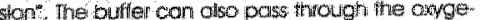

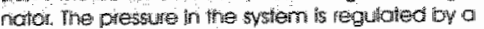

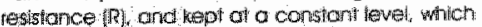

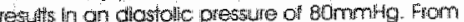

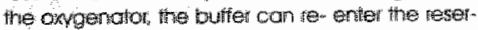

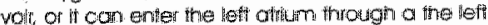

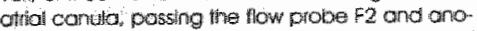

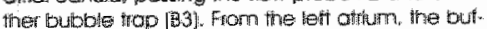

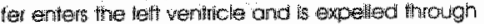
the kell veriericulor oustow trow possing onother

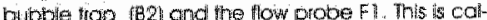
focl the "ejecting murine heart mode. The heart is prowcing its own cononory pewfiston. the teft attiol

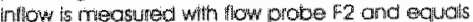

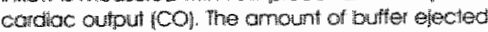

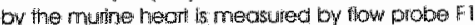

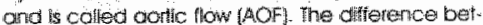
wem $\mathrm{CO}$ and AOF equals the amount of buffer perfusing the conongy swstem and is colled coro

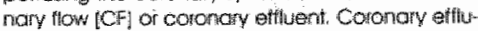
ont is sumpled throughout ine complets durotion of live exparmental protocol for determination of kactate and LDH lariote detivciogenasel relase

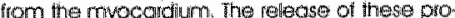
teins ate poumeters for ancerobic motobolism ond myocondial ced darmoge, respertwev th odchiton, a pressure cotheter is inserted hingugi

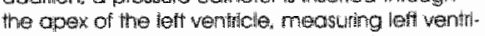
Cular oresiste development [LP fronsducen.

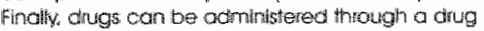

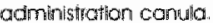

investigated the effects of pre- ischemic IGF-I administration on cardiac functional recovery and cell death. We found a protective effect of [GF-1 administration on both cardiac functional recovery and cell death. To unravel the intracellular signaling pathways involved in this phenomenon, we applied pharmacological inhibition of PI-3K and PKC and investigated the effects on cardiac functional recovery and cell death, in addition to the downstream MAPK activation.

\section{Fibroblast growth factor-1 during chronic myocardial infarction.}

In literature, research concerning fibroblast growth factors mainly concentrated on FGF-2 and its ability to induce angiogenesis. The effects of FGF-1 are less well known, although recently, this growth factor received more attention. FGF. I is involved in arteriogenesis, rather than angiogenesis. Recently, the arteriogenic effects of FGF-I have been described by Fernandez et al..$^{225}$ The effects of FGF-1 on cardiac remodeling and function are unknown. In vitro studies demonstrate FGF-1 mediated effects on collagen synthesis, cellular proliferation and hypertrophy of cardiac myocytes. One could therefore expect FGF-1 to influence cardiac remodeling and therefore cardiac function 
after MI. However, so far no in vizo studies have been published describing the role of FGF-I in chronic MI.

\section{Hypothesis:Cardiac-specific FGF-1 overexpression improves cardiac remodeling and function following chronic myocardial infarction.}

In chapter 5, we used a transgenic mouse model of cardiac specific FGF-I overexpression to investigate the effects of FGF-1 on remodeling in chronic MI. The effects on cardiac function and structure (remodeling) were investigated using an electromagnetic flow probe and immunohistological staining techniques, one week after the surgical induction of MI.

\section{Fibroblast growth factor-1 during myocardial ischemia and reperfusion}

Recently, the cardioprotective effects of FGF-l have been described in vitro (reduction in apoptotic cell death) and in vivo (FGF-l reduced infarct size e.33 $^{33}$ or postponed infarct formation ${ }^{224}$ ). However, these studies did not investigate the effects of FGF- 1 on cardiac functional recovery and cell death during. myocardial ischemia. While the intracellular signaling pathways for $\mathrm{FGF}-2$ mediated protection are partially defined, the intracellular signaling pathways for FGF-1 have not been clarified. Since Htun et al. ${ }^{2.33}$ demonstrated that FGF-I administration mimicks $\mathbb{P}$ in an FGF-RI mediated fashion, and since FGF-2 mediated protection is PKC and TK dependent ${ }^{235}$, we proposed the following hypothesis.

\section{Hypothesis: FGF-1 enhances cardiac functional recovery and decreases myocardial cell necrosis following ischemia and reperfusion.}

Chapter 6 describes the cardioprotective effects of FGF-1 during acute ischemia and reperfusion. Hearts of FGF-1 transgenic mice were subjected to global ischemia and reperfusion in the ex vivo isolated heart model. In addition, we unraveled the intracellular pathway involved in $\mathbb{F G F}-1$ mediated cardioprotection using selective pharmacological inhibition of several intracellular signaling proteins potentially involved in FGF-1 mediated cardioprotection (FGF-RI, TK and PKC).

In chapter 7 , the results of the experiments described in this thesis will be discussed, as well as some possible implications of these data for future research. Finally, the outlook of growth factor therapy, especially concerning IGF1 and FGF-1, in acute and chronic myocardial ischemia is discussed 


\section{References}

1. de Milliono PAR: Influence of medical intervention on sympathatic activity in heart failure. University of Masstricht, 2002. $127 \mathrm{p}$.

2. Doevendans $P A_{r}$ Gorgels AP, van der Zee $R$, et al: Electrocardiographic diagnosis of repertusion during thrombalytic therapy in acute myocardial infarction. Am J Cardiol 1995; 75:12061210.

3. van Krimpen C, Smits JFM, Cleutjens JPM, at al.: DNA synthesis in the non-infarcted cardioc Interstitium ofter left coronary artery ligation in the rat: effects of coptopril. $J$ Mol Cell Cordioll $1991: 23: 1245-1253$.

4. Smits JFM, van Krimpen C. Schoemaker RG, et al.: Angiotensin 2 receptor blackade after myocardial infarction in rats: effects an hemadynamics, myocardial DNA synthesis, and interstitial collagen content. Cardlowasc Pharmacol 1992;20:772-778.

5. Palmen M, Lucassen AJN, Daemen MJAP, et al.: Molecular cardiology part 6: Cardiac anglogensis and growth factors. Cardiologie 1998; 5:406-413.

6. Relss $\mathrm{K}$, Kajstura J, Zhang $\mathrm{X}$, ef al.: Acute myocardial inforction lleads to upregulation of the IGF-1 autocrine system, DNA replication, and nuclear mifotic division in the remaining vioble cardlac myocytes. Exp Cell Res 1994;213:463-472.

7. Serneri $G G N$, Modestl $P A$, Boddl $M_{n}$ ef al.: Cardiac growth factors in human hypertrophy. Relations with myocardial contractility and wall stress. Circ Res $1999 ; 85 ; 56-67$.

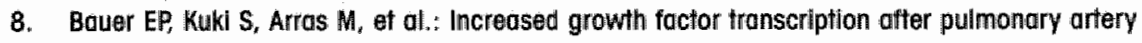
banding. Eur J Cordio-thorac Surg 1997;11:818-823.

9. Schuitz JEL, Witt SA, Nieman ML, et all: Fibroblost growth factor-2 mediates pressure-indiuced hypertrophlc response. J Clin Invest 1999;104:709-719.

10. Dhalla NS, Elmosethi AB, Hata $T_{s}$ et al.: Status of myocardial antioxidants in ischemia-reperflusion Injury. Cardiovasc Res 2000;47:446-456.

11. Park JL, Lucchesi BR: Mechanisms of myocardial reperfusion injury. Ann Thorac Surg 1999;68:1905-1912.

12. Yellon DM, Baxter GF: Reperfusion injury revislted; is there a role for growth factor signaling in limiting lethal reperfusion injury? Trends Cordlovisc Med 1999:9:245-249.

13. Dumont EAWJ, Hofstra $L$, van Heerde $W L$, et al.: Cardiomyocyte death induced by myocardial ischemla and reperfusion; measurement with recombinant human annexin-V in a mouse madel. Circulation 2000;102:1564-1568.

14. Saraste $A_{4}$ Pulkki $K$, Kallajoki $M_{*}$ et al.: Apoptosis in human acute myocardial infarction. Circutation 1997;95:320-323.

15. Gottlleb RA, Engler RL: Apoptosis In myocardial ischemia-reperfusion. Ann NY Acad SCI $1999 ; 874: 412 \times 426$.

16. Heyndrickx GR, Millard RW, McRitchie RJ, et al.: Regionol myocardlal functional and electrophysiological alterations after brlef coronary artery occlusion in concious dogs. J Clin Invest $1975,56: 978-985$.

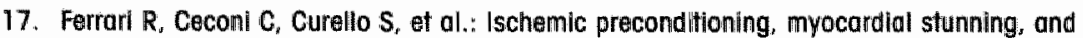
hybernation: basic aspects. Am Heart J 1999;138:561-568.

18. Braunwald $E$, Kloner RA: The stunned myocardium: prolonged, postischemic ventricular dysfunction. Circulation 1982;66:11:46-1149.

19. Diamond GA, Forrester JS, deLuz PL, et al:: Post-extrasystolic potentiation of ischemic myocarditum by atrial stimulation. Am Heart J 1978;95:204-209. 
20. Rahimtoola SH: Coronary artery bypass surgery for chronic angina-1981. a perspective. Circulation 1982;65:225-241.

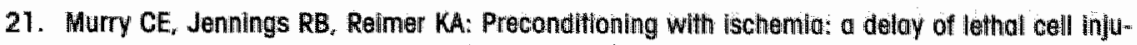
$r y$ in ischemic myocardium. Girculation 1986; 74:1124-1136.

22. Reimer KA, Murry CE, Yamasawa $\mathrm{L}$, et al... Four brlet periods of myocardial ischemia cause no cumulative ATP loss or necrosis. Am J Physiol 1986;251:H1306-1315.

23. ang $\mathrm{X}-\mathrm{M}$, Baxter GF, Heads RJ, al.: Infarct limitation of the second window of protection in a concious rabbit model. Cardiovasc Res 1996;31:777-783.

24. Marber MS, Latchman DS, Walker WM, et al.: Cardiac stress protelin elewation 24 hours after brief ischemia or heat stress is associated with resistance to myocordial infarction. Circulation 1993;88:1264-1272.

25. Yellon DM, Baxter GF: A "second window of protection" or delayed preconditioning phenomenan: future horizons for myocardial protection? J Mol Cell Cardiol 1995;27:1023-1034.

26. Kuzuya $\mathrm{T}$, Hoshida $\mathrm{S}$, Yamashita $\mathrm{N}$, et al.: Delayed effects of sublethal ischemla on acquisition of tolerance to ischemia. Circ Res 1993:72:1293-1299.

27. Miller $\mathrm{DL}$, van Winckle $\mathrm{DM}$ : Ischemic precondifloning limits infarct size following ischemia and reperfusion in in situ mouse hearts. Cardlowasc Res 1999;42:680-684.

28. Ytrehus $K$, Liu $Y$, Downey JM: Preconditioning protects ischemic rabbit heart by protein kinase C activation. Am J Physiol 1994;266:1145-1152.

29. Liu GS, Thornton J, Van Winkle DM, et al.: Protection against infarction affordled by precondttioning is medlated by $A 1$ adenosine receptors in rabbit heart. Circulation 1991;84:350-356.

30. Gray MO, Karliner JS, Mochly-Rosen D: A selective epsilon-protein kinase $C$ antagonist Inhibits protection of cardiac myocytes from hypoxia-induced cell deathi. $\mathrm{J}$ Biol Chem 1997;272:30945-30951.

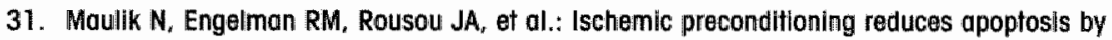
upregulating anti- death gene Blc-2. Circulation 1999;100 (suppl 2):369-375.

32. Cohen MV, Liu GS, Downey JM: Preconditioning causes improved wall motlon as well as smaller infarcts after transient caronary occlusion in rabbits. Circulation 1991:84:341-349.

33. Tian $R_{r}$ Mioo W, Spindler M, et al.: Long-term expression of protein kinase $C$ in adult mouse hearts improves postischemic recovery. Proc Notl Acad Sol USA 1999;96:13536-

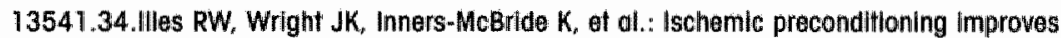
preservation with crystalloid cardioplegia. Ann Thorac Surg 1994;58:1481-1485.

35. Yabe $K-1$, Tanonaka $K$, Koshimizu $M$, et al.: A rale of PKC in the improvement of energy metabolism in preconditioned heart. Bas Res Cardiol 2000;95:215-227.

36. Wu S, Li HY, Wong TM: Cardloprotection of preconditioning by metabolic inhibition in the rat ventricular myocyte. involvement of kappa-opiold receptar. Circ Res 1999;84:1388-1395.

37. McCully JD, Levitsky S: Alternatiwes for myocardial protection: adenosine-enhanced ischem/c preconditioning. Ann NY Acad Scl 1999;874:295-305.

38. Ikonomidis JS, Shiral T, Weisel RD, ef al.: Preconditloning culfured human pedlatric myocytes requires adenosine and protein kinase $\mathrm{C}$. Am J Physiol 1997;272:H1220-H1230.

39. Borst MM, Simonis $G$, Rothele $\mathrm{J}$, ef al.: Blokade of $\mathrm{A}$ I adenosine receptors prevents the ischemia-induced sensitisation of adenylyl cyclase: evidence for a protiein kinose C-mediated pathway. Bas Res Cardiol 1999;94:472-480.

40. Lochner $A$, Genade $S$, Tromp $E$, et al.: Ischemic precondifioning and the beta-adrenergic signal transduction pathway. Circulation 1999; 100:958-966.

41. Ping $P$, Zhang J, Pierce WM, et al.: Functional proteomic analysis of Protein Kinase $C$ epsilon signaling complexes in the normal heart and during cardioprotection. Circ Res 2001;88:59-

62 . 
42. Ping $P$, Zhang $J$, Qiu $\Psi$, et al.: Ischemic preconditioning induces selective tramslocation of protein kinase $\mathrm{C}$ isoforms epsiton and $\mathrm{n}$ in the heort of cancious rabbits without subceillular redistribution of total protein kinase $C$ activity. Circ Res 1997;81:404-414.

43. Shlimkhovich $B Z$, Prayklenk $K$, Kloner $R A$ : Role af protein kinase $C$ as a cellular medlator of Ischemic preconditioning: a critical review. Cardiavase Res 1998,40,9-22.

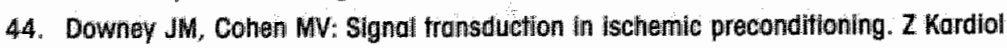
1995:84:77-86.

45. Guo $Y$, sones WK, Xuan $Y-T_{\text {, a }}$ al al. The late phase of ischemic preconditioning is abrogated by targeted disruption of the inducable NO synthase gene. Proc Nath Acad Sci USA 1999;96:1 1507-11512.

46. Mochly-Rosen D: Lacalization of protein kinases by anchoring proteins: a theme in signal transduction. Sclence 1995;268:247-251.

47. Pass JM, Zheng $Y$, Wead WB, et al.: PKC-epsilon activation induces dichotomous cardiac phenotypes and modulates PKC-epsilon-RACK interactions and RACK expression. Am J Physiol $2001 ; 280 ; 946-955$.

48. Milchell $M B_{r}$ Meng $\mathrm{X}, \mathrm{AO} \mathrm{L}$, et al.: Preconditioning of isolated rat heart is mediated by Protein Kinase C. Circ Res 1995,76:73-81.

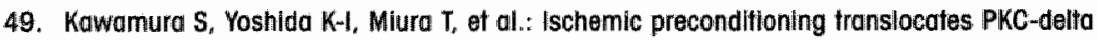
and epsillon which mediate functional protection in isoloted rat heart. Am J Physiol 1998:275:2266-2271.

50. Albert CJ, Ford DA: Protein kinase $C$ translacation and PKC-dependent protein phosphoryllathon during myocardial ischemia. Am J Physiol 1999;276:H642-H650.

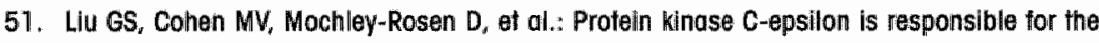
protaction of preconditioning in robbit cardlomyocytes. J Mol Cell Cardiol 1999;31:19371948 .

52. Dlu $Y$, Ping $P$, Tang $X-L$, et al.: Direct evidence that protein kinase $C$ plays an essential role in the development of late preconditioning against myocardial stunning in concious rabbits and that epsilon is the isoform involved. J Clin Invest 1998;101:2182-219

53. Lowensteln CJ: NO news is good news. Proe Natl Acad Sci USA 1999;96:10953-10954.

54. Takeishi $Y$, Jallil $T$, Ball NA, et al.: Responses of cardiac protein kinase $C$ isotorms to distinct pathologlcal stimull are differentially regulated. Circ Res 1999:85:264-271.

55. Ping $P$, zhang J, zheng $Y \times T$, et al.: Demonstration of selective protein kinase $C$-dependent activation of Src and Lek tyrosine kinoses during ischemic preconditioning in conclous rabbits. Circ Res 1999;85:542-550.

56. LI RCX, Ping P, Zhang d, et al.: PKC-epsilon modulates NF-kappa-B and AP-1 via mitogenactivated protein kinases in adult rabbit cordiomyocytes. Am J Physiol 2000;279:16791689.

57. Baines CP, Wang $L$, Cohen MV, et al.: Protein tyrosine kinase is downstream of protein kinose C for ischemic preconditianing's antl-infarct effect in the rabbit heart. $\mathrm{J}$ Mol Cell Cordiol 1998; 30:383-392.

58. Song D, O'Regan MH, Phillips JW: Proteln kinose inhibltors attenuate cardiac swelling-induced amino acid release in the rat. J Pharm Pharmacol 1998;50:1280-1286.

59. Wang $Y$, Hiral $K$, Ashrat $M$ : Activation of mitochondrial ATP-sensitive $K+$ channel for cardiac protection against ischemic injury is dependent on protein kinose $C$ activity. Circ Res 1999:85:731-741.

60. Speechly-Dlck ME, Grover GJ, Yellon DM: Does ischemic preconditioning in the human heart involve protein kinase $\mathrm{C}$ and the ATP-dependent $\mathrm{K}+$ channal? Studies af contractile function after stimulated ischemia in an atrial in vitro model. Circ Res 1995;77:1030-1035. 
61. Wang Y Ashraf M: Role of proteln kinase $\mathrm{C}$ in mitochondrial K-ATP channel-mediated protection against Ca2+overlood injury in rat myocordium. Circ Res 1999:84:1156-1165;

62. Kevelaitis $E_{u}$ Oubenaissa $A_{r}$ Peynet $d_{x}$ et al.: Preconditioning by mitochondrial ATP-sensitive potasslum channel openers. Circulation 1999;100 (suppl 2):345-350.

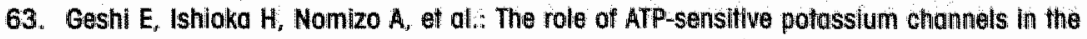
mechanism of ischemic preconditioning. J Cardiovasc Phermacol 1999;34:446-453.

64. Kukreja RC: Role of Katp channnel in heal shock and pharmocological preconditioning. Ann NY Acad Sci 1999;874:211-221.

65. Nichols CG, Ripoll C, Lederer WJ: ATP-sensitive potassium chonnel modulation of the guined pig ventricular action potential and contraction. Circ Res 1991;68:280-287,

66. O'Rourke B: Mitochondrial K-ATP channels in preconditioning. Circ Res 2000;87:845-855.

67. Sato T, Sasakl N, Seharaseyon J, et all: Selective pharmacologicall agents implicate mitochondrial but not sarcolemmal K-ATP channels in ischemic cardioprotection. Circulation $2000: 101: 2418-2423$

68. Dana A, Yellon DM: Angina: Who needs it? Cardioprotection in the preconditloning era. Cardiowasc Drug Ther 1998;12:515-528.

69. Cohen G, Shirai T, Weisel RD, et al.: Optimal myocardial preconditioning in humans. Ann NY Acad Sci 874;1999:306-318.

70. Yellon $\mathrm{DM}$, Dand $\mathrm{A}$ : The preconditioning phenomenon; a fool for the scientist or a clinical ream lity? Circ Res 2000;87:543-550

71. Llang BT: Direct preconditloning of cardiac ventricular myocytes vio adenosine A1 receptor and KATP channel. Am J Physiol 1996;271:H1769-1777.

72. Cleveland JC Jr, Meldrum DR, Cain RS, et al.: Oral sulfonylurea hypoglycemic agents prevent ischemic preconditioning in human myocardium. Two parodoxes revislied. Circulation 1997;:96:29-32.

73. Klaner RA $A_{r}$ Shook $T$, Przyklenk $K$, et al.: Previous angina alters in-hospital outcome in TIMI 4. A clinical corralate to preconditioning? Circulation 1995;91:37-45.

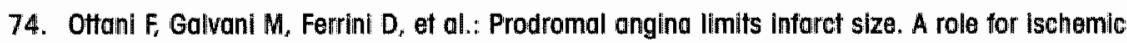
preconditioning. Circulation 1995;91:291-297.

75. Kloner $\mathbb{R A}$, Shook $T$, Antman $E M$, ef al.: Prospective femporal analysis of the onset of preinfarction angina versus outcome; an ancillary study in TIMI-9B. Circulation 1998;97:10421045.

76. Jenkins DP, Pugsley WB. Alkhulaifl AM, et al.: Ischaemic preconditioning reduces troponin T release in patients undergoing coronary artery byposs surgery. Heart 1997;77:314-318.

77. Lu $E-X$, Chen $S-X$, Yuan $M-D$, et al.: Preconditioning improves myacardial preservation in patients undergoing open heart operatlons. Ann Thorac surg 1997;64:1320-1324.

78. Yellon DM, Alkhulaifi AM, Pugsley WB: Preconditioning in the human myocardilum. Lancet 1993:342:276- 277.

79. Perrault LP, Menasche $P, B e l$, et al.: Ischemic preconditioning in cordlac surgery: a word of caution. J Thorac Cardiowasc Surg 1996:112:1378-1386.

80. Illes RW, Swoyer KD: Prospective, randomized clinical study of ischemlc preconditioning as an adjunct to intermittent cold blood cardioplegia. Ann Thorac Surg 1998;65:748-752.

81. Perrault LP, Menasche P: Preconditioning: can nature's shleld be ralsed against surglcal ischemic-reperfusion Injury? Ann Thorac Surg 1999;68:1988-1994.

82. Mair J. Wieser $C$, Seibt $I$, et al.: Troponin $T$ to dlagnose myocardial infarction in bypass surgery. Lancet 1991;337:434-435.

83. Kirsch $\mathrm{M}_{v}$ Baufreton $\mathrm{C}$, Fernandez $\mathrm{C}$, et al.: Preconditioning with cromakallim Improves longterm myocardial preservation for heart transplantation. Ann Thorac Surg 1998;66:417-424. 


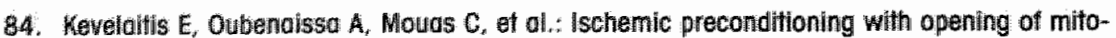
chondrid atenosine triphosphate-sensitive potassium channels or $\mathrm{Na} / \mathrm{H}$ exchange inhibition: which is the best protective strategy for heart transplants? J Thorac Cardiovase Surg $2001 ; 121: 155-162$.

85. Yellon DM, Baxter GF, Garcia-Dorado D, ef al. Ischaemic preconditioning present position and future directions. Cardiovasc Res 1998;37:21-33,

86. Rinderknecht $E$. Humbel RE: The amino acid sequence of human insuline-like growth factor-1 and its structural homology with proinsulin. I Biol Chem 1978;253:2769-2776.

87. Paimiter RD, Brinster RL; Hommer RE, ef al.: Dramatic growth of mice that develop from eggs microinjected with mettalothionein-growth hormone fusion genes. Nature 1982;300:611615.

88. Mathews LS, Harnmer RE, Brinster RL, ef al.: Expression of insulin-like growth factor 1 in fransgenic mice with elevated levells of growth hormone is correlated with growth. Endlocrinology 1988; 123:433-437.

89. Zapf J, Walter $H_{t}$ Froesch ER: Radiaimmunological determination of insulin-like growth factors 1 and 2 in normal subjects and in patients with growth disorders and extrapanereatic tumor hypoglycemila. J Clin Invest 1981;68:1321-1330.

90. Laron Z, Anin S, Klipper-Aurboch Y, ef al:: Effects of insulin-like growth factor on linear growth, thead circumference, and body fat in patients with Laron-type dwarfism. Lancet 1992;339:1258-1261.

91. Schmid C: Insulin-like growth factors. Cell Biol Int 1995;19:445-457.

92. Ito $H_{x}$ Hiroe $M$, Hirato $\gamma$, ef al: insulin-like growth fectar-1 induces hypertrophy with enhanced expression of muscle specific genes in cultured rat myocytes. Circulation 1993;87:17151721.

93. Delafontaine $\mathrm{P}$ : Insulin-like growth factor 1 and its binding proteins in the cardiovascular system. Cardiovase Res 1995;30:825-834.

94. Ullilch A, Gray A, Tam AW, et al.: Insulim-like growth factor-1 receptor primary structure: comparison with insulin receptor suggests structural determinants that define functional specificitу. ЕМBO J 1986;5:2503-2512.

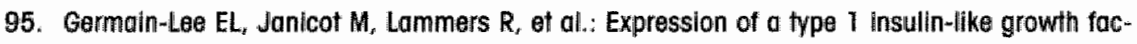
for peceptor with low affinity for Insullin-llke growth factor 2. Biochem $J 1992 ; 281: 413-417$.

96. Froesch ER, Schmid $C_{x}$ Schwander $L_{n}$ ef al : Actions of insulin-like growth foctors. Ann Rew Physiol 1985:47:443-467.

97. Foncea $R$, Andersson $M$, Ketterman $A$, el al.: Insulin-like growth factor-1 rapidly activates multiple signal transduction pathways in cultured rat cardloc myocytes. J Biol Chem 1997;272:19115-19124.

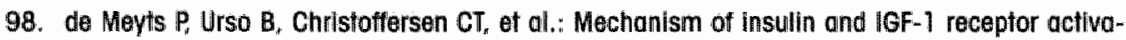
tion and signal transduction specificity. Receptor dilmer cross-linking, bell shaped curves, and sustained versus transient signaling. Ann NY Acad SGI 1995;766:388-401.

99. Kornfeld S: Structure and function of the mannose-6-phosphate/insulin-like growth factor-2 receptars. Annu Rev Blochem 1992;61:307-330.100. Powell-Broxton L, Hollingshead P, Warburton $\mathrm{C}_{\text {, ef al. }}$ IGF- 1 is required for normal embryonic growth in mice. Gen Dev 1993:7:2909-2917.

101. Powell-Braxton $L$, Hollingshead $P$, Gilitinan $D$, ef al.: Inactivation of the IGF-1 gene in mice results in perinaild lethality. Ann NY Acad SCI 1993;692:300-301.

102. Dechiara TM. Eistratladis A, Robertson EJ: A growth-deficiency phenotype ln heterozygous mice carrying an insulin-like growth factor 2 gene disrupted by fargeting. Nature $1990 ; 345: 78-80$. 
103. DeChiara TM, Robertson $\mathrm{EJ}_{w}$ Efstratiadis A: Parental imprituing of the mouse insulin-like growth factor-2 gene. Cell 1991; 64:849-859.

104. Lilu J-P, Baker J, Perkins AS, al.: Mice carrying null mutations of the genes encoding insulin-like growth foctor 1 (IGF-1) and type 1 IGF-1 receptor (IGF1 1). Call 1993;75:59-72.

105. Wang ZQ, Fung MR, Barlow DP, et al.: Regulation of embryonic growth and Iysosomal targeting by the imprinted IGF2r/Mpr gene. Nature 1994;372:464-467.

106. Nolan CM, Lawlor MA: Variable accumulation pf insulin-like growth factor-2 in the mouse tissues deficient in insulin-like growth factor-2 receptor. Int J Blochem Cell Biol 1999;31:14211433.

107. Han VK, D'Ercole AJ, Lund PK: Cellular localization of somatomedin (insullin-like growth facfor) messenger RNA in the human fetus. Science 1987;236:193-197.

108. Baker J, Llu J-P, Robertson EJ, et all.: Role of insulin-like growth factors in embryonic and postnatal growth. Cell 1993;75:73-82.

109. Antin $\mathrm{PB}_{\text {s }}$ Yalskievych T, Dominguez JL, et al.: Regulation of avian precardlac mesoderm development by insulin and insulin-like growth factors. J Cell Physiol 1996:168:42-50.

110. Donath MY, Zapf J, Eppenberger-Eberhardt $M_{\text {, I }}$ al.: Insulin-like growth factor 1 stimulates myofibril development and decreases smooth muscle alpha-actin of adult cardiomyocytes. Proc Natl Acad Sci USA 1994:91:1686-1690.

111. Kajstura J, Cheng W, Reiss $K_{\text {, }}$ et al.: The IGF-1-|GF-1 receptor system modulates myocyte proliferation but not myocyte cellular hypertrophy in vitro. Exp Cell Res 1994;215:273-283.

112. Reiss $\mathrm{K}$, Cheng $\mathrm{W}$, Kajstura $\mathrm{J}$, et al.: Fibrablast proliferation during myacardlial development in rats is regulated by FGF-1 receptors. Am J Physiol 1995;269:H943-H951.

113. Kanekar $S$, Barg TK, Terracio $L$, el al.: Modulation of heart fibroblast migration and collagen gel contraction by IGF-1. Cell Adhes Commun 2000; 7:513-523.

114. Engeimann GL: Coordinate gene expression during neonatall rat heart development. A possible role for the imyocyte in extracellutar matrix blogenesis and capillary anglogenesis. Circ Res $1993 ; 27: 1598-1605$.

115. Anversa P, Olivetti G, Loud AV: Morphometric study of early postnatal devalopment in the left and right ventricular myocardium of the rat. Hypertrophy, hyperplasia, and binucleation of myocytes. Circ Res 1980;46:495-502.

116. Engeimann GL, Dlonne $\mathrm{CA}_{\text {w }}$ Jaye MC: Acidic fibroblast growth factor and heart development; role in myocyte proliferation and capillary angiogenesis. Clrc Res 1993:72:7-19.

117. Schneider MD, Parker TG: Cardiac growth factors. Prog Growth Fact Res 1991;3:1-26.

718. Armstrong MT, Lee DY, Armstrong PB: Regulation of proliferation of the fetal myocardlum. Dev Dyn 2000;219:226-236.

119. Donohue TJ, Dworkin LD, Lango MN, ef al.: Induction of myocardlal insullin-like growth factor1 gene expression in left ventricular hypertrophy. Circulation 1994;89:799-809.

120. Hansson $\mathrm{H}-\mathrm{A}$, Nilsson.A, Isgaord J, eft al.: Immunohistochemical localisation of insulin-like growth factor 1 in the adult rot. Histochem 1988;89:403-410.

121. Krishnamurthi RV, Maxwell L, Bassett NS, et al:: The spatial and temporal distribution of insulin-like growth factor-1 following experimental myocordial infarction in the rat. Cardlovasc Pathol 1997;6:197-203.

122. Relss K, Meggs LG, LI P, et al.: Upregulation of IGF-1, IGF-1 receptor, and late growth related genes in ventricular myocytes acutely after infarction in rats. J Cell Physlol 1994:158:160168.

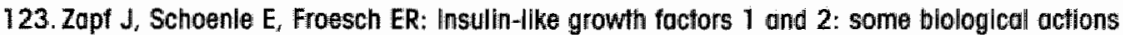
and receptor binding characteristics of two purified constituents of non-suppressible insulinlike activity of human serum. Eur J Biochem 1978;87:285-296. 
124. Dowglas RG, Gluckman $\mathrm{PD}$, Boll $\mathrm{K}$, et al.: The effects of Infusion of insulinelike growth foctor (IGF) 1 , IGF-2, and insulin on glucose and protein metabolism in fostened lambs. $\mathbf{J}$ Clin Invest 1991,88:614-622.

125. Decker RS, Cook MG, Behnike-Barclay M, at all: Some growth factors stimulate cultured adult rabbit ventricular myacyte hypertrophy in the absence of mechanical loading. Cinc Res $1995 ; 77: 544-555$.

126. Fuller $\$ 3$, Myneft $J R$, Sugden PH: Stimuiation of cardiac protein synthesis by insulin-like growth factors. Blochem $J 1992,282 ; 85-90$.

127. Reiss $K$, Cheng $W$, Ferber $A$, all: Overexpression of insulin-like growth factor- 1 in the heart is coupled with myocyte proliferation in transgenic mice. Proc Natl Acad SCl USA 1996;93:8630-8635.

128. Reiss $K$, Cheng $W$, Pierzchalski $P$, ell al.: Insulin-like growth factor-1 receptor and its ligand regulate the reentry of adult ventricular myocytes into the cell cycle. Exp Cell Res 1997;235:198-209.

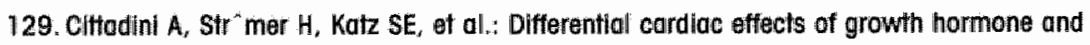
Insullin-like growth factor-1 in the rot. Circulation 1996;93:800-809.

130. Tanako $\mathrm{N}$, Ryoke T, Hongo $\mathrm{M}$, ef al: Effects of growth hormone and IGF-1 on cardiac hypertrophy and gene expression in mice. Am J Physiol 1998;275:393-399.

131. Redaelli G, Malhatra A, LI B, et al.: Effects of constitutive overexpression of insullin-like growth factor- 1 on the mechanical characteristics and molecular properties of ventricular myocytes. Circ Res 1998;82:594-603.

132. Freestone NS, Ribaric S, Mason WT: The effect of insulin-like growth factor-1 on adult rat cardiac contractillity. Mol Cell Blochem 1996; 163/164:223-229.

133. Bis| G, Podio V, Voletto MR, al.: Radionuclide angiographic evaluation of the cardiovascular effects of recombinant human IGF-1 in normal adults. Eur J Endocrinol 1999;140:322-327.

134. Lembo $G$, Rockman $H A$, Hunter JJ, eft al.: Elevated blood pressure and enhanced myocardial contractility in mlce with severe IGF-1 deficiency. J Clin Invest 1996;98:2648-2655

135. Froesch ER, Muller WA, Burgi H, et al.: Non-suppressible Insulin-like activity af human serum. Two biological propertles of plasma extracts with non-suppressible insulin-like activity. Blochlm Blophys Acta 1966:121:1360-1374.

136. Relss $\mathrm{K}_{t}$ Kajstura J, Capasso JM, at al.: Impairment of myocyte contractility following coronary artery narrowing is associated with activation of the myocyte IGF-1 autocrine systhem, enhanced expression of late growth related genes, and myocyte nuclear division in rats. Exp Cell Res 1993;207:348-360.

137. Frishs I, Stamm C, CaO-Dahn H, el al.: Insulin-like growth factor-1 improves postischemic recovery in hypertrophied hearts. Ann Thorac Surg 2001;72:1650-1656.

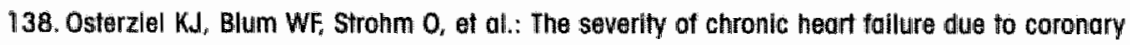
artery disedise predicts the endocrine effects of shori-term growth hormone administration. J Cilin Endocrinol Metab 2000;85:1533-1539.

139. Osterziel $\mathrm{K}_{4}$ Ranike MB, strohm $\mathrm{O}_{n}$ et al.: The somototrophic system in patients with dilated cardiomyopathy: relation of insulin-like growth factor-1 and its alterations during growth hormone therapy to cardlac function. Clin Endlocrinol 2000;53:61-68.

140. Jin $H$, Yang $R$, Gillet $N$, ef al.: Benificlal effects of growth hormone and insulin-like growth factor- 1 in experimental heart foilure in rats treated with chronic ACE inhibition. Cardiovasc Pharmacol 1995:26:420-425.

141. Cittadini A, Grossman JD, Napoll $R_{\text {r }}$ at al.: Growth hormone attenuates early left ventricular remodeling and improves cardioc function in rats with large myocardial infarction. J Am Coll Cardiol 1997:29:1109-1116. 
142. Ambler GR, Jahnstion BM, Maxwell $L$, et al... Improvement of doxorubicin induced cardlomyopathy in rats treated with insulin-like growth factor 1 . Cardiovase Res 1993:27:1368-1373.

143. $4 \mathrm{~B}$, Setoguchi $M_{i}$ Wang $X_{\text {, in }}$ et al: Insulin-like growth factor-1 attenuates the detrimental impact of non- occlusive coronary artery constriction on the heart. Clic Res 1999;84:10071019.

144. LI Q, Li B. Wang $X$, et al: Overexpression of insulin-like growth factor-1 in mice protects from myocyte death after infarction, attenuating ventricular dillatation, wall stress, and cardlac hypertrophy. J Clin Invest 1997;100:1991-1999,

145. Duerr RL, Huang S, Mircliakbar $\mathrm{HR}_{r}$ et al.: Insulln-like growth foctor-1 enhances ventricullar hypertrophy and function during the onset of experimental cardiac failure. $\mathrm{J}$ Clin Invest 1995;95:619-627.

146. Kluge A, Zimmermann R, Munkel B, et all.: Insulin-like growth factor 1 is involved in inflammation linked angiagenic processes after microembolisation in porcine heart, Cardiovasc Res 1995;29:407-415.

147. Scheinowitz M, Abramow D, Eldar M: The role of insulin-like and basic fibroblast growth thactors on ischemic and infarcted myocardium: a mini review. Int J Cardiol 1997,59:1-5.

148. Roesel $\mathrm{JF}_{\text {n }}$ Nanney LB: Assessment of differential cytokine effects on anglogenesis using an in vivo model of cutaneous wound repair. J Surg Res 1995;58:449-459.

149. Smith LEH, Shen W, Perruzzl C, et all.: Regulation of wascular endothellal growth factordependent retinal neovascularization by Insullin-like growth factor-1 receptor. Nat Med 1999;5:1390-1395.

150. Butt RP, Bishop JE: Mechanical loading enhances the stimulatory effect of serum growith factors on cardiac fibroblast procollagen synthesis. J Mol Cell Cardial 1997;29:1141-1151.

151. Butt RP, Laurent G.J, Bishop JE: Mechanical load and polypeptide growth factors stimulate cardlac fibroblast activlty. Ann NY Acad Sci 1995;752:387-393.

152. van Eickels $M_{\text {, Vetter }} H_{\text {, Grohe }} \mathrm{C}$ : Anglotensin-converting enzyme (ACE) inhibition attenuates insulin-like growth factar-1 (IGF-1) induced cardlac fibroblast proliteration. Br J Pharmacal 2000;131:1592-1596.

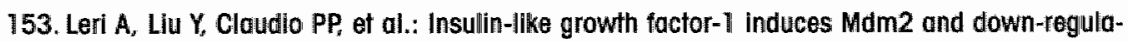
tes $\mathrm{p} 53$, attenuating the myocyte renin-angiotensin sytem and stretch-mediated apoptosils. Am J Pathol 1999;154:567-580.

154. Chen DB, Wang L, Wang $\mathrm{PH}$ : Insullin-like growth factor 1 retards apoptotic signaling induced by ethanol in cardiomyocytes. Life Sci 2000;67:1683-1693.

155. Wang $L$, Ma W, Markovich $R$, et al:: Regulation of cardiomyocyte apoptotlic signaling by insullin-llke growth factor 1. Circ ReS 1998;83:516-522.

156. Buerke $M$, Murohara $T$, Skurk $C$, ef al.: Cardioprotective etfect of insulin-like growth factor 1 in myocordial ischemia followed by reperfusion. Proc Natll Acad Sci USA 1995;92:8031-8035.

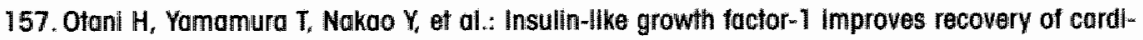
ac performance during reperfusion in isolated rat heart by a wortmannin-sensitive mechanism. J Cardiovasc Pharmacol 2000;35:275-281.

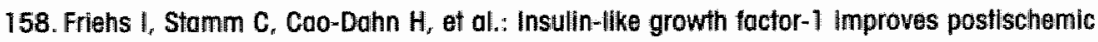
recovery in hypertrophied hearts. Ann Thorac Surg 2001;72:1650-1656.

159. Laron Z: Isulin-like growth factor-1 (IGF-1): a growth hormone. Mol Pathal 2001;54:311. 316.

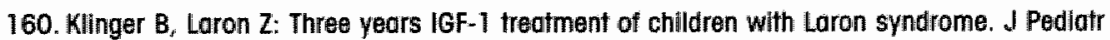
Endacrinal Metab 1995; 8:149-158.

161. Jorgensen JO, Pedersen $S A$, Thuesen $L$, et al.: Benificial effects of growth hormone treatment in GH-defiecient odults. Lancet 1989, $1: 1221-1225$. 
162. Donath MY, Sufsch $G$, Yon $X$ W, et al.: Acute cardiovascular effects of insulin-like growth focfor-1 in potients with chronic heart follure. J Clin Endocrinol Metab 1998;83:3177-3183.

163. Votterrani $M$, Giustina $A$, Maneill $F_{x}$ ef al.: Role of growth hormone in chronic heart fallure: clinical implications. Ifai Heart $₫ 2000 ; 1: 723-728$.

164. Osterziel KJ, Strohm 0 , Schuler $J$, ef al.: Randomised, double-blind, placebo-cantralled trial of human recombinant growth hormone in patients with chronic heart faillure due to dillated cordiomyopathy. Lancet 1998;351:1233-1237.

765. Isgaard $J$, Bergh $\mathrm{CH}_{\text {, Caidahl }} \mathrm{K}_{*}$ et al.: A placebo-controlled study of growth hormone in potients with congestive heart failure. Eur Heart J 1998;19:1704-1711.

166. Nishimura $T$, Nakatake $Y$, Konishi $M$, et al.: Identification of a novel FGF, FGF-21, preferentially expressed by the liver: Biachim Biophys Acta 2000; 1492:203-206.

167. Xie MH, Holcomb I, Devel B: FGF-19, a novel fibroblast growth factor with unique specificity for FGF-R4. Cytakine 1999;1 1:729-735.

168. Gospodarowlcz D: Localisation of a fibroblast growth factor and its effects alone and with hydrocortisone on 3 T3 cell growth. Nature 1974;249:123-127.

169. Gospodarowicz D. Weseman J, Moran J: Presence in brain of a mitogenic agent promoting prol feratlon of myablosts in low density culture. Nature 1975;256:216-219.

170. Jave $M_{s}$ Howk $R$, Burgess $W$, et al.: Human endothelial cell growth factor: cloning, nucleotide sequence, and chromosome lacation. Science 1986;233:541-545

171, Abraham $\mathrm{JA}_{\text {r }}$ Mergla $\mathrm{A}$, Wang $\mathrm{JL}$, ef al.: Nucleotide sequence of a bovine clone encoding the anglogenic protein, basic fibroblast growth factor. Sicience 1986;233:545-548.

172. Gimenez-Gallego $G$, Rodkey J, Bennett $C$, et al.: Broin-dierlved acidic fibroblast growth factor: complete amino acid sequence and homologies. Science 1985;230:1385-1388.

173. Esch $F_{v}$ Bailrd $A_{s}$ Ling $N$, of al:: Primary structure of bovine pituitary basic fibroblast growth tactor (FGF) and comporison with the amino-terminal sequence of bovine brain acidic FGF Proc Natl Acad Scl USA 1985;82:6507-6511.

174. Baird A, Klagsbrun $M$ : Nomenclature meeting report and recommendations januari 17, 1991. Ann NY Acad Sci 1991;638:13-16.

175. Gospodarowicz D: Fibroblast growth factor and its involvement in developmental processes. Curr Top Dev Biol 1990;24:57-93.

176. Battegay EJ: Angiogenesis: mechanistic insights, neovascular diseases, and therapeutilc prospects. J Moll Mad 1995; 73:33:3-346.

177.Speir $E_{2}$ Tonner $V$, Gonzalez AM, ef al.: Acidic and basic fibroblesi growth factors in adult rat heart myocytes; localization, regulation in culture, and effects on DNA synthesis. Circ Res 1992;71:251-259.

178. Spirito $\mathrm{P}$, Fu Y-M, Yu Z-X, et al.: Immunohistochemical localization of basic and acidic fibroblast growth foctors in the developing rat heart. Circulation $1991 ; 84: 322-332$.

179.Rakusan K: Coranary anglogenesis; from morphometry to molecular blology and back. Ann NY Acad Scl 1995; 752:257-266.

180.Siavin J: Fibroblast growth factors: at the heart of angiogensis. Cell Bial Int 1995;19:431. 444.

181. Gospodarowicz $\mathrm{D}$, Cheng J: Heparin protects basic and acidic FGF from inactivation. J Cell Physiol 1986; 128:475-484.

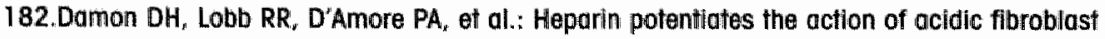
growth factor by prolonging its blological half-life. J Cell Physiol 1989;138:221-226.

183.Gospodarowicz D: Biological activities of fibroblast growth foctors. Ann NY Acad Sci $1991: 638: 1-8$. 


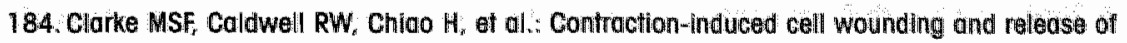
fibroblast growth factor in heart. Circ Res 1995;76:927-934.

185. Sheikh $F_{n}$ Sontag DP, Fandrich RR, et al.: Overexpression of FGF-2 increases cardiac myocyte viability after injury in isolated mouse heart. Am J Physiol 2001;280:H1039-H1050.

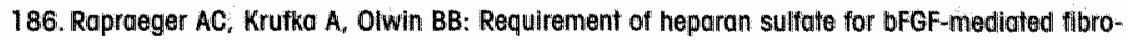
blast growth and myoblast differentiation. Science 1991;252:1705-1708.

187. Patstone $G$, Pasquale EB, Maher PA: Different members of the fibrablast growth factor receptor family are speclfic to distinct cell types in the developing chicken embryo. Dev Blol 1993; 155:107-123.

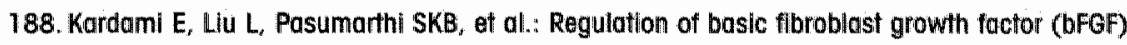
and FGF receptors in the heart. Ann NY Acad Sci 1995;752:353-369.

189. Jin Y. Posumarthi KBS, Bock ME, et al.: Cloning and expression of fibroblast growth factor receptor-1 isoforms in the mouse heart evidence for isoform switch during heart development. J Mol Cell Cardiol 1994;26:1449-1459.

190. Moore JW, Dionne $\mathrm{C}$, Jaye M, et al.: The mRNAs encoding acidic FGF, basic FGF and FGF receptor are coordinately downregulated during myogenic differentiation. Development $1991 ; 111: 741-748$.

191. Ledoux D, Mereau $A_{r}$ Pieri I, al.: High affinity receptors to acidic and basic flbroblast growth factor (FGF) are detected mainly in adult brain membrane preparations but not in liver, kidney, intestine, lung or stomach. Growth Factors 1991;5:221-231.

192. Hughes SE: Differential expression of the fibroblast growth factor receptor (FGFR) multigene family in normal human adult fissues. J Histochem Cytochem 1997;45:1005-1019.

193. Johnson DE, Williams LT: Structural and functional diversity in the FGF receptor multigene family. Adv Cancer Res 1993;60:1-41.

194. Plotnikov AN, Schlessinger J, Hubbard SR, et al.: Structural basis for FGF receptor dimerization and activation. Cell 1999:98:641-650.

195. Kackx MM, Muhring J Knaapen MWM, et al.. RNA synthesis and splicing interferes with DNA synthesis in situ and labeling techniques used to detect apoptosis. Am J Pathol $1998 ; 152: 885-888$

196. Mohommadl M, McMahon $G$, Sun L, et al.: Structures of the tyrosine kinase domaln of flbroblast growth factor receptor in complex with inhibltors. Sclence 1997;276:955-960.

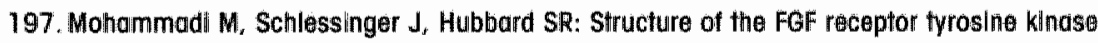
domain reveals a novel autoinhibitory mechanism. Cell 1996;86;577-587.

198. Mohammadi $\mathrm{M}_{a}$ Dionne $\mathrm{CA}$, LI W, et al.: Point mutation in FGF receptor eliminates phosphatidylinositol hydrolysis without affecting mitagenesis. Nature 1992;358:681-684.

199. Klint P, Claesson-Welsh L: Signal transduction by fibroblast growth factor receptors. Front Bloscl 1999;4:165-177.

200. Bogoyevitch MA, Glennon PE, Andersson MB, et al.: Endothelin-1 and fobroblast growth factors stimulate the mitogen-activated protein kinase signaling cascade in cardlac myoctes. J Biol Chem 1994;269:1110-1119.

201. Calin $S$, Jeanny J-C, Mascarelli $F_{r}$ et al.: In vivo involvement of heparan sulfate proteoglycan in the bloavallability, internallization and catabalism of exogenous basic fibroblast growth factor. Mol Pharmacol 1999;55:74-82.

202. Hanneken $A$, Ying $W$, Ling $N_{\text {c }}$ et al.: Identification of soluble forms of fibroblast growth factor receptor in blood. Proc Natl Acad Sci USA 1994;91:9170-9174.

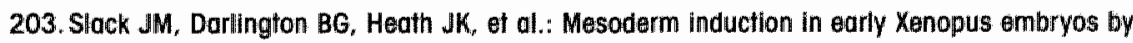
heparin-binding growth factors. Nature 1987:326:197-200. 
204. Clegg $\mathrm{CH}$, Linkhart $\mathrm{TA}$, Oiwin BB, et al: Growth factor control of skeletal muscle differentia flon: commitment to terminal differentiation occurs in 61 phase and is repressed by fibroblast growth factor. $J$ Cell Biol 1987; 105:949-956.

205. Gospodarowicz D. Neufeld G, Schweigerer L. Malecular and biologilcal characterization of fibroblast growth tactor, an anglogenic factor which also controls the proliferation and differentitation of mesoderm and neurectoderm derived cells. Cell Differ 1986; 19:1-17.

206. Pasumarthl KBS, Kardaml E, Cattinl PA: High and low molecular weight fibroblasts growth factor- 2 increase proliferation of neonatal rat cardiac myocyles but have differential effects an binueleation and nuclear morphology. Circ Res 1996;78:126-136.

207. KNint $P$, Kanda S, Kloog $Y$, el al.: Contribution of SrC and Ras pathways in FGF-2 induced endothellal cell differentiation. Oncogene 1999;18:3354-3364.

208. Mikawa T: Retroviral fargeting of FGF and FGFR in cardiomyacytes and coranary vasculor cells during heart development. Ann NY Acad Scl 1995;752:506-516.

209. Sugi Y, Sasse J, Lough J: Inhibition of precardiac mesoderm cell proliteration by antisense oligodeoxynucleotlde complementary to fibroblast growth foctor-2 (FGF-2). Dev Biol $1993 ; 157: 28-37$

210. Asahara T, Bauters C, Zheng LP, et al.: Synerglstic effect of vascular endlothelial growth factor and basic fibroblast growth factor on angiogenesis in vivo. Circulation 1995:92:365-371.

211. Gospodarowicz D, Moran J, Braun D, et al.: Clonal growth of bovine wascular endothelial cells: fibroblast growth factors as a survival agent. Proc Natl Acad Scl USA 1976;73:41204124.

212. Fu Y-M, Spirito $P, Y u Z-X$, ef al.: Acldic fibroblast growth factor in the developing rat embrya. J Cell Biol 1991;114:1261-1273.

213. Deng CX, Wynshaw-Boris A, Shen MM, et al:: Murine FGF-RT is required for early postimplantation growth and axial organization. Gen Dev 1994;8:3045-3057.

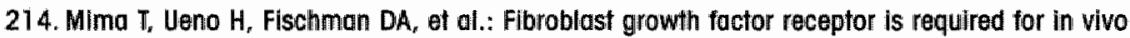
cardiac myocyte proliferation at early embryonic stages of heart development. Proc Natl Acad Sci USA 1995;92:467-471.

215. Zhou M, Sutliff RL, Paul RJ, et al.: Fibroblast growth factor 2 controls vascular tone. Nat Med 1998;4:201- 207.

216. Pellieux C. Folettl A, Peduto G, at al.: Dilated cardiomyopathy and impaired hepertrophic response to anglotensin-11 in mice lacking FGF-2. J Clin Invest 2001;108:1843-1851.

217. Kato S, Sekine K: FGF-FGFR signaling in vertebrate organogenesis. Cell Mol Biol $1999 ; 45: 631-638$.

218. Padua RR, Kardaml E: Increased basic fibroblast growth factor (bFGF) accumulation and distinct patterns of lacallzation in Isoproterenol-induced cardiomyocyte injury. Growth Factors 1993;8:291-306.

219. Yanaglsawa-Miwa A, Uchida $Y$, Nakamura $F$, et al.: Salvage of infarcted myocardium by angiogenic actlon of basic fibroblast growth factor. Science 1992;257:1401-1403.

220. Fullto $M$, Ikemoto $M$, Kishishi $M$, et al.: Elevated basic fibroblast growth factor in pericardial fluid of patients with unstable angina. Circulation 1996;94:610-613.

221. Cuevas $P$, Barrios V, Gimenez-Gallego $G$, et al.: Serum levels of basic fibroblast growth factor in acute myocardial infarction. Eur J Med Res 1997:2:282-284

222. Kawamoto $A$, Kawata $H$, Akal $Y$, et al.: Serum levels of VEGF and basic FGF in the subacute phase of myocardial infarction. Int J Cardiol 1998;67:47-54.

223. Iwakura $A$, Fujita $M_{\text {r Ikemoto }} M_{r}$ et al.: Myocardial ischemia enhances the expression of acidic flbroblast growth factor in human pericardial fluid. Heart Vessels 2000;15:1 1 2-116. 
224. Buehler A, Matire A, Strohm $\mathrm{C}_{*}$ ef al.: Anglogenesis-independent cardioprotection in FGF-1 transgenic mice. Cardiovasc Res 2002;55:768-777.

225. Fernandez B, Buehler $A$, Woifram $S$, ef al.: Transgenic myocardial overexession of Fibroblast growth factor-1 increases coronary artery density and branching. Cire Res 2000;87:207213.

226. Cuevas $P$, Carceller $F$, Martinez-Coso $V$ : Cardiopratection from ischemia by fibroblast growth factor; role of inducible nitric oxide synthose. Eur d Med Res 1999:2:465-468.

227. Horrigan MCG, Macisoac All, Nicolini FA, ef al.: Reduction in myocardial infarct slze by basic fibroblast growth factor after temporary coronary artery occlusion in a canine model. Circulation 1996;94:1927-1933.

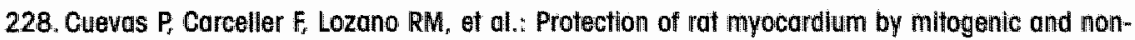
mitogenic fibroblast growth factor during post-ischemic reperfusion. Growth Factors 1997:15:29-40.

229. Cuevas $P_{i}$ Carceller $F$, Cuevas $B$, ef al.: A non-mitogenic form of acidic fibroblast growth factor reduces neutrophil infiltration in rat ischemic reperfused heart. Eur J Med Res 1997;2:1391.43.

230. Cuevas $P_{x}$ Reimers $D$, Carceller $F_{r}$ et al.: Fibroblast growth factor- 1 prevents myocardial apoptosis triggered by ischemia reperfusion injury. Eur J Med Res 1997;2:465-468.

231. Iwai-Kanai $E_{*}$ Hasegawa $K$, Fujita $M$, ef al. : Basic fibroblast growth foctor pratects cardiac myocytes firom iNOS-medlated apoptosis. J Cell Physial 2002;190;54-62.

232. Cuevas P, Carceller $F$, Hernandez-Madrid $A$, et al.: Protective effects of acidic fibroblast growth factor against cardiac arhythmias induced by ischemia and reperfusion in rats. Eur J Med Res 1997;2:33-36.

233. Htun $P$, Ito WD, Hoefer $\mathrm{IE}_{x}$ et al.: Intramyocardlal infusion of FGF-1 mimics ischemic precondlfloning in pig myocardlum. J Mol Cell Cardial 1998;30:867-877.

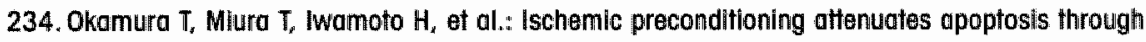
protein kinase C in rat hearts. Am J Physiol 1999;277:1997-2001.

235. Padua RR, Merie P-L, Doble: BW, al.: FGF-2 induced negative inotropism and cardioprotectlon are inhibited by chelerythrine: Involvement of sarcolemmal calcilum-independent protein kinase C. J Mol Cell Cardlol 1998;30:2695-2709.

236. Ishlbashil $Y$, Urabe $Y$, Tsutsull $H$, at al.: Negative inotrophlc effect of basic fibroblast growth factor an adult rat cardiac myocyte. Circulation 1997;96:2501-2504.

237. Merle PL, Usson $Y$, Robert-Nicoud $M_{x}$ et al.: Basic FGF emhances calcium permeable channel openings in adult rat cardlac myacytes: implication in the bFGF-induced increase of freet Ca2 + content. J Mol Cell Cordiol 1997;29:2687-2698.

238. Folkman J Klagsbun M: Anglogenic factors. Science 1987;235:442-447.

239. Battlier A, Facc, Scheinowitz $M$, et all.: Intracoronary injection of flbroblast growth factor enhences anglogenesis in infarcted swime myocardlum. J Am Coll Cardiol 1993;22:20012006.

240. Schaper W: Collateral vessel growth in the humon heart; role of fibroblast growth factor-2. Circulation 1996;94:600-601.

241. Watanabe $\mathrm{E}$, Smith DM, Sun $\mathrm{J}$, et al.: Effect of basic fibroblast growth factor on anglogenesis in the inforcted parcine heart. Bas Res Cardial 1998;93:30-37.

242. Bouters $\mathbb{C}$ : Growth factors as a potentiall new treatment for ischemic heart disease. Clim Cardiol 1997;20 (suppl 2):52-57.

243. Tomanek RJ. Doty MK, Sandra A: Early coronary angiogenesis in response to thyroxine; growth characteristics and upregulation of basic fibroblast growth factor. Circ Res 1998;82:587-593. 
244. Concalves LM: Fibrobiast growth factor-mediated anglogenesis for the treatment of ischemia. Rev Part Cardiol 1998; 17:11-20.

245. Harada K, Grossmon W, Fredman $M$, ef al: Basic fibroblast growth factar improves myocardial function in chronically ischemic porcine hearts. J Cin invest 1994;94:623-630.

246. Landau $\mathrm{C}_{x}$ Jacobs $\mathrm{AK}$, Hatidenschild $\mathrm{CC}$ : Intrapericardial basic fibroblast growth factor induces myocardial anglogenesis in a rabbit model of chronic Ischemia. Am Heart J 1995: 129:924:931.

247. Uchida Y, Yanagisawa-Miwa A, Nakamura $F$, et al.: Angiogenic therapy of acute myocardial infarction by intrapericardial injection of basic fibroblast growth factor and heparin sulfate: an experimental study. Am Heart J 1995; 130:1 182-1188.

248. Lazarous DF, Scheinowitz $M$, Shou $M$, et al.: Effects of chronic sysfemic administration of basic fibroblest growth factor on collateral development in the canine heart. Circulation $1995: 91: 145-153$.

249. Isner JM: The role of anglogenic cylokines in cardiovoscular disease. Clin Immunol Immunopathol 1996;80:S82-591.

250. Carmeliet P: Mechanisms of anglogenesis and arteriogenesis. Nat Med 2000;6:389-395.

251. Ware JA, Simons M: Anglogenesis in ischemic heart disease. Nat Med 1997;3:158-164.

252. Bernotat-Danielowski S, Sharma HS, Schott RJ, et al: Generation and localisation of monoclonal antibodies against fibrablast growth foctors in ischaemic collateralised porcine myocardium. Cordlovasc Res 1993;27:1220-1228.

253. Banal $S$, Jaklitsch MT, Casscells $W$, et al.: Effects of acidic fibroblast growth factor on normal and ischemic myocardium. Circ Res 1991;69:76-85.

254. Carmelliet P: Fibroblast growth factor-1 stimulates branching and survival of myocardial arteries, a goal for therapeutic angiogenesis? Circ Res 2000;87:176-178.

255. Schlaudraff $K$, Schumocher B, v.Specht BU, at al.: Growth of "new" coronary wascular structures by anglogenetic growth factors. Eur J Cardio-thorac Surg 1993;7:637-644.

256. Schumacher B, Specht von B-U, Haberstroh J, et al.: The stimulation of neo-angiogenesis in the ischemic heart by the human growth tactor FGF. J Cardiovasc Surg 1998;39:445-453.

257. Sellke FW, LI J, Stamier A, et al.: Angiogenesis induced by acidic fibroblast growth factor as an alternative method of revascularization for chronic myacardial ischemia. Surgery $1996 ; 120: 182 \cdot 188$

258. Schumacher $B$, Pecher $P$, Specht von $B U$, at al.: Induction of neoanglogenesis in ischemic myocardlum by humon growth factors. Circulation 1998;97:645-650.

259. Chua CC, Chua BHL. Zhao ZY, ef al.." Effect of growth factors on collogen metabolism in cultured human heart fibroblasts. Conn Tiss Res 1991;26:271-281.

260. Tseng SC, Savion N, Stern R, ef al.: Fibroblast growth factor modulates synthesis of collagen in cultured endothelial cells. Eur J Bilochem 1982;122:355-360.

261. Vladavsky I, Gospodorowicz D: Structural and functional alterations in the surface of vascular endothelial cells associated with the formation af a confluent cell monolayer and with the withdrawal of fibroblast growth factor. J Supramal Struct 1979;12:73-114.

262. Rifkin DB, Mascatell D: Recent developments in the cell biology of bosic fibroblast growth factor. J Cell Blol 1989;109:1-6.

263. Corda $S$, Mebazaa Ax Gandolfini M-P, et al.: Throphic effect of human pericardial fluid on adult cardiomyocytes: differential role of fibroblast growth factor 2 and factors related to ventricular hypertrophy. Circ Res 1997;81:679-687

264. Schulz JEJ, Witt SA, Nieman ML, et al.: Fibroblast growth factor-2 mediates pressure-Induced hypertrophic response. J Clin invest 1999;104:709-719. 
265. Tomita Y, Kusama $Y$, Seino $Y$, al.: Inereased accumulation of acidic fibroblast growth factor in left ventricular myocytes of patients with idiopathic dilated cardilamyopathy. Am Heart $\mathrm{J}$ 1997:134:779-786.

266. Harder BA, Schaub MC, Eppenberger HM, ef al.: Influence of fibroblast growth factor (bFGF) and Insulin-like growth factor (IGF-1) on cytoskeletal and contractile structures and on atrial natriuretic factor (ANF) expression in adult rat ventricular myocytes in culture. $\mathrm{J}$ Mol Coll Cordiol 1996;28:19-31.

267. Ueno H, Li JJ, Masuda S, et al: Adenowirus-mediated expression of the secreted form of basic fibroblast growth factor (FGF-2) induces cellular proliferation and angiogenesis in vivo. Arterioscler Thromb Vasc Bial 1997:17:2453-2460.

268. Cuevos $\mathrm{P}$, Carcelter $F_{\text {, Ortega }} \mathrm{S}$, et al.: Hypotensive activity of fibroblast growth factor. Sclence 1991;254:1208-1210.

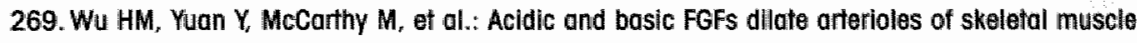
through a NO-dependent mechanism. Am J Physiol 1996;271:H1087-H1093.

270. Laham RJ, Sellke FW, Edelman ER, ef al.: Local perivascular delivery of basic fibroblast growth factor in patients undergoing coronary bypass surgery. Circulation 1999; 100:18651871

271. Laham RJ, Chronos NA, Pike $M_{\text {e }}$ et al.: Intracoronary basic growth factor (FGF-2) In patients with severe ischemic heart disease: Results of a phase 1 Open-label dose escalation study. $J$ Am Coll Cardiol 2000;36:2132-2139.

272. Simons $M_{s}$ Annex BH, Laham RJ, et al.:. Pharmacological treatment of coronary artery disecise with recombinant fibroblast growth factor-2; a double blind, randomized, controlled cilnical trial. Circulation 2002; 105:788-793.

273. Post MJ, Laham $R_{a}$ Sellke FW, et all.: Therapeutic anglogenesis in cardlology using protein formulations. Cardiovase Res 2001;49:522-531.

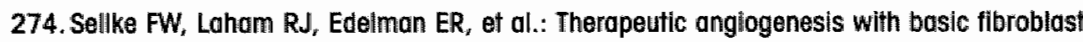
growth factor: technique and eorly results. Ann Thorac Surg 1998;65:1540-1544.

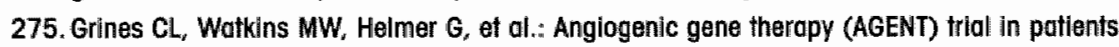
with stable angina pectoris. Circulation 2002; 105:1291-1297.

276. Folkman J: Angiogenic therapy of the human heart. Circulation 1998;97:628-629.

277. Unger EF, Concalves $L$, Epstein SE, al al: Effects of a single intracoromary injection of basic fibroblast growth factor in stable angina patients. Am J Cardlol 2000;85:1414-1419.

278. de Windt LJ, Willems $J$, Reneman RS, et al.: An improved isolated, left ventricular ejecting, murine heart model. Eur J Physlol 1999;437: 182-190. 


\section{Chapter 2}

\section{Cardiac Angiogenesis and Growth Factors}

M. Palmen\#, A.J.N. Lucassen*, M.J.A.P. Daemen@,

E.D. de Muinck\#, R, van der Zee\#, PA. FM. Doevendans\#

\#Departments of Cardiology and@ Pathology, University Hospital Maastricht,

Cardiovascular Resedich Institute Maastricht (CARIM) * Department of Cardiology, Radbout Hospital Nijmegen

Cardiblogle 1998;5:406-413.

Chapter 4, Molecular Cardiology, Cardiologie 1999 


\section{Summary}

Angiogenesis is defined as the formation of capillary vessels by the mechanism. of capillary sprouting, in response to stimulation with angiogenic growth factors. Angiogenesis is a process that is required for adequate adaption of the vascular network to the changing tissue demands. Therefore, it plays an important role in cardiac hypertrophy and tissue healing following myocardial infarction (MI) and peripheral vascular disease. In recent years the knowledge of the molecular mechanisms involved in the process of angiogenesis have been unraveled. Several growth factors have been identified that play a dominant role in endothelial cell division and vessel formation. The role of vascular endothelial growth factor (VEGF) and fibroblast growth factor (FGF) have been assessed at the basic level, in animal models and both growth factors are currently being evaluated in the clinical setting. Modulation of angiogenesis (therapeutic angiogenesis) may offer a new way of treatment for patients suffering from ischemic cardiovascular disease.

\section{Introduction}

The process of angiogenesis can be described as the formation of capillaries from the preexisting vascular network by a process called capillary sprouting. Angiogenesis occurs in response to certain angiogenic stimuli, for instance tissue hypoxia, which leads to expression of growthfactors and their receptors. They may initiate angiogenesis .

This in contrast to its fetal counterpart called vasculogenesis, which is defined as primary differentiation of endothelial cells from their angioblast precursors into a primary capillary plexus. From this capillary plexus, the vascular system will develop. While vasculogenesis predominantly occurs during fetal life and induces formation of the primary vasculature, angiogenesis can be considered as a remodeling process of the preexisting capillary network in order to meet the changing tissue demands.

For the adequate guidance of both vasculogenesis and angiogenesis, a complicated interplay between different growth factors and their receptors is required. Because angiogenesis plays an important role in a myriad of different physiologic as well as pathologic processes $s_{f}$ like wound healing, inflammation, tumor growth and tissue ischemia, modulation of the regulators of angiogenes can offer a new pathway for treatment. ("therapeutic angiogenesis").

In this paper, angiogenesis and the role of growth factors will be reviewed, in concert with the current impact of therapeutic angiogenesis and its future perspective. After explanation of the complicated process of capillary sprouting 
and the different factors involved, attention will focus on physiologic vascullogenesis in the fetal and neonatal heart, as well as angiogenesis in pathologic conditions of cardiac pressure and volume overload. Subsequently, some regulators involved in angiogenesis will be discussed. As an example of angiogenesis promoting growth factors, FGF and VEGF and their respective receptors will be described.

\section{Cardiac hypertrophy and anglogenesis}

An acute increase in workload of the heart, for instance after an acute MI, results in an augmentation of wall stress. Augmentation of wall stress is a stimulator for cardiac hypertroply to compensate for the loss of contractile. function of the ventricle.' This increases the metabolic demand of the hypertrophic cardiomyocytes and necessitates a concomitant augmentation in coronary blood flow. In cardiac hypertrophy, however, the distance of the individual myocytes to the nearest capillary vessel increases (increased oxygen-diffusion distance), leading to a relative hypoxia of the cardiac tissue. This hypoxia predisposes for the rapid deterioration of contractile function, eventually leading to heart failure.

Cardiac hypoxia, however, is a powerful stimulus for release of angiogenesisinducing substances like FGF and VEGF. Through the process of angiogenesis, the capillary network can accomodate to the altered tissue demand of nutrients and restore the oxygen diffusion distance. In that way, tissue loss can be prevented and simultaneously tissue function can be restored.

During pressure overload-induced cardiac hypertrophy, angiogenesis does occur in order to compensate for the increased metabolic demand of the hypertrophied cardiomyocytes. However, it usually fails to completely compensate for the magnitude of this hypertrophy. In contrast to a pressure overload situation, angiogenesis in volume overload induced hypertrophy occurs at a sufficient high rate to compensate for the magnitude of hypertrophy. This leads to restoration of capillary density and preserved oxygenation of cardiac tissue. Examples of this phenomenon can be observed in hyperthyroidism and physiologic hypertrophy of the athletes heart. ${ }^{2.5}$

\section{Angiogenesis by capillary sprouting}

During angiogenesis new vessels form by a process called capillary sprouting." In angiogenesis a complicated interplay between the extracellular matrix (ECM) and capillaries is required. Individual steps in vessel formation bave to occur in a fixed order to obtain a properly formed outgrowth of the capillary 
network. This expansion of the capillary network is mandatory for provision of adequate bloodflow to compensate for the demand in oxygen that was the initiating stimulus for new vessel formation. These morphologic processes (see figure A-D) in the capillaries and the ECM needed for adequate capillary sprouting require the next three, subsequently occurring stages:

1) Digestion of the basement membrane.

During the first stage (figure $A$ and B), the capillaries dilate as the result of either mechanical, metabolic or inflammatory stimuli. Dilation leads to activation of endothelial cells and augmentation of the sensitivity of these endothelial cells for the angiogenic actions of growth factors like FGF and VEGF. Moreover, hypoxia will induce production of other substances, like Transforming growth factor- $\beta 1$, (TGF- $\beta 1)$ and Platelet Derived Growth Factor (PDGF), which may be released from several cell types, including fibroblasts, vascular smooth muscle cells and cardiomyocytes ${ }^{7}$ In response to stimulation, the endothelial cells secrete plasminogen activator and several proteolytic enzymes (matrix metal loproteases such as collagenases and serine proteases such as plasminogen activator) wich can induce disruption of the capillary basement membrane and subsequently dissolve the ECM surrounding the capillary. During the breakdown of the ECM, a complicated interplay of several matrix metalloproteases and anti-proteolytic enzymes (Tissue Inhibitor of MetalloProteinases, TIMP) is required in order to regulate ECM turnover (synthesis and degradation).

normal dormant sopilary

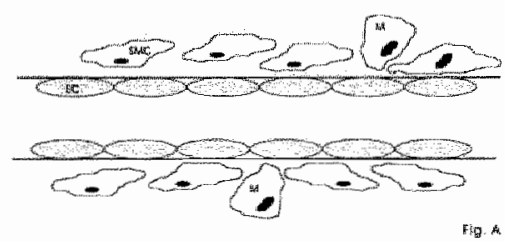

phase 2

proliterction and migrotion of endotheligi cells
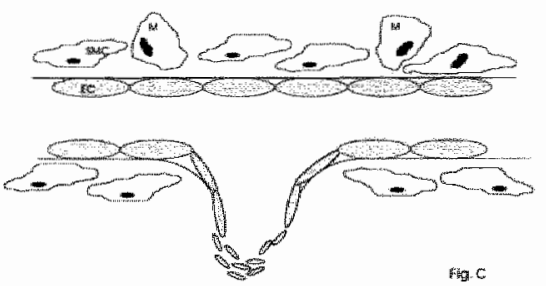

phase 1

digestion of the basd membone
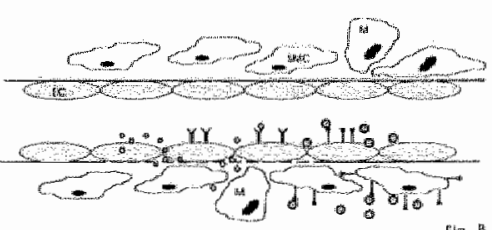

Pig.

\section{phose 3}

copillary fube fornation complated
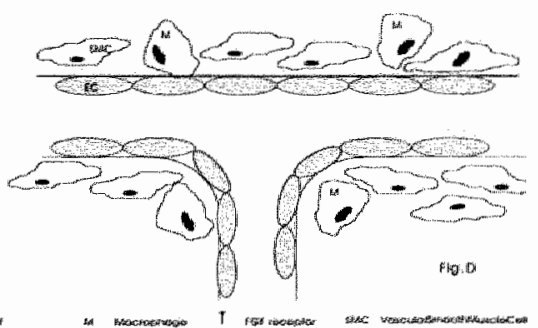


\section{2) Endothelial cell proliferation and endothelial cell migration.}

First the basement membrane and the surrounding ECM have to be degraded. Platelets, monocytes and other cells (cardionyocytes, vascular smooth muscle cells and fibroblasts) continue with the production of growth factors wich induce DNA-synthesis, division and migration of endothelial cells (figure B). The proliferating endothelial cells start to form pseudopodia (elongation). Elongation is followed by migration of newly formed endothelial cells through the defects in the basement membrane (figure C). This process is most likely guided by chemotactic factors (cytokines) secreted by the inflammatory cells. 3) Endothelial tube formation and differentiation of the newly-formed endothelial cells.

Finally the newly formed endothelial cells line up to form tube-like structures (figure D). The lumen is created through expansion of cytoplasmatic vacuoles that fuse to give rise to a functional vessel. These processes are followed by maturation and differentiation of the endothelial cells. Subsequently, the connections with already existing capillaries are made and blood flow is established. Finally, a new basement membrane is formed which completes vessel maturation. ${ }^{6}$

The table shows an overview of some of the most important growth factors involved in angiogenesis and their receptors. Also the cell types producing these growth factors and the effect of these growth factors on angiogenesis are outlined in this table. ${ }^{.39 .47}$

\section{Vasculogenesis in fetal and neonatal life}

In the embryo formation of blood vessels (vasculogenesis) starts with the formation of blood islands. Blood islands consist of angioblasts, which are considered to be the precursors of the future endothelial cells, that will outline the cardiovascular system. Blood islands also contain hematopoetic stem cells, the progenitors of the blood cells. The entire process of vasculogenesis occurs under strict control of growth factors (for instance VEGF), which are expressed abundantly during fetal and neonatall life.

Recent information shows however, that this so-called fetal vasculogenesis may not be restricted to fetal life, but may still be initiated in the adult organism. Indeed, infusion of these adult human angioblasts into an ischemic hind. limb resulted in abundant vessel formation in the ischemic tissue."

\section{Angiogenesis; triggers}

Angiogenesis in the heart may occur at physiologic conditions, like endurance 


Growh fodtor
Receptors

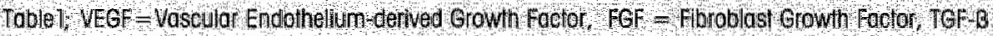

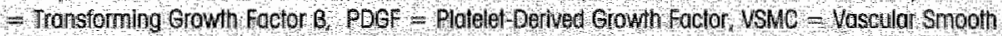

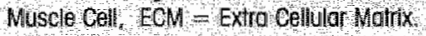

training, exposure to high altitude or severe cold. In addition, pathologic conditions like slowly progressive coronary artery occlusion and cardiac hypertrophy can induce angiogenesis. In general, angiogenesis can be induced by three main mechanisms:

"Ischemia: In the heart, angiogenesis is induced when cardiomyocytes are deprived from oxygen as is the case in progressive narrowing of the coronary artery system. Schaper et al. ${ }^{10}$ showed in a dog model, that gradual and progressive coronary artery occlusion induces collateral vessel growth when the coronary stenosis has progressed to a critical value, due to ischemia in the area. perfused by that coronay vessel. The trigger for angiogenesis is thought to be myacyte ischemia. Thus, tissue hypoxia proves to be a major stimulus for regulation of collateral growth. Coronary angiogenesis can be induced by a complex interplay of several growth promoting molecules and their receptors, like basic and acidic FGF (the two isoforms of the FGF family mainly involved in angiogenesis), VEGF and such factors as TGE- $\beta, P D G F$, Tumor Necrosis Factor- $\alpha$ (TNF $\alpha$ ) and IGF-1.

In slowly progressive narrowing of the coronary artery, angiogenesis will occur in parallel with the progression of obliteration of the coronary artery lumen. In acute coronary syndromes, angiogenesis in response to ischemia is not capa- 
ble of preserving ischemic tissue from deterioration, because the time necessary for induction and completion of an adequate collateral network is not available. Myocardial infarction is inevitable.

"Mechanical factors: Though ischemia may be the most important stimulus for induction of angiogenesis in the heart, evidence is accumulating that mechanical factors are also involved in the induction of capillary angiogenesis. Tomanek et al. ${ }^{5}$ showed that mechanical factors, associated with an increase in capillary perfusion, like stretch of the capillary wall, shear stress and wall tension, provide an initiating stimulus for formation of new capillaries during the process of cardiac enlargement. Moreover ${ }_{\mu}$ the increase in diastolic interval in bradycardia (the athletes heart) and an increase in left ventricular end diastoJic volume (LVEDV) may induce angiogenesis.

"Inflammatory factors: Finally, angiogenesis can be induced in response to inflammatory stimuli. These stimuli activate endothelial cells and platelets, which express adhesion molecules for monocytes and other inflammatory cells. Subsequently, these cells may produce angiogenic growth factors. However, this mechanism of angiogenesis is closely related to the angiogenic processes induced by ischemia because the same cell types and cellular responses are involved.

Rakusan ${ }^{\bar{a}}$ postulates that there are multiple and continuous interactions among the three main mechanisms of induction of angiogenesis and that each process of angiogenesis may be considered to result of a mixture of these three mechanisms. For instance, inadequate tissue oxygenation will result in hypoxia, associated with an (adenosin-induced) vasodilation. This leads to an increased stretch of the capillary vessel wall (mechanical stress). The concomitant increase in local blood flow will lead to an increase in shear stress. This may induce activation of endothelial cells and platelets wich, in turn, produce a variety of different adhesion molecules and growth factors, that can initiate angiogenesis.

\section{Induction of angiogenesis in cardiac hypertrophy}

Mechanical factors, like the increase in LVEDV, resulting in increased myocyte stretch and wall tension, and changes in duration of the diastolic interval during cardiac enlargement stimulate angiogenesis. Furthermore, during volume overload, longitudinal stretch of capillaries occurs due to an increase in the longitudinal and transverse axis of the dillated heart. These angiogenesis inducing mechanical factors are active during physiologic hypertrophy and volume overload. Adequate angiogenesis normalizes capillary density and maintains sufficient cardiac tissue perfusion. The different angiogenic response in pres- 
sure and volume overload induced hypertrophy was demonstrated in an animal model. The capillary density was found to be normal in the epi- mid-andendocardial layers of a volume overloaded rat heart. ${ }^{12}$ The same phenomenon can be observed in physiologic hypertrophy, as seen in well trained athletes. The capillary density in the hypertrophic myocardium of these people is completely normal, although a considerable amount of cardiomyocyte hypertrophy occurs.

The molecular mechanisms of induction of cardiac hypertrophy, both in physiologic and pathophysiologic conditions were described earlier. I In cardiac hypertrophy, in addition to expansion of the cardiomyocytes and ECM, also the coronary vasculature needs to expand in order to maintain a normal coronary flow reserve (obtained by an increase in cross sectional area of pre-capillary vessels) and normal oxygen diffusion distances (accomplished by the process of capillary angiogenesis].

In the pressure overloaded ventricle, concentric hypertrophy rather than cardiac chamber enlargement accurs, and the mechanical stimuli for angiogenesis are absent. In pathologic pressure overload induced hypertrophy, capillary angiogenesis fails to compensate for the magnitude of hypertrophy, leading to inadequate myocardial tissue perfusion that may contribute to myocyte loss and progression into cardiac failure. Several factors may play a role in this mismatch between myocyte growth and capillary vessel formation. For instance during pressure overload, minimal coronary vascular resistance increases due to structural alterations in coronary arterioles. The increase in cardiac mass itself causes an augmentation of coronary perfusion pressures, changes in flow, which can ultimately lead to vascular remodeling. As a result, the cross sectional area of the coronary vasculature is reduced. ${ }^{5}$ Furthermore, a reduction in the number of arterioles occurs concomitant with cell loss and fibrosis of the myocardium. ${ }^{13}$

Moreover, coronary flow is directly compromized. This can be explained by the increased pressure in the innermost layers of the myocardium (subendocardium, even during diastole when normally coronary flow is maximal. This leads to a decreased filling of the subendocardial plexus. Subendocardial ischemia has been shown to be detrimental for cardiac function, and can result in deterioration of function towards fullblown congestive heart failure. Due to the increase in intraventricular pressure and vascular resistance and the reduction in the number of vessels, the coronary flow reserve is decreased. In conditions where coronary atherosclerosis already compromises coronary flow, the flow reserve diminishes even further.

Interestingly, the angiogenic response in the hypertrophied adult heart seems to differ from that in the embryonic and early neonatal heart. This difference 
may be explained by the abrupt decrease in expression of angiogenic growth factors and their receptors in the heart, which occurs shortly after birth. ${ }^{14-18}$ In the embryonic heart, the rate at which angiogenesis occurs is dependent on the moment of increased workload. If pressure overload is induced in early neonatal life, when the neonatal expression pattern of growth factors is still intact, abundant coronary angiogenesis occurs. ${ }^{19}$ There is circumstantial evidence that even in the pressure overloaded adult heart, the induction of a fully compensatory vascular network may only be a matter of time. It is thought that although angiogenesis cannot keep up with the rate of hypertrophy during the period of induction of hypertrophy, it could potentially catch. up when wall stress is normalized. The final result is a normal capillary density in a hypertrophied adult heart.

\section{The Fibroblast Growth Factor family and the receptors}

FGFs are general growth promoting peptides which affect cell proliferation and cell differentiation during fetal, neonatal, and during adult life. At least in vitro, FGFs stimulate all stages of angiogenesis, like endothelial cell migration, proliferation, release of proteolytic enzymes and capillary tube formation. ${ }^{20.21}$ Both aFGF and $\mathrm{bFGF}$ are involved in angiogenesis and vasculogenesis, under physiologic and pathologic conditions, during embryogenesis and also during adult life. ${ }^{21}$ Kanda et al. ${ }^{22}$ showed that aFGF and bFGF induce proliferation, migration and differentiation of endothelial cells leading to functional tubelike structures. ${ }^{21.22}$

In humans, aFGF (FGF-1) and bFGF (FGF-2) genes are localised on chromosomes 5 and 4 , respectively. In the adult heart two low molecular weight forms of aFGF and bFGF are present. In the neonatal heart, a high molecular weight form of bFGF is present. ${ }^{20}$ Unlike other growth promoting substances, aFGF and bFGF lack the classic secretory sequence that is needed for exteriorising these peptides. The mechanism of secretion is still a point of discussion in literature. aFGF and $\mathrm{BFGF}$ are mainly located in the ECM and are protected from degradation when associated with subendothelial matrix heparan sulfate, probably serving as a reservoir that is activated when the ECM is degraded by proteolytic enzymes liberated from hypoxic or dying cells. Another hypothesis postulates that FGF is released directly from dying cells. ${ }^{21}$ aFGF and bFGF belong to a large family of peptide growth factors consisting of 21 members (FGF-1-21), all of which have multiple effects on a myriad of cell types derived from mesoderm, (cardiomyocytes, endothelial cells, fibroblasts, vascular smooth muscle cells VSMC)] and neurectoderm (oligodendro- 
cytes, astrocytes and retinal epithelial cells). Also the release of FGFs is provided by a variety of different cell types (including cardiomyocytes, monocytes/macrophages, lymphocytes, endothelial cells and vascular snooth muscle cells).

Untill now, four distinct high affinity FGF receptors have been described. After binding of FGF to the cell surface receptor, activation of the signal transduction pathway is initiated and gives rise to intracellular actions. These actions include activation of several enzymes and transcription factors leading to changes in gene expression, protein assembly, activation of the cell cycle and DNA synthesis. ${ }^{23}$ In that way, FGF provides a mechanism for induction of cell growth, division and cell differentiation.

Other growth factors (VEGE, PDGF) are also capable of inducing proliferation and migration of endothelial cells, but they lack the differentiation inducing potential in endothelial cells. ${ }^{22}$

\section{VEGF and VEGF-receptors}

VEGF is a direct angiogenesis inducing cytokine, that is produced in response to ischemia but also through the paracrine effects of other angiogenetic cytokines (TGF- 31 and PDGF). Four isoforms of VEGF are known, resulting from alternative splicing of the VEGF gene product. Unlike the FGF receptors which are expressed on variety of cell types, VEGF-receptors are thought to be restricted to endothelial cells. Therefore, only endothelial cells can be influenced by mitogenic effects of VEGF. Recently, the expression of VEGF receptors on VSMC was demonstrated. ${ }^{24}$ VEGF binds to several distinct VEGF receptors, namely the KDR/F/k-1 receptor, the Flt-1 receptor and the Filt-4 receptor.

VEGF and its receptors are expressed during fetal life angioblasts." They are important for adequate vasculogenesis which is supported by the fact that both VEG F-deficient gene targeted mice and mice with VEGF-receptor deficiency have an aberrant vasculogenesis.25, resulting in early embryonic death. In VEGF deficient mice due to lack of fusion of endothelial cells. In the receptor deficient mice no endothelial cells are present.

Interestingly, in the adult heart, VEGF, Flt-l and Flk-1 mRNA's are upregulated after myocardial infarction. In addition, intra-arterial gene transfer of VEGF reduces intimal thickening and thrombotic occlusion complications in an rabbit arterial injury model. ${ }^{23}$ In addition to its angiogenetic properties, VEGF may also play an important role in the process of atherosclerosis by its effects on maintainance and reparr of the luminal endothelium. 


\section{Clinical implications: therapeutic angiogenesis}

The recently obtained knowledge about the role of these growth factors in angiogenesis may have interesting implications for daily clinical practise. The local application of growth factors could induce angiogenesis to treat cardiac ischemia. Although angiogenesis will not prevent cardiac cell death after an acute coronary artery occlusion, angiogenesis is necessary for adequate tissue perfusion during the healing and remodeling of the heart after MI. In the case of gradually increasing coronary artery stenosis, angiogenesis may even prevent myocardial cell loss by providing the heart with an adequate collateral network. Also in peripheral artery disease, angiogenesis promoting growth factors may provide an alternative for conventional revascularisation procedures ("molecular bypass grafting"),

The dilemma of growth factor therapy is based on the involvement of these proteins in tumor angiogenesis. Angiogenesis plays a critical role in the growth of malignant tumors, in which the matching growth of capillaries provides the tumor with enough nutrients for an exponential increase in size." This could be a major drawback for routine use of growth factors with an angiogenesisinducing potential. In addition, excessive vessel formation encountered in diabetic retinopathy could be enhanced.

Several recent publications show that growth factor therapy to induce angiogenesis (therapeutic angiogenesis) is not longer a distant future goal, but should be considered an useful tool in the treatment of vascular disease. In several animal models, administration of aFGF and bFGF proved to be benificial for reducing infarct size and increasing capillarisation, myocardial perfusion and cardiac function in the situation of acute or chronic cardiac ischemia. ${ }^{36-34}$

Also VEGF therapy opens a new pathway for utilising its angiogenetic properties for the benefit of patients suffering from ischemic vascular disease. Both in the situation of coronary artery occlusion and peripheral artery disease, VEGF administration leads to increased perfusion of the ischemic tissue and an improvement in function. ${ }^{3941}$ VEGF biotherapy is currently being used in clinical trials.

Recent investigations pointed out that VEGF and bFGF have a synergistic effect in producing angiogenesis. Since the combined administration of both VEGF and bFGF resulted in augmentation of collateral formation and better hemodynamic performance when compared to single administration of one of the two substances. ${ }^{42}$ 


\section{Conclusions}

Angiogenesis is a complicated and fascinating process. It is involved in many physiologic as well as pathologic conditions. With elucidation of the mechanisms of action of the different growth factors and their receptors involved in angiogenesis, new pathways for treatment come within reach of the clinician. Growth factor therapy may be used for the treatment of many diseases, like myocardial ischemia and peripheral vascular disease. These treatments could be used in addition to conventional revascularisation procedures or in cases not suitable for surgical interventions. Currently, dinical trials are being conducted in this field. 


\section{References}

1. A. van der Laarse, C. Ruwhiof, P.A. Doevendans ef ol. Molecular Cordiology Part 2. Molecular aspects of eardiac thypertrophy and heart follure. Cardiologie, 1998;4:328-333.

2. Y.Chen, R.J.Torry, R.J.Tomanek at al. Proportional arteriolar growth accompanies cardiac hypertrophy induced by wolume overlood. Am.J.Physiol. 1994;267:H2132-H2137.

3. E.A.Breisch, F.C.White, C.M. Bloor et al. Exercise-induced cardiac hypertrophy: a correlation of blood flow and microvasculature. J.Appl.Physiol. 1986;60:1259-1267.

4. W.A.Chillan, R.D.Wangler; M.L.Marcus ef al. Thyroxin-induced left ventricular hypertrophy in the rat. Anatomical and physiological evldence for angiogenesis. Circ. Res. 1985:57:591598.

5. R.J.Tomanek, R.J. Torry. Growth of the coronary vosculature in hypertrophy:mechanisms and model dependance. Cell. Mol.Blol.Res, 1994;40:126-136.

6. K.Rakusan: Coronary angiogenesis. from morphometry to molecular biology and back. Ann.N.Y.Acad.Sel. 1995; 725: 257-266.

7. A.Brogl, T.WU, A.Namikl, J.M.Isner. Indirect anglogenefic cytokines upregulate VEGF and bFGF expression in vascular smooth muscle cells, whereas hypoxia upregulates VEGF expression only. Circulation. 1994; 90: 649-652.

8. S.C.Tyagl. Vasculogenesis and anglogenesis: extracellular matrix remodeling in caronary colloteral arteries and the ischemic heart. J.Cell.Blochem. 1997;65:388-394.

9. T.Asahara. T.Murohara, J.M. Isner et al. Isolation of putative progenitor endathelial cells for anglogenesis. Sclence 1997;275:964-967.

10. W. Schaper. Anglogenesis in the adult heart. Bas.Res.Cardiol. 1991; 86: 51-56.

11. M.S.Pepper, Manipulating anglogenesis; from basic science to bedside. Arterioscler. Thromb. Vasc. Biol. 1997:17:605-619.

12. S.Batra, K. Rakusan . Geometry of capillary networks in valume overloaded rat heart. Micravasc. Res. 1991;42:39- 95.

13. P.Anversa, J.M.Capasso. Loss of intermediate-sized coronary arteries and capillary proliferation after left ventricular fallure in rats. Am.J.Physlol. 1991;260:H1552-1560.

14. C.Schmid. Insulin-like growth tactors. Cell. Biol.Int.1995; 19:445-457.

15. J.Baker, J.-P.Litu, A.Etstratidis of al. Role of insulin-like growth factors in embryonic and postnatal growth. Cell. 1993; 75:73-82.

16. E.Kardomi, L.Liu, P.A.Cottini et al. Regulation of basic fibroblast growth factor (bFGF) and FGF receptors in the heart. Ann.N.Y.Acod.Scl. 1995;752:353-369.

17. E.Speir, V.Tamner, W.Casscells et al. Acidic and basic fibrablast growth factors in the adult rat heart myocytes; Localisation, regulation in culture, and effect on DNA synthesis. Clic. Res. 1992; 71:252-259.

18. G.L.Engelmann, G.A.Craig. M.C.Jaye. Actdic fibroblast growth factor and heart development. Role in myocyte proliferation and angiogenesis. Circ.Res. 1993;72:7-19.

19. K.Rakusan, M. F.Flanagan, R. Van Pragh el al. Morphometry of human coronary captllaries during normal growth and the effect of age in left ventricular pressure-overload hypertrophy. Circulation. 1992;86:38-46.

20. K.B.S.Pasumarthi, E.Kardami. P.A.Cattini. High and low molecular weight fibroblast growth factor-2 increase proliferation of neonatal rat cardioc myocytes but have differential effects on binucleation and nuclear morphology. Circ. Res. 1996; 78:126-136. 
21. J.Slawin. Fibroblast growth factors: at the heart of angiogenesis. Cel. Biol. Int. 1995; 19:431444.

22. S.Kanda, E.Landgren, L.Claesson-Welsh at al. Fibroblast growth factor receptor 1-induced differentiation of endothelial cell line established from fsA58 large transgenic mice.

Cell.Growth.Ditf. 1996; 7:383-395.

23. E.D. de Muinck, W.H. van Gilst, A. van der Laarse, P.A. Doevendans: Molecular cardiology. Port 3: Restenosis. Cordiologie 1997;4:469-475

24. L.L.Couper, S.R.Bryant, V.Lindner et al. Voscular endothelial growth foctor increases the mitogenic response to fibroblast growth factor- 2 in vascular smooth muscle cells in viva via expression of tms-like tyrosine-kinase-1. Circ. Res. 1997;81:932-939.

25. F.Shalaby, J.Rossant, A.C.Schuh et al. Failure of blood island formation and vasculogenesis in Flk-1 deficient mice. Nature 1995;376:62-66.

26. P.Carmeliet, W.Ferreira, A.Nagy et al. Abnormal bloodwessel development and lethality in embryos lacking a single VEGF allele. Nature 1996;380:435-439.

27. J.Li, L.F.Brown. M.Simons et al. VEGE, flk-1 and flt-1 expression in a rat myocardial infarction model of anglogenesis. Am.J.Physiol.1996;270:H1803-H1811.

28. T.Asahara, D.Chen, J.M.Isner et al. Accelerated restitution of endothelial intergrity and endothellum-dependent function after phVEGF165 gene fransfer. Circulation. 1996:94:3219-3302.

29. T.Coutfinhal, M.Kearny, J.M.Isner ef al. Vascular Endothelial Growth Factor/Vascular Permiability Factor (VEGF/NPF) in normal and atherosclerotic human arteries.

Am.J.Pathol $1997 ;$ 150:1673-1685.

30. A.Yanagisawa-Miwa, Y.Uchida, $H$.tto et al. Salvage of infarcited myacardium by anglogenic action of basic fibroblost growth factor. Science 1992;257:1401-1403.

31. A.Battler, M.Scheinowitz, N.Savian et al. Intracoronary injection of basic fibroblast growth factor enhances anglogenesis in infarcted swine myocardium. J.Am.Coll.Cardiol. 1993;22: 2001-2006.

32. D.F.Lazarous, M.Scheinowitz, E.F.Unger ef al. Effects of chronic systemic administration basice fibroblast growth factor on collateral development in the canine heart. Circulation 1995;91:145-153.

33. Y.Uchida, A.Yanagisawa-Miwa, T.Morlta at al. Anglogenetic therapy of acute myocardial Infarcfion by intrapericardial injection of basic fibroblast growth factor and haparin sulfate: an experimentall study. Am. Heart.J.1995; 130:1182-1188.

34. C.Landau, A.K.Jacobs, C.C.Haudenschild. Intrapericardifal basic fibrablest growth tactor induces myocardial angiogenesis in a rabbit model af chronic ischemia. Am. Heart.J 1995; 129:924-931.

35. K.Harada, W.Grossman, M.Simans at al. Basic fibroblast growth factor improves myocardial function in chronically ischemic porcine hearts. J.Clin.Invest. 1994;94:623-630.

36. F.W.Sellke, J.LI, M.Simons et al. Angiogenesis induced by acidic fibroblust growth factor as an olternative method of revascularization for chronic myocardial ischemia. Surgery 1996; 120:182-188.

37. F.W.Sellke, S.Y.Wang, M.Simons et al. Basic fibroblast growth foctor enhances endotheliumdependent relaxation of the collateral-perfused coronary microcirculation. Am. J. Physiol. $1994 ; 267: 1303-1311$.

38. F.J.Giordano, P.Ping, K.Hammond ef al. Intracoronary gene transfer of fibroblast growth factor-5 increases blood flow and contractile function in an ischemic region of the heart. Nat. Med. 1996;2:534-539.

39. S.Banal, M.T.Jaklisch, E.F.Unger ef al. Anglagenic-induced enhancement of collateral blood flow to ischemic myocardium by Vascular Endothellal Growth Factor in dlogs. Circulation 
1994:89:2183-2189.

40. Y.Tsurumi, S. Takeshita, J.M. Isner ef al. Direct intramuscular gene fransfer of naked DNA encoding for vascular endothellal growth factor augments collateral development and tissue perfusion. Circulation. 1996; 94: $3281-3290$.

41. J.M. Isner, A.Pleczek, J.F.Symes ef al Clinical evidence of anglogenesis after arterial gene transter of phVEGF165 in petient with ischaemic limb. Lancet 1996;348:370-374.

42. T.Asahara, C.Bauters, J.M.Isner at al. Synergisfic effect of vascular endothelial growth factor and basic fibroblast growth factor on angiogenesis in vivo. Circulation. 1995;92:356-371.

43. W.Risau. Mechanisms of angiogenesis. Nature 1997;386:671-674.

44. P.Carmeliet, D.Collen. Genetic analysis of blood vessel formation. Trends Cardiovasc.Med. $1997 ; 7: 271-281$.

45. P.R.Colville, D.A.Willoughby. Growth factors in angiogenesis: current interest and therapeutic potential. Moll.Med. Todaly. 1997;3:14-23.

46. K.Schlaudraff, B.Schumacher, R. Fasol efl al. Growth of "new" coronary vascular structures by anglogenetle growth foctors. Eur.J.Cardio-thorac. Surg. 1993; 7:637-644.

47. W.R.MacLellan, J.Howker, M.D.Schneider. Myocardial growth factors, in A.R.Marks, M.B. Taubman (eds); Molecular Blology of Cardiovascular Disease. New York, Marcel Dekker Inc. 1997;327-378. 
Chapter 3

\section{Cardiac remodeling after myocardial infarction is impaired in IGF-1 deficient mice.}

M. Palmen, M., Daemen, R. Bronsaer WR. Bassen, H.R. Zandbergen, M. Kockx, J. F Smits, R, van der Zee, PA Doevendans

Cardiovase. Res. 2001; 50:516:524 


\section{Abstract}

Objective: To obtain more insight in the role of IGF-1 in cardiac remodeling and function after experimental myocardial infarction. We hypothesize that cardiac remodeling is altered in IGF-1 deficient mice, which may affect cardiac function.

Methods: A myocardial infarction was induced by surgical coronary artery ligation in heterozygous IGF-1 deficient mice. One week after surgery, left ventricular function was analyzed ${ }_{s}$ and parameters of cardiac remodeling were measured.

Results: No significant difference in cardiac function was found between infarcted wildtype and knock-out animals, despite a marked reduction in capillarization and blunting of the hypertrophic response of the interventricular septum in the IGF-1 deficient group. Furthermore, decreased DNA synthesis and increased apoptosis rates were observed in the IGF-1 knock-out mice.

Conclusion: IGF-1 deficient mice show preservation of cardiac function 1 week after MI, despite an altered cardiac remodeling process.

\section{Introduction and background}

IGF-1 (Insulin-like Growth Factor-1) is a pleiotrophic growth promoting peptide which is produced in the liver upon stimulation with growth hormone $(\mathrm{GH})$. In addition to circulating IGF-1 levels, local production in several tissues allso serves as a source of IGF-1. After release into the circulation IGF-I is bound to specific IGF binding proteins that regulate the interacti ons of IGF-1 with the IGF-1 receptors (IGF-IR) in distant tissues. IGF-1 has a myriad of distinct, but interrelated growth-inducing effects on the organism. During adult life, IGF-1 plays a role in many pathological processes involved in cardiovas cular disease. IGF-1 induces cardiomyocyte hypertrophy, both after exogenous administration under physiologic condition $\mathrm{s}^{4,5}$, and following an acute augmentation of cardiac workload ${ }^{6}$, for instance after myocardial infarction (MI). A controversial issue is the potential ability of IGF-1 to stimulate cardiomyocytes to re-enter the cell-cycle, thereby inducing cardiomyocyte prolife ration. ${ }^{1.89}$ Recent studies suggest a role for IGF-1 in the protection of cardiomyocytes against apoptosis both in vitro and in vivo. ${ }^{10.10}$ In concert with several other growth promoting peptides like VEGF and FGF-1/2, IGF-1 stimulates angiogenesis. ${ }^{12,0,13}$

In addition to its involvement in modifying the architecture of the heart in response to changing demands, IGF-1 may also influence cardiac function 
directly, although these efiects are less clear. Increased IGF-1 levels in the heart improve cardiac performance both in normal hearts and after MI9, either by an increased local expression of IGF-1 or after exogenous administration. Also in the failing human heart, GH and IGF-1 administration enhance cardiac performance. ${ }^{x / 10.14}$ IGF-1 deficiency was, however, also shown to atgment cardiac function and increase conscious blood pressure in a physiologic non-MI setting ${ }^{15}$, illustrating the apparently conflicting data on the effects of IGF-1 on hemodynamics.

We hypothesize that IGF-1 deficiency results in altered cardiac remodeling and a decrease in cardiac function following induction of MI. To gain more insight into the effects of IGF-I on cardiac function and structure, the effects of reduced IGF-1 levels on functional and structural aspects of cardiac remodeling following chronic myocardial infarction were assessed in a mouse model.

\section{Methods}

Heterozygous IGF-1 deficient mice (with a C57blJ6 background) were generated by Genentech (San Francisco, USA) and kindly provided by L. PowellBraxton. ${ }^{15,16}$ The animals were genotyped by PCR and Southern Blotting. Measurement of IGF-1 plasma levels was perfor med independently by Genentech, using ELISA. Heterozygous (IGF $+/-$ ) animals were used, because nearly all of the homozygous (IGF-/.) animals die in utero or shortly after birth. In fact, we were able to grow only five IGF $-/$ - animals to adulthood (not included in the study). Their body weights were 8-10 g compared to 31.8 grams of the average WT littermate. The mice that survived surgery were subsequently assigned to one of four experimental groups:

1) Heterozygous animals with SHAM surgery (HZ/SHAM) $(n=10)$

2) Heterozygous animals with experimental MI $(\mathrm{HZ} / \mathrm{MI})(\mathrm{n}=13)$

3) Wildtype littermates with SHAM surgery (WT/SHAM) $(n=8)$

4) Wildtype littermates with experimental MI (WT/MI) $(n=8)$

\section{Induction of a myocardial infarction}

Male and female heterozygous IGF-1 +1 -were included. All experiments were conducted with permission of the Animal Welfare Committee of the University of Maastricht. The surgical procedure and technical aspects of MIinduction in mice have recently been published by Lutgens et al. ${ }^{17}$ Briefly, at the age of 10-12 weeks, the animals were anesthetized with pento barbital $(100 \mathrm{mg} / \mathrm{kg}$ ) and artificially wentilated. After opening the chest, the pericardium was opened and the left anterior descending coronary artery was ligated at 
the junction with 6-0 prolene. After ligation, the chest wall was closed and a BrdU-filled osmotic minipump (Alzet 2001, Alza Corporation, Palo Alto, CA; Serva, Heidelberg, Germany; infusion rate $13 \mathrm{mg} / \mathrm{kg} / \mathrm{day}$ for 7 days) was introduced subcutanously between the scapulae. SHAM animals underwent the same procedure without ligation of the artery.

\section{Assessment of LV function parameters}

After one week animals were reanesthetized and a catheter tip manometer (Microtip 1.4 F; Millar Instruments, Houston, TX, USA) was inserted and advanced into the aortic arch, where aortic pressure was measured.

Subsequently, the catheter was advanced into the left ventricle, where continuous registrations of the left ventricu lar pressure signal were made. After stabilization of LV function and heart rate, left ventricular systolic pressure (sLVP), end-diastolic pressure (LVEDP) and maximal positive $(+\mathrm{dP} / \mathrm{dt})$ and negative $(-\mathrm{dP} / \mathrm{dt})$ rates of pressure development were recorded for processing. Data were sampled at a rate of $2 \mathrm{KHz}$.

\section{Assessment of structural parameters}

Tissue processing; Following LV function measurements, the thorax was opened and the heart was arrested in diastole by infusion of cadmium chloride $(0,1 \mathrm{M})$ into the left atrium. The heart and circulation were perfused antegradely at physiologic pressures through the left atrium and the perfusate was evacuated through the dissected inferior caval vein. The perfusion was started with phosphate buffered saline (PBS; pH 7.4) containing $1 \mathrm{mg} / \mathrm{ml}$ sodium nitroprusside for 1 minute and continued with a fixative (5\% formalin in PBSj. After perfusion, heart (except the atria), lungs and liver were dissected and weighed. Subsequently, the tissues were immersion-fixed in 10\% formalin in PBS for 24 hours, processed and embedded in paraffin for morphologic and histologic analysis.

The heart was cut longitudinally, perpendicular to the infarcted area and aortic root (left ventricular outflow tract), resulting in an anterior and a posterior part. From both parts $2 \mu \mathrm{m}$ and $4 \mu \mathrm{m}$ sections were cut. Both tissue sections were analyzed. In a separate group of animals, the posterior part of the heart was cut transversely, to obtain transverse sections of the papillary muscle. Morphometry; Infarct size was determined on Azan-stained $4 \mu \mathrm{m}$ sections. Infarct size was assessed by computerized morphometry (Quantimet 570 , Leica, The Netherlands) and expressed as a percentage of the total left ventricular wall circumference. In the same Azan-stained sections, changes in general architecture of the ventricle were assessed. For that purpose, interventricular septum and left ventriular free wall (LVFW) thickness were measured by 
computerized morphometry. All animals had a transmural infarct. Infarcts encompassing $<30 \%$ of the left ventricular circumference (typical apical infarcts) were excluded from the study.

Imwuinohistochemistry: Capillarization was assessed on $2 \mu \mathrm{m}$ BS-1 Isolectin B4 (Sigma, L2140, USA) stained sections of the non-infarcted papillary muscle and the interventricular septum. Staining techniques are described elsewhere. 18 Capillary to fiber ratio ( $\mathrm{C} / \mathrm{F}$ ratio) was determined microscopically in the septum and the papillary muscle, by dividing the total number of capillaries by the total number of cardiomyocytes. C/F ratio was measured with an eyepiece grid (400X magnification) in 6 microscopic fields. For capillary density (CD), total tissue area was detected morphometrically, using a calibrated grid, after which the number of capillaries was assessed in that same field. In that way, the number of capillaries per square $\mu \mathrm{m}$ of tissue could be calculated. Moreover, from identical fields the total number of cardio myocytes was counted to calculate myocyte density (MD) per square $\mu \mathrm{m}$ of tissue. ${ }^{12}$ Since there were no differences between the $\mathrm{C} / \mathrm{F}$ ratio's in the papillary muscle and the interventricu lar septum, subsequent measurements of the MD and CD were confined to the interventricular septum.

To detect 5-Bromo-deoxyuridine (BrdU) incorporation, the Total Labeling Fraction (TLF = number of BrdU-positive/ total number of counted nuclei $100 \%)$ for $\mathrm{BrdU}$ was calculated in the borderzone of the infarcted left ventricle, the center of the non-infarcted right ventricle and the non-infarcted septum. Cell numbers were determined microscopically with an eyepiece grid (400X magnification). A total of 3000 nuclei per heart were counted in two tissue sections (1000 nuclei at the borders of the infarcted area and 1000 nuclei in the center of the non-infarcted septum, all in the same section). All measurements were performed by one investigator (M.P.), and intra-observer variation was less than $10 \%$. The investigator was blinded for the experimental group.

In order to assess the amount of apoptosis, a modified TUNEL assay (Terminal transferase dUTP Nick End Labeling) was performed. ${ }^{20}$ The percentage of TUNEL positive nuclei was expressed as percentage of total nuclei as described above (TLF for TUNEL). TUNEL positive labeled nuclei were counted in the infarcted area, the borderzone and the non-infarcted septum and expressed as a percentage of the total amount of nuclei in those areas. The TUNEL technique is very sensitive and therefore needs a careful titration of proteolytic pretreatment and Tdt concentration, otherwise a high fraction of non-apoptotic nuclei will be labeled. In a recent study, a molecular explanation for this phenomenon was found. ${ }^{21,22}$ It was demonstrated in this study that besides apoptotic nuclei, non-apoptotic nuclei that show signs of active 
gene transcription are labeled by the TUNEL technique. These cells are still active and are transcribing genes that might be related or completely unrellated to the apoptotic cell death pathway. In a true apoptotic cell the nuclear DNA is cleaved in oligonucleosomal sized fragments and caspase activation can be demonstrated. In the present study we used a stringent TUNEL technique to exclude the aspecific labeling and an activated caspase- 3 staining was performed. Activated caspase was detected by an antibody against cleaved caspase-3 (Pharmingen, USA). The polyclonal antibody of Pharmingen is raised against the $17 \mathrm{kd}$ cleaved fragment of the human caspase- 3 and was used at a dilution of 1/200 after citrate microwave pretreatment of the sections. Tonsil tissue was used as positive control. DNA laddering was not performed because of the low apoptosis rates in the infarcted area. ${ }^{23}$ The total number of caspase positive cells was divided by the total number of nuclei in the infarcted area.

\section{Statistics}

Data are expressed as means \pm SEM. The effects of surgery and genotype were evaluated with the Mann-Whitney test. The level of statistical significance was considered to be at $\mathrm{P}<0.05$. Intra-observer variability was smaller than $10 \%$ for all the parameters measured. 


\begin{tabular}{lllll} 
& Body weights & Lung weight & Heart weight & HW/EW ratt \\
\hline WT/SHAM & $32.3 \pm 1.6$ & $0.222 \pm 0.02$ & $0.154 \pm 0.0075$ & $0.0050 \pm 0.00019$ \\
\hline WT/MI & $31.3 \pm 1.6$ & $0.258 \pm 0.02$ & $0.170 \pm 0.0074$ & $0.0055 \pm 0.00015$ \\
\hline HZ/SHAM & $25.0 \pm 1.1 *$ & $0.172 \pm 0.005 *$ & $0.132 \pm 0.0064$ & $0.0052 \pm 0.00013$ \\
\hline HZ/MI & $26.3 \pm 0.8 *$ & $0.191 \pm 0.01 *$ & $0.147 \pm 0.0065 *$ & $0.0058 \pm 0.00$
\end{tabular}

Table 1

shown are the waigth porameters for the 4 experimental groups (in grams). \# $=p<0.05$, significant for WT/SHAM vs.

HZ/SHAM, * $=p<0.05$, significont for WT/MI vs. HZ/MI.

\section{Results}

General: Body weights and organ weights of IGF-1 +/-animals were lower than those in their non-transgenic littermates. No changes in HW/BW ratios were observed, neither between SHAM and MI groups, nor between both genotypes (Table 1). IGF-1 plasma levels in IGF $+/$ - animals were $65 \%$ of normal WT plasma levels. No statistical significant differences could be observed between male and female animals in both genotype groups.

Surgical mortality was approximately $40 \%$. Sporadically, death occurred due to anesthesia. The other deaths ocurred during the operation due to complications related to the size of the MI. These mice suffered from extreme bradycardia and asystole, but not from ventricular fibrillation, the most common fatal arrhythmia in man following acute MI. The majority of deaths was seen in the MI groups, in equal amounts in both groups ( 8 out of 18 in the WT/MI group and 10 out of 26 the HZ/MI group). Only 6 SHAM animals died.

During cardiac function measurements, 2 WT/MI mice and 3 animals in the HZ/MI group died before function measurements were completed.

Infarct size and structural ventricular chamber parameters (table 2a):

Coronary artery ligation resulted in a MI encompassing 30-50\% of the left ventricular wall circumference. No significant differences were observed in infarct size between the IGF- $1+/$ - animals and their non-transgenic littermates (WT/MI: $43.6 \pm 9.3 \%$ vs. HZ/MI: $40.3 \pm 8.7 \%$ ). LV diameter increased in both MI-groups.

After MI, septum thickness in the WT/MI group increased as compared to the WT/SHAM group, indicating a compensatory hypertrophic response to the acute increase in workload in the non-infarcted interventricular septum. In the IGF-1 +/- animals, septum thickness did not change significantly after MI, indicating a blunted compensatory hypertrophic response after MI. The 

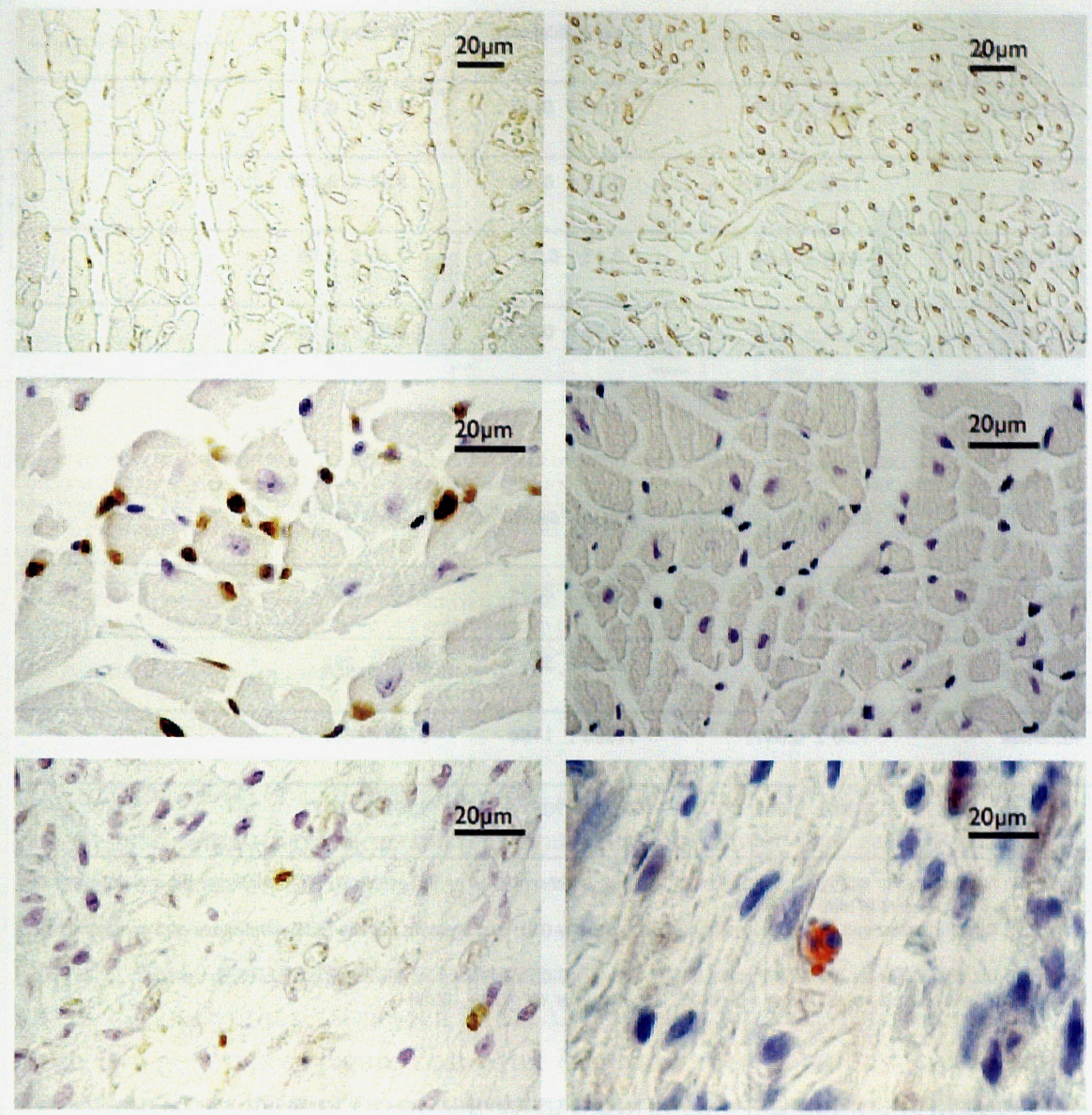

Figure 10. and 1b.: This is a representative lectin stained tissue section in the non-infarctied septurn of a WT/MI mouse (1 a) compared to the same area in a HZ/MI mouse (1 b) (100x). Cardiomyacwtes are clearly larger in the WT group after MI.

Ic. and Id. Flgure $1 \mathrm{C}$. shows the anti-Brdu staining in the non-infarcted interwentricular septum (250x). Anti-Brdu pasitivity is confined to non-cardiomyocyles and not to cardiomyocyles. Figure 1 d. shows an anti-BrdU stained section of the non-thfarcted septum of a HZ/SHAM animal [1 60X).

1e. and 11 ;: These plictures show an example of a TUNEL [1e., 160x] and an octivated caspase 3 staining (11. $250 \mathrm{x}$ ) in the infarcted area of a HZMMl mouse. 


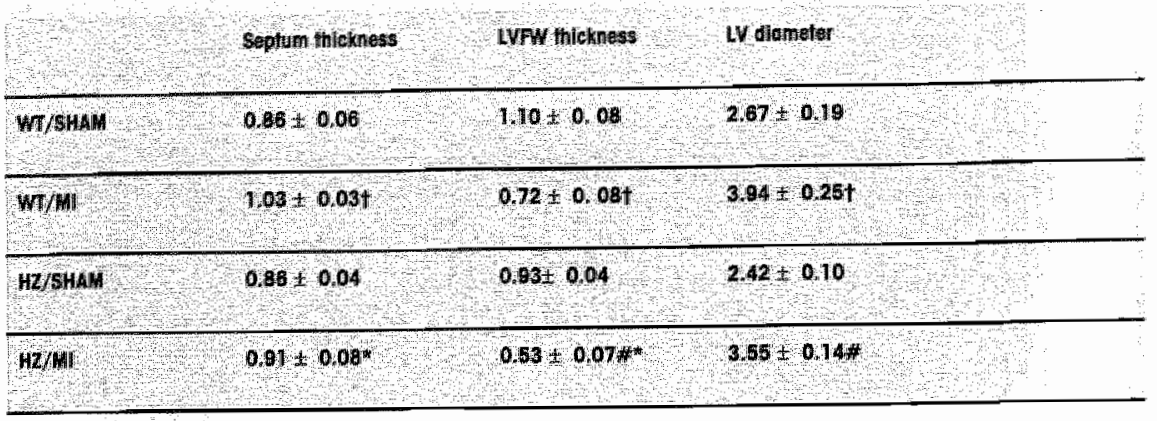

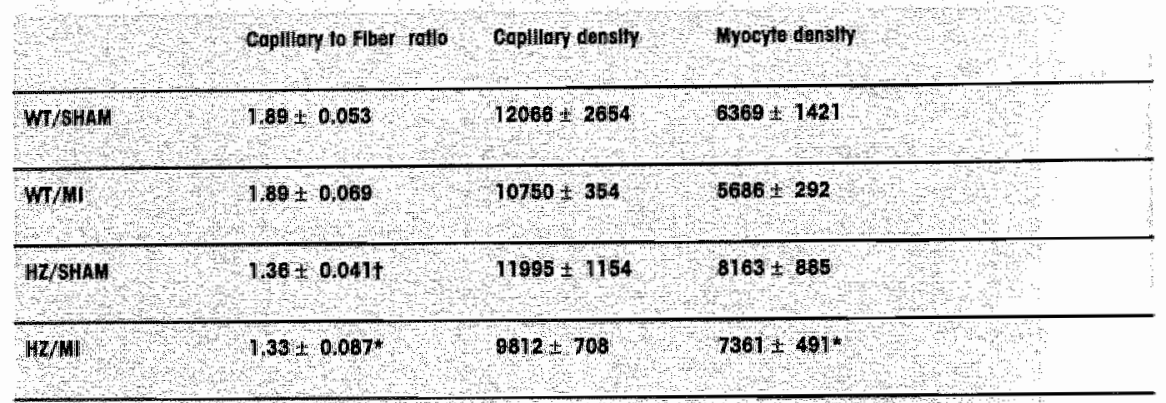

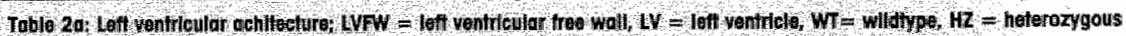

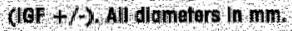

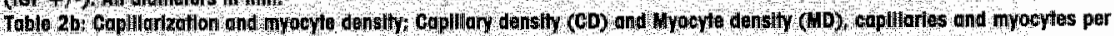
minn:

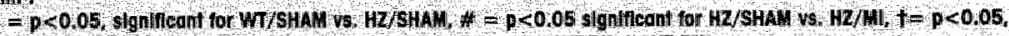

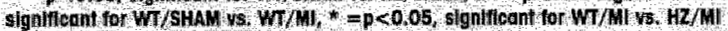

thickness of the infarcted area of the LVFW decreased in both MI groups $(p<0.05)$. In the IGF $+/$ - group, infarct thickness was smaller when compared to WT mice $(p<0.05)$. However, the difference in LVFW thickness was also present between both SHAM groups $(\mathrm{p}<0.05)$ (Table 2$)$.

Capillarization of the non-infarcted myocarditum (table $2 \mathrm{~b}$ ):

No significant differences were found in baseline MD values between both genotypes, although a trend was observed towards increased MD in IGF+/mice. Induction of MI did not change myocyte diameter significantly, although a trend toward decreased MD was observed in both genotypes after MI. Myocytes were smaller in IGF $+/$ - animals after infarction when compared to the WT/MI group (Figures la and lb), as indicated by the increased MD in this group $(\mathrm{p}<0.05)$. CD did not differ neither between genotypes, nor between infarct and SHAM group, although a trend was observed to decreased $\mathrm{CD}$ after $\mathrm{MI}$ in both genotypes.

C/F ratio's of both [GF-1 +/- groups were lower than those obtained in their wildtype littermates $(1.89 \pm 0.053$ for WT/SHAM vs. $1.36 \pm 0.041$ for 

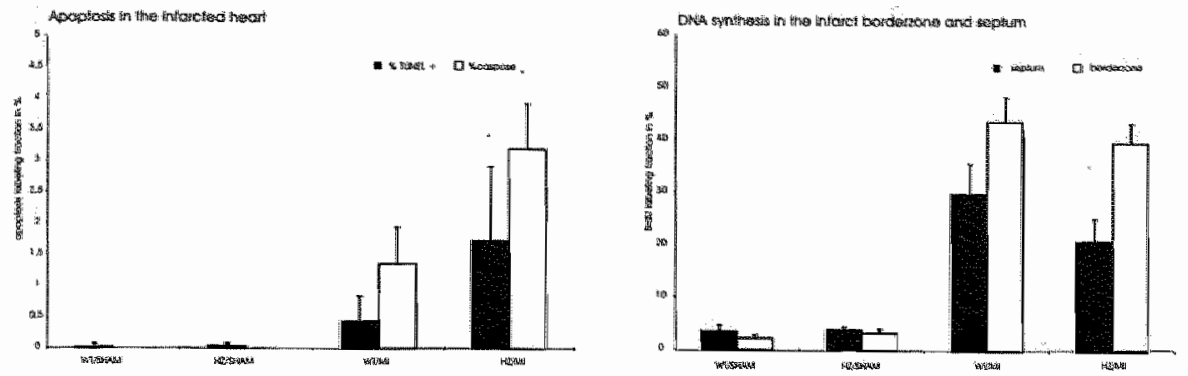

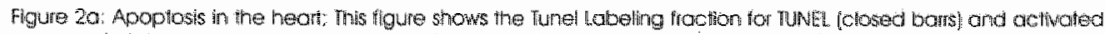

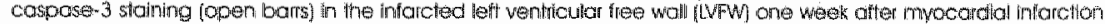

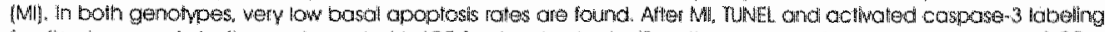

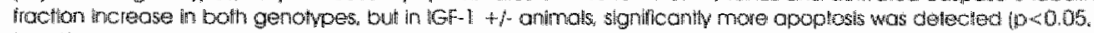
Wor-Whitrey

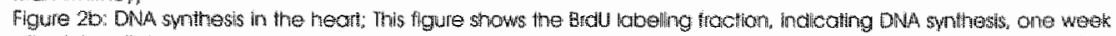

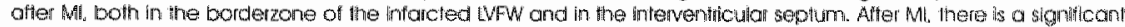

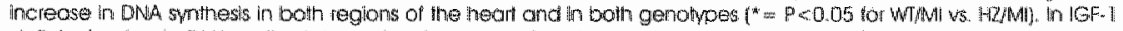

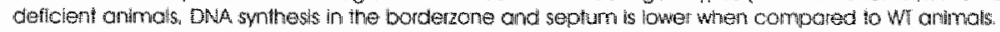

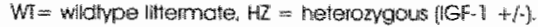

HZ/SHAM, $\mathrm{p}<0.05)$. Induction of $\mathrm{MI}$ did not change the $\mathrm{C} / \mathrm{F}$ ratio in both genotypes. Altogether, these data indicate that the lower $\mathrm{C} / \mathrm{F}$ ratio's in $1 \mathrm{GF}$ $+/$ - animals can be explained largely by changes in $M D$, not by changes in $C D$ (Table 2).

Cellular DNA synthesis and apoptosis in the heart (Figure 2): A very low basal rate of DNA synthesis was seen in SHAM animals, with no differences between two genotypes (Figure 2b). After MI, BrdU incorporation increased in the interventricular septum and, even more pronounced, in the borderzone of the infarcted ventricle. Septum BrdU labeling fraction in the HZ/MI group was only $60 \%$ when compared to the values in infarcted wildtype animals $(p<0.05)$. In the borderzone of the infarcted area, no differences in BrdU labeling between both genotypes were found. By lightmicroscopy, we investigated the interventricular septum where the plane of section was perpendicular to the axis of the myocytes, and counted the BrdU positive nuclei that were not defined to cardiac myocytes. In fact, $>99 \%$ of BrdU positive nuclei were localized in non-cardiomyocytes. In the borderzone of the infarcted area, similar results were obtained. In the SHAM operated mice, very low numbers of apoptosis were detected. (figure $1 \mathrm{c}$ and $\mathrm{ld}$ ).

A very low basal rate of apoptosis was found in the non-infarcted hearts, with no differences between the two SHAM groups (Figure 2a). MI induction in wild types increased TUNEL labeling from $<0.01 \%$ to $0.4 \%$. In the infarcted LVFW of IGF $+/$ - animals, TUNEL labeling fraction increased to $1.7 \%$ $(p<0.05)$ (Figure le and $1 \mathrm{f})$. In the non-infarcted area no differen ces were 


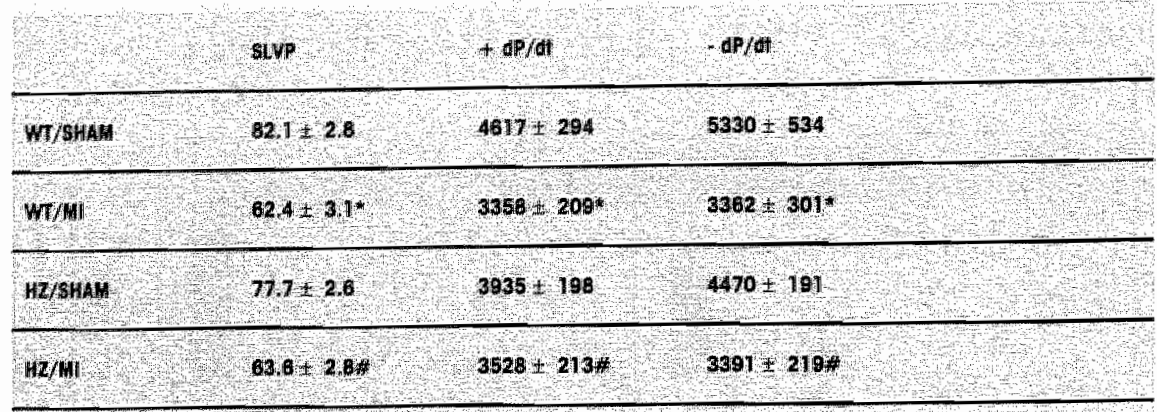

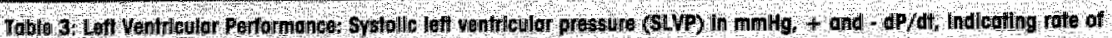

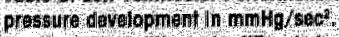

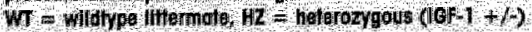

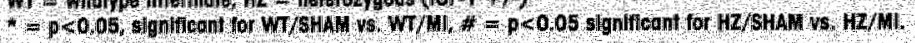

seen between the genotypes. The staining for cleaved caspase-3 showed a similar pattern in the infarcted area, with significantly more positive nuclei in IGF-I deficient hearts $(3.20 \pm 0.73 \%)$ when compared with WT $(1.35 \pm 0.59 \%, p<0.05)$. TUNEL and cleaved caspase- 3 labeling in the infarcted area was confined to non-cardiomyocytes, although in the borderzo ne, several positive cardiomyocytes were detected.

Cardiac function (Table 3): Left ventricular function measurements, performed one week after operation, revealed no significant baseline differences between the two SHAM-operated groups. However, after infarction a significant reduction of sLVP (from $82.1 \pm 5.5$ to $62.4 \pm 7.7$ in WT animals, from $77.7 \pm 8.2$ to $63.6 \pm 9.3$ in IGF-1 deficient animals, $p<0.05$ ) was found when compared to the SHAM groups (Table 3). Similar results were obtained for cardiac contractility and cardiac relaxation values with a decrease in both positive and negative $\mathrm{dP} / \mathrm{dt}$ values after MI in both genotypes (Table 3). No significant changes were seen between the IGF-1 deficient and the WT infarct groups.

\section{Discussion}

The major finding in this study is that following $\mathrm{MI}$, cardiac performance in IGF $+/$ - animals was not affected, despite a blunted cardiac remodeling response. $I G F-1+/$ animals had a blunted hypertrophic response of the interventricular septum, in addition to a general decrease in $\mathrm{C} / \mathrm{F}$ ratio, mainly due to an increased MD. Furthermore, DNA synthesis was decreased, in conjunction with a 4-fold increase in apoptosis rates. 


\section{Role of IGF-1 in cardiac remodeling}

Although IGF-1 $+/$ - animals had lower body and organ weights, their HW/BW ratio was not disturbed, which underscores the general growth promoting effects attributed to IGF-1. Data in this study indicate that IGF-1 deficiency is associated with smaller cardiomyocytes and a blunted hypertrophic response of the interventricular septum after MI. We studied myocyte density, using computerized morphometry. In both genotype groups, a nonsignificant decrease in MD was observed after MI. In WT/MI animals, MD was lower compared to animals in the HZ/MI group and occurred conconitantly with an increase in septum thickness. In HZ/MI animals, a nonsignificant decrease in MD was accompanied by only a modest increase in septum thickness. This phenomenon of myocyte hypertrophy and thinning of the septum could be explained by side to side slippage of cardiomyocytes ${ }^{24}$ or by early apoptosis ${ }^{25}$ of cardiomyocytes in the interventricular septum in the $\mathrm{HZ} / \mathrm{MI}$ group. If so, the early apoptosis peak potentially has been missed. In literature, overwhelming evidence is present for a role of IGF-I in cardiac hypertrophy. Both administration of IGF-I to healthy animals and excessive production of $\mathrm{GH}$ in humans with acromegaly leads to cardiac hypertrophy without structural signs of cardiomyopathy. ${ }^{5,26}$ Also in the infarcted heart, IGF-l has been shown to play a major role in reactive hypertrophy after acute coronary artery occlusion. $\mathrm{GH}^{14}$, IGF-1 administration ${ }^{5 .,}$ and IGF-1 overexpression $^{10}$ augment the hypertrophic response of the non-infarcted contractile tissue and preserve cardiac performance after myocardial infarction. The data presented in this study provide further evidence for a role of IGF-I in the regulation of the compensatory hypertrophic response of the non-infarcted area of the heart, in addition to general growth promoting effects on cardiomyocytes.

Furthermore, IGF- $\downarrow$ has been shown to regulate angiogenesis in vivo. Duerr et.al. ${ }^{7}$ showed in a rat model of MI and Kluge et al..$^{13}$ in a porcine model of cardiac microembolization, that IGF- 1 administration increased cardiac angiogenesis. Here we report that IGF-I deficiency is associated. with decreased $\mathrm{C} / \mathrm{F}$ ratios of the non-infarcted myocardium, both under physiologic conditions and after MI. As explained above, C/F ratios did not change after MI in both genotypes, albeit because of different mechanisms. In wildtype animals, the unchanged $\mathrm{C} / \mathrm{F}$ ratio was due to a decrease in $\mathrm{MD}$ and a matching decrease in capillary numbers, while the unchanged $\mathrm{C} / \mathrm{F}$ ratio in IGF $-1+/$ - animals can be explained by the blunted hypertrophic response of cardiomyocytes and lack of angiogenesis. This suggests a balance between cardiac hypertrophy and cardiac angiogenesis in both mouse models. 
IGF-I deficiency was associated with decreased DNA synthesis in the interventricular septum and infarct borderzone and increased rates of apoptosis in the infarcted area of the heart. The increased apoptosis rates in the infarcted area may account for the augmented thinning of the infarcted area of IGF-1 $+/$ hearts, compared to WT infarcts. Part of this difference might be explained by the baseline difference in LVFW thickness that was observed between both SHAM groups (table 2a). IGF-1 is known to enhance cellular proliferation, although its effects on cardiomyocyte proliferation remain controversial. ${ }^{1.98}$ In our study, the majority of BrdU incorporation in the infarcted area was not confined to cardiomyocytes, but rather detected in non-cardiomyocytes. This was also found by Kuizinga et al..$^{27}$ in rats and by Lutgens et.al. ${ }^{17}$ in mice.

IGF-I is known to play an important role in apoptosis, both in vitro and in vivo. In vitro, stretch-induced apoptosis of cardiomyocytes was attenuated by IGF-1 administration. ${ }^{28}$ In a murine model of ischemia reperfusion ${ }^{29}$ and in a chronic MI study in mice overexpressing IGF $1^{10}$, this growth factor was shown to protect against apoptosis and to reduce myocyte death. In the present study we used a stringent TUNEL technique to exclude the aspecific labeling. DNA laddering was not performed because of the low apoptosis rates in the infarcted area. ${ }^{23}$ Therefore, an activated caspase- 3 staining method was done, which confirmed the TUNEL results. In literature, acute MI induces apoptosis of cardiac myocytes in the borderzone. ${ }^{30}$ In this study, apoptosis was detected mainly in non-myocytes, rather than in cardiomyocytes, although several apoptotic myocytes were detected in the borderzone of the infarcted area. In the center of the infarcted area, myocyte necrosis occurred and nuclei were absent in these ghost cells.

In literature, there is an ongoing discussion about the mechanism of $\mathbb{I G F - 1}$ induced protection from apoptosis. Apoptosis is clecreased by IGF-I by interference with known pro-apoptotic pathways. Leri et al. ${ }^{28}$ showed that IGF-1 overexpression induced increased levels of $\mathrm{p} 53-\mathrm{Mdm} 2$ complexes leading to decreased p53 transcriptional activity and conversely to decreased bax, angiotensinogen and ATl receptor transcription, all of which are associates with increased apoptosis levels of cardiac myocytes. In addition, ATII decreased. Bcl-2 expression did not change. In addittion, Wang et al. ${ }^{31}$ showed that IGF-1 administration to cardiac myocyte cultures increased cell viability and decreased DNA fragmentation. In addition, Bax induction and caspase- 3 activation were attenuated. Furthermore, Chen et al. ${ }^{32}$ showed that IGF-1-induced attenuation of apoptosis could be prevented by inhibition of PI-3K.

We showed that induction of MI resulted in left ventricular dysfunction. Since liwer and lung weigths did not increase due to MI induction and no late $(>24 \mathrm{~h}$ 
post-MI) mortality occurred, we conclude that no overt heart failure was present. Furthermore, no differences in cardiac function parameters were found between WT and IGF-I deficient animals, which is in agreement with the data presented by Lembo et al. ${ }^{15}$ This group reported no baseline changes in cardiac contractillity in these IGF-1 $+/$ - mice, using comparable methods for LV performance measurements. Here we show that also in the infarcted IGF1 deficient heart, cardiac performance was not altered, although obvious changes in the architecture of the ventricle were observed. One of the explanations for the lack of functional changes might be the timing of the measurements. Potentially, early changes and late remodeling may have been missed. When we compare the + and $-\mathrm{dP} / \mathrm{dt}$ data obtained with the Millar $1.4 \mathrm{~F}$ catheter and compare these with values in literature, several groups obtained higher values, using comparable techniques. ${ }^{15.33}$ Reported $\mathrm{dP} / \mathrm{dt}$ values by other groups are in the same magnitude. ${ }^{34.35}$ Differences could be explained by the use of other anesthetics (penthotal ws ketamine/thiobutabarbital) ${ }^{3.3}$, strain differences and the closed chest vs. an open-chest mouse model. ${ }^{36}$ In literature, conflicting data on the role of IGF-1 on cardiac function have been reported. Both reduced and increased IGF-1 levels have been reported to enhance left ventricular performance. $\mathrm{Li}$ et al. ${ }^{10}$ showed that IGF-l overexpression in mice increased cardiac performance following MI. In contrast, $\mathrm{GH}^{37}$ and IGF-1 deficient mice (the latter producing only $30 \%$ of normal IGF-1 levels) $)^{15}$, showed an overall increase in $\mathrm{LV}$ performance, in addition to increased conscious blood pressure. These, apparently contradicting, observations have been explained by increased beta adrenergic receptor density with GH deficiency and increased adenyl cyclase activity in IGF-I deficiency.

The role of IGF-I in cardiac remodeling is investigated thoroughly in literature. This study provides further evidence for a pivotal rol of IGF-I in cardiac remodeling following MI. IGF-I deficiency leads to a blunted cardiac remodeling following MI, as indicated by the attenuation of the hypertrophic response, increased apoptosis and decreased cellular proliferation. However, this is not accompanied by a decreased cardiac performance for reasons mentioned above. Other studies in which IGF-I is administered, show that IGF-I can improve structure and function of the failing heart. This study further underlines the need for evaluation of the role of IGF-1 in human post-MI remodeling and functional adaptation in order to come to a better therapy for patients to prevent heart failure. 


\section{Conclusions}

In this study we showed that heterozygous IGF-1 deficiency in mice leads to a blunted cardiac remodeling response following MI, while cardiac function appears not to be affected, one week after MI. These data suggest an important stimulatory role of IGF-I in cardiac hypertrophy, DNA synthesis and apoptosis.

\section{Acknowledgements}

We are indepted to Jacques Debets, Peter Leenders, Anique Jansen and dr. Jack Cleutjens for their technical support. We thank Genentech for determination of the IGF-I serum levels. 


\section{References}

1. Schmid C. Insulin-like growth factors. Cell Biol int 1995;19:445-457.

2. Froesch ER, Schmid C, Zopf $J$ et al. Actions of insullin-like growth factors. Ann Rew Physiol $1985 ; 47: 443-467$.

3. Macllellan WR, Hawker J, Schneider MD. Myocardial growth factors. In: Marks AR, Toubman MD, eds. Molecular Biology of Cardiovascular Disease. New York: Marcel Dekker Inc., 1997:327-378.

4. Ito $\mathrm{H}$, Hiroe $\mathrm{M}_{2}$ Marumo $\mathrm{F}$ et al. Insulin-like growth factor-1 Induces hypertrophy with enhanced expression of muscle specific genes in cultured rat myocytes. Circulation 1993;87:1715$\$ 721$.

5. Cittadini A, Str 'mer $H$, Douglas. PS et al. Differential cardlac effects of growth hormone and Insulin-like growth factor-1 in the rat. Circulation 1996:93:800-809.

6. Donohue TJ, Dworkin LD, Catanese WM et al. Induction of myocardial Insullin-llke growth factor-1 gene expression in left ventricular hypertrophy. Circulation 1994;89:799-809.

7. Duerr RL, Hwang $S$, Ross J JR et al. Insulin-like growth factor-1 enhances ventricular hypertrophy and function during the onset of experimental cardlac failure. J Glin Invest 1995;95:619-627.

8. Reiss $K$, Cheng $W$, Anversa $P$ et al. Overexpression of Insullin-llike growth factor- I in the heart Is coupled with myocyte prollferation in transgenic mice. Proc Natl Acad Sci USA 1996;93:8630-8635.

9. Reiss $K$, Kajstura J, Anwersa $P$ et al. Acule myocardial infarction leads to upregulation of the IGF-1 autocrine system, DNA replication, and nuclear mitotic dlvision in the remaining viable cardiac myocytes. Exp Ceil Res 1994;213:463-472.

10. Li $Q$, L B, Anversa $P$ et al. Overexpression of insulin-like growth factor- 1 in mice protects fram myocyte death after infarction, attenuating ventricular dilatation, wall stress, and cardiac hypertrophy. J Clin Invest 1997;100:1991-1999.

11. Wang $L$, Weigiong $M$, Wang $P H$ et al. Regulation of cardiomyocyte apoptotic signaling by Insulin-like growth factor 1, Circ Res 1998;83:516-522.

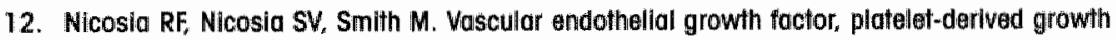
factor, and insulin-like growth factor-1 promote rat aortic anglogenesis in viltro. Am J Pathol 1994: 145:1023- 1029.

13. Kluge $A$, Zimmermann $\mathbb{R}$, Schaper $W$ et al. Insulin-like growth factor 1 is involved in inflammation linked anglogenic processes after microembolisation in porcine heart. Cardiovasc Res 1995:29:407-415.

14. Cittadini A, Grossman JD, Douglas PS ef al. Growth hormone attenuates early left ventricular remodeling and improves cardiac function in rats with large myocardial infarction. J Am Coll Cardiol 1997;29:1109-1116.

15. Lembo $G$, Rockman HA, Powell-Braxton $L$ et al. Elevated blood pressure and enhanced myocardial contractility in mice with severe IGF-1 deficlency. J Clin Invest 1996;98:2648-2655.

16. Powell-Braxton $L$, Hollingshead $P$, Steward $T A$ et al. IGF- $I$ is required for normal embryanlic growth in mice. Gen Dev 1993;7:2909-2917.

17. Lutgens E, Daemen MJAP, Smits JFM et al. Chronic myocardial infarction in the mouse: cardiac functionol and structural changes. Cardlovasc Res 1999;41:586 593.

18. Nelissen-Wrancken HJM, Kuizinga MC, Smits JFM ef al. Early captopril treatment inhibits DMA synthesis in endothelial cells and normalization of maximal coronary flow in infarcted rat hearts. Cardiovasc Res 1998;40:156-164.

19. Nelissen-Vrancken HJMG, Debets JJM, Smits JFM et al. Time-reiated normalisation of maxi- 
mat coronary flow in isolated pertused heants of rats with myocardial infarction. Circuiation $1996,93: 349-355$.

20. Kockx MM, Muhring J, Jacob $W$ at al. Blotin-or digoxigenin-conjugated nucleotides bind to matrix vesicles in atherosclerotic plaques. Am J Pathol 1996:148:1771-1777.

21. Kockx MM, Murring J, De Meyer GRY of. RNA synthesis and splicing interferes with DNA synthesis in siltu and labeling techniques used to detect apoptosis. Am J Pathol 1998; 152:885-888.

22. Yaolta $\mathrm{H}$, Ogawa $K$, Maruyama $Y$ ef al. Apoptosis in relevant clinical siltuations: contribution of apoptosis in myocardial infarction. Cardiovasc Res 2000;45;630-641.

23. van Heerde WL, Robert-Otferman $S$, Reuteingsperger CPM et al. Markers of apoptosis in cardlovascular tissues; focus on Annexin V. Cardiovase Res 2000;45:549-559.

24. Olivetti $G$, Quainl $F$, Anversa $P$ ef al. Cellular basis of ventricular remodeling affer myocardial Intarction in rats. Cardloscience 1995;6:101-106.

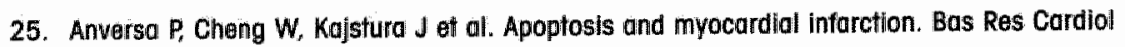
1998;93:8- 12.

26. Tanaka N, Ryake $T$, Ross. J at al. Etfects of growth hormone and IGF-1 on cardiac hypertrophy and gene expression in mice. Am J Physiol 1998;275;393-399.

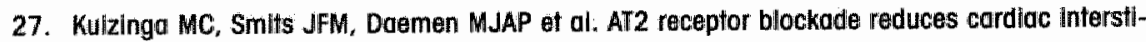
tial cell DNA synthesis and cardiac function after rat myocardial infarction. J Mol Cell Cardiol 1998;30:425- 434.

28. Lerl A, Liu $Y$, Anversa $P$ et al. Insulin-like growth factor- 7 induces Mdim2 and down-regulates p53, attenuating the myocyte renin-angiotensin sytem and stretch-mediated apoptosis. Am J Pothol 1999;154:567-580.

29. Buerke M, Murohara T, Lefer AM. Cardicprotective effect of insulln-like growth factor I in myocardlal ischemia followed by reperfusion. Proc Natl Acad Scl USA 1995:92:8031-8035.

30. Saraste A, Pulkki K, Voipio-Pulkki L-M ef al. Apoptosis in human acute myocardial infarction. Circulation 1997;95:320-323.

31. Wang $\mathrm{L}$, Ma W, Wang PH et al. Regulation of cardiomyocyte apoptotic signaling by insulinlike growth factor 1. Circ Res 1998;83:516-522.

32. Chen DB, Wang $\mathrm{L}$, Wang $\mathrm{PH}$. Insulin-like growth factor 1 retards apoptotic signaling induced by ethanol im cardiomyocytes. Life Sel 2000;67:1683-1693.

33. Lorenz JN, Robbins $\mathrm{J}$. Measurement of introventricular pressure and cardlac performance in the intact cllosed-chest anesthetized mouse. Am J Physiol 1997;272:1137-1146.

34. Koch WJ, Rockmen HA, Lefkowitz RJ at al. Cardiac function in mice overexpressing the betoadrenergic receptor kinase or a beta-ARK inhibltor. Science 1995;268;1350-1353.

35. Milano $\mathrm{CA}_{\text {, Allen }} \mathrm{LF}_{\mathrm{x}}$ Lefkowitz RJ et all. Enhanced myocardial function in transgenic mice overexpressing the beta-2 adrenerglic receptor. Science 1994;264:582-586.

36. Doevendans PA, Daemen MJ, Smits JF. Cardlovascular phenotyping in mice. Cardiovasc Res 1998:39:34-49.

37. Brown L, Wyse B, Sernia C. Adrenoceptor-medlated cardiac and vascular responses in genetically growth hormone deftcient rats. Blochem Pharmacol 1993;45:22.23-2229. 


\section{Chapter 4}

\section{IGF-1 improves cardiac functional recovery and enhances cell survival during ischemia and reperfusion \\ A PI-3K and PKC mediated mechanism.}

Meindert Palmen' MD, Mal J.A.PDaemen?, MD, PhD, Leon J. De Windr: PhD, Jodil Willems s, Willem R.M. Dassen: PhD, Sylvia Heeneman". PhD, Marc Van Bilsen, PhD, and Pleter A.FM. Doevendans: $M D$, PhD.

From the Depts, of Cardiology. Pathology", and Physiology: Cardiovascular Research Instifute Maastricht (CARIM). Maastilcht, the Netherlands

Submitted 


\section{Abstract}

Insulin-like Growth Factor-1 (IGF-1) is a pleiotrophic growth promoting peptide involved in cardiac remodeling and growth. Recently, attention focused on its cardioprotective potential during ischemia and reperfusion.

We investigated the effects of IGF-I on cardiac functional recovery and myocardial cell death following ischemia and reperfusion (I/R). For this purpose, we used heterozygous IGF-1 deficient mice (IGF- $1+/$-) and wild type (WT) littermates and an isolated, ejecting murine heart model of global myocardial $\mathrm{I} / \mathrm{R}$. We found no differences between WT and IGF+/-mice concerning both cardiac functional recovery and myocardial cell death. However, $65 \mathrm{nM}$ of recombinant human IGF-1, administered before induction of ischemia, resulted in enhanced cardiac functional recovery in both genotypes, in conjunction with augmentation of myocardial cell survival. These IGF-I mediated protective effects could be partially blocked by simultaneous pre-ischemic administration of a protein kinase $\mathrm{C}(\mathrm{PKC}$ ) inhibitor (chelerythine $5 \mu \mathrm{M}$ ) and could be completely blocked by pre-ischemic administration of a PI-3K blocker (LY294002, 100nM).

We conclude that a $40 \%$ reduction of IGF-I plasma levels does not affect cardiac tolerance to ischemia. However, pre-ischemic IGF-1 administration enhances cardiac functional recovery and improves cell survival following $I / R$. These effects prove to be completely PI-3K and partially PKC dependent.

\section{Introduction}

Insulin-like Growth Factor-1 (IGF-1) is a 7.6 Kd pleiotrophic growth promoting peptide, produced in the liver in response to growth hormone (GH) stimulation. Actions of IGF-1 in remote tissues largely depend on the interaction of IGF-1 with so-called IGF-BPs (IGF-binding proteins) and subsequent binding of the protein to the high affinity cell surface receptor (IGF-RI), located on target cells. ${ }^{1.5}$

Together with IGF-2, IGF-1 and its cognate receptor IGF-RI are critically involved in cardiac development ${ }^{6}$, as homozygous IGF-1 deficient mice display high intrauterine mortality ${ }^{7.9}$, whereas IGF-RI-/- animals are not viable? ${ }^{3}$ or display a major growth retarded phenotype. In In addition to systemic production, IGF-1. is produced locally in most tissues, including the myocardium, "in response to certain pathological stimuli like ischemia. IGF-1, and IGF-RI, become upregulated within hours after induction of an acute myocardial infarction (MI). ${ }^{12-14}$ Subseçuently, the locally produced IGF-1 plays a pivotal role in the remodeling process of the infarcted ventricle. Both IGF-I admi- 
nistration and IGF-1 overexpression induce myocardial non-myocyte cell proliferation and (a physiological type of) cardiac hypertrophy. In addition, IGF-1 overexpression and administration of IGF-1 decrease apoptotic cell death and ventricular dilation in the chronically infarcted ventricle, thereby improving cardiac function. ${ }^{15,3521}$ Similarlly, heterozygous IGF-1 deficiency results in impaired cardiac remodeling following chronic MI. ${ }^{22}$

Only recently, attention focused on the short-term effects of IGF-1 in both physiological and pathophysiological conditions. It has been demonstrated that under physiological circumstances, [GF-l instantly improves cardiac performance ${ }^{25-25}$ Surprisingly, also severe IGF-I deficiency resulted in enhanced myocardial contractility. ${ }^{26}$ Also during acute ischemia and reperfusion (I/R), IGF-I might serve as a protective agent, improving functional recovery and attenuating myocardial cell death.

Recently, Otani et al ${ }^{2 y}$ showed that IGF-1, when administered during reperfusion in an isolated rat heart model of $\mathbb{L} / \mathrm{R}$, improves cardiac functional recovery following myocardial ischemia, and that this protection is PI- $3 \mathrm{~K}$ dependent. A number of studies focused on the influence of pre-ischemic IGF-I administration on myocardial cell survival (both necrosis and apoptosis) following an (sub)acute ischemic event. ${ }^{20,28,29}$ In a subacute model of myocardial ischemia, Li et al. ${ }^{20}$ demonstrated that IGF-l overexpression attenuates the detrimental impact of non-occlusive coronary artery constriction, by decreasing myocardial cell necrosis, without an effect on myocardial cell apoptosis. Similarly, IGF- ${ }^{2 z}$ and insulin ${ }^{30}$ administration during reperfusion were sufficient to reduce the amount of necrotic myocardial cell death following global $\mathrm{I} / \mathrm{R}$,

Other studies reported that pre-ischemic IGF-1 administration attenuates ischemia-induced cardiomyocyte apoptosis, both in vivo and in vitro. ${ }^{28,29}$. The anti-apoptotic effects attributed to IGF-I are likely to be accomplished by binding to the IGF-RI and the subsequent activation or modulation of downstream effector molecules like PI-3K, Akt-I kinase and stress activated MAPkinase $\beta_{3} 8^{31.32}$ and subsequent down-regulation of pro-apoptotic pathways (myocyte renin-angiotensin system, p53 and p53-inducible genes, Bax and activated caspase- 3$)^{13,34}$

The mechanism of $1 G F-1$ mediated protection during acute $I / R$ is still unclear. Like FGF-I ${ }^{25},{ }^{2} F_{-1}-1$ might mimic ischemic preconditioning (IPC).

In this study, we investigated whether either reduced or enhanced circulating IGF-1 levels might influence cardiac functional recovery and myocardial cell survival. In addition, we tried to denominate the pathway of IGF-1 mediated protection. For this purpose, we used heterozygous [GF-I deficient mice in an ex vivo ejecting murine heart model of $\mathrm{I} / \mathrm{R}$. We found no significant differen- 
ces in cardiac functional recovery and myocardial cell survival between IGF-1 $+/$ - mice and WT littermates. However, pre-ischemic administration of $65 \mathrm{nM}$ IGF-I improved cardiac functional recovery and enhanced myocardial cell survival in both genotypes. These effects could be completely blocked, using a PI-3K inhibitor, but could onlly be partially blocked through pharmacological PKC inhibition.

\section{Materials and Methods}

Adult heterozygous IGF-I deficient mice (IGF $+/-$ ), displaying $60 \%$ of the normal plasma IGF-1 levels, were characterized by means of Polymerase Chain reaction (PCR) and assigned to experimental groups ( 8 groups, $n=6$ animals per group) according to genotype, as described before. ${ }^{22}$ In the first set of experiments, we investigated the effect of genotype on tolerance to ischemia. In subsequent experiments, we investigated whether pre-ischemic exogenous IGF-I administration could improve tolerance to ischemia. Hereto, we administered $65 \mathrm{nM} 27$ of rhIGF-1 to both WT and IGF-1 +/- hearts ( $\mathrm{n}=$ 6 for both groups) for 10 min during Langendorff perfusion and measured the effects on cardiac functional recovery and cell death following I/R. To dissect the intracellular signaling pathways involved in this phenomenon, we selectively inhibited PI-3K and PKC as target proteins involved in IGF-1 mediated protection.

All experiments were performed according to the guidelines of the Institutional Animal Care and Use Committee of the Maastricht University. Animals were kept under standard housing conditions. They had ad libitum access to normal chow and tab water.

\section{Chemicals}

All chemicals for the Krebs-Henseleit solution were purchased at the highest purity available $[\mathrm{D}(+)$ Glucose, pyruvate [Sigma, st. Louis, $\mathrm{MO}], \mathrm{NaCl}$, $\mathrm{CaCl}$, Kcl, MGSO4, KH2PO4, NaHCO3, Na-EDTA [Merck, Darmstad, Germany], Insulin [Actrapid, Novo Nordisk, Bagsvaerd, Denmark]].

Recombinant human IGF-] was purchased from Chiron (Oakland, CA).

\section{Perfusion system}

We used the isolated ejecting murine heart model, as described previously in more detail by our group. ${ }^{36,57}$ This murine "assisted mode" isolated heart model closely resembles the in vivo situation. Both the generation of cardiac output 
and left ventricular pressure development approach the normal physiologic state in the mouse, aided by the use of a specially designed aortic cannula, matching the hemodynamic impedance characteristics of the murine ascending aorta ${ }^{36}$ Briefly, mice were anesthetized with pentobarbital $(50 \mathrm{mg} / \mathrm{kg}$ i. p., Nembutal Sanofi Sante, Massluis, the Netherlands). Following thoracotomy, the heart was excised quickly and immersed in ice-chilled Krebs-Henseleit solution. Immediately, the aorta was cannulated and the hearts were mounted on the perfusion system and retrograde Langendorff perfusion with recirculating, prefittered Krebs-Henseleit ( $\mathrm{pH}$ range $7.40-7.45$ ) was commenced at a perfusion pressure (after load) of $50 \mathrm{mmHg}$, after which the hearts resumed spontaneous beating. Mean Arterial Pressure (MAP = systemic afterload) was monitored just downstream of the aortic cannula. The Krebs-Henseleit solution had the following composition; $118 \mathrm{mM} \mathrm{NaCl}, 4.7 \mathrm{mM} \mathrm{KCl}, 3.0 \mathrm{mM}$ $\mathrm{CaCl} 2,1.2 \mathrm{mM} \mathrm{MgSO} 4,25 \mathrm{mM} \mathrm{NaHCO}, 0.5 \mathrm{mM} \mathrm{Na}-\mathrm{EDTA}, 10 \mathrm{mM}$ $\mathrm{D}(+)$-glucose and $1.5 \mathrm{mM}$ sodium pyruwate. Insulin was omitted from the buffer, because the cardioprotective effects of insulin might obscure the IGF1 related cardioprotective effects. ${ }^{30}$ Nominal free $\left[\mathrm{Ca}^{2+}\right]$ was $2.5 \mathrm{mM}$ in the presence of $0.5 \mathrm{mM}$ EDTA, while $\mathrm{PO} 2$ values exceeded $650 \mathrm{mmHg}$. Subsequently, a left ventricular pressure catheter (polyethylene PE50 catheter) was introduced via the apex of the left ventricle and connected to a pressure transducer (Baxter Healthcare, Irvine, CA, USA). The left atrium was cannulated through one of the lung veins. The perfusate and the heart were kept at $38.5^{\circ} \mathrm{C}$.

\section{Hemodynamic data acquisition}

All hemodynamic parameters (including Aortic Flow [AOF], Coronary Flow $[C F]$, Cardiac Output [CO], Left Ventricular Developed Pressure [LVDP], Left Ventricular Systolic Pressure [LVP..], dP/dtw, Left Ventricular Diastolic Pressure [LVP.], Left Ventricular End Diastolic Pressure (LVEDP) and $\mathrm{dP} / \mathrm{dt}$ ) were recorded on a personal computer, using specialized software (Hemodynamic Data Acquisition System, Technical Department, University of Manstricht). CO was defined as the sum of CF and AOF. CF was determined from the difference between $A O F$, as measured with an $1 \mathrm{~N}$ in-line aortic flow probe placed in the aortic outflow tract, and the left atrial filling flow, also described as $\mathrm{CO}$, as measured by a $2 \mathrm{~N}$ in-line flow probe, placed in the left atrial inflow tract. The hearts were paced at a rate of 450 beats per minute (slightly above the intrinsic heart rate of approximately 430 , as was tested for this strain). 


\section{Experimental protocol}

After completion of the experimental set-up, antegrade perfusion was commenced by opening the left atrial conduit, maintaining a left atrial filling pressure (preload) of $10 \mathrm{mmHg}$ and an afterload in the aortic outflow tract measuring 50mmHg. After 15 minutes of normoxic antegrade perfusion, basal hemodynamic parameters were calculated and coronary effluent was collected For the determination of enzyme release. Subsequently, the left atrial inflow was occluded, and the heart was perfused in the Langendorff mode for an additional 10 minutes. At this time, the aortic outflow tract was occluded, thereby initiating a 20 minute period of normothermic global myocardial ischemia. Throughout the ischemic period, evaporation from the epicardial surface and temperature fluctuations were prevented by placing the heart in a water-jacketed mantle and submerging it in $38.5^{\circ} \mathrm{C}$ perfusion buffer. In pilot experiments ( $n=3$ for WT and $n=4$ for $I G F-1+/$ ), we found that 15 minutes of ischemia resulted in a relatively small effect on cardiac functional recovery (data not shown), 20 minutes of ischemia resulted in a $60 \%$ reduction $\mathrm{CO}$. Therefore, we chose for a 20 minute ischemic period.

After completion of the ischemic period, retrograde reperfusion (perfusion pressure of $50 \mathrm{mmHg}$ ) was initiated and the hearts were allowed to recover for 10 minutes, after which the left atrial inflow was re-opened, switching from Langendorff to the ejecting mode at pre-ischemic pre- and afterload values. After 60 minutes of reperfusion, the heart was quickly removed from the aortic cannula (atria remained connected to the cannula) and both ventricles and were flash-frozen between aluminium clamps (previously cooled in liquid nitrogen) and stored at $-80^{\circ} \mathrm{C}$ for further analysis.

During the extent of the protocol, hemodynamic data were recorded and coronary effluent was sampled both pre-ischemically ( $t=15 \mathrm{~min}$. and 25 min.) and during reperfusion ( $t=5,10,15,20,35,60$ min. post-ischemia) for the detection of lacate and lactate dehydrogenase (LDH) release, being markers for anaerobic metabolism and myocardial cell damage, respectively. To stabilize LDH, Bovine Serum Albumin (BSA) was added to a final concentration of $3 \%$. Lactate and LDH were assessed spectrophotometrically using a Cobas Bio autoanalyzer as described earlier by Apstein et al. ${ }^{38}$ and Mergmeyer and Bernt et al. ${ }^{39}$, respectively.

\section{IGF-1 administration and pharmacologicall inhibition of intracellular signaling proteins}

To investigate the protective effects of exogenous IGF-I administration on 
cardiac functional recovery and myocardial cell survival, we administered $65 \mathrm{nM}$ of rhIGF-1, 10 minutes prior to $\mathrm{l} / \mathrm{R}$, using Langendorff perfusion (in 6 animals, both for WT and IGF-1 +/-J. We found a significant protective effect of IGF-1 concerning an improvement of cardiac functional recovery and an attenuation of myocardial cell death.

To investigate the intracellular signaling pathway responsible for IGF-1 mediated protection, in a separate set of experiments rhIGF-1 (65nM) was administered simultaneously with either a PKC inhibitor (Chelerythrine-chloride $[5 \mu \mathrm{M}]$, dissolved in $\mathrm{dH} 2 \mathrm{O}$, for 10 minutes] or a PI-3K inhibitor (LY294002,

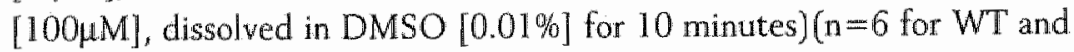
IGF-1 +/-). The concentrations of the inhibitors used were both well above the IC50 values and had been previously shown to completely inhibit the target protein.

For these studies, the experimental protocol was slightly modified. Baseline hemodynamics were recorded after 15 minutes of stabilization. Subsequently, the perfusion mode was switched from antegrade to Langendorff, to allow thIGF-1 (65nM) or IGF/CHE and IGF/LY administration for 10 minutes. rhlGF-1 and the IGF/inhibitor solutions were administered through a side hole of the aortic cannula. The solution was administered using a perfusor to assure constant levels and concentrated 8 times, to reduce the amount of unsaturated buffer perfusing the heart. We chose for a retrograde mode of perfusion (Langendorff) to diminish the amount of inhibitor to be administered, and to prevent the inhibitor from entering the perfusion system. After completion of drug delivery, the heart was subjected to the 20 minutes of ischemia, followed by 60 minutes of reperfusion, as described above.

\section{Immunoblotting and immonoprecipitation}

To investigate the activation of different intracellular signaling pathways in control hearts ( $n=3$, for $W T$ and IGF-I $/-$ ), not subjected to $/ / R$, and in all experimental groups subjected to 20 minutes of ischernia followed by 60 minutes of reperfusion, frozen ventricular tissue samples were powdered with a morter and pestle and further homogenized at $4^{\circ} \mathrm{C}$ in a buffer containing $0.5 \%$ Triton, $0.5 \% \mathrm{NP} 40,10 \mathrm{mM}$ Tris (pH 7.5), $2.5 \mathrm{mM} \mathrm{KCI}, 150 \mathrm{mM} \mathrm{NaCl}$, $20 \mathrm{mM}$ ?-Glycerolphosphate, $50 \mathrm{mM} \mathrm{NaF}, 1 \mathrm{mM}$ Orthovenadate, $10 \mu \mathrm{g} / \mathrm{ml}$ Leupeptin, $1 \mathrm{mM}$ DTT, $10 \mu \mathrm{g} / \mathrm{ml}$ soytrypsin inhibitor and $200 \mathrm{mM}$ benzamine, using a polytron tissue homogenizer (Kinematica AG, Switserland), and centrifuged for 20 minutes at $7000 \mathrm{xg}$. Samples containing equal amounts of protein $(20-40 \mathrm{Hg})$ were separated by SDS-PAGE $(8-12 \%)$ and western blotting was performed as described previously. Antibodies and other supplies 
were obtained from the following sources; Polyclonal PKC-E antibody was from Upstate Biotechnology (Lake Placid, NY, USA). New England Biolabs (Beverly, MA, USA) supplied polyclonal anti-phospho-specific antibodies against ERK1./2, JNK1/2 and p38, and polyclonal ERK1/2, JNK and p38 antibodies. Data were quantified by assessment of the integrated optical density (IOD). For each western blot (pERK, ERK, pJNK, JNK, pp38, p38, and PKC$\varepsilon)$, two gels were needed to quantify all eight groups. To correct for any differences in running and staining conditions, two random samples were run on each gel, the IOD's of these random samples were used to correct the other samples. To detect PKC translocation, separate cytosolic and particulate fractions were prepared from ventricular tissue. ${ }^{\text {.1 }}$ Briefly, tissue samples were homogenized in $25 \mathrm{mM}$ Tris- $\mathrm{Cl}$, pH 7.5, 4mM EGTA, 2mM EDTA, $5 \mathrm{mM}$ dithiothreitol, $1 \mathrm{mM}$ phenylmethylsulfonyl fluoride, $1 \mathrm{\mu g} / \mathrm{ml}$ leupeptin, and incubated on ice for 30 minutes. Afterwards, samples were spun at 100,000 $\mathrm{x}$ $\mathrm{g}$ for 30 minutes. $\left(4^{\circ} \mathrm{C}\right)$. The supernantant was used as cytosolic fraction, while the remaining pellet was rehomogenized with the same lysis buffer, now containing 1\% Triton X-100, and incubated on ice for 30 minutes. After spinning the samples for 30 minutes at $100,000 \times \mathrm{g}$, the supernantant was saved as the particulate fraction.

\section{Statistics}

The results are presented as means +/- Standard Error of the Mean (SEM]). The effect of genotype was evaluated using Mann-Whitney or Kruskall-Wallis test depending on the number of groups to be compared. The influence of time and genotype and their interactions, on hemodynamic parameters and enzyme release was assessed, using a 2-way ANOVA. A level of $P<0.05$ was considered to be of statistical significance.

\section{Results}

\section{General}

IGF-1 deficient animals had a normal life span and displayed normal fertility. The average body weight was lower in the IGF- 1 deficient mice $([n=30]$ $31.5 \pm 2.2 \mathrm{~g})$, when compared to their WT littermates $([n=30] 38.9 \pm 2.2 \mathrm{~g}$, $\mathrm{P}<0.05)$. Also heart weight (HW) was smaller in IGF-1 $+/$ - mice $(163 \pm 12$ mg vs. $194 \pm 11 \mathrm{mg}, \mathrm{p}<0.05$ \}. HW/BW ratios were similar in both genotypes $\left(\mathrm{IGF}-1+/-; 5.2 \pm 0.2^{*} 10^{-3}\right.$ vs. WT; $\left.5,1 \pm 0.2 * 10^{3}\right)$, underlining the general growth promoting role of $1 \mathrm{GF}-1$. 


\begin{tabular}{|c|c|c|c|c|c|c|c|c|c|c|c|c|}
\hline & & & $6 F^{\circ}$ & 5y & Wops & 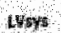 & Wroig & UYDDP & A: 4 PIS: & AP// & UDA & Locflate \\
\hline 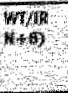 & 98 & $\begin{array}{l}97 \\
019\end{array}$ & मी & $\begin{array}{l}213 \\
48\end{array}$ & $\begin{array}{l}77, \\
47\end{array}$ & $\begin{array}{l}924 \\
3\end{array}$ & गी & $\begin{array}{l}107 \\
17\end{array}$ & $\begin{array}{l}400 \\
35\end{array}$ & 31305 & $\begin{array}{l}2+4,4 \\
+4\end{array}$ & 15 \\
\hline$(\mathrm{m} / \mathrm{G})$ & $\begin{array}{l}126 \\
16\end{array}$ & $\begin{array}{l}97 \\
4 \\
\end{array}$ & $\begin{array}{l}20 \\
94\end{array}$ & $\begin{array}{l}220 \\
\mathrm{x} \\
4\end{array}$ & $\begin{array}{l}442 \\
3 / 2\end{array}$ & $\begin{array}{l}911 \\
3 \\
3\end{array}$ & $\begin{array}{l}6 \\
14 \\
4\end{array}$ & $\begin{array}{l}120 \\
10\end{array}$ & $\begin{array}{l}620 \\
54\end{array}$ & $\begin{array}{l}3 \% 96 \\
27 \%\end{array}$ & $\begin{array}{l}256 \\
4 \quad \\
4\end{array}$ & $\begin{array}{l}5 \mathrm{~d} \\
5 \mathrm{P}\end{array}$ \\
\hline Hofige & $\begin{array}{l}12,3 \\
4, \\
4\end{array}$ & $\begin{array}{l}02 \\
14\end{array}$ & 83 & 263 & & $\begin{array}{l}691 \\
1, \\
6\end{array}$ & $\begin{array}{l}6,6 \\
1,9\end{array}$ & $\begin{array}{l}6,1 \\
2 \\
\\
\end{array}$ & $\begin{array}{l}4644 \\
001\end{array}$ & $\begin{array}{l}3901 \\
390\end{array}$ & $\begin{array}{l}34, \\
10 \%\end{array}$ & $\begin{array}{l}\mathrm{BSO} \\
\mathrm{CO}\end{array}$ \\
\hline$(n)$ (n) & $\begin{array}{l}40 \\
0 ;\end{array}$ & की & $\begin{array}{r}25 \\
4 \times 3\end{array}$ & $\begin{array}{l}31,4 \\
17\end{array}$ & 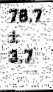 & of & $\begin{array}{l}711 \\
1,3\end{array}$ & $\begin{array}{l}17,6 \\
28\end{array}$ & 6862 & $\begin{array}{l}3590 \\
46\end{array}$ & $\begin{array}{l}28,6 \\
9,2\end{array}$ & $\begin{array}{l}129 \\
207\end{array}$ \\
\hline $\begin{array}{l}(n+6) \\
(n y+6)\end{array}$ & का & $\begin{array}{l}61 \\
08\end{array}$ & $\begin{array}{l}30 \\
\mathrm{~A}\end{array}$ & $\begin{array}{l}270 \\
10\end{array}$ & $\begin{array}{l}66.5 \\
4\end{array}$ & $\begin{array}{l}701,9 \\
47\end{array}$ & $\begin{array}{l}\text { bी } \\
4, f \\
2,\end{array}$ & $\begin{array}{l}62 \\
+18\end{array}$ & $\begin{array}{l}483 \\
44\end{array}$ & $\begin{array}{l}3818 \\
205\end{array}$ & $\begin{array}{l}301 \\
3 \\
4 \times 0\end{array}$ & $\begin{array}{l}662 \\
132\end{array}$ \\
\hline$(\mathrm{scc} \theta)$ & $\begin{array}{l}117 \\
04\end{array}$ & $\begin{array}{l}81 \\
0.6\end{array}$ & $\begin{array}{l}\text { 10 } \\
14 \\
04\end{array}$ & $\begin{array}{l}276 \\
4,\end{array}$ & $\begin{array}{l}044 \\
32\end{array}$ & $\begin{array}{l}1058 \\
06{ }^{\prime}\end{array}$ & $\begin{array}{l}79 \\
10\end{array}$ & $\begin{array}{l}1 \% 4 \\
\text { ग }\end{array}$ & $\begin{array}{l}071 \\
399\end{array}$ & (3059 & $\begin{array}{l}\sin , 2 \\
6 / 2\end{array}$ & $\begin{array}{l}889 \\
+ \\
89\end{array}$ \\
\hline WT/AY & $\begin{array}{l}110 \\
94\end{array}$ & $\begin{array}{l}1,3 \\
02\end{array}$ & $\begin{array}{l}40 \\
04\end{array}$ & $\begin{array}{l}281 \\
18\end{array}$ & $\begin{array}{l}692 \\
6,0\end{array}$ & $\begin{array}{l}\text { 1he } \\
4,2 \\
4\end{array}$ & $\begin{array}{l}\mathrm{b} \\
6 \mathrm{t} \\
2 \mathrm{y}\end{array}$ & $\begin{array}{l}106 \\
16\end{array}$ & $\begin{array}{l}4004 \\
404\end{array}$ & $\begin{array}{l}424 \\
28 \pi\end{array}$ & $\begin{array}{l}27,5 \\
6,\end{array}$ & $\begin{array}{l}327 \\
B, 3\end{array}$ \\
\hline$(0-\infty)$ & $\begin{array}{l}39 \\
00\end{array}$ & $\begin{array}{l}040 \\
4 \\
03\end{array}$ & $\begin{array}{l}58 \\
016\end{array}$ & $\begin{array}{l}315 \\
20\end{array}$ & $\begin{array}{l}860 \\
40\end{array}$ & $\begin{array}{l}10 \\
40\end{array}$ & $\begin{array}{l}6, \\
40\end{array}$ & $\begin{array}{l}147 \\
4,4\end{array}$ & $\begin{array}{l}6554 \\
613\end{array}$ & $\begin{array}{l}3674 \\
2 \% 8\end{array}$ & $\begin{array}{l}248 \\
27\end{array}$ & 60 \\
\hline
\end{tabular}

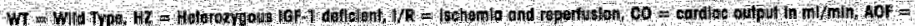

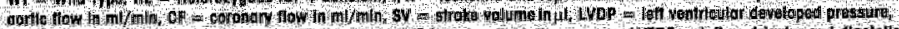

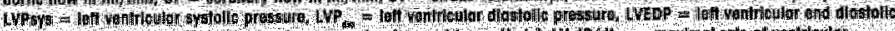

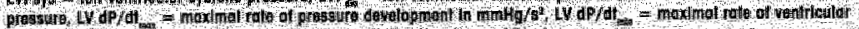

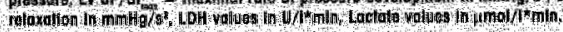

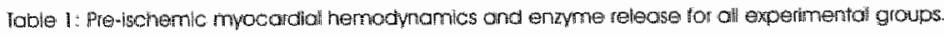

\section{Baseline hemodynamics}

During the 15 minutes stabilization period, hemodynamic parameters did not change in all experimental groups, indicating a stable base-line hemodynamic situation. No significant differences were found for pre-ischemic hemodynamic parameters or lactate and LDH release between IGF-1 $+1-$ mice and WT littermates, indicating an equal baseline hemodynamic situation (Table 1). A trend was observed towards better pre-ischemic hemodynamics in IGF-l deficient mice. Pre-ischemic cardiac contractility was significantly increased in $1 G F^{-1}+i$ - mice, when compared to WT animals. Other parameters showed a similar trend, but differences did not reach statistical significance.

Induction of ischemia resulted in a rapid deteroration of cardiac function. Cardiac functional recovery was equally impaired in both IGF-1 $+/$ - and WT littermates. AoF (Figure la) decreased 93\% in IGF-1 $+/-$ and 107\% in WT (going from antegrade to retrograde flow) at initiation of antegrade reperfusion and gradually decreased during 60 minutes of reperfusion. Similarly, LVDP (Figure $\mathrm{lc}$ ) and dP/dt (data not shown) decreased respectively $31 \%$ 

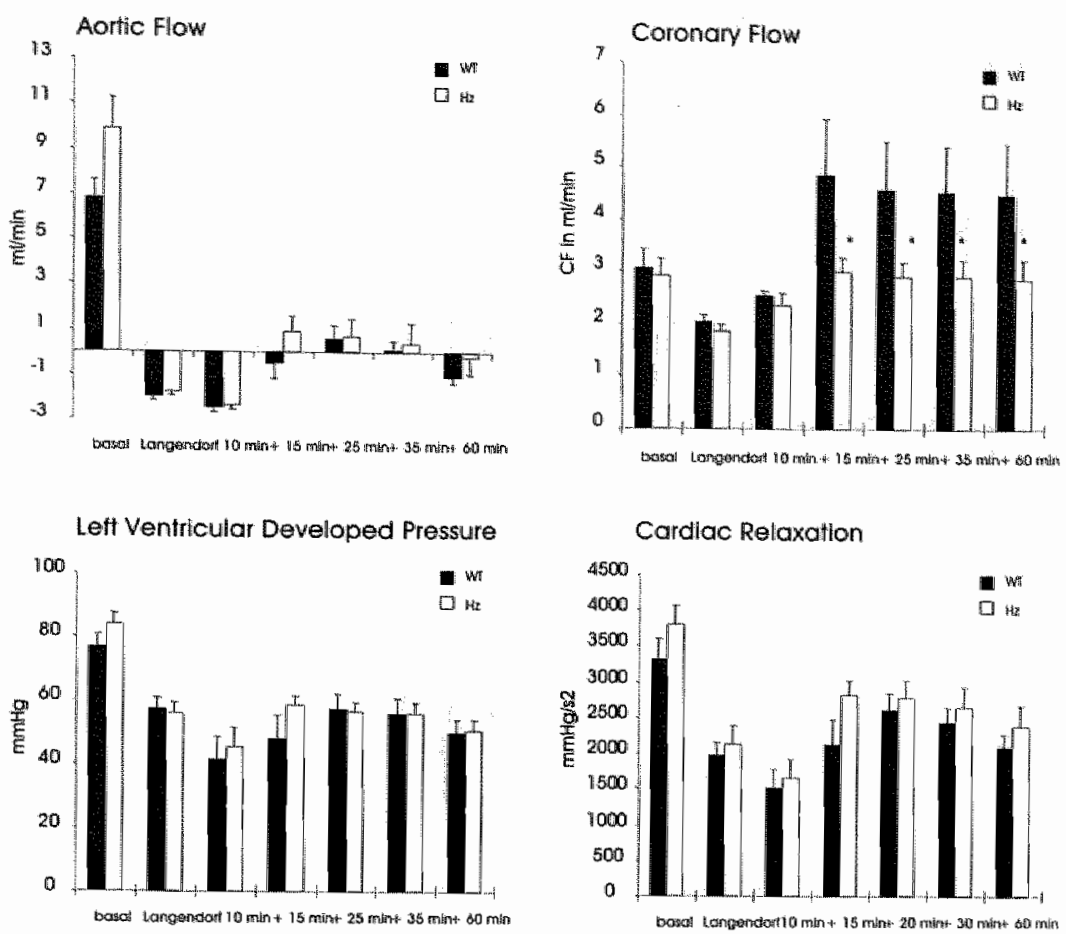

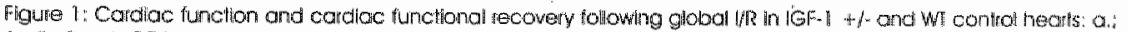

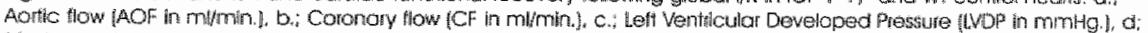

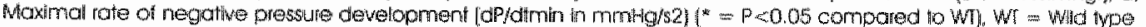

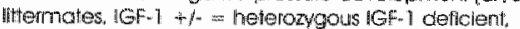

and $38 \%$ in IGF-1 $+/-$ and $38 \%$ and $41 \%$, respectively in WT mice, demonstrating the same gradual decline during the 60 minutes of reperfuson, indicating severe systolic impairment.

Also diastolic function was impaired. In both genotypes, LVPdia gradually doubled during reperfusion, compared to pre-ischemic values (data not shown), while $\mathrm{dP} / \mathrm{dt}$ decreased $26 \%$ and $36 \%$ in $1 \mathrm{GF}-1+/ \%$ and $\mathrm{WT}$ animals respectively (Figure Id). In WT animals, coronary flow increased $60 \%$ during reperfusion, while IGF-I +/- mice failed to show an increase in coronary flow (Figure $1 b, p<0.05$ ).

Pre-ischemic $\mathbb{L D H}$ release was low and similar in both genotypes (WT: $26 \pm 7.8 \mathrm{mU} / \mathrm{l}$, vs. $26 \pm 4.4 \mathrm{mU} / \mathrm{l}$, Figure $2 \mathrm{a}$ ). Following 20 minutes of ischemia, LDH values increased 4 -foll and remained elevated from the baseline level throughout the reperfusion phase. No significant differences between genotypes could be observed.

Baseline pre-ischemic lactate release was similar in both genotypes (WT; 

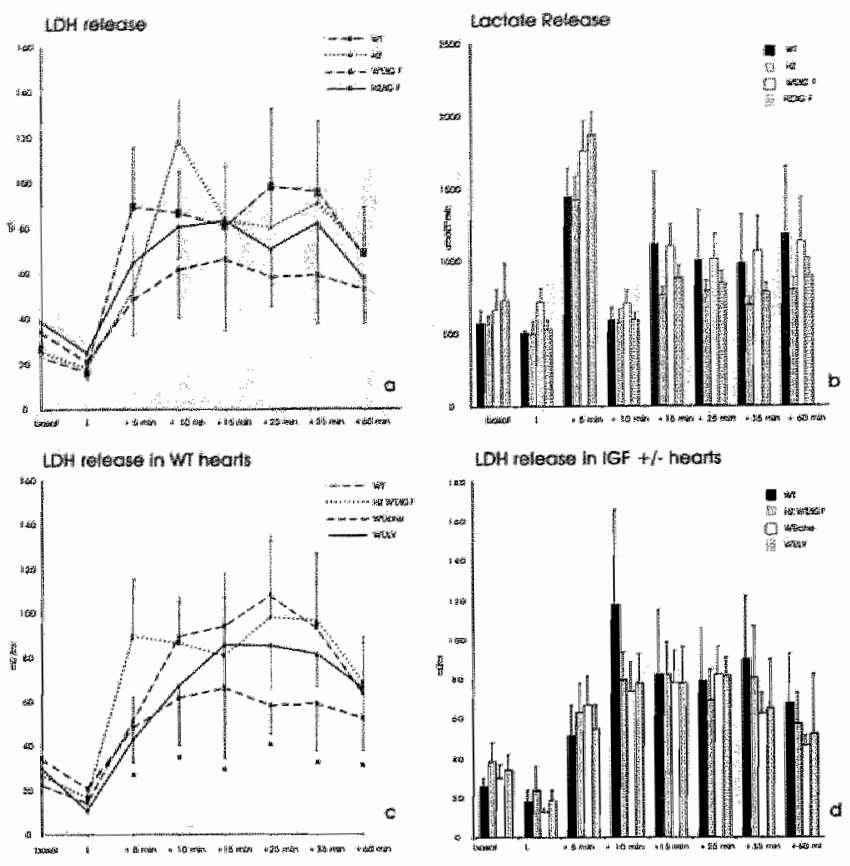

Fol 2: 2 re and port

ischema loctotie

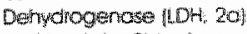

and boctate \{2ly? reloose

in $167-1$ peoted and

Whatheoted conthol ISF-1

$+\%$ and will meorts Foure

$2 \mathrm{c}$ and $2 \mathrm{O}$ deple LDH

and lactiofe teledse hin

WT contro hereits and wh

heoris thoctod with entrey

S5MM G. 1 MT/GT), क

combined ist-1/pikc ining.

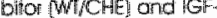

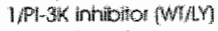

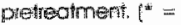

fis 005 compored to WI

loctche relectes in

mmoliming and $\mathrm{QDH}$

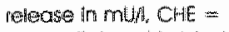

chelterylline chlotue. LY

$-\mathrm{LY} 29$ 4002 "Gascli ind.

cotes the prentschemtc

period, "L" indicales

Largendorlif repertusion

$+115,+25_{*}+35_{y}+80$

min?" triclicotes 15,25 .

35. and 60 miln oi ante

grode repertusion.

$\left.573 \pm 83, \mathrm{IGF}-1 ; 562 \pm 58 \mu \mathrm{mol} / \mathrm{I}^{*} \mathrm{~min}\right)$. During the first minutes of reperfusion, a lactate washout peak was observed (Figure 2b), after which lacatate release returned to baseline in both genotypes.

\section{IGF-1 pretreatment improves cardiac functional recovery and enhan- ces myocardial cell survival}

Hearts pre-treated with $65 \mathrm{nM}$ rhIGF-1 also displayed a decreased cardiac function following ischemia. However, $\mathrm{AOF}$ and LVDP, the most sensitive parameters for cardiac functional recovery, were higher compared to non-treated hearts, but equal in both genotypes (Figure $3 \mathrm{a}$ and $3 \mathrm{c}$ ). No significant differences were observed for the changes in $-\mathrm{dP} / \mathrm{dt}$ values. IGF-l pre-treatment increased post-ischemic CF in IGF-I +1 - hearts to the level of (both the IGF1 pre-treated and the non-treated) WT hearts (Figure 3b). No differences in lactate release were observed when IGF-1 treated animals were compared with the non-treated groups (Figure $2 b$ ). However, $\mathrm{LDH}$ release was significantly attenuated in IGF-I pre-treated animals (for both genotypes) and remained lower during the remainder of the experiment (Figure 2a). 

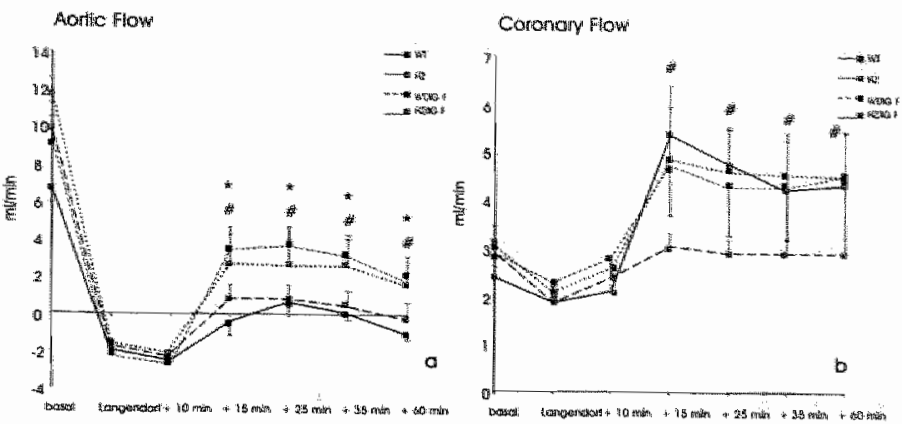

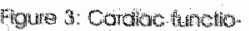
inst reowern in untooted

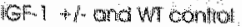
heonts and lGFin +1 and Wheorts cheireated witt

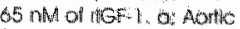
How (AOF in minhthe b: Cononary thow $1 \mathrm{CH}$ in.

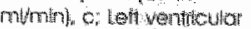
developed bresshe llop in noming) o: Maximal. fore of regentue bressino doveroment lopstitmith in nombyst ${ }^{*}=p<005$ cormarad to untromed Wh: $=$ - 40.005 compo

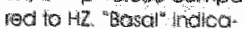
tes the pre-hotherne pert od, "it" indicotes?
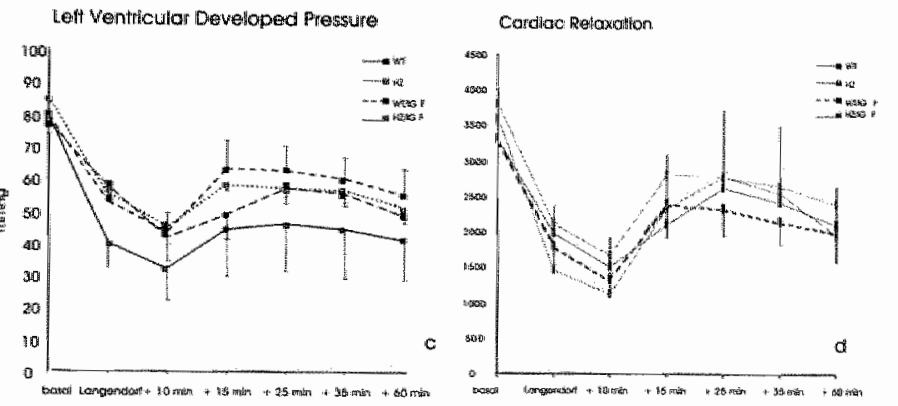

longendorfi ropertusion.

- $15,+25+35,+60$

min. indcoltes $15,25,35$. and 60 min af antegrode repert fution:

\section{PKC inhibition causes partial abrogation of IGF-1 mediated cardiac protection}

IGF-1 administration combined with simultaneous PKC inhibition (IGF. $1 / \mathrm{CHE}]$, resulted in a partial attenuation of IGF-1 mediated protection from l/R induced myocardial damage. While cardiac contractility and cardiac relaxation were not significantly reduced by pre-ischemic PKC inhibition (Fig $4 a$ and $b$ ), post-ischemic AOF was significantly lower, when compared to hearts that received only rhIGF-1 (Fig $4 c, P<0.05$ ).

$\mathrm{LDH}$ release increased following $\mathrm{I} / \mathrm{R}$ and remained higher in $\mathrm{rhIGF}-1 / \mathrm{CHE}$ treated hearts, when compared to IGF-I treatment alone. LDH relcase did not increase to the levels of untreated hearts (Figure 2c), indicating a partial attenuation of IGF-1 mediated protection of cell survival due to PKC inhibition. Lactate release was similar in rhIGF-1/CHE and rhIGF-1 treated hearts, indicating that PKC inhibition does not alter the metabolism in these hearts (Figure 2d). No differences were found between WT and IGF-1 $+/$ - for both cardiac functional recovery and enzyme release (data not shown).

\section{PI-3K inhibition completely abolishes IGF- 1 mediated protection}

While PKC inhibition did not completely abolish the IGF-1 mediated protec- 

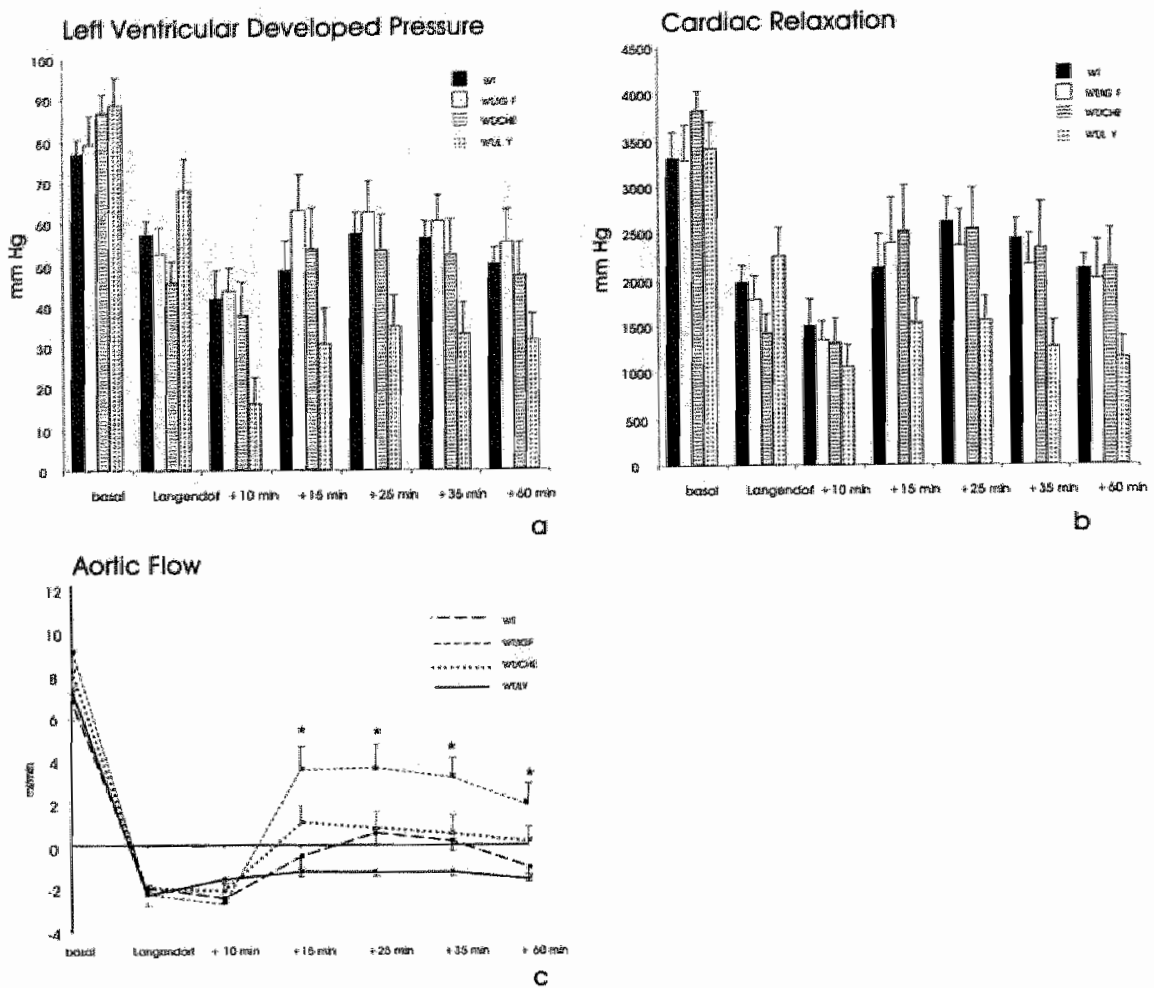

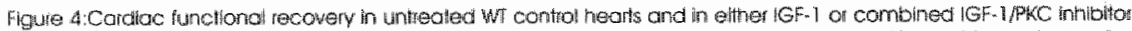

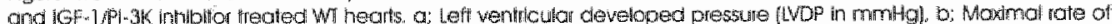

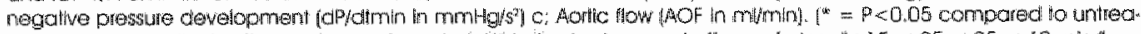

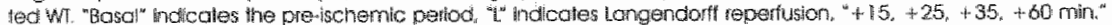
indicates $15,25,35$, and 60 min of antegrode nepertusion.

tion of cardiac hemodynamics and preservation of myocardial cell integrity, inhibition of PI-3K resulted in a complete abrogation of IGF-1 mediated cardioprotection.

Post-ischemic recovery of LVDP (Figure 4a), cardiac relaxation (Figure 4b) and $A O F$ (Figure $4 \mathrm{C}$ ) were reduced to the level of untreated hearts. PI-3K. inhibition even resulted in more severely depressed cardiac functional recovery in IGF $1 / L Y$ treated animals, when compared to untreated $W T_{j}$ indicating that even in the untreated heart, PI-3K activity provides some degree of protection. No differences were observed between WT and ICF-1 +/- hearts (data not shown).

Also $1 \mathrm{CF}-1$ mediated protection of myocardial cell survival was completely inhibited by $\mathrm{PL}-3 \mathrm{~K}$ blockade. LDH release following $\mathrm{V} / \mathrm{R}$ increased to the level of unveated hearts (Figure $2 \mathrm{c}$ ), indicating that $1 \mathrm{GF}$ - 1 mediated protection of cell survival is completely PI-3K dependent. As in the rhIGF-1/CHE group, lactate release was not influenced by PI-3K inhibition (Figure 2d), indicating 
no effect on aerobic metabolism.Again, no differences were found between IGF-1 +/- heart and WT littermates (data not shown).

\section{Signaling pathways involved in IGF-1 mediated cardiac protection}

Pre-ischemic ICF-l administration results in a mild cardioprotective effect on both functional recovery and cell survival following global myocardial ischemia and reperfusion. Our next goal was to assess the relative activation status of various intracellular signaling pathways that may underlie this phenomenon. In WT and IGF-1 +/- control hearts, not subjected to I/R (WT and IGF-I $+/-, n=3)$, the ratio of particular/cytosolic PKC- $\varepsilon,(p / c$ ratio) was decreased in $[G F-1+/-$ mice. $I / R$ resulted in increased $P K C-\varepsilon$ translocation in IGF-1 $+/{ }$ but not in WT hearts. IGF-1 administration further increased the $\mathrm{p} / \mathrm{c}$ ratio in $I G F-1+/$ - hearts, while $p / c$ ratio in WT hearts remained unaffected. Surprisingly, PKC- $\varepsilon$, and PI-3K blockade resulted in enhanced PKC- $\varepsilon_{y}$ translocation, as $\mathrm{p} / \mathrm{c}$ ratio's increased in both genotypes.

IGF-1 +/- control hearts displayed enhanced $\mathrm{pERK}-\mathbb{1}$ activation, when com-

\section{|GF-1 mediated cardioprotection}
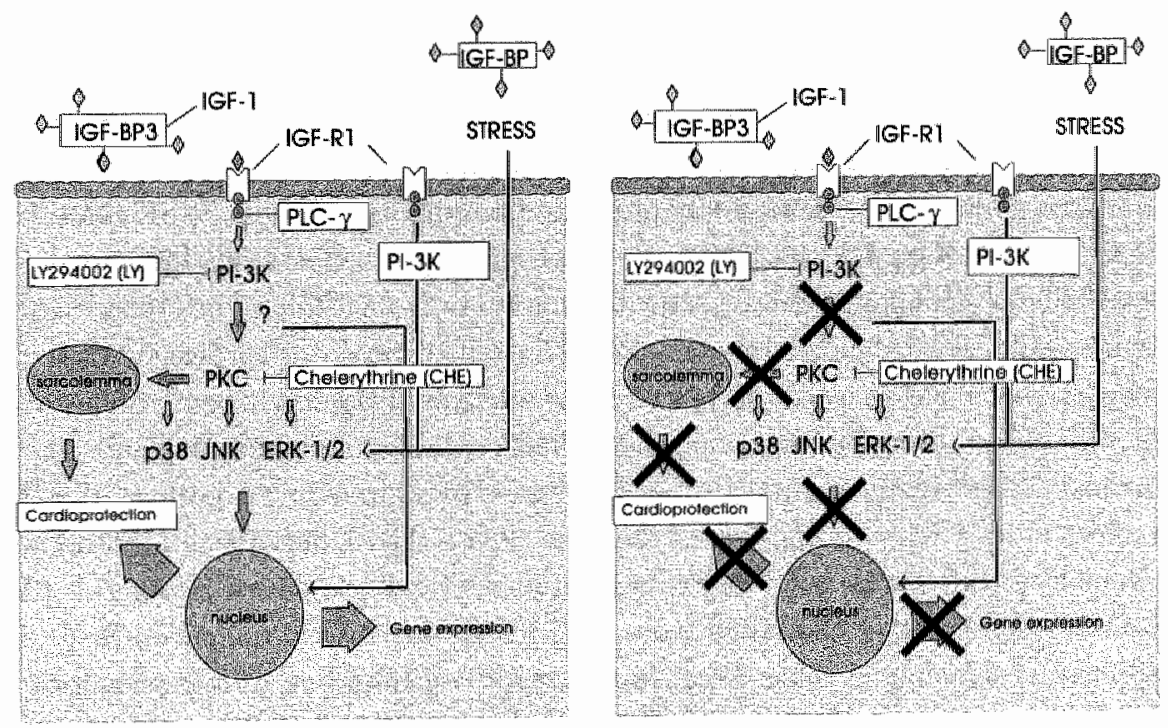

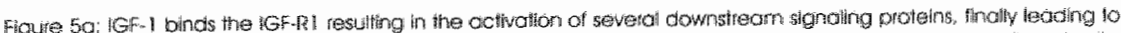

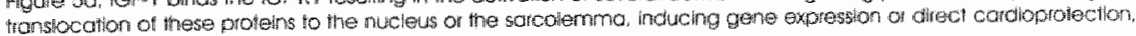
resperituen.

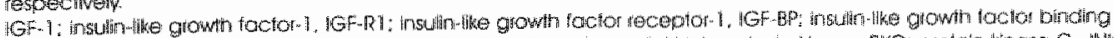

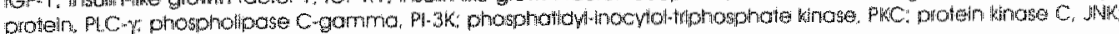

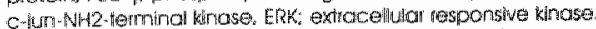

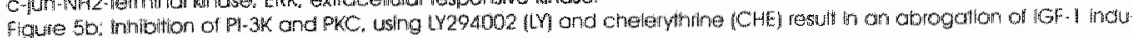
oced cordoptoterion: 
pared to WT littermates. Compared to control hearts, phosphorylated ERK$1 / 2$ increased in both genotypes following $1 / R$. Surprisingly, IGF 1 administration decreased the pERK/ERK ratio in both genotypes, while PKC-E, and PI$3 \mathrm{~K}$ blockade enhanced ERK-1/2 activation. JNK-1/2 activation was decreased in $I G F-1+1$ - control hearts, when compared to WT littermates. $1 / \mathrm{R}$ resulted in NN activation in both genotypes, while IGF-I administration decreased pINK-1/2 levels to baseline. Again, PKC- $\varepsilon$, and PI-3K inhibition enhanced JNK-1/2 phosphorylation.

P38 levels were similar in WT and IGF-1 $+/$ - control hearts. I/R resulted in decreased $\mathrm{p} 38$ phosphorylation, while $I G F-1$ administration prior to $I / R$ further decreased the activation of $\mathrm{p} 38$ in WT, while increasing pp38 in heterozygous IGF-1 animals. Again, PKC- $\varepsilon$, and Pl-3K inhibition increased $\mathrm{p} 38$ activation. No differences were found in amount of the non-phosphorylated isoform of each of the MAPKs in all experimental groups (data not shown).

\section{Discussion}

In this study, we demonstrated that reduced IGF-1 plasma levels do not alter cardiac tolerance to ischemia. Pre-ischemic administration of rhIGF-I resulted in augmentation of cardiac functional recovery and attenuation of myocardial cell damage following global myocardial I/R. These IGF-1 mediated protective effects could be partially blocked by simultaneous pre-treatment with a PKC inhibitor and could be completely prevented by pharmacological PI-3K inhibition. These results link the IGF-I mediated protective effects to a known intracellular signaling pathway, activated during ischemic preconditioning. Under physiological circumstances, IGF-1 instantly improves cardiac performance in vitro ${ }^{23.24}$, ex vivo and in vivo ${ }^{25}$, most likely by sensitizing myofilaments to $\mathrm{Ca}^{2+}$, thereby improving the excitation/contraction coupling and intrinsic contractility of individual myocytes. ${ }^{42}$ This is in contrast with work of Lembo et al. 2 , who demonstrated that also severe [GF-1 deficiency (30\% of circulating IGF-I plasma levels) is associated with enhanced myocardial contractility and elevated blood pressure, ${ }^{25}$ mainly because of enhanced $\beta$ adrenergic signaling in these mice. In this study, we found no differences in pre-ischemic hemodynamic performance between WT and IGF-1 $+/$ - hearts, although a trend to better cardiac function was observed in the IGF-1 deficient hearts. This could be explained by the fact that hearts were isolated from the animals and mounted in a (cristalloid perfused) system, devoid of circulating $[G F-]$. This means that lower plasma IGF-I levels do not lead to a sustained depressed cardiac function. 
IGF-1 mediated protection of cardiac functional recovery following $I / R$ In this study, we observed no differences in the hemodynamic response to I/R between WT and heterozygous IGF-I deficient hearts, indicating that a $40 \%$ reduction in plasma levels does not alter tolerance to ischemia. If any, the decrease in tolerance to ischemia in IGF-I deficient hearts should have been present before the heart was isolated from the animal and mounted in a cristalloid-perfused system.

In our hands pre-ischemic administration of $65 \mathrm{nM} \mathrm{IGF-1,} \mathrm{resulted} \mathrm{in} \mathrm{enhan-}$ ced cardiac functional recovery following global myocardial I/R. In literature, only a limited number of studies reported the protective potential of IGF-1 on cardiac function following $\mathrm{l} / \mathrm{R}$. Otani et al. ${ }^{i 7}$ recently demonstrated in an isolated rat heart model of $I / R$, that administration of IGF-I improves cardiac functional recovery in a PI-3K dependent manner. However, in this study, IGF-1 was administered during reperfusion alone.

\section{[GF-1 mediated protection of myocardial cell survival}

While IGF-1 mediated protection of functional recovery following I/R is illdefined in literature, a vast number of studies focused on the influence of preischemic IGF-I administration on myocardial cell survival (both necrosis and apoptosis) following an acute ischemic event. Buerke et al ${ }^{28}$ showed in a murine model of regional myocardial $I / R$, that pre-ischemic IGF-1 administration resulted in attenuation of myocardial injury ri.e. decreased cytosolic enzyme release [necrosis], attenuation of neutrophil accumulation [a marker for reperfusion damage], and decreased cardiomyocyte apoptosis rates). IGF-1 ${ }^{27}$ and insulin ${ }^{30}$ administration during reperfusion alone were sufficient to reduce the amount of necrotic myocardial cell death following global I/R. Although insulin pretreatment failed to show a decrease in infarct size in a rat model of $\mathrm{I} / \mathrm{R}^{43}$, insulin pretreatment preserved both systolic and diastolic function in a porcine $\mathrm{I} / \mathrm{R}$ model. ${ }^{44}$

In this study, we demonstrated that pre-ischemic IGF-I treatment resulted in enhanced myocardial cell survival during reperfusion and that these protective effects are PI-3K and PKC mediated.

In addition to decreasing myocardial cell necrosis, several studies reported that pre-ischemic IGF-1 administration attenuates ischemia-induced cardiomyocyte apoptosis, both in wivo and in vitro. ${ }^{28,29}$ The anti-apoptotic effects attributed to IGF- 1 are likely to be accomplished by binding to the IGF-RI and the subsequent activation or modulation of downstream effector molecules like PI-3K, Akt-1 kinase and stress activated MAP-kinase p38, as was recently 
elegantly demonstrated by Yamashita et al. ${ }^{33}$ This is in line with the observations by Fujio et $\mathrm{l}^{32}$, who demonstrated a PI-3K dependent Akt- 1 upregulation, in conjunction with attenuated apoptosis levels after IGF-1 stimulation of serum-deprived cardiomyocytes. Transfection of cardiomyocytes with a dominant negative Akt-1 adenoviral construct completely blocked the IGF-Imediated attenuation of apoptosis in vitro, while in vivo transfection with a constitutively active Akt- $\mathrm{I}$ adenovirus resulted in protection from apoptosis, independent of [GF-] suppletion. In addition to the PI-3K/Akt-1 pathway, IGF-1 also downregulates the pro-apoptotic myocyte renin-angiotensin system through the attenuation of $\mathrm{p} 53$ and p53-inducible genes. ${ }^{33}$ Finally, IGF-1 attenuates the activation of several other pro-apoptotic signaling molecules, like Bax and activated caspase-3, while upregulating the activity of anti-apoptotic $\mathrm{BCl}-2^{34}$

In this study, attention was not focused on the anti-apoptotic effects of IGF-I and the study design is not suitable for this purpose, since completion of the apoptosis cascade takes more than 60 minutes of reperfusion. As expected, TUNEL stainings of these hearts, subjected to 20 minutes of ischemia followed by 60 minutes of reperfusion revealed very low apoptosis rates (data not shown). To study the anti-apoptotic effects of IGF-1, above mentioned study designs using in vivo models of ischemia, followed by 24 hours of reperfusion are much more suitable. ${ }^{45}$

Pre-ischemic IGF-l adminstration mimicks a state of myocardial ischemic preconditioning

While the intracellular signaling pathways for [GF-] mediated alterations in cardiae romodeling abul ruiction durting sub-acute or chronic myocardial ischemia have been clearly defined, the pathway(s) responsible for protection of cardiac functional recovery and attenuation of necrotic cell death during acute ischemia (and reperfusion), still have to be unraveled. Here, we hypothesized that IGF-I related protection is mediated by the PI-3K-dependent activation of PKC. Indeed, several lines of evidence showed that IGF- $1^{27}$ and insulin ${ }^{30}$ mediated protection are PI-3K dependent. However, the work by Banes et al. ${ }^{3 n}$ revealed that, at least in the rabbit, insulin-associated cardioprotection was not dependent on PKC translocation.

We demonstrated that IGF-1 mediated protection of both cardiac functional recovery and attenuation of necrotic cell death is dependent on PKC and PI$3 \mathrm{~K}$ activation. While PI-3K inhibition completely blocked the protective effects on both necrosis and function, PKC inhibition only resulted in a partial abrogation of $[G F-1$ induced cardioprotection. This might be explained by the 
notice that IGF-I also displays insulin-like effects. IGF-I might improve glucose uptake during reperfusion, thereby enhancing aerobic metabolism, although lactate release was not decreased after IGF-l pre-treatment. Our results suggest that IGF-1, like FGF-1 ${ }^{46}$ mimicks IPC. In addition, Tong et $a^{47}$ recently demonstrated that IPC activates PI-3K upstream from PKC. Another point mentioning is the duration of IGF-I mediated protection. In spite of the fact that IGF-1 resulted in protection throughout the complete 60 minutes of reperfusion, it remains to be determined whether or not [GF-] mediated protection stretches beyond this hour and persists after a more sustained period of reperfusion.

\section{Conclusions}

Here we demonstrated that $40 \%$ reduction in IGF-1 plasma levels does not alter tolerance to ischemia and reperfusion. However, pre-ischemic administration of $65 \mathrm{nM}$ of IGF-1 resulted in enhanced cardiac functional recovery and attenuation of myocardial necrotic cell death, following $\mathrm{I} / \mathrm{R}$. These effects proved to be completely PI-3K and partially PKC-dependent, linking IGF-I mediated cardioprotection to a known intracellular signaling pathway activated during IPC (Figure 5a and b). 


\section{References}

1. Schmid C: Insulin-like growth factors. Cell Biol Int 1995;19:445-457.

2. Froesch ER, schmid C, Schwander $L$, al. Actions of insulin-like growth factors. Ann Rev Physiol 1985;47:443-467.

3. Schnelder MD. Parker TG: Cardiac growth factors. Prog Growth Fact Res 1991,3:1-26.

4. Maclellan WR, Howker J, Schnelder WD: Myocardial growth factors, in Marks AR, Taubman MD (eds): Malecular Blology of Canclovascular Disease. New York, Marcel Deikker inc.., 1997. pp. $327-378$.

5. Delafontaine $P$ : Insullin-like growth factor 1 and its binding proteins in the cardiowasiculat system. Cardiovasc Res 1995;30:825-834.

6. Donath MY, Zapf J, Eppenberger-Eberhardt $M$, at al: Insullin-like growth factor 1 stimulates myofibril development and decreases smooth muscle alpha-actin of adult cardiomyocytes. Proc Natl Acad Sci USA 1994;91:1686-1690.

7. Liu J-P, Baker $J$, Perkins AS, of all: Mice carrying null mutations of the genes encoding insulin-like growth factor 1 (IGF-1) and type 1 IGF-1 receptor (IGF 1 I). Cell 1993:75:59-72.

8. Powell-Braxton $L$, Hollingshead $P$, Warburton $C_{\text {, ef }}$ al.: IGF-1 is required for nomal embryonic growth in milce. Gen Dev 1993;7:2909-2917.

9. Warburton C, Powell-Braxton L: Mouse modelis of IGF-1 deflency generated by gene torgeting.. Receptor 1995:35-41.

10. Baker J, Lilu J-P, Robertson EJ, et al.: Role of insulin-llke growth factors in embryonic and postnatal growth. Cell 1993:75:73-82.

11. Hansson H-A, Wilsson.A, Isgaard J, et al.: Immunohistochemical localisation of Insulin-like growth factor 1 in the adult rat. Histochem 1988;89:403-410.

12. Reiss K, Meggs LG, LI P, et al.: Upregulation of IGF-1, IGF-1 receptor, and late growth related genes in ventricular myocytes acutely after infarction in rats. J Cell Physiol 1994;158:160168.

13. Reiss $K$, Kajstura J, Zhang $X$, et al.: Acute myocardial infarction leads to upregulation af the IGF-1 autocrine system. DNA replication, and nuclear mitotic division in the remaining viable cardiac myocytes. Exp Call Res 1994;213:463-472.

14. Krishnamurthi RV, Maxwell L, Bassett NS, et al.." The spatial and temporal distribution of insulin-like growth factor-1 following experimental myocardial infarction in the rat. Cardiovasc Pathol 1997:6:197-203.

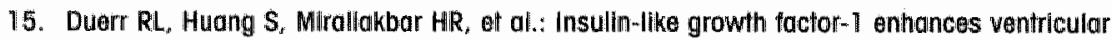
hypentrophy and functlon during the onset of experimental cardiac failure. $\mathrm{J}$ Clin Invest $1995 ; 95: 619-627$.

16. Reiss $K$, Cheng W' Ferber $A$, et al.: Owerexpression of insulin-like growth factor-1 in the heort is coupled with myocyte proliteration in transgenic mice. Proc Natl Acad SCI USA $1996 ; 93: 8630-8635$.

17. Li Q, Li B. Wang $X$, et al ; Overexpression of insulin-like growth factor-1 in mice protects from myocyte death affer infarction, attenuating ventricular dilatation, wall stress, and cardiac hypertrophy, J Clin Invest 1997; 100:1991-1999.

18. Reiss $K$, Cheng $W$, Pierzchalski $P_{\text {n }}$ et al.: Insulin-like growth foctor- 1 receptor and its ligand regulate the reentry of adult ventricular myocytes into the cell cycle. Exp Cell Res 1997;235:198-209.

19. Tanaka N, Ryoke T. Hongo M, et al.: Effects of growth hormone and IGF-1 on cardiac hypertrophy and gene expression in mice. Am J Physio! 1998;275:393-399. 
20. LI $B$, Setoguchi $M$, Wang $X$, ef af: Insulin-like growth factor- 1 attenuates the detrimentol impact of non-occlusive coronary artery constriction on the heart. Circ Res 1999;84:10071019.

21. Duerr RL, McKirnan MD, Gim RD, et al.: Cardiowascular effects of Insulin-like growth factor-1 and growth hormone in chronic left ventricular fallure in the Circulation 1996;93:21882196.

22. Poimen $\mathbf{M}$, Daemen $\mathbf{M J}_{\text {, Bronsaer }}$, et al.: Cardlac remodeling after myocardial infarction is impaired in IGF-1 deficient mice. Cordiovasc Res 2001:50:516-524.

23. Freestone $\mathrm{NS}_{n}$ Ribaric S, Mason WT: The effect of insulin-like growth factor-1 on adult rat cardiac contractility. Mol Cell Biachem 1996; 163/164:223-229.

24. Redaell G, Malhotra A, LI B, ef al.: Effects of constitutive overexpression of insulin-llke growth factor- 1 on the mechanical characteristics and molecular properties of ventricular myocytes. Circ Res 1998;82:594-603.

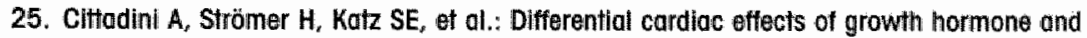
Insul in-like growth factor-1 in the rat. Circulation 1996;93:800-809.

26. Lembo $G$, Rockman HA, Hunter JJ, et al.: Elevated blood pressure and enhanced myocardlal contractility in mice with severe IGF-1 deficiency. J Clin Invest 1996;98:2648-2655.

27. Otanl $H$, Yamamura $T$, Nakao $Y$, ef al.: Insullin-llke growth factor-1 improves recovery of cardiac performance during reperfusion in isolated rat heart by a wortmannin-sensitlve mechanism. J Cardiovasc Pharmacol 2000;35:275-281.

28. Buerke M, Murohara T, Skurk $\mathrm{C}$, et al.: Cardioprotective effect of Insulin-like growth factor 1 in myocardial ischemia followed by reperfusion. Proc Natl Acad Sci USA 1995;92:8031-8035.

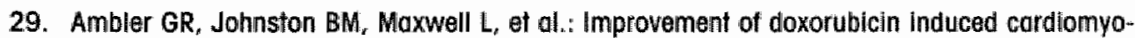
pathy in rats treated with insulin-like growith factor 1. Cardiovasc Res 1993;27:1368-1373.

30. Baines $C P$, Wang $L$, Cohen $M V$, et al.: Myocardial protection by insulin is dependent on phosphatidylinositol 3-kinase but not an protein kinase $\mathrm{C}$ or Katp channels in the Isolated rabbit heart Bas Res Cardiol 1999;94:188-1198.

31. Yamashita K, Kajstura J, Discher DJ, et al.: Reperfusion-activated Akt kinase prevents apoptosis in transgenic mouse hearts overexpressing insulin-llke growth factor-1. Circ Res 2001;88:609-614.

32. Fujio $Y$, Nguyen T, Wencker $D$, elt al: Akt promotes survival of cordlomyocytes in viltro and protects against ischemia-reperfusion Injury in the mouse heart. Circulation 2000; 101:660667.

33. Leri $A_{4}$ Liu $Y$, Claudio PP, et al.: Insulin-like grawth factor-1 inciuces Mdm2 and down-regulates p53, attenuating the myocyte renin-anglotensin sytem and stretch-mediated apoptasis. Am J Pathol 1999;154:567-580.

34. Wang $L$, Ma W, Markovich $R$, et al.: Regulation of cardiomyocyte apoptotic signaling by insulin-like growth factor 1. Circ Res 1998;83:516-522.

35. Htun $P$, Ito WD, Hoefer IE, ef al.: Intramyocardial infusion of FGF-1 mimics ischemic precondltioning in pig myocardium. J Mol Cell Cardial 1998;30:867-877.

36. de Windt $L$, Willems $J$, Reneman RS, et al.: An improved isolated, left ventricular ejecting, murine heart model. Eur J Physial 1999;437:182-190.

37. de Windit $L J$, Willems $J$, Roemen THM, et al.: Ischemia-reperfused isolated working mouse hearts: membrene damage and type IIA phospholipase A2. Am JI Phystol 2001;280:25722580.

38. Apstein CS, Puchner SE, Brachfeld N: Improved autamated lactate determination. Anal Blochem 1970;38:20-34. 
39. Bergneyer HU, Bermt E: UV assays for lactate dehydrogemese with pyruvote and NADH. Weintimeir, Verlog Chemie, 1974, vol 2.

40. Heeneman $S_{x}$ Hoendeler $J$, Saito $\gamma$, et al: Anglotensin II induces transactivation of two populations of the PDGFb receptor: Key role for the p66 adaptor protein Shc. J Biol Chem $2000,275: 15926-15932$.

41. de Windr $\mathrm{LJ}$, Lim $\mathrm{HW}$, Haq $\mathrm{S}$, al al. Caicineurin promotes protein kinase $\mathrm{C}$ and $\mathrm{C}$-Jun $\mathbb{N H 2}$ terminal kinase activation in the heart. J Biol Chem 2000;275:13571-13579.

42. Cittadini $A$, ishiguro $X$ Stromer $H$, ef al.: Insulin-like growth factor- 1 but not growth hormone augments mammallan myocardial contractilly by sensitizing the myofllament to $\mathrm{Ca} 2+$ through a Wortmannin-sensifive pathway. Circ Res 1998;83:50-59.

43. Bellows SD, Kloner RA: Glucose-Insulln-potassium does not reduce myocardial infarct slze in an ischemic/reperfusion rabbit model. J Thromb Thrombolysis 1998;5:25-27.

44. Zhu $P, L u, L, X, Y$, et al.: Glucose-insulin-potassium preserves systolic and diastolic function in ischemia and reperfusion in pigs. Am J Physiol 2000;278:595-603.

45. Dumont EAWJ, Hofstra $\mathrm{L}$, van Heerde Wh, af al: Cardlomyocyle death induced by myocardial ischemia and reperfusion; measurement with recombinant human annexin- $V$ in a mouse madel. Circulation 2000;102:1564-1568.

46. Palmen $M$, Daemen MJAP, Willems $J$, al.: FGF-1 protects the myocardium during ischemia and reperfusion through a tyrosine kinase and protein kinase $\mathrm{C}$ dependent pathway. Circulation 2000; 1102:156(A).

47. Tong $H$, Chen $W_{x}$ Steenbergen $C$, at al.: Ischemic preconditioning activates phosphatidylinositol-3-kinase upstream of PKC. Circ Res 2000;87:309-315. 


\section{Chapter 5}

\section{Cardiac-specific overexpression of hFGF-1 deteriorates cardiac function and alters remodeling following chronic myocardial infarction in mice}

Meindert Palmen'. Mat J. Daemen', Daan J. Lips', Alexandra Buehler", Chiel de Theije', H. Reinier Zanabergen, Ronald J.P. Bronsaer', Rene Zimmermann', Rlen van der Zeel, Ebo D. de Muinck', Willem. R. Dassen', Martin v, Eickels, Mark M. Kockx, Jos F, Smits, Pieter A. Doevendans?

Depts. Cardiology, Pathology and Pharmacology' Cardiovascular Research Instifute Maastricht, University of Maastricht, the Netherlands Dept. Exp. Cardiology, Max-Planck-Institute and Kerckhoff-Clinic, Bad Nauhelm, Germany.

Dept. Pathology, APCAM, AZ Middelheim, Antwerp, Belgium".

Submitted 


\section{Abstract}

Fibroblast growth factors (FGF) play an important role in cardiovascular physiology, mainly due to their angiogenic properties and enhancement of cell survival. We investigated the effects of constitutive cardiac-specific human FGF1 overexpression on cardiac function and remodeling of the scar tissue and remote myocardium in mice following experimental myocardial infarction (MI).

\section{Methods}

FGF-1 transgenic mice were assigned to four experimental groups: Wild Type (WT)/SHAM $(n=6)$, WT/MI, $(n=6)$, FGF/SHAM $(n=8)$ and FGF/MI $(\mathrm{a}=9)$. MI was induced by coronary artery ligation. One week later, cardiac function was measured, using an electromagnetic flow probe positioned around the ascending aorta. After basal hemodynamic measurements, maximal cardiac output was obtained after volume expansion. In Lectin-B4 and AZAN stained sections, cardiac capillarization and left ventricular architecture were assessed. Cell turnover patterns in the scar tissue were assessed using BrdU, TUNEL and activated Caspase- 3 assays.

\section{Results}

Cardiac Index ( $\mathrm{CI}=\mathrm{CO} /$ bodyweight $)$ decreased in both experimental groups after MI. In FGF/MI animals, both basal CI $\left(0.12 \pm 0.06 \mathrm{ml} / \mathrm{min}^{*} \mathrm{~g}\right)$ and $\mathrm{CI}$ after volume loading $\left(0.27 \pm 0.08 \mathrm{ml} / \mathrm{min}^{*} \mathrm{~g}\right)$ were lower in comparison with WT littermates $\left(0.17 \pm 0.05\right.$ and $\left.0.38 \pm 0.05 \mathrm{ml} / \mathrm{min}^{*} \mathrm{~g}\right)$. Capillary to fiber ratio's (C/F) were increased in both FGF groups (FGF/SHAM; $1.70 \pm 0.10$, FGF/M1; $1.72 \pm 0.13$ vs. WT/SHAM; $1.43 \pm 0.06$ and WT/M1; $1.48 \pm 0.10$ ). This was associated with decreased myocyte densities in FGF-1 transgenic mice $(4430 \pm 61.4 / \mathrm{mm} 2)$ when compared with their WT littermates $(6343 \pm 494 / \mathrm{mm} 2)$, indicating larger cardiomyocytes and an enhanced hypertrophic response of the remote myocardium. In addition, higher apoptosis rates (FGF/MI; $1.05 \pm 0.25 \mathrm{vs}$. WT/MI; $0.69 \pm 0.30 \%$ ) and lower collagen content (FGF-1; $34.7 \pm 2.1$ vs. $41.0 \pm 1.9 \%$ in WT/MT) were found in the scar tissue of FGF-1 transgenic mice, while DNA synthesis in the scar tissue was not different.

\section{Conclusions}

Cardiac-specific FGF-1 overexpression induces deterioration of cardiac function and an altered cardiac remodeling response following chronic experimental myocardial infarction. 


\section{Introduction}

Fibroblast Growth Factor-1 (FGF-1) or acidic FGF is a peptide growth factor involved in angiogenesis and cell survival. Together with basic FGF (FGF-2), $\mathrm{FGF}\rfloor$ belongs to a large family of growth factors and is expressed in virtually every tissue of the body. In the heart, FGF-I can be produced by a myriad of cell types, including cardiomyocytes ${ }^{1.3}$, endothelial cells ${ }^{1,3}$, macrophages ${ }^{1,4,5}$ and fibroblasts.' Together with peptides like VEGF and FGF-2, FGF-I contributes to the process of angiogenesis, by inducing the formation of capillaries and growth of collaterals to ischemic tissue. In a porcine ameroid constrictor model of myocardial ischemia, FGF-1 administration in the vicinity of the occluded vessel augmented myocardial perfusion to the collateral-dependent myocardium. Recently, intramyocardial delivery of FGF-1 protein to patients suffering from ischemic heart disease by direct injection distally to the anastomosis site of the internal mammary artery bypass graft on the left anterior descending artery (LAD) was tested. This method has been shown to result in an angiographically visible increase in collateral formation. ${ }^{7}$ So far little is known about the role of FGF-1 following myocardial infarction. FGF-1 appears to have direct cardioprotective effects during acute ischemia, and initiates angiogenesis and arteriogenesis. ${ }^{6.14}$ Recently, Fernandez et al. ${ }^{10}$ showed in his FGF-I transgenic mouse strain that FGF-1 overexpression increased coronary artery branching and enhanced coronary flow ex vivo, suggesting arteriogenesis rather than angiogenesis. However, other aspects of cardiac remodeling following an ischemic event may be impaired. Potentially, constitutively elevated levels of FGF in the myocardium could impair wound healing and even turn out to be detrimental to effective scar formation and remodeling of the remote myocardium. Elevated levels of FGF-2 in a model of cutanous wound healing impaired proper scar formation and diminished tensile strenght., 5, ${ }^{11} \mathrm{To}$ address the role of FGF- 1 in cardiac wound healing in more detail, the effects of increased FGF-1 levels on cardiac structural and functional adaptations following chronic MI were studied in a murine model.

\section{Materials and methods}

Mice with cardiac-specific overexpression of the human isoform of FGF-1 were generated in Hannover: and were kindly provided by prof. W. Schaper and dr. R. Zimmermann (Max Planck Institute in Bad Nauheim, Germany). The construct consists of the CMV enhancer, hooked up to the ventricular myosin light chain-2 promotor (MLC-2v) and the $2.2 \mathrm{~kb}$ human FGF-l cDNA, completed by a SV40 polyadenylation site. This construct resulted in a 
2-3 fold cardiac-specific FGF-1 overexpression, as confirmed by Northern and Western Blotting and immunohistochemistry. ${ }^{10}$ Male and female mice were bred and kept under standard housing conditions according to the University of Maastricht facility guidelines. Experiments were approved by the Institutional Animal Care and Use Committee of the University of Maastricht. Genotyping of mice ocurred by means of polymerase chain reaction. Mice were assigned to four experimental groups; 2 Myocardial Infarction (MI) groups (WT/MI; $=6, F G F / M I ; n=9)$ and 2 SHAM control groups (WT/SHAM; $n=6$, FGF/SHAM; $n=8$ ).

Myocardial infarction: An antero-apical MI was induced by ligation of the LAD in adult mice (12-14 weeks). ${ }^{2}$ Briefly, animals were anesthetized with pentobarbital $(100 \mathrm{mg} / \mathrm{kg})$ and artificially ventilated. After opening the chest, a 6-0 prolene suture was placed around the junction of the LAD and tied, and the thorax was closed. After implantation of a 5-bromo-deoxyuridine (BrdU)filled osmotic minipump (Alzet 2001, Alza Corporation, Palo Alto, CA; Serva, Heidelberg, Germany; infusion rate $13 \mathrm{mg} / \mathrm{kg}^{*}$ day) between the scapulae, for detection of DNA synthesis, the animals were allowed to recover at $30 \%$ oxygen and an ambient temperature of $30^{\circ} \mathrm{C}$. SHAM operated animals underwent the same surgical procedure except for coronary artery ligation.

Hemodynamic measurements: One week after surgery, cardiac function was assessed. For that purpose, animals were re-anesthetized with pentobarbital. $\mathbb{1}-\mathrm{F}$ heat-stretched catheters were introduced into the left femoral artery and vein. The femoral artery cannula was connected to a pressure transducer (Micro-Switch, model 156PC 156WL, Honeywell Inc., Amsterdam, the Netherlands) for on-line monitoring of mean arterial pressure (MAP) and pulse pressure. Animals were connected to the ventilator and the left side of the chest overlying the second intercostal space was opened. After dissection of the overlying (thymal) tissue, the ascending aorta was visualized.

Subsequently, an aortic mini-flow probe (Skalar, Delft, The Netherlands) was placed on the ascending aorta and connected to a Skalar MDL400 sine-wave flowmeter (Skalar). A heating pad with thermo-couple was used for maintenance of constant body temperature. Preceding the hemodynamic study, the mouse was allowed to recover from manipulations. After stabilization and recording of basal values for cardiac performance (COrest), $2.5 \mathrm{ml}$ of warm $\left(37^{\circ} \mathrm{C}\right)$ Ringer's solution was rapidly infused wia the left femoral vein catheter to create an acute volume overload to obtain maximal cardiac output (CO). All data were stored on a computer at $2 \mathrm{kHz}$ for later analysis. $\mathrm{CO}$ (in rest and maximal) and MAP and total peripheral resistance (TPR) at rest were analyzed. Because both male and female animals were studied, cardiac index $(\mathrm{Cl}=\mathrm{CO} /$ body weight $)$ was calculated, to correct for differences in the 
weight of the heart (HW) and body (BW). After completion of the measurements, the heart was arrested in diastole by infusion of $0.1 \mathrm{M}$ Cadmium Chloride through the femoral venous line.

Morphometry: Subsequently, the theart and circulation were perfused through the left atrium with a PBS-nitroprusside and formalin solution, as described before. 12 Heart, lungs and liwer were excised quickly, weighed, fixed in formalin $10 \%$ and further processed for histologic analysis. The heart was cut longitudinally perpendicular to the infarcted area and the aortic root. Infarct size and left ventricular architecture were assessed with computerized morphometry (Quantimet 570, Leica, the Netherlands), using Azan-stained $4 \mu \mathrm{m}$ sections of both the anterior and posterior wall of the heart.

Capillarization was assessed on Iso-Lectin B4 stained sections. On computerized images (Quantimet 570,400x magnification), capillary to fiber ratio (C/F ratio), capillary density (CD) and myocyte density (MD) were measured in the interventricular septum.

DNA synthesis was measured by means of an $\alpha$-BrdU immunohistochemical staining as described before. 12 With $400 \mathrm{x}$ magnification an average of 1000 nuclei in the septum and 1000 nuclei in each of the infarct borderzones were counted using a light microscope and an eyepiece grid. The BrdU labeling fraction was calculated by dividing the BrdU positive with the total amount of nuclei counted.

With a TUNEL assay, ${ }^{13}$ apoptosis rates were measured in the non-infarcted septum and the center of the infarcted area. An average of 6000 nuclei in both areas of the heart were measured. The TUNEL labeling fraction (TLF) was expressed as the amount of TUNEL positive divided by the total amount of nuclei counted. In addition, a staining for activated caspase-3 was performed. For this purpose, we used an antibody raised against the $17 \mathrm{kd}$ cleaved fragment of human caspase-3 (1:200; Pharmingen, San Diego CA, USA), after citrate microwave pretreatment of the sections (unpublished data). Tonsil tissue was used as a positive control.

The degree of myocardial fibrosis was assessed using Sirius Red staining for collagen. ${ }^{12}$ With a computerized quantification method (Quantimet $570,400 \mathrm{x}$ magnification], the collagen content of the heart was determined in the noninfarcted septum and the infarcted area and expressed as percentage of the total amount of cardiac tissue. An average of 20 microscopic fields in the septum and 35 fields in the infarcted area were measured. The epicardial, pericardial layer and perivascular areas were not incorporated in the measurements.

To distinguish myofibroblasts from non-fibroblast cells, we performed an Anti Smooth Muscle Actin (ASMA) staining. The percentage of ASMA positive 
infarcted tissue was quantified using computerized morphometry and expressed as a percentage of the total amount of infarcted tissue.

\section{Statistics}

Data are expressed as means \pm SEM. The effects of myocardial infarction and genotype were evaluated with the Mann-Whitney test. The level of statistical significance was considered to be at $\mathrm{p}<0.05$.

\section{Results}

Heart weights, BW, and HW/BW ratio's were similar for both genotypes. Surgical mortality was approximately $30 \%$, and occurred mainly in the two infarct groups. No differences were found for survival post-MI between both genotypes. We investigated two transgenic founderlines (referred to as lines 1

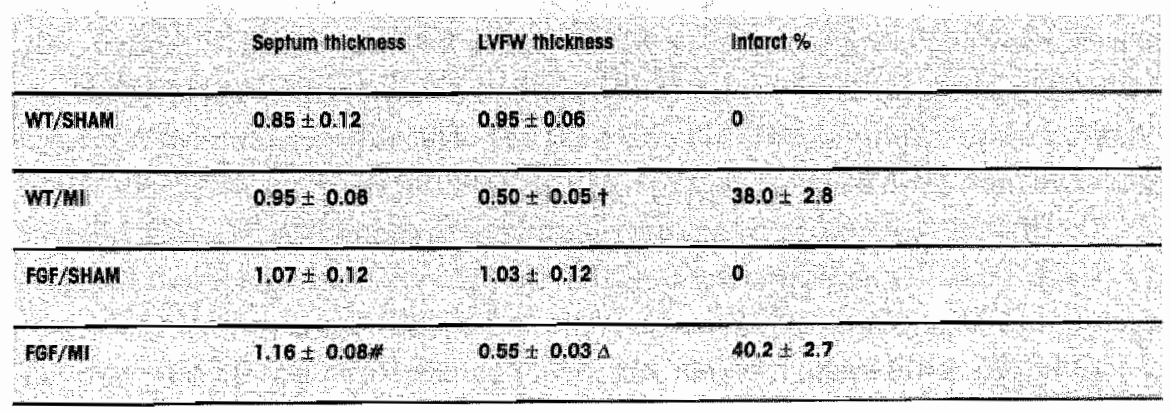

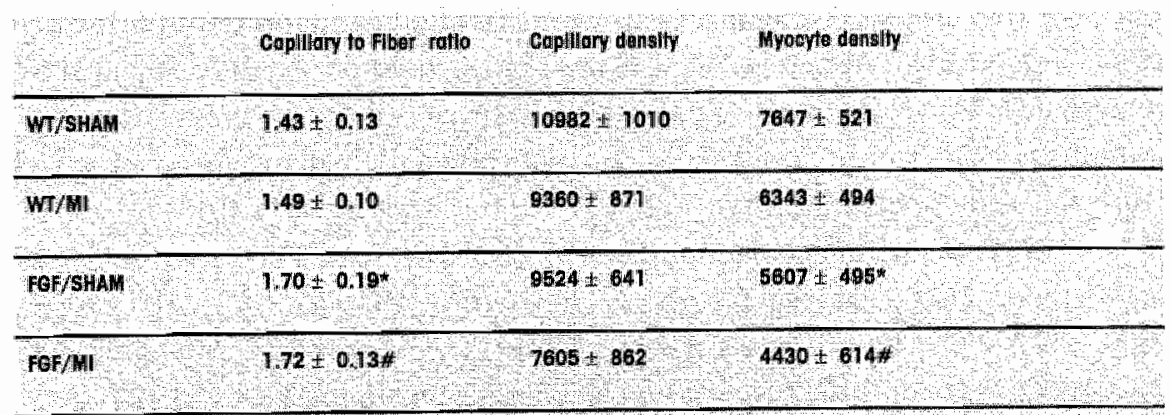

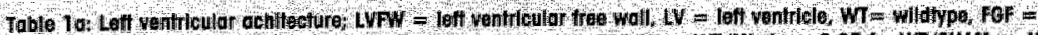

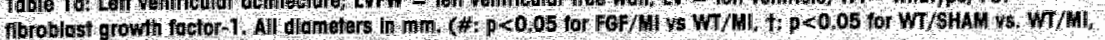

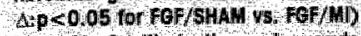

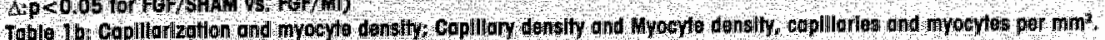

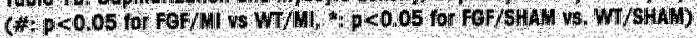


and 2), carrying the same construct, to rule out insertion and copy number related differences. We found no differences between both founderlines for all parameters measured.

\section{Remodeling in the interventricular septum}

Septum thickness (Sth), left ventricular free wall (LVFW) and infarct thickness, infarct size and left ventricular dilatation were measured on AZAN stained sections (table la). Both genotypes had similar infarct sizes $(38.0 \pm 2.8 \%$ for WT/MI v. $40.0 \pm 2.7 \%$ for FGF/MI). In both WT animals and FGF-I overexpressing mice, induction of MI resulted in a nonsignificant increase in Sth. Also, no significant changes between genotypes were found in infarct thickness and LV dilation after MI.

Cardiac capillarization (table $1 \mathrm{~b}$ ): Capillarization of the myocardium was studied in the interventricular septum, using Iso-Lectin B4-stained sections. C/F ratio's were higher in SHAM animals of the FGF-1 overexpressing group $(1.70 \pm 0.1)$ when compared to their WT littermates $(1.43 \pm 0.1, \mathrm{p}<0.05)$. Baseline values for myocyte density (MD) were lower in the FGF groups, indicating larger cardiomyocytes ( $5607 \pm 495$ per $\mathrm{mm}^{2}$ for FGF/SHAM vs. $7647 \pm 521$ per $\mathrm{mm}^{2}$ for WT/SHAM, $\mathrm{p}<0.05$ ). This difference in MD remained evident after $\mathrm{MI}$ induction [WT/MI; $6343 \pm 494$ per $\mathrm{mm}^{2}$, vs. FGF/MI; $4430 \pm 614 \mathrm{~mm}^{2}, p<0.05$ ). No differences were found in basal capillary density (CD). Thus, basal differences in $\mathrm{C} / \mathrm{F}$ ratio between both genotypes can be ascribed to larger cardiomyocytes, as indicated by the decreased MD. Accordingly, neither genotype nor MI induction affected CD.

Apoptosis and DNA synthesis were studied in the granulation tissue (scar tissue) at one week after MI. Apoptosis was detected by both the TUNEL and the activated caspase- 3 staining. Cells were classified as apoptotic if both markers were positive. Apoptosis of cardiomyocytes could not be detected at this time point. However, the level of TUNEL positive cells in the granulation tissue of the FGF-1 overexpressing mice was significantly higher when compared with the same tissue in the WT mice (WT, $0.6 \pm 0.1 \% \mathrm{vs} .1 .1 \pm 0.1 \%$ for FGF$1[\mathrm{p}<0.05])$. Accordingly, the number of activated caspase-3 positive cells was increased in FGF-1 transgenics when compared to WT mice (WT; $0.87 \pm 0.15$ vs. FGF- $1 ; 1.10 \pm 0.16,[p<0.05])$. In contrast, DNA synthesis in the granulation tissue was not different between the FGF-1 overexpressing and WT animals (Table 2).

The collagen deposition, as demonstrated by Sirius Red staining (figure 1), showed no differences in the non-infarcted interventricular septum between the 4 experimental groups. However, the collagen content of the granulation 
tissue formed after MI in WT mice was higher $(41.0 \pm 1.9 \%)$ when compared with FGF-1 mice $(34.7 \pm 2.1 \%, \mathrm{p}<0.05)$. To investigate whether the mhum of myofibroblasts in the infarcted area was changed, we performed an ASMA

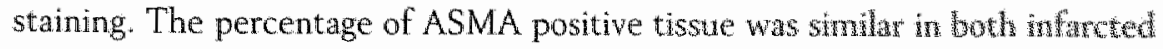
groups [WT/MI; $6.9 \pm 1.3 \%$ vs. FGF/MI; $6.9 \pm 1.0$ w), wdichting that we

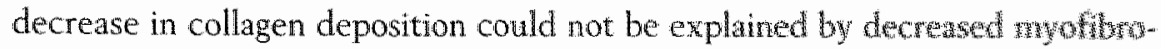
blast numbers.

FGF 1 overexpression deterionates cardiac function after $M(1,3$ ras 2 )

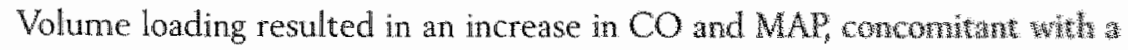

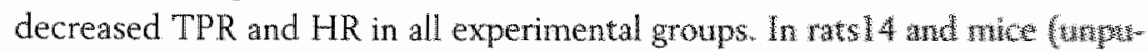

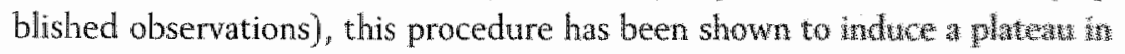
cardiac output in infarcted hearts, proportional to the degree of cardusc $d y$ s. function. Baseline cardiac function was depressed in $F \mathrm{G} / \mathrm{FH} \mathrm{M}$ mperated animals, when compared to their WT littermates (CI for FGF/SHAM=

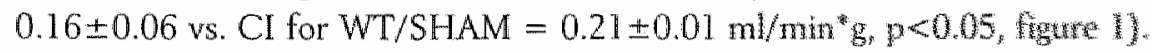
However, maximal $\mathrm{CI}$ after volume loading was equal in both genotwpe grownow

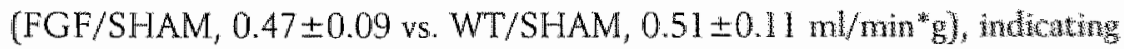
that maximal cardiac performance is not blunted in nom-infarcted IGF-I transgenic mice. Recordings in both MI groups revealed a statistical stgwhicuta decrease in cardiac function due to MI induction, both before and after whe me loading (figure 1). In the FGF/MI group, CI was lower when connpared to the CI values in WT littermates both at baseline (FGF/M, 0.12 0000 w. WT $/ \mathrm{MI}_{1}, 0.17 \pm 0.05 \mathrm{ml} / \mathrm{min}^{*} \mathrm{~g}, \mathrm{p}=0.09$ ) and even more pronounced, folvwing volume overload (FGF/MI, $0.27 \pm 0.08$ vs. WT/MI, $0.38 \pm 0.05$ $\left.\mathrm{ml} / \mathrm{min}^{*} \mathrm{~g}, \mathrm{p}<0.05\right)$. No differences in HR (WT/MI; $509 \pm 27 \mathrm{vs}$. FGF/MR; $516 \pm 26 \mathrm{bpm})$ and TPR (WT/MI; $5.7 \pm 0.89$ vs. FGP/MI; $5.6 \pm 1.18$ $\mathrm{mmHg} / \mathrm{ml} / \mathrm{min}$ ) were found that could account for the decreased $\mathrm{Cl}$ in

\begin{tabular}{|c|c|c|c|c|}
\hline & $\%$ TUNEL + & $\%$ caspase + & $\%$ Brdu $+\ln s$ & $\%$ BrdU + In LVFW \\
\hline WT/SHAM & $<0.001$ & $<0,001$ & $0.9 \pm 0.7$ & 0.910 .4 \\
\hline $\mathrm{WT} / \mathrm{Ml}$ & $0.6 \pm 0.1 *$ & 09102 & $44.5 \pm 2.3 \%$ & $10.6+6.0$ \\
\hline FGF/SHAM & $<0,001$ & $<0.001$ & $1,4 \pm 0.2$ & $10 \pm 0.1$ \\
\hline FGF/MI & $1110.1 \% \mathrm{Y}$ & $1.1 \pm 0.2 \#$ & $43.1+7.2 y$ & $13,2 \pm 7,6 y$ \\
\hline
\end{tabular}



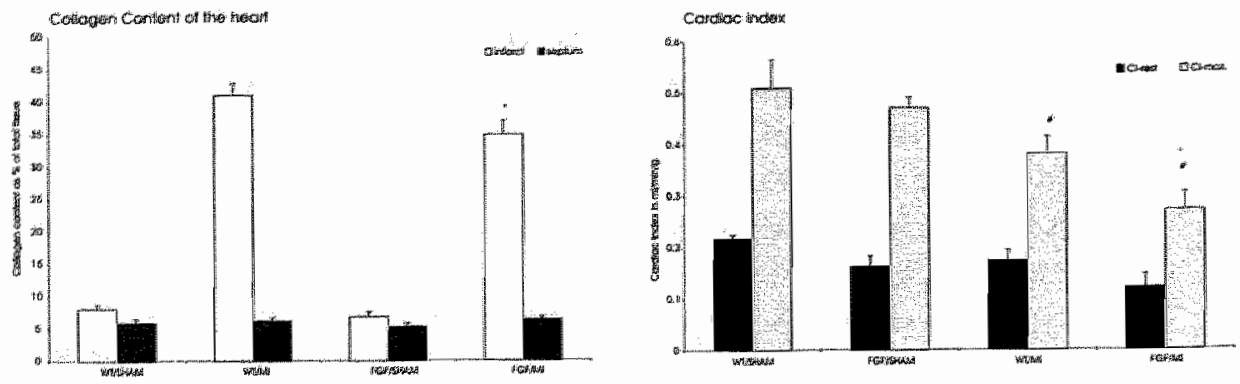

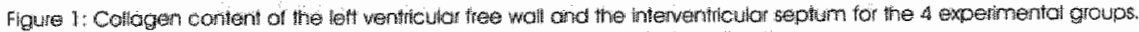
Collogeri content is axpressed os a percentage of the total amernt of cordioc tissue.

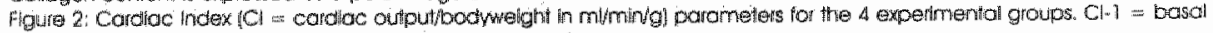
cordide index, $\mathrm{Cl}-2$ = cordioc inciex following wolume looding.

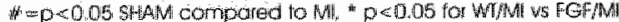

FGF/MI animals, indicating an intrinsic decrease in cardiac contractility in relation with a decreased stroke volume.

\section{Discussion}

This study was performed to assess the effects of constitutive hFGF-1 overexpression on morphological and functional adaptation of the murine heart after MI. The most important findings are that constitutive cardiac-specific FGF-1 overexpression in mice results in alterations in the left ventricular remodeling process and deterioration of cardiac function after MI.

\section{Morphology and cardiac remodeling following MI}

Angiogenesis: FGF-1 and FGF-2 play a pivotal role in coronary but also peripheral vascular disease ${ }^{151 \%}$, mainly because of their essential role in angiogenesis. Formation of new capillaries requires a complex interaction between severall angiogenic growth factors and their receptors. In addition to the FGF famiIy of growth factors, the VEGF proteins and their tyrosine kinase receptors are indispensable for adequate remodeling of the capillary network in response to changes in tissue oxygen consumption. The role of FGF-2 in ischemic heart disease has been studied thoroughly. However, little is known about FGF-1 and its role in chronic MI. By promoting angiogenesis, FGF-2 and FGF-1 induce growth of bridging collaterals to ischemic tissue. ${ }^{6,79.23}$ Recently, Fernandez a $a^{10}$ showed an increase in the number of epicardial vessels without an effect on CD in the same FGF- 1 transgenic mice that we used in this study, indicating a role for FGF-1 in arteriogenesis rather than angiogenesis. Also in the present study, no difference in CD was found. However, overex- 
pression of FGF-1 resulted in higher basal C/F ratio's when compared to WT littermates. This increased $\mathrm{C} / \mathrm{F}$ ratio depends on the presence of larger cardiomyocytes. Indeed, no changes were abserved in CD between both genotypes. Another important finding is that FGF-1 overexpression did not result in reduced infarct extension, although FGF-I is considered to be a protective agent against acute myocardial ischemia. ${ }^{.}$This is in accordance with Buehler et al. ${ }^{24}$, who showed that FGF-1 overexpression delayed rather than prevented infarct formation in an ischemia and reperfusion model.

Cardiac hypertrophy: MD was decreased in both FGF-1 transgenic groups when compared to their respective WT littermates. Following $\mathrm{Ml}$, a trend towards a decrease in MD was observed in both FGF-1 overexpressing and WT animals, indicating that a genotype independent compensatory hypertrophic response in the non-infarcted septum occurred.

In FGF/MI animals, Sth was increased when compared to WT/MI animals. In previous reports, FGF-2 was shown to induce morphological hypertrophy of cardiomyocytes and the expression of a number of fetal genes, considered molecular markers of hypertrophy, like $\alpha$-smooth muscle actin and atrial natriuretic factor in isolated neonatal cardiomyocytes. ${ }^{25}$ The decreased MD at baseline in the transgenics indicates a role for FGF-1 in the determination of myocyte size.

\section{Cell furnover in the scar tissue}

DNA synthesis: In this study, we found no differences in BrdU incorporation between both genotypes after MI. Unger et al ${ }^{2 i}$ showed that $F \mathrm{GF}-2$ administration to ischemic myocardial tissue resulted in increased cellular proliferation, mainly confined to endothelial cells and fibroblasts in both the infarcted and the collateral dependent viable part of the myocardium. In our study however, no significant differences were found concerning cellularity and cellular proliferation in the infarcted LVFW. However, our experimental design was not suited for detection of temporal changes in cellular proliferation.

Apoptosis: In addition to its more long-term effects on the processes involved in cardiovascular remodeling, FGF-1 also exerts short term effects on the cardiovascular system. FGF-1 is known to act as a direct cardioprotective substance ${ }^{9.24}$ and it prolongs cell survival during ischemia/reperfusion induced damage to the heart ${ }^{27}$ and decreases myocardial apoptosis rates." Previous studies in the same FGF 1 transgenic lines showed increased resistance to ischemia/reperfusion trauma and a delay in the development of maximal infarct- 
suce." In our study, comparable infarct sizes were measured one week after MI, which is confirmed by data from Buehler et a ${ }^{24}$ The results observed in the acute studies of in vivo ischemia/reperfusion indicate that the cardioprotective effects are not mediated by increased collateral formation, but merely result from a trophic cardioprotective effect of FGF-1. In contrast, our study shows that $\mathrm{FGF}-1$ overexpression during remodeling following $\mathrm{Ml}$ results in higher apoptosis rates in the scar tissue when compared to their WT littermates, at least one week after MI induction. A possible explanation for higher apoptosis rates in $\mathrm{FGF}-1$ overexpressing hearts in this study might be that the wound healing process is delayed in FGF-1 transgenic hearts and that the peak of apoptosis occurs later or low level apoptosis is maintained for longer period. However, we did not find differences in the influx of myofibroblast numbers and the total cell number in the infarcted LVFW between both groups. Effects on collagen synthesis: FGF-1 and FGF-2 decrease collagen formation by cultured fibroblasts by induction of collagenases. In this study, we found that FGF-1 overexpression in vivo decreased collagen content with no significant change in myofibroblast numbers in the infarcted LVFW, indicating decreased collagen deposition by myofibroblasts or increased collagen degradation. ${ }^{28}$ These results suggest that FGF-1 is involwed in collagen turnover during myocardial remodeling following MI. The decreased collagen content could lead to an unfaworable left ventricular architecture which renders the heart more prone to the phenomenon of systolic stretch and bulging of the aneurysm, thereby contributing to the deterioration of the contractile function of the heart.

\section{Cardiac function following MI}

Administration of FGF's in experimental stucies resulted in improved cardiac performance by augmentation of collateral formation during chronic myocardial ischemia and direct cardioprotection from ischemic damage in the setting of acute MII in vivo. ${ }^{30}$ Administration to a rat heart ax vivo resulted in decreased cardiac function at baseline, but increased cardiac functional recovery following ischemia and reperfusion." These results suggest that FGF-2 may be negative inotropic in the physiologic situation, but that it protects the heart during acute myocardial ischemia and reperfusion. Accordingly, this study shows that CI was significantly lower in the FGF/SHAM group when compared to WT littermates, although maximal cardiac contractility, as indicated by $\mathrm{Cl}_{\text {m, }}$ was not altered. More interestingly, after MI, CImax was significantly depressed in animals overexpressing FGF-1, when compared to WT littermates. This could be explained by an inadequate remodeling response following 
MI, resulting in unfavorable changes in cardiac architecture, thereby disturbing an effective contraction pattern. Indeed, collagen deposition in the infarcted LVFW was decreased in FGF-I overexpressing hearts after MI induction. This might increase the compliance of the infarcted area, thereby rendering the heart more prone to systolic stretch leading to diminished cardiac output. Although fibroblast growth factors have an effect on vascular tone, acting as potent vasodilator ${ }^{32.34}$, we did not find changes in TPR and heart rate when compared to WT littermates. Therefore, the decreased cardiac performance can be attributed solely to a decrease in stroke volume, rather than to altered vascular responses in these transgenics.

In the majority of both animal and human studies, FGF-1 administration and FGF-2 overexpression/-administration proved to be beneficial for the heart in situations of acute ${ }^{8,9,27}$ and chronic ischemia $a^{6,7,20,23,30,35,-37}$ by inducing collateral growth and improving function. The present study shows that constitutive overexpression of FGF-1 may be detrimental for adequate remodeling of the heart, eventually leading to adverse effects on cardiac performance. In accordance with this concept, a model of skin wound healing showed that the effect of FGF-2 on wound healing was beneficial on the short run. However, chronically elevated FGF-2 levels impaired the healing process."."

\section{Conclusion}

Constitutive cardiac specific FGF-1 overexpression results in an altered cardiac remodeling response following myocardial infarction, accompanied by a deterioration rather than preservation of cardiac function. Results of this study might have important implications for future growth factor trials. Potentially, beneficial effects of growth factors in cardiac remodeling do not depend on the presence of growth factors alone. More important parameters may be the time frame during which this growth factor is upregulated and the availability of its receptors. When this information becomes available, growth factors can be administered at the appropriate time point when they are most effective. In that way, growth factor therapy can be much more effective in modulating cardiac remodeling.

\section{Acknowledgements}

We are indebted to dr. J.P.M. Cleutjens, J.J.M. Debets, and P.J.A. Leenders for their technical suport, 


\section{References}

1. Battegoy EJ: Anglogenesis: mechanistic insights, neovascular diseases, and theropeutic prospects. J Mol Med 1995:73:333-346.

2. Speir E, Tanner $V$, Gonzalez AM, ef al: Acidic and basic fibroblasi growth factors in adulf rat heart myochtes; localization, regulation in culture, ond effects on DNA synthesis. Circ Res $1992,71: 251-259$.

3. Engelmann GL, Dionne CA, Jaye MC: Acidic fibroblast growth factor and heart development; role in myocyte proliteration and capillory angiogenesis. Circ Res 1993;72:7-19.

4. Rakusan K: Coronary angiogenesis; from morphometry to molecular blology and back. Arn NY Acad Scl 1995;752:257-266.

5. Slovin J: Fibroblast growth factors: of the heart of angiogenesis. Cell Biol Int 1995;19:431444.

6. Sellke FW, LI d, Stamler A, et al.: Anglogenesis induced by acidic fibroblast growth factor as an altermative method:

of revascularization for chronic myocardial ischemia. Surgery 1996;120:182-188.

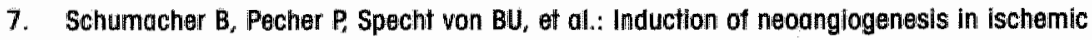
myacardium by human growth factors. Circulation 1998;97:645-650.

8. Cuevas $P$, Reimers $D$, Carceller $F$, et al.: Fibroblast growth factor-1 prevents myocardial apoptosis triggered by ischemilo reperfusion injury. Eur J Med Res 1997;2:465-468.

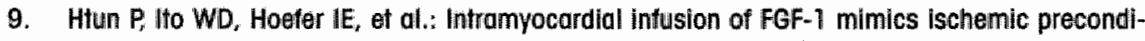
tloning in pig myocardium. J Mol Cell Cardiol 1998:30:867-877.

10. Fernandez. B, Buehler $A_{s}$ Wolfram $S$, et al.: Transgenic myocardial overexpression of Fibroblast growth factor- 1 Increases coronary artery densilly and branching. Circ Res 2000;87:207213.

11. Davidson JM, Broadley KN: Manipulation of the wound-healing process with basic fibroblast growth foctor. Ann NY Acad Scl 1991;638:306-315.

12. Lutgens $E$, Daemen MJAP, de Muinck ED, et al.: Chronic myocardial infarction in the mouse: cardiac functional and structural changes. Cardiovasc Res 1999;41:586-593.

13. Bikfalvi A: Significance of anglogenesis in tumour progression and mefastasis. Eur J Cancer 1995;31:1101-1104.

14. Pfeffer MA, Pfeffer JM, Fishbein MC, ef al.: Myocardial inforct size and ventricular function in ráts. Circ Res 1979;44:503-512.

15. Bauters $\mathrm{C}$ : Growth factors as a potential new treatment for Ischemic heart disease. Clin Cardiol 1997;20 (suppl 2):52-57.

16. Hirko MK, Lin PH, Gosselin C, at al.: In vivo tissue distribution of fibroblast growth factor-1 after intra-arterial delivery. ASAIO 1995:41:630-633.

17. Bauer EP, Kukl S, Arras $M$, al a.: Increased growth factor transcription after pulmonary artery banding. Eur J Cardio-thorac Surg 1997:11:818-823.

7B. Hughes SE: Locallsatlon and differential expression of the fibroblast growth factor receptor (FGFR) multigene family in normal and atherasclerotic human arteries. Cardiovase Res 1996;32:557-569.

19. Schumacher $B$. Specht von $B-U$, Haberstroh $J$, et al.: The stimulation of nea-anglogenesis in the ischemic heart by the human growth factor FGF. $』$ Cardiovase Surg 1998;39:445-453.

20. Battler $A_{*}$ Facc, Scheinowitz $M$, ef al: Intracoronary injection of fibroblast growth factor entences anglogemesis in infarcted swine myocardium. J Am Coll Cardiol 1993:22:2001 2006. 


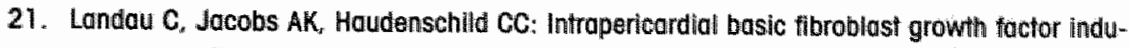
ces myocardial anglogenesis in a rabbit model of chronic ischemia. An Heart $\mathrm{J}$ $1995 ; 129: 924 \cdot 931$.

22. Lazarous DF, Scheinowitz $M$, Shou $M$, ef all.: Effects of chronic systemic administration of basic fibroblast growth factor on collateral development in the conine heart. Circulation 1995;91:145-153.

23. Yanagisawa-Miwa $A$, Uchida $Y$, Nakamuro $F$, ef al.: Salvage of infarcted myocardium by anglogenic action of basic fibroblast growth factor. Science 1992;257:1401-1403.

24. Buehler A, Ito WD, Fernandez B, ef al.: Cardiac overexpressilon of FGF-1 doubles time to Infarction following coranary occlusion-reperfusion in transgenic mice. Circulation 1998;98:A.

25. Harder BA, Schaub MC, Eppentberger HM, et al.: Influence of fibroblast growth factor (BFGF) and Insulin-like growth factor (IGF-1) on cytoskeletal and contractile structures and on atrial natrluretic factor (ANF) expression in adult rat ventricular myocytes in culture. J Mol Cell Cardiol 1996;28:19-31.

26. Unger EF, Banai $S$, Shou $M$, at al.: Basic fibrobiast grawth factor enhances myocardial collateral growth in a canine model. Am $J$ Physiol 1994;266:1588-1595.

27. Cuevas $P$, Carceller $F$ Lozano RM, et al.: Protection of rat myocardium by mitogenic and nonmitogenic fibroblast growth factor during post-ischemic reperfusion. Growth Factors 1997:15:29-40.

28. Chua CC, Chua BHL, Zhao ZY, et al.: Effect of growth factors on collagen metabollism in cultured human heart fibroblasts. Conn Tiss Res 1991;26:271-281.

29. Giordano FJ, Ping P, McKirnan MD, et al.: Intracoronary gene transfer of fibroblast growth factor-5 increases blood flow and contractile function in an ischemle region of the heart. Nat Med 1996:2:534-539.

30. Harada $K_{r}$ Grossman W, Friedman $M_{s}$ ef al.: Basic fibroblast growth factor improves myocardial function in chronically ischemic porcine hearts. J Clin Invest 1994,94:623-630.

31. Padua RR, Merle P-L, Doble BW, et al.: FGF-2 induced negative inotropism and cardloprotection are inhibited by chelerythrine: involvement of sarcolemmal calcium-Independent protein kinase C. J Mol Cell Cardiol 1998;30:2695-2709.

32. Wu HM, Yuan $Y$, McCarthy M, et all.: Acidic and basic FGFs dilate anterloles of skelotal muscle through a NO-dependent mechanism. Am J Physiol 1996;271:H1087-H1093.

33. Cuevas $P_{x}$ Carceller $F$, Ortega $S_{v}$ et al.: Hypotensive activity of flbroblast growth foctor. Sclence $1991 ; 254: 1208-1210$.

34. Cuevas P, Garcia-Calvo M, Carceller F, et al.: Correction of hypertension by normalization of endothelial levels of basic fibroblast growth factor and nitric oxide synthase in spontaneously hyperterisive rats. Proc Natl Acad Sci USA 1996;93:11996-12001.

35. Sellke FW, Wang SY, Friedman M, et al.." Basic FGF enhances endothelium-dependent reloxation of the collateral-perfused coronary microcirculation. Am J Physiol 1994;267:13031311.

36. Asahara $T$, Bauters $C$, Zheng $L$, et al.: Synergistic effect of vascular endothellal growth factor and basic fibroblast growth factor on anglogenesis in vivo. Circulation 1995;92:365-371.

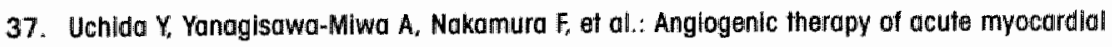
infarction by intrapericardial injection of basic fibroblast growth factor and heparin sulfate: an experimental study. Am Heart a 1995;130:1182-1188. 


\section{Chapter 6}

\section{Fibroblast Growth Factor-1}

improves cardiac functional recovery and enhances cell survival following ischemia and reperfusion:

\section{a FGF-R1, PKC and tyrosine kinase dependent mechanism.}

Meindert Palmen', MD, Mat.J Daemen?' MD, PhD, Leon J. De Windt; PhD, Jodil Willems', Willem R. Dassen!, PhD, sylvia Heeneman? PhD, Rene Zimmermann", PhD, Mare Van Bilsen', PhD, and Pieter A. Doevendans', MD, PhD.

From the Depts, of Cardiology', Pathology? and Physiology, Cardiovascular Research Instifute Maastricht (CARIM), Maastricht, the Netherlands, Vascular Genomics, Bad Nauheim, Germany:

Submitted 


\section{Abstract}

In the past 25 years, the family of Fibroblast growth factors (FGF) received much attention because of their pivotal role in the initiation and completion of angiogenesis. More recently, the attention has focused on the cardioprotective role of FGFs during acute ischemia and reperfusion-induced myocardial damage. We inwestigated the cardioprotective effects of increased FGF-1 levels during ischemia and reperfusion and the intracellular signaling pathways responsible for these effects. In an ex tivo murine setup of myocardial ischemia and reperfusion, cardiac-specific hFGF-1 (human FGF-1) overexpression was associated with enhanced post-ischemic hemodynamic recovery and decreased LDH (Lactate Dehydrogenase) release during reperfusion. FGF-1 transgenic control hearts demonstrated increased PKC- $\varepsilon$ (Protein Kinase C) translocation and increased ERK-1/2 MAPK (Mitogen Activated Kinases) phosphorylation. To unravel the intracellular signaling pathways responsible for cardioprotection, pharmacological inhibitors of the FGF receptor (FGF-RI), PKC and tyrosine kinases (TK) were administered. Pre-ischemic administration of each of the inhibitors resulted in complete blockade of the FGF-1 induced protective effects on cardiac functional recovery, in conjunction with decreased ERK phosphorylation and attenuation of PKC translocation. In conclusion, chronic FGF-1 overexpression induces cardioprotection and improves cell survival, thereby mimicking ischemic preconditioning, through a pathway that involves FGF-R1, PKC and TK-mediated ERK-1/2 acvtivation.

\section{Introduction}

Fibroblast Growth Factor-1 (FGF-1) or acidic FGF is a multifunctional peptide that belongs to the large family of fibroblast growth factors. FGF- 1 is produced by a myriad of cell types, including cardiomyocytes ${ }^{1.2}$, endothelial cells ${ }^{1.2}$, macrophages 1 and fibroblasts.' In the heart, FGF-1 and its most important receptor (FGF-RI), play a pivotal role in the regulation of cardiac morphogenesis ${ }^{3}$, angiogenesis ${ }^{4}$, arteriogenesis ${ }^{5}$ and cardiac remodeling following myocardial infarction (MI). "Recently, it was reported that FGFs mediate direct cardioprotective effects during acute ischemia and reperfusion (I/R), by induction of an ischemic preconditioning (IPC)-like state. Both FGF-2 administration: and overexpression" resulted in cardioprotection. Furthermore, these studies demonstrated that FGF-2 mediated protection was dependent on MAPKs, TK and PKC-isoform activation.

FGF-1 is also considered to be protective in ischemic heart disease. Pre-ischemic administration of FGF-1 decreases cardiomyocyte apoptosis rates follo- 
wing ischemia and reperfusion in vitro, thereby enhancing cell survival."

Moreover, Htun et al. showed that pretreatment with FGF-1 induced a state of IPC in a porcine model of regional myocardial ischemia. Finally, Buehler et a1. "showed that constitutive cardiac-specific FGF-1 overexpression delayed MI formation in vivo.

Several intracellular mediators considered to play a pivotal role in IPC and cardioprotection have been denominated. One of the crucial steps in ischemic preconditioning involves the activation of distinct PKC isoforms, most notably, the $\mathrm{e}$-isoform. Upon activation, PKC isoforms translocate to distinct subcellular localizations, where they mediate their protective effects and initiate gene transcription." Hence, PKC-activation induces cardioprotection in several animal models ${ }^{10,12-4 s}$ "including the mouse ${ }^{15.17}$ In addition to PKC isoforms, TK have been implicated in IPC-mediated protection. During IPC, the TK isoforms Src and Lck become activated in a PKC-dependent fashion. ${ }^{13,18}$ While much is known about the pathways involved in the long term effects of FGF-ll on mitogenesis and protein synthesis which are mediated through high affinity binding to $F G F-R 1$ receptor, very little is known about the mechanisms of growth factor-mediated cardioprotection and the intracellular signaling pathways involwed. Whether or not reported FGF-induced cardioprotective effects are receptor (FGF-R I) mediated or depend on interaction of FGFs with, yet unknown, intracellular targets, is still a point of debate in literature. Although FGF-1 and 2 lack a leader sequence, necessary to exteriorize the protein, FGF's are released during contraction of cardiac myocytes, allowing a receptor-mediated mechanism. "This was underlined by Htun et al. , who showed that exogenous FGF-1 mediated protection is receptor-mediated. However, several reports suggest that exogenous FGI-1 and FGF-2 are internalized by formation of a complex with FGF RI ${ }^{24}$, which might indicate the existence of an intracellular target for this growth factor complex. In this study, we investigated the effects of constitutive cardiac-specific hFGF-1 overexpression on cardiac functional recovery and cell survival following acute, global myocardial ischemia and reperfusion in an isolated, working mouse heart set-up. A marked cardioprotective effect of FGF-1 overexpression was demonstrated, which critically depended upon activation of intracellular signaling pathways utilizing FGF-RI, and the activation of PKC and TK.

\section{Methods}

Adult, male transgenic mice with cardiac-specific overexpression of the human isoform of FGF-1 (hFGF-1) were described previously." The transgene construct is composed of a CMV entancer and a $2.2 \mathrm{~kb}$. MLC-2v promotor 
driving the $2.1 \mathrm{~kb}$. human FGF-1 CDNA, completed by a SV40 polyadenylation site. This transgene resulted in a 2-3 fold cardiac-specific $\mathrm{FGF}^{2}-1$ overexpression, as confirmed by Northern and Western Blotting. 5 All experiments described in this study were approved by the Institutional Animal Care and Use Committee of the Maastricht University.

\section{Perfusion system}

All the chemicals used for the Krebs-Henseleit solution were of the highest purity grade available and purchased from Merck (Darmstadt, Germany), except for the D(+)-glucose and pyruvate (Sigma, St. Louis, MO, USA) and the (human) insulin (Actrapid, Nowo Nordisk Farma B.V., Alphen a/d Rijn, the Netherlands). For this study, a mouse heart perfusion system as described by De Windt et $\mathrm{al}^{12,22}$ was used. This murine "assisted-mode" isolated heart model closely resembles the in vino situation in the mouse, regarding both the generation of cardiac output and left ventricular pressure curves."

\section{Isolated ejecting mouse heart preparation}

Mice were genotyped by PCR. Mice were anesthetized with pentobarbital (Nembutal, Sanofi Sante, Maassluis, The Netherlands, $50 \mathrm{mg} / \mathrm{kg}$ i.p.). After thoracotomy, the heart was excised quickly and placed immediately in icechilled perfusion buffer. The hearts were perfused with recirculating, prefiltered Krebs-Henseleit solution (KH) consisting of (in mM): $\mathrm{NaCl} 118, \mathrm{KCl} 4.7$, $\mathrm{CaCl} 23.0, \mathrm{MgSO} 41$. 2, $\mathrm{KH} 2 \mathrm{PO} 4$ 1.2, $\mathrm{NaHCO} 325, \mathrm{Na}-\mathrm{EDTA} 0.5, \mathrm{D}(+)-$ glucose 10 , and pyruvate 1.5 , which was gassed with carbogen $(95 \% \mathrm{O} 2,5 \%$ CO2). In the presence of $0.5 \mathrm{mM}$ EDTA, nominal free $\left[\mathrm{Ca}^{2+}\right]$ was $2.5 \mathrm{mM}$. Insulin levels in the perfusate were $0.15 \mathrm{U} / \mathrm{l}$. $\mathrm{PO} 2$ pressure exceeded 650 mmHg and $\mathrm{pH}$ values ranged between 7.40 and 7.45 . The temperature of the heart was maintained at $38.5^{\circ} \mathrm{C}$.

The native ascending aorta was connected to the aortic cannula, mounted in the perfusion system, and immediately perfused retrogradely at a pressure of $50 \mathrm{mmHg}$, after which the heart resumed spontaneous beating. A specially designed aortic cannula was used, matching the hemodynamic impedance characteristics of the murine ascencing aorta ${ }^{2}$ Subsequently, a PE-50 catheter was introduced via the apex to measure left ventricular pressure. The left atrium was cannulated through a pulmonary vein, using a $20-\mathrm{G}$ cannula at a fixed preload of $10 \mathrm{mmHg}$. Mean Arterial Pressure (MAP) was monitored just downstream from the aortic cannula, using an identical pressure transducer. Finally, a water jacket $\left(38.5^{\circ} \mathrm{C}\right)$ was placed around the heart, in order to avoid temperature fluctuations. The hearts were paced at a frequency of 450 beats 
per minute (except during ischemia), well above the intrinsic heart rate of approximately 380 beats per minute.

\section{Hemodynamic data acquisition}

All hemodynamic parameters were recorded continuously using specialized software (Hemodynamic Data Acquisition System, Technical Department, Mastricht University) allowing online measurement, calculation and presentation of Aortic flow (Aof), Cardiac Output (CO), systolic Left Ventricular Pressure (LVP ${ }_{\infty}{ }_{j}$, diastolic Left Ventricular Pressure (LVP ), Left Ventricular End Diastolic Pressure (LVEDP), Mean Arterial Pressure (MAP) and LV $\mathrm{dP} / \mathrm{dt}$ and $\mathrm{dP} / \mathrm{dt}$. Left Ventricular Developed Pressure (LVDP) was defined as the difference between LVP and LVEDP. CO was defined as the sum of AOF and coronary flow (CF). CF was determined from the difference between left atrial filling flow, as measured by the $2 \mathrm{~N}$ inline flowprobe, and $\mathrm{AOF}$, as measured by the $1 \mathrm{~N}$ inline flow probe. Before each experiment, flow probes and pressure transducers were calibrated.

\section{Experimental Protocol}

After positioning the left atrial inflow catheter and pacing electrodes, antegrade perfusion and online data aquisition was started, after which the heart was allowed to stabilize for 20 minutes. In the last minute of this period, coronary effluent was collected and baseline hemodynamic measurements were calculated. Subsequently, both left atrial filling flow and the aortic outflow tract were closed using an occluder, thereby initiating the no-flow normothermic ischemic period. In separate pilot experiments, we investigated the optimal duration of the ischemic period in three mice. The most pronounced effects on cardiac function were observed after 25 minutes of ischemia and this period was used in the subsequent experiments. After completion of normothermic ischemia, the aortic clamp was released, allowing retrograde reperfusion of the coronaries for 10 minutes. After reperfusion in the Langendorff (retrogradel mode, the left atrial inflow was reopened to allow antegrade perfusion. After additional 60 minutes of reperfusion, the heart was removed quickly from the system, flash frozen and stored at $-80^{\circ} \mathrm{C}$ for further analysis. Coronary effluent was collected at $5,10,15,25,35$ and 60 minutes reperfusion and directly frozen in liquid nitrogen. To stabilize $\mathrm{LDH}$ in the effluent, bovine serum albumin (BSA) solution was added to a final concentration of $3 \%$. 


\section{Biochemical analysis}

Lactate and lactate dehydrogenase (LDH) concentrations were measured in the coronary effluent as markers of anaerobic metabolism and myocardial cell death. Lactate and L.DH were assessed spectometrically using a Cobas Bio autoanalyser according to the method of Apstein et al. ${ }^{23}$ and Bergmeyer and Bernt et al. ${ }^{24}$.

\section{Pharmacological interventions}

To obtain pharmacological inhibition of several intracellular signaling peptides,

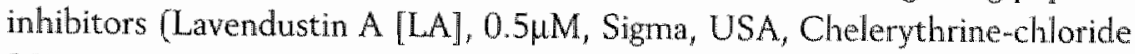

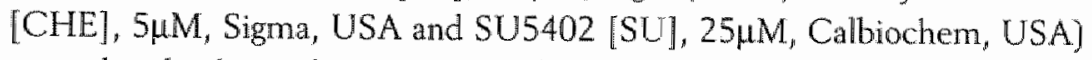
were dissolved in either DMSO or $\mathrm{dH} 2 \mathrm{O}$, according to the guidelines of manufacturer, diluted in $\mathrm{KH}$ solution and administered at final doses known to be well above the IC50 values to WT or TG ( $n=6$ per group).

LA is a cell-permeable general inhibitor of cytoplasmic tyrosine kinases, while SU5402 selectively inhibits the intracellular kinase of the FGF-R1, thereby preventing receptor dimerization, ${ }^{8,25} \mathrm{LA}$ and SU were dissolved in $0.01 \%$ DMSO. ${ }^{10}$ Chelerythrine-chloride was used to inhibit PKC and was dissolved in $\mathrm{d} \mathrm{H}^{2} \mathrm{O}$.

Baseline hemodynamic values were obtained after 15 minutes of stabilization. Subsequently, the system was switched from the ejecting mode to the Langendorff mode for drug administration, to reduce the amounts of inhibitor used and to prevent the inhibitor from entering the perfusing system. The inhibitors were administered during 10 minutes via an artic cannula side hole, located $3 \mathrm{~mm}$ above its entrance. A perfusor pump was used to assure constant inhibitor levels. The inhibitor $/ \mathrm{KH}$ solution was concentrated 8 times, in order to limit perfusion with unsaturated buffer. After completion of drug delivery, the heart was subjected to 25 minutes of ischemia, followed by 60 minutes of reperfusion. Coronary effluent was sampled following hemodynamic stabilization, during drug delivery and during the reperfusion phase. The remaining part of the protocol was executed as described before.

Pilot experiments $(\mathrm{n}=3$ for both WT and FGF 1 TG) ensured that switching from ejecting mode to Langendorff mode and back again did not influence cardiac function or cardiac functional recovery. Since certain inhibitors were dissolved in DMSO (0.01\%) we tested whether either inhibitor or DMSO alone influenced cardiac function ( $n=3$, data not shown) and no effect was demonstrated. 


\section{Immunoblotting and Immonoprecipitation}

Ventricular tissue samples (subjected to $\mathrm{I} / \mathrm{R}$ ) were powdered with a morter and pestle and further homogenized at $4{ }^{\circ} \mathrm{C}$ in a buffer containing $0.5 \%$ Triton, $0.5 \% \mathrm{NP} 40,10 \mathrm{mM}$ Tris ( $\mathrm{pH} 7.5), 2.5 \mathrm{mM} \mathrm{KCl}, 150 \mathrm{mM} \mathrm{NaCl}, 20 \mathrm{mM} \beta-$ Glycerolphosphate, $50 \mathrm{mM} \mathrm{NaF}, 1 \mathrm{mM}$ Orthovenadate, $10 \mu \mathrm{g} / \mathrm{ml}$ Leupeptin, $1 \mathrm{mM}$ DTT, $10 \mu \mathrm{g} / \mathrm{ml}$ soytrypsin inhibitor and $200 \mathrm{mM}$ benzamine, using a polytron tissue homogenizer (Kinematica AG, Switserland), and centrifuged for 20 minutes at $7000 \times \mathrm{g}$. Samples containing equal amounts of protein (2040 g) were separated by SDS-PAGE (8-12\%) and western blotting was performed as described previously. ${ }^{26}$ Antibodies and other supplies were obtained. from the following sources; Polycional PKC- $\varepsilon$ antibody was from Upstate Biotechnology (Lake Placid, NY, USA). New England Biolabs (Beverly, MA, USA) supplied polyclonal anti-phospho-specific antibodies against ERKI/2, JNK1/2 and $\mathrm{p} 38$, and polyclonal ERK1/2, JNK and p38 antibodies. Data were quantified by assessment of the integrated optical density (IOD).

To detect PKC translocation, separate cytosolic and particulate fractions were prepared from ventricular tissue. ${ }^{27}$ Briefly, tissue samples were homogenized in $25 \mathrm{mM}$ Tris-Cl, pH 7.5, 4mM EGTA, 2mM EDTA, $5 \mathrm{mM}$ dithiothreitol, $1 \mathrm{mM}$ phenylmethylsulfonyl fluoride, $1 \mu \mathrm{g} / \mathrm{m}$ leupeptin, and incubated on ice for 30 minutes. Afterwards, samples were spun at $100,000 \mathrm{x}$ g for 30 minutes. $\left(4^{\circ} \mathrm{C}\right)$. The supernantant was used as cytosolic fraction, while the remaining pellet was rehomogenized with the same lysis buffer, now containing $1 \%$ Triton X-100, and incubated on ice for 30 minutes. After spinning the samples for 30 minutes at $100,000 \times \mathrm{g}$, the supernantant was saved as the particulate fraction.

To investigate the effects of genotype and inhibitors on MAPK-activation and PKC translocation during ischemia alone, 3 animals per group underwent 25 minutes of ischemia, omitting reperfusion. After the ischemic period had been completed, hearts were flash-frozen and tissue samples were prepared as described above, followed by Western blotting and densitometry.

\section{Statistics}

The results are presented as means $\pm S E M$. The effect of genotype was evaluated using Mann-Whitney or Kruskall-Wallis test, depending on the number of groups to be compared. The influence of time and genotype and their interactions, on hemodynamic parameters and enzyme release was assessed, using a 2-way ANOVA. A level of $\mathrm{P}<0.05$ was considered to be of statistical significance. 


\section{Results}

\section{General}

Average body weight was similar in both groups (WT $[n=36] ; 29.6 \pm 0.8 \mathrm{~g}$,

FGF $[\mathrm{n}=39] ; 28.3 \pm 0.9 \mathrm{~g}, \mathrm{P}=\mathrm{ns}$.), as were heart weights and heart weight/ body weight ratio's CWT; HW $=1.53 \pm 10 \mathrm{mg}, \mathrm{HW} / \mathrm{BW}=5.3 \pm 0.3^{*} 10^{3}, \mathrm{FGF}$; $\mathrm{HW}=15 \mathrm{I} \pm 8 \mathrm{mg}, \mathrm{HW} / \mathrm{BW}=5.1 \pm 0.4^{*} 10^{-3}, \mathrm{p}=\mathrm{ns}$ ). To correct for differences in the site of genomic incorporation and copy number of the transgene construct, we investigated two distinct founder lines (line I and line 2), which carried the same transgene construct. No differences between both lines were found in HW and HW/BW ratios, basal cardiac function, response to ische$\mathrm{mia} / \mathrm{reperfusion}$ or to inhibitor compounds. To this end, equal amounts of both lines were used for these experiments.

\section{Pre-ischemic hemodynamics}

No differences were observed in pre-ischemic intrinsic heart rates between both genotypes [TG vs. WT], and amounted to $\pm 380 \mathrm{bpm}$. Hemodynamic

\begin{tabular}{|c|c|c|c|c|c|c|c|c|c|c|c|c|}
\hline & $\infty$ & ADP & EF & $\mathrm{sy}$ & Yyop & urs & uvilo & YNeOP & $+6 r / d t$ & ewP/dt & Ln & Iothotot \\
\hline$\left(\mathrm{w}^{-6)}\right.$ & $\begin{array}{l}144 \\
0=7\end{array}$ & $\begin{array}{l}102 \\
1,2 \\
1,2\end{array}$ & $\begin{array}{l}3,3 \\
0.6\end{array}$ & $\begin{array}{l}1068 \\
6\end{array}$ & $\begin{array}{l}61 \\
4,1\end{array}$ & $\begin{array}{l}879 \\
8 \$\end{array}$ & $\begin{array}{l}30 \\
1,6\end{array}$ & $\begin{array}{l}3 \\
4\end{array}$ & 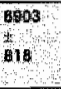 & $\begin{array}{l}3457 \\
87\end{array}$ & $\begin{array}{l}27 x \\
68\end{array}$ & 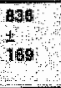 \\
\hline $\begin{array}{l}\mathrm{Fot} \\
\mathrm{n}=\mathrm{O})\end{array}$ & $\begin{array}{l}12 \\
16\end{array}$ & $\begin{array}{l}17 \\
17 \\
12\end{array}$ & $\begin{array}{l}2.8 \\
6 \\
6\end{array}$ & 42 & 709 & $\begin{array}{l}\text { A9, } \\
6 \mathrm{n}\end{array}$ & $\begin{array}{l}71 \\
18\end{array}$ & $\begin{array}{l}01 \\
16\end{array}$ & $\begin{array}{l}6429 \\
\text { a18 }\end{array}$ & $\begin{array}{l}\mathrm{H}(\mathrm{m}) \\
\mathrm{H}\end{array}$ & $\begin{array}{l}\text { या } \\
4 \\
4\end{array}$ & $\mathrm{t}$ \\
\hline W/4 & $\begin{array}{l}126 \\
16\end{array}$ & $\begin{array}{l}70 \\
6\end{array}$ & $\begin{array}{l}47 \\
07\end{array}$ & $\begin{array}{l}269 \\
24 \\
24\end{array}$ & $\begin{array}{r}658 \\
+8 \\
73\end{array}$ & $\begin{array}{l}102,9 \\
7 \\
14\end{array}$ & $\begin{array}{l}6, \\
36\end{array}$ & $\begin{array}{l}1 \% 2 \\
2,6\end{array}$ & $\begin{array}{l}7217 \\
171\end{array}$ & $\begin{array}{l}386 \\
367\end{array}$ & $\begin{array}{l}274 \\
48 \\
48\end{array}$ & $\begin{array}{l}701 \\
163\end{array}$ \\
\hline $\begin{array}{l}r a f, 444 \\
(n=6)\end{array}$ & $\begin{array}{l}111 \\
0\end{array}$ & $\begin{array}{l}12 \\
0\end{array}$ & $\begin{array}{l}40 \\
02\end{array}$ & $\begin{array}{l}236 \\
25\end{array}$ & $\begin{array}{l}\text { bia } \\
\text { z }\end{array}$ & MOPA & $\begin{array}{l}61 \\
1,0\end{array}$ & $\begin{array}{l}120 \\
12\end{array}$ & 871 & $\begin{array}{l}\text { ar } 16 \\
\text { ag }\end{array}$ & $\begin{array}{l}20 \\
42\end{array}$ & $\begin{array}{l}0 x \mathrm{a} \\
210\end{array}$ \\
\hline $\begin{array}{l}\text { Wuflhis } \\
(n=6)\end{array}$ & $\begin{array}{l}87 \\
4\end{array}$ & $\begin{array}{l}6.5 \\
2 \\
3\end{array}$ & $\begin{array}{l}3 \\
04\end{array}$ & $\begin{array}{l}241 \\
\mathrm{a}\end{array}$ & $\begin{array}{l}760 \\
4\end{array}$ & $\begin{array}{l}0,8 \\
3 \%\end{array}$ & $\begin{array}{l}62 \\
41\end{array}$ & $\begin{array}{l}1 / 10 \\
42\end{array}$ & $\begin{array}{l}0825 \\
109\end{array}$ & 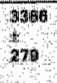 & $\begin{array}{r}281 \\
40\end{array}$ & 87 \\
\hline$(n+6)$ & $\begin{array}{l}706 \\
06\end{array}$ & $\begin{array}{l}7.1 \\
0,6\end{array}$ & $\begin{array}{l}8 \\
0.4\end{array}$ & $\begin{array}{l}24,4 \\
17\end{array}$ & $\begin{array}{l}785 \\
4 \%\end{array}$ & $\begin{array}{l}1051 \\
+1 / 9\end{array}$ & $\begin{array}{l}80 \\
18\end{array}$ & $\begin{array}{l}177 \\
16\end{array}$ & $\begin{array}{l}8199 \\
4 \\
462\end{array}$ & $\begin{array}{l}4344 \\
250\end{array}$ & $\begin{array}{l}261 \\
61 \\
15\end{array}$ & $\begin{array}{l}4 \mathrm{Bu} \\
\mathrm{t} \\
24\end{array}$ \\
\hline $\begin{array}{l}\text { (ntwsil } \\
(n)=6)\end{array}$ & $\begin{array}{l}139 \\
1 \% 2\end{array}$ & $\begin{array}{l}112 \\
0,9\end{array}$ & $\begin{array}{l}26 \\
0,4\end{array}$ & $\begin{array}{l}11,8 \\
29\end{array}$ & $\begin{array}{l}117 \\
\mathrm{x}^{2} \\
33\end{array}$ & $\begin{array}{l}105 \\
04\end{array}$ & $\begin{array}{l}72 \\
12 \\
17\end{array}$ & $\begin{array}{l}232 \\
32\end{array}$ & $\begin{array}{l}7128 \\
0140\end{array}$ & $\begin{array}{l}3069 \\
4\end{array}$ & $\begin{array}{l}30.6 \\
\text { की }\end{array}$ & $\begin{array}{l}67 \text { if } \\
568\end{array}$ \\
\hline $\begin{array}{l}f(n) d \\
(n=6)\end{array}$ & $\begin{array}{l}11,5 \\
1 ; 8\end{array}$ & $\begin{array}{l}0.0 \\
1,4\end{array}$ & $\begin{array}{l}26 \\
+ \\
0.5\end{array}$ & $\begin{array}{l}280 \\
4,0\end{array}$ & $\begin{array}{l}761 \\
7,9\end{array}$ & की 610 & $\begin{array}{r}105 \\
21\end{array}$ & 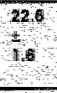 & $\begin{array}{l}7168 \\
2 \\
\text { Dq9 }\end{array}$ & $\begin{array}{l}3471 \\
207 \\
207\end{array}$ & $\begin{array}{l}281 \\
81\end{array}$ & की \\
\hline
\end{tabular}


parameters dic not change over the 15 minutes of stabilization, indicating a stable base-line hemodynamic situation. No hemodynamic differences were observed between both genotype groups, indicating an equal pre-ischemic hemodynamic situation (Table 1).

\section{FGF - 1 protects cardiac functional recovery and improves cell survival following ischemia and reperfusion.}

Following an ischemic period of 25 minutes, cardiac function deteriorated in both transgenic mice and non-transgenic littermates. In WT mice, AoF decreased dramatically from $10.0 \pm 1.2 \mathrm{ml} / \mathrm{min}$ antegrade to only retrograde flow ($114(\%)$, indicating severe systolic dysfunction, while in FGF transgenic hearts recovery of Aof was partially preserved (a $44 \%$ decrease from $9.7 \mathrm{ml} / \mathrm{min}$ to $5.2 \mathrm{ml} / \mathrm{min}$, antegrade flow, $\mathrm{P}<0.001$, Figure la $)$ Similarly, LVP. $(-73 \%)$ and LVDP $(-91 \%$, Figure lb) decreased to very low values in WT hearts, while in FGF-1 TG hearts, only a modest decrease was observed (11\% decrease for LVP. [data not shown] and $22 \%$ decrease in $L V D P, P<0.001$ ). In addition, $L V$ $\mathrm{dP} / \mathrm{dt}$. (Figure $1 \mathrm{c}$ ) and $\mathrm{dP} / \mathrm{dt}$-values decreased dramatically in WT mice $(-90 \%$ and $-87 \%$ respectively), while in FGF-1 transgenic mice only a minor
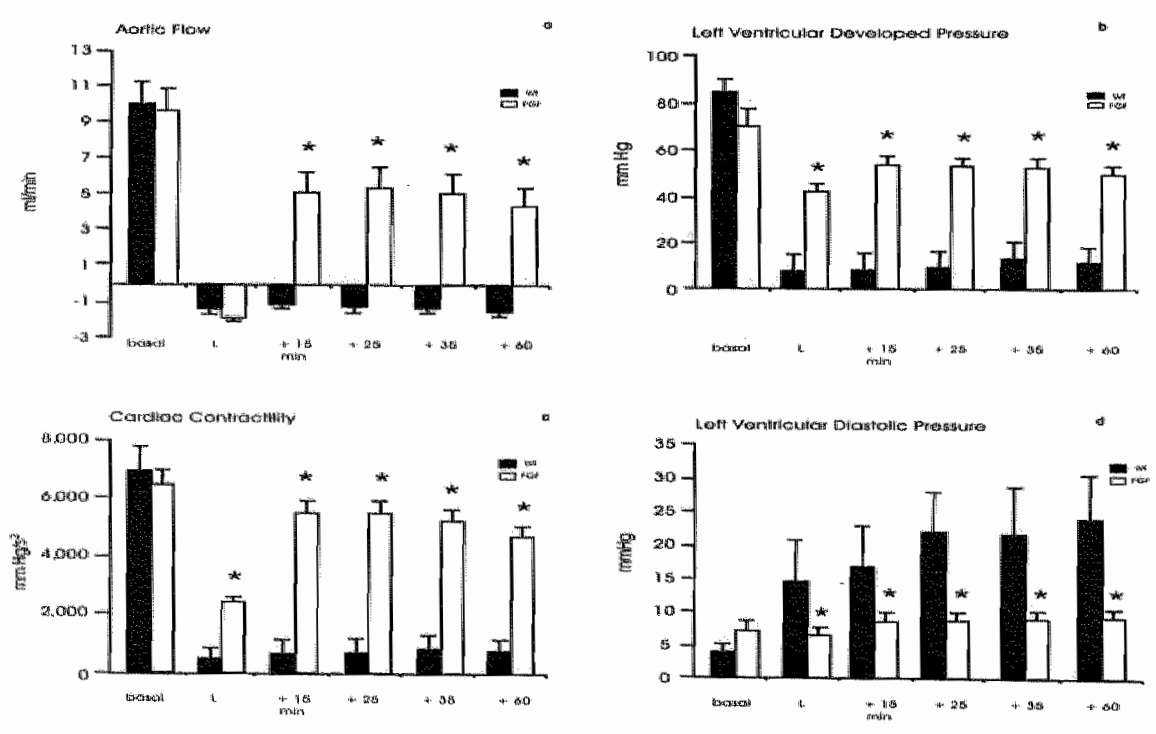

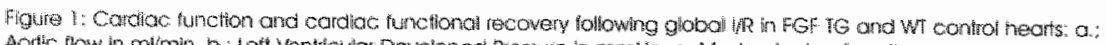

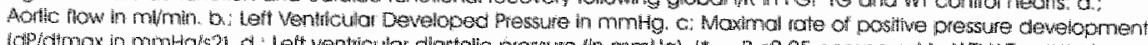

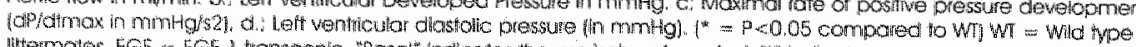

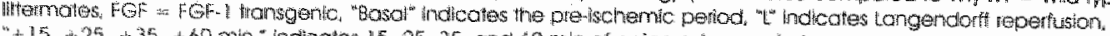

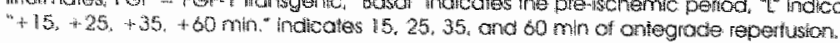



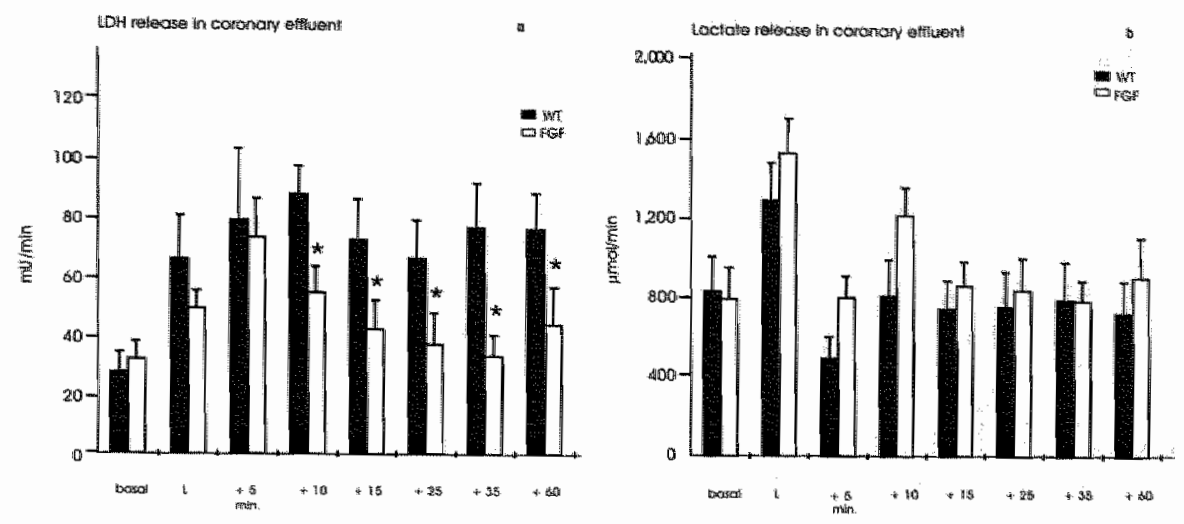

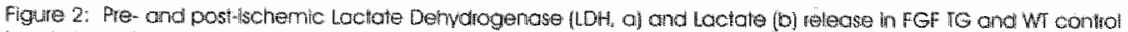

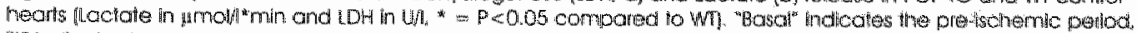

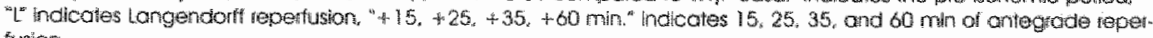
fustor.

decrease was observed $(-15$ and $-7 \%$, respectively, $\mathrm{P}<0.001$ compared to WT). Also post-ischemic diastolic function was largely preserved in FGF-1 TG hearts compared to their WT counterparts. In WT mice, LVP. increased 6-fold following $1 / R$, indicating severe diastolic dysfunction, while in FGF-1 transgenic mice, near complete preservation of LVP $(+28 \%, \mathrm{P}<0.001 \mathrm{com}-$ pared to WT) was observed (Figure Id). No differences in LVEDP were found between both genotypes (data not shown). No differences between both genotypes were found for $\mathrm{CF}$ values for each of the different time points measured, indicating that CF was not increased due to FGF-1 overexpression. Baseline, pre-ischemic LDH values were similar in both experimental groups (WT; $27.1 \pm 6.8 \mathrm{U} / \mathrm{I}^{*} \mathrm{~min}$. vs. FGF $-1 ; 31.5 \pm 6.1 \mathrm{U} / 1^{*}$ min., $\mathrm{P}=\mathrm{ns}$ ). Induction of global cardiac ischemia resulted in increased LDH release in both genotypes during the first 5 minutes of reperfusion, (78.5 $\pm 23.7 \mathrm{U} / \mathrm{I}^{*} \mathrm{~min}$., vs. $72.8 \pm 12.8$ $U / 1^{*}$ min., $\mathrm{P}<0.05$, compared to baseline) In WT mice, $\mathrm{LDH}$ release further increased (max. of 3.2 fold) and remained elevated throughout the 60 minttes of reperfusion, indicating ongoing myocardial cell damage. In contrast, in the FGF-1 group, LDH release quickly dropped to baseline levels after an initial washout peak and remained at baseline levels throughout the remainder of the reperfusion period (Figure $2 \mathrm{a}$ ).

Pre-ischemic lactate release was equal in both experimental groups, (WT; $836 \pm 169 \mu \mathrm{mol} / /^{*}$ min vs. FGF; $798 \pm 150 \mu \mathrm{mol} / /^{*}$ min., $\mathrm{P}=$ ns, Table 1). Following ischemia, a washout peak for lactate was observed in both groups during the first minutes of reperfusion (WT; $1297 \pm 190 \mu \mathrm{mol} / \mathrm{I}^{\mathrm{k}} \mathrm{min}$. vs. FGF; $1535 \pm 175 \mu \mathrm{mol} / /^{*} \mathrm{~min}$.), after which lactate release returned to baseline values. No significant differences were abserved between both genotypes throughout the protocol (Figure $2 \mathrm{~b}$ ). 


\section{Unraveling the signaling pathways involved in FGF-1 mediated cardi- ac protection}

Cardiac-specific FGF-1 overexpression results in a marked cardioprotective effect on both functional recovery and cell surviwal following global myocardial ischemia and reperfusion. Our next goal was to assess the relative activation status of various intracellular signaling pathways that may underly this phenomenon.

In FGF-1 TG control hearts, not subjected to $/ / \mathrm{R}$ (WT and TG, $n=3$ ), both phosphorylated and non-phosphorylated ERK-1/2 were increased, resulting in a normal phospho-ERK/ERK ratio (Figure 3a). In addition, in TG control hearts, PKC-E translocation to the particulate fraction was constitutively enhanced. No differences in $\mathrm{p} 38$ and JNK phosphorylation were found between $W T$ and TG control groups (Figure $3 c$. and $3 \mathrm{~d}$ ). No differences were found in amount of the non-phosphorylated isoform of each of the MAPKs in all experimental groups (data not shown).

Because the differences in cardiac functional recovery were already apparent directly after initiation of reperfusion, we decided to perform a separate experiment in which WT and FGF-1 TG hearts were subjected to 25 minutes of ischemia alone and investigated the effects on MAPK and PKC activation. Twenty-five min of ischemia resulted in enhanced phosphorylation levels of all three MAPK's (ERK-1/2, JNK-1/2, p38). Compared to WT hearts, FGF-1 TG hearts showed higher phospho-ERK/ERK ratio's (Figure 3b). No differences were found for JNK (Figure 3c) and p38 (Figure 3d) activation between both genotypes after induction of ischemia. In addition, PKC- $\varepsilon$ translocation to the particulate fraction was enhanced following ischemia in both experimental groups. The level of PKC- $\varepsilon$ translocation in WT hearts increased to the pre-ischemic level of TG (Figure $3 \mathrm{a}$ ). This was associated with a decrease in cytosolic PKC-E.

When hearts were subjected to 60 minutes of reperfusion, following the ischemic stimulus, the genotype-dependent differences in ERK-activation and PKC translocation completely disappeared (data not shown).

\section{Tyrosine kinase activation underlies FGF-1 mediated cardioprotection}

No intrinsic effects of the agents or DMSO $(0.01 \%)$ were found on cardiac function and $\mathrm{LDH} /$ lactate release, tested during 85 minutes of antegrade perfusion. No significant differences were found between experimental groups for both pre-ischemic systolic (AOF, LVP., LVDP, LV dP/dt..) and diastolic $(L V P$, , LVEDP, and $L V d P / d t$ ) function (Figure 4a-d). Ischemia resulted in a 

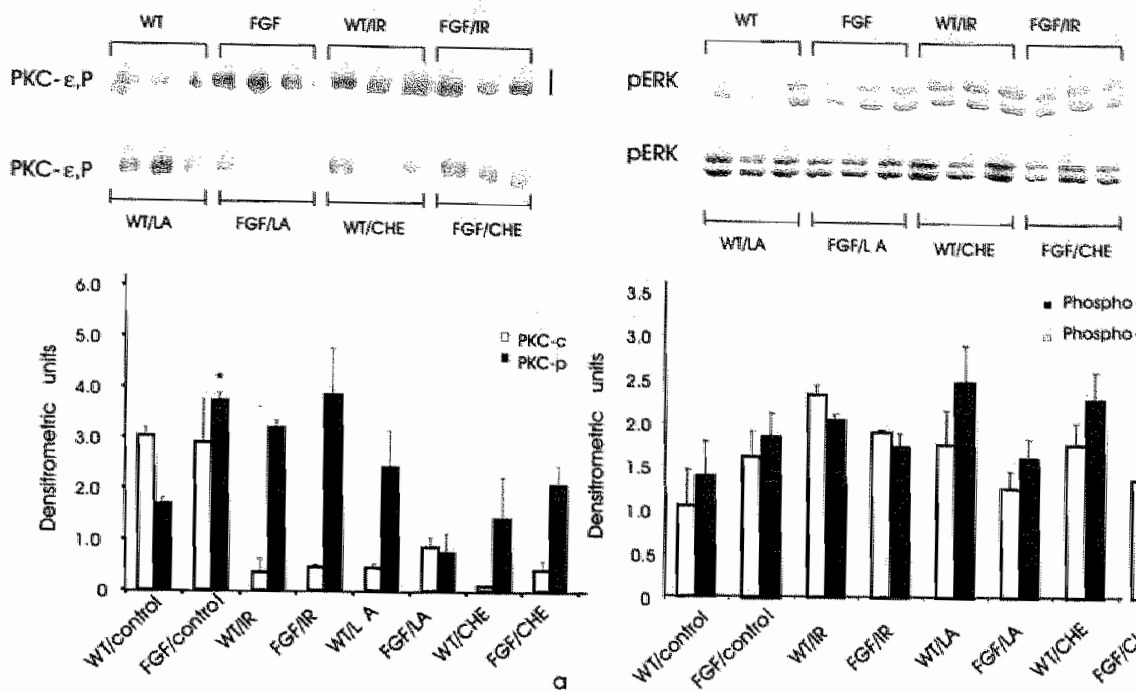

PERK
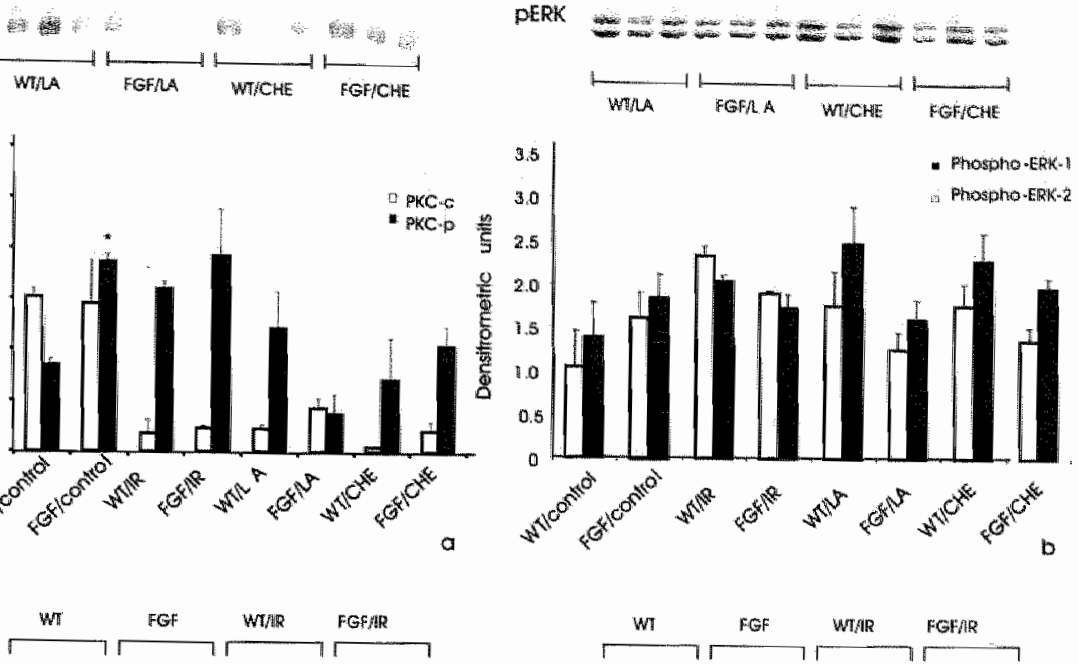

PJNK

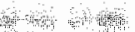

has

pp.38
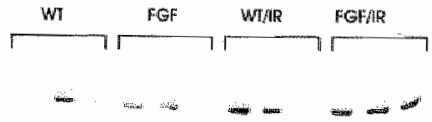

p.JNIK
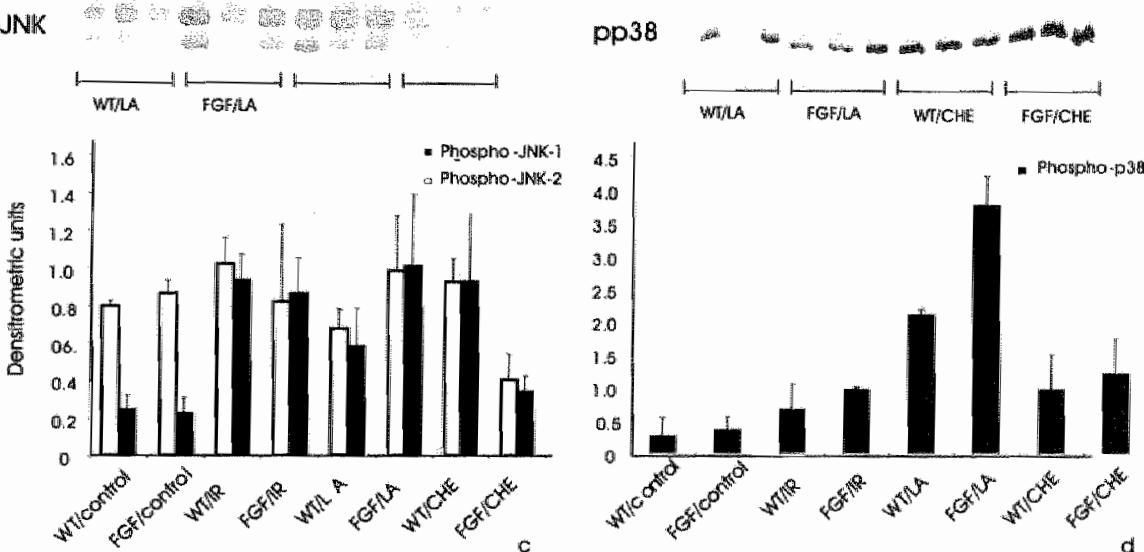

Figue 3 :

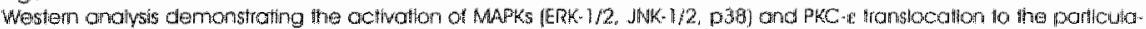

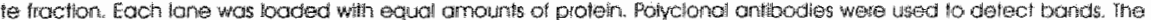

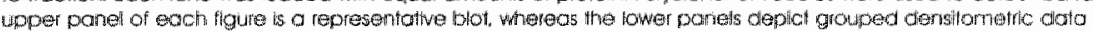

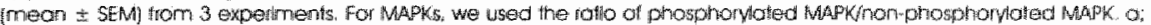

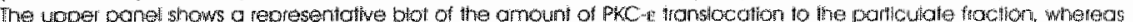

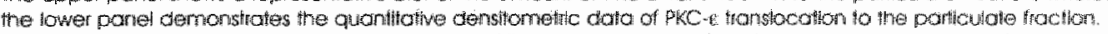

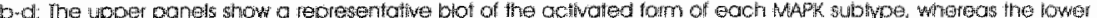

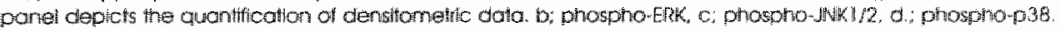
$*=0,0.05$ SOE WT w FGF 


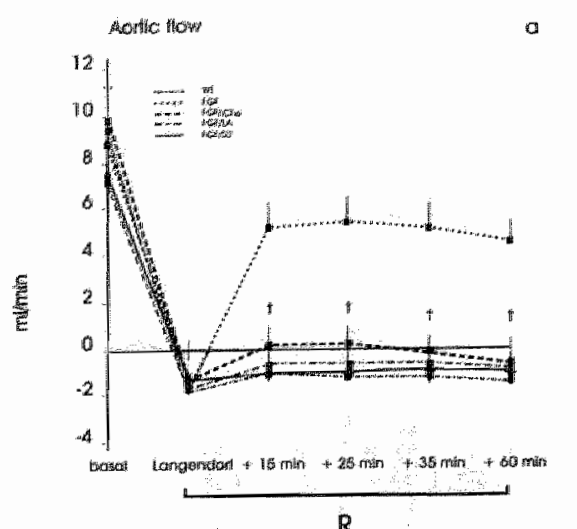

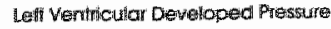

b
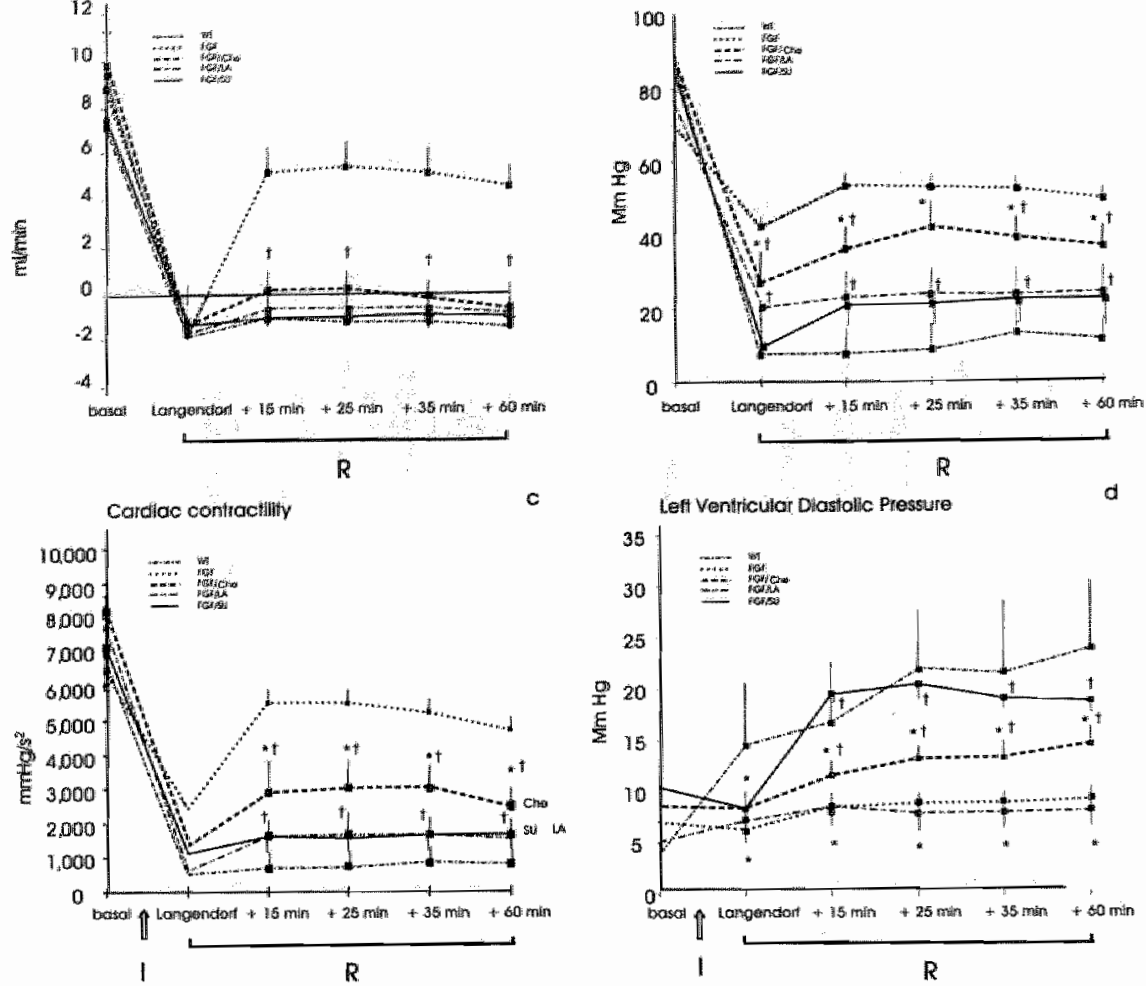

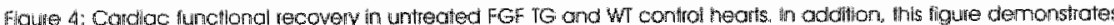

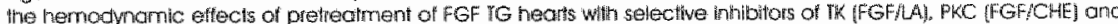

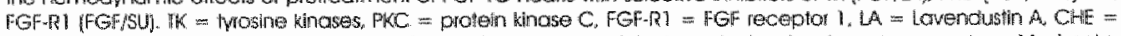

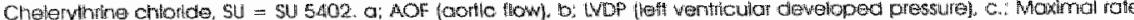

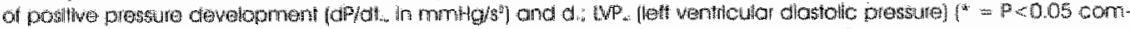

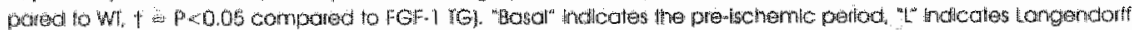

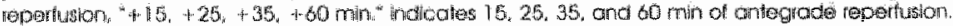

dramatic decrease in both systolic and diastolic cardiac function in WT animals, similar to the non-treated WT animals (data not shown). LA administrantion did not influence WT parameters (data not shown), but completely blocked the hemodynamic protective effects of FGF-1 in TG animals, while postischemic LDH release was comparable to non-treated TG hearts. This indicated that the cardioprotective effect of $\mathrm{FGF}-\mathrm{I}$ on functional recovery, but not necrosis, was dependent on TK activity (Figure 5). Finally, addition of LA reduced the activation of ERK (expressed as phospho-ERK-1/2/ERK-1/2 ratios) in FGF transgenic hearts to the level of untreated WT controls (Figure 3b), indicating that attenuation of cardioprotection in FGF hearts was accompanied by a decreased activation of pERK in these hearts. LA treatment also reduced p.JK activation (Figure $3 c$ ), although no differences were observed 


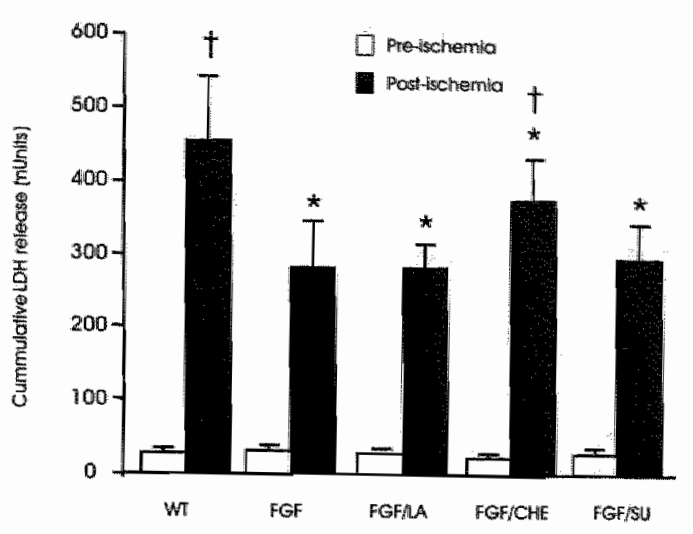

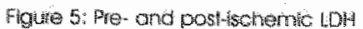

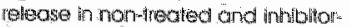 treoted FGF 1 th hearis and wh con-

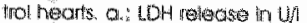

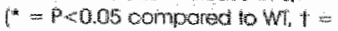 P 0 0.0.5 comparad to FGF- Y Ye]

between both genotypes. Surprisingly, LA administration resulted in a marked upregulation of $\mathrm{p} 38$ activation in both genotypes (Figure 3d).

Pharmacological inhibition of Protein Kinase C (PKC) results in partial abrogation of FGF-1 induced protection.

Compared to the non-treated FGF-1 group, the CHE-treated group (FGF/CHE) showed a moderate but significant decrease in cardiac functional recovery following ischemia and reperfusion, indicating partial abrogation of the FGF-1-induced cardioprotective effect (Figure 4a-d). Similarly, CHE pretreatment in FGF-I transgenic hearts resulted in an increased LDH release following I/R compared to non-treated FGF-1 TG and decreased PKC translocation to the particulate fraction (Figure 3a). Induction of ischemia resulted in decreased cytosolic levels of PKC- $\varepsilon$ in all experimental groups (data not shownj.

\section{Inhibition of FGF-RI attenuates FGF-1 induced protection}

SU5402 did not affect cardiac functional recovery in WT hearts (data not shown). When administered to FGF-1 hearts, SU5404 completely abrogated the FGF- 1 induced protection of cardiac functional recovery that was observed in the non-treated FGF-1 group (Figure 4a-d). As in LA treatment, LDH release in $S U$ treated FGF transgenic hearts remained low following $I / R$ and comparable to untreated FGF TG, despite decreased cardiac functional recovery, indicating that FGF-RI blockade did not prevent FGF-1 mediated protection of cell survival. 


\section{Discussion}

In a murine ex vivo working heart model of ischemia and reperfusion, we found marked cardioprotective effects of cardiac-specific FGF-1 overexpression on cardiac functional recovery and cell survival. The protective effects on cardiac functional recovery are dependent on the activation of FGF-R1, PKC and TK, as pharmacological inhibition of these signaling peptides abolished the cardioprotective effect of FGF-1. FGF-1 mediated protection of cell viability was partially PKC-dependent and completely FGF-RI and TK independent. To our knowledge, this is the first report directly linking FGF-1 mediated cardiac protection to a known IPC pathway.

Several groups observed beneficial effects of FGF-1 during acute myocardial ischemia. Buehler et al. "showed in an in wivo model of regional myocardial I/R that FGF-1 overexpression results in delayed infarct formation, when compared to WT counterparts. This effect proved to be only temporary since the same infarct size was eventually reached, indicating a trophic effect of FGF-I rather than cardioprotection due to increased collateral flow and limitation of infarct size. This is in agreement with data from our group, demonstrating that coronary artery ligation in these FGF-1 transgenic mice does not result in attenuation of infarct size, one week after permanent coronary artery ligation.6 The trophic effects of FGF-1 were previously reported by Htun et al, who demonstrated that FGF-I administration to pigs prior to myocardial ischemia mimicked a state of ischemic preconditioning. ${ }^{8}$

\section{Intracellular signaling pathways involved in FGF-mediated protection}

Several mechanistic studies have been performed, mainly focusing on the denomination of the signaling pathways involved in $\mathrm{FGF}^{2}-2$ mediated protection. In these studies, strong involvement of TK and PKC was demonstrated. Previously, Padua et al. ${ }^{\text {th }}$ showed in an ex vivo rat heart model of global myom cardial $l / R_{\text {, that }}$ pretreatment with FGF-2 improved cardiac functional recovery in a PKC and TK dependent manner. Recently, Sheikh et al." elegantly demonstrated that FGF-2 overexpression increased cardiomyocyte viability in an ex wivo cordiac ischemia and reperfusion model. FGF-2 overexpression was associated with constitutively enhanced phosporylation levels of p38 and pJNK, in addition to enhanced expression of PKC- $\alpha$ and $\varepsilon$. Surprisingly, no effects on cardiac functional recovery following $\mathrm{I} / \mathrm{R}$ were reported, while exogenous FGF-2 administration did result in moderately enhanced functional recovery. Also Bogoyevitch et al. ${ }^{2 *}$ demonstrated PKC $-\alpha,-\delta$ and $\varepsilon$ upregulation after FGF-1 administration to isolated cardiac myocytes. 


\section{FGF-1 mediated cardioprotection}

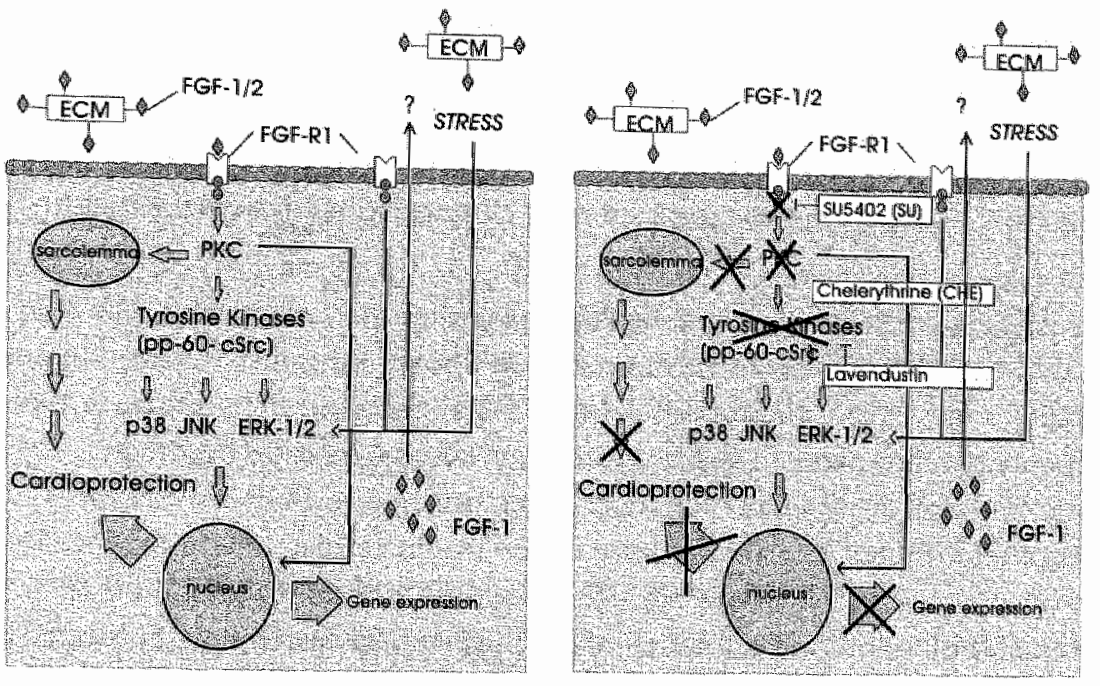

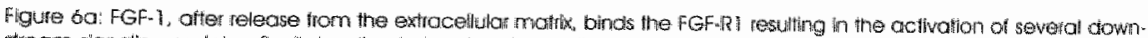

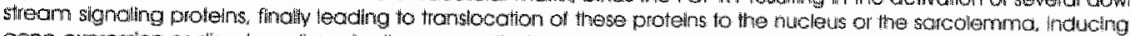
gene expression on difect cordiopotaction, raspertively.

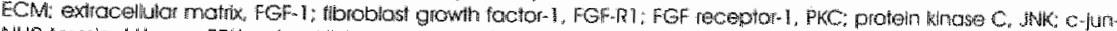
NH2- ferminal knose. ERk extrocellular responswe knose

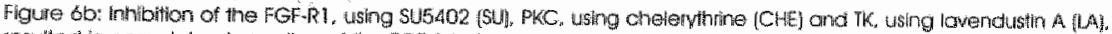

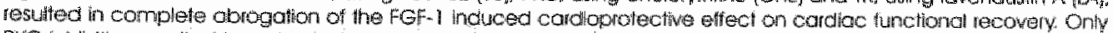

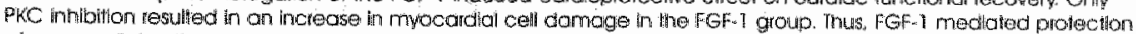

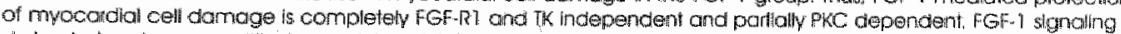
during scherric preconalifoning and the inhliotiors

We and others showed in different models that the protective effects of FGF 1 and FGF-2 ${ }^{19}$ can be completely abrogated by selective PKC inhibition.

Although this indicates that PKC is required for FGF-1-mediated cardioprotection, it does not necessarily imply that PKC translocation is depending on activation of the FGF-RI. It merely suggests that PKC translocation is a prerequisite and indispensable for the preconditioning phenomenon to occur.

There is some evidence that FGF-1 induced protection is TK mediated, as is FGF-2 mediated protection. ${ }^{10}$ Htun et al. ${ }^{8}$ showed that FGF-1 administration and its binding to FGF-RI induces TK activation. We demonstrated that FGF1 induced protection of cardiac functional recovery could be completely abrogated by administration of LA, indicating that TK activation is necessary for FGF-1 induced cardioprotection. However, the FGF-1 induced protection of cell viability during $I / R$ is not TK dependent, as TK inhibition did not affect $\mathrm{LDH}$ release in FGF-1 TG hearts.

We demonstrate that administration of SU5402, a FGF-RI blocker, resulted in complete abrogation of protection of function. This is in agreement with

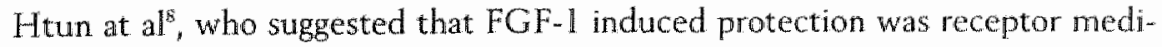


ated. Surprisingly, the protective effects of FGF-I on cell survival could not be inhibited by FGF-RI blockade, indicating that prevention of $1 / \mathrm{R}$-induced cell death is, at least partially, dependent on intracellular FGF-1.

\section{Effects of FGF-1 on cardiac cell survival during ischemia and reperfu- sion}

In the FGF-1 group, LDH release during reperfusion was attenuated when compared to WT animals. However, as already shown previously ${ }^{21}$, this release accounts for only $8 \%$ of the total LDH content of the heart. Therefore, in this model only a minor part of the total cardiomyocyte population becomes necrotic. The relatively small reduction in necrosis due to FGF-1 overexpression can therefore not explain the large difference in cardiac functional recovery that was observed between both genotypes. Interestingly, inhibition of PKC translocation, but not inhibition of FGF-RI and TK activation, enhanced cell death in FGF-1 TG animals. This suggests that FGF-1 dependent protection on cell survival following $\mathrm{I} / \mathrm{R}$ is partially PKC dependent, but completely FGF-RI and TK independent.

FGF-1 is known to decrease apoptosis in an in vitro model of hypoxia and reoxygenation. ${ }^{2}$ However, it seems unlikely that delayed activation of programmed cell death is the mechanism underlying the protective effects on cell damage and function that we observed, since the protective effects of FGF-1 became apparent immediately after starting reperfusion and completion of the sequential activation of the cascade involved in the process of apoptosis would take longer than 25 minutes. In addition, we performed a TUNEL assay on FGF-1 TG and WT hearts (data not shown), which showed no signs of apoptosis after 60 minutes of reperfusion.

Because myocyte necrosis or apoptosis cannot account for the large functional differences in cardiac functional recovery due to FGF-I overexpression, we hypothesized that FGF-I attenuates myocardial stunning, a process occurring in the reperfused heart, in which certain areas of the heart that were previously ischemic, are still viable but not contracting. ${ }^{29}$ Several groups demonstrated that stunning can be prevented by IPC. ${ }^{30.31}$ Furthermore, Htun et all demonstrated that FGF-I induces a state that mimicks IPC. The fact that TK and FGF-RI inhibition did not attenuate the FGF-1 mediated protection of cell survival further underlines this hypothesis.

\section{Effects of FGF-1 on ancerobic metabolism}

In our model, we observed a lactate washout peak 5 minutes after the start of 
reperfusion, indicating anaerobic glycolysis during the ischemic phase. Lactate release returned to baseline within 10 minutes after the start of reperfusion. This indicates that after 10 minutes, little anaerobic metabolism is present in the reperfused heart and the myocardium is adequately perfused in both genotypes. One might hypothesize that lactate release would remain elevated longer in the WT group when compared to FGF-1 animals, because FGF-1 acts as a vasodilator ${ }^{32}$ facilitating the re-opening of coronary arterioles and capillaries. However, both at baseline and throughout the rest of the experimental protocol no differences in lactate release between both genotype groups could be observed. In addition, no effects on lactate release could be observed in inhibitor-treated WT and TG hearts.

\section{Possible implications for future growth factor therapy}

In the majority of both animal and human studies, $\mathrm{FGF}-1$ and FGF-2 overexpression or exogenous administration were demonstrated to be beneficial for the heart in situations of acute ischemia. "The results of this study suggest that pre-ischemic FGF-1 administration might protect the heart from subsequent ischemic damage. In addition, one could speculate that administration of FGF-1 to cardioplegia solutions during cardiac surgery might further reduce ischemia and reperfusion-induced damage.

One of the limitations of this model is that FGF-1 is present before the ischemic period is commenced, which does not resemble the human situation of reperfusion during myocardial infarction. Additional studies are required to investigate whether $F G F-1$ also protects cardiac function and reduces reperfusion damage when administered only during restoration of flow. If this hypothesis could be confirmed, new treatment options are within reach. One of these is to administer FGF- 1 simultaneously with thrombolytic therapy in patients suffering from acute myocardial infarction, with the purpose to reduce infarct size and improve cardiac functional recovery.

\section{Conclusions}

Cardiac specific FGF- $\mathbb{1}$ overexpression results in augmentation of cardiac functional recovery and attenuation of reperfusion-induced myocardial cell necrosis during ischemia and reperfusion. The protective effects attributed to FGF-I were linked to a known IPC pathway, by demonstrating that protection is FGF-RI, PKC and TK dependent. (Figure 6a and b) These findings might have important implications for future growth factor therapy, and prevention of reperfusion induced damage. 


\section{References}

1. Battegay EJ: Angiogenesis: mechanistic insights, neovoscular diseases, and therapeutic prospects. J Mol Med 1995; 73:333-346.

2. Engelmann $\mathrm{GL}$, Dionne $\mathrm{CA}_{i}$. Jaye MC: Acidic fibroblest growth factor and heart development; role in myocyte proliferation and capillary angiogenesis. Clic Res 1993; 72:7-19.

3. Zhu $X_{i}$ sosse $J$, McAllister $D$, ef al.: Evidence that fibroblast growth factors 1 and 4 participate in regulation of cardiogenesis. Dev Dyn 1996;207:429-438.

4. Schumacher $\mathrm{B}$, Pecher $\mathrm{P}$, Specht von $\mathrm{BU}$, al.: Induction of neoangiogenesis in ischemic myocardium by human growth factors. Circulation 1998;97:645-650.

5. Fernandez B, Buehler A, Wolltram $S$, al al.: Transgenic myocardial overexession of Fibroblast growth factar-1 increases coronary artery densify and branching. Circ Res 2000;87:207213.

6. Palmen $M$, Doemen MJAP, Buehler $A$, et al.: Impaired cardiac remodeling and function after myocardial infarction in FGF-1 transgenic mice. Circulation 1999; 100:250A.

7. Cuevas $P$, Reimers D, Carceller $F$, et al.: Fibroblast growth factor- 1 prevents myocardial apoptosis triggered by ischemia reparfusion injury. Eur J Med Res 1997;2:465-468.

8. Htun $P_{1}$ Ito WD, Hoefer IE, ef al: Intramyocardial intusion of FGF-1 mimics ischemic precondifloning in pig myocardlum. J Mol Cell Cardlol 1998;30:867-877.

9. Buehler $\mathrm{A}_{\text {" }}$ Martire A, Zimmermann $\mathrm{R}$ et al.: Angiogenesis-independent cardioprotection in FGF -1 transgenic mice. Cardlovasc. Res 2002;55:768-777.

10. Padula RR, Merle P-L, Doble BW, et al.: FGF-2 induced negative inotropism and cardioprotection are inhibited by chelerythrine: involvement of sarcolemmal calcium-independent protein kinase C. J Mol Cell Cardiol 1998;30:2695-2709.

11. Sheikh F, Sontag DP, Fandrich $\mathrm{RR}_{\text {, }}$ ef al.: Overexpression of FGF-2 increases cardiac myocyte viability after injury in isolated mouse heart. Am J Physial 2001;280:H1039-H1050.

12. Ping $P$, Zhang $J_{\text {, }}$ Qlu $Y$, et al.: Ischemic preconditloning induces selective translocation of protein kinase $\mathrm{C}$ isoforms epsilon and $\mathrm{n}$ in the heart of concious rabbits without subcellular redistrlbution of total protein kinase $C$ activilty. Circ Res 1997;81:404-414.

13. Baines $\mathrm{CP}_{\text {, Wang }} \mathrm{L}_{r}$ Cohen $\mathrm{MV}$, et al.: Protein tyrosine kinose is downstream of protein kinase C for ischamic preconditioning's anti-infarct eftact in the rabbit heart. $\mathrm{J}$ Mol Ceit Cardiol 1998; 30:383-392.

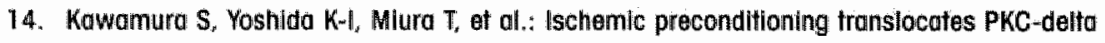
and epsilon which mediate functional protection in isolated rat heart. Am J Physiol $1998 ; 275: 2266-2271$.

15. Miller DL, van Winckle DM: Ischemlc preconditioning limits infarct size following ischemia and reperfusion in in situ mouse hearts. Cardiovasc Res 1999;42:680-684.

16. Pass JM, zheng $Y$. Wead WB, et all: PKC-epsilon activation induces dichotomous cardiac phenotypes and modulates PKC-epsilon-RACK interactions and RACK expression. Am J Physiol 2001:280:946-955.

17. Tlan $R_{x}$ Mloo $W$, Spindler $M$, et al.: Long-term expression of proteln kinase $C$ in adult mouse hearts improves postlschemlc recovery. Proc Natl Acad Sci USA 1999;96:13536-13541.

18. Ping $P$, Zhang J, Zheng $Y-T$, et al.: Demonstration of selective protein kinase C-dependent actlvation of Src and Lck tyrosine kinases during ischemic preconditioning in concious rabbits. Circ Res 1999;85:542-550.

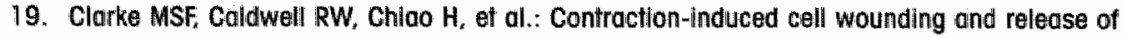
fibroblast growth factor in heart. Circ Res 1995;76:927-934. 
20. Liu $L_{x}$ Pasumarthi KB, Padua $R R$ et al.: Adult cardiomyocytes express tunotional high-affinity receptors for basic fibrablast growth factor. Am J Physiol 1995,268, 1927 1938.

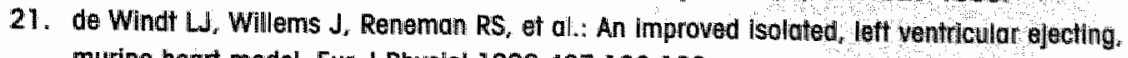
murine heart model. Eur J Physiol 1999;437:182-190.

22. de Windt $L$, Willems $J$, Roemen THM, et al.: Ischemia-repertused Isolated working mouse hearts: membrane damage and type IIA phosphoilpose A2. Am J Physiol 2001,280:2572. 2580.

23. Apstein CS, Puchner SE, Brachfeld N: Improved automated lactate determination. Anal Biochem 1970;38:20-34.

24. Bergmeyer $\mathrm{HU}$, Bernt $\mathrm{E}$ : UV assays for lactate dehydrogenase with pyruvate and $\mathrm{NADH}$. Weinheim, Verlog Chemie, 1974, vol 2.

25. Mohammadi $M$, McMahon $G$, Sun $L$, at all: Structures of the tyrosine kinase domain of fibroblast growth factar receptor in complex with inhibitors. Science 1997; 276:955-960.

26. Heeneman $S$, Haendeler $J$, Saito $Y$, ef al.: Anglotensin II Induces transactivation of two populations of the PDGFb-receptor: Key role for the p66 adaptor protein Shc. J Blol Chem 2000:275:15926-15932.

27. de Windt LJ, Lim HW, Haq S, et al.: Galcineurin promotes pratein kinase $\mathrm{C}$ and $\mathrm{C}$-Jun NH2. terminal kinase activation in the heart. J Blol Chem 2000;275:13571-13579.

28. Bogoyevitch MA, Glennon PE, Andersson MB, et al.: Endothelin-1 and fibroblast growth factors stimulate the mitogen-activated protein kinase signaling cascade in cardlac myocytes. J Biol Chem 1994;269:1110-1119.

29. Braunwald $E$, Kioner RA: The stunned myocardium: prolonged, postischemic ventricular dysfunction. Circuliation 19:82;66:1146-1149.

30. Cohen MV, LIU GS, Downey JM: Preconditioning causes improved wall motion as weil as smaller infarcts ofter transient coronary acclusion in rabbits. Circulation 1991;84:341-349.

31. Sumeray MS, Yellon DM: Ischaemic preconditioning reduces Infarct size following global ischaemia in the murine myocardlum. Bas Res Cardiol 1998:93:384-390.

32. Zhou M, Sutliff RL. Paul RJ, ef al.: Fibroblast growth factior 2 controls vascular tone. Nat Med $1998 ; 4: 201-207$. 


\section{Chapter 7}

\section{General discussion and Future outlook}




\section{Acute myocardial ischemia and remodeling after myocar- dial infarction}

Rupture of an intracoronary atherosclerotic plaque leads to acute thrombotic coronary artery occlusion, which in turn results in myocardial ischemia. When reperfusion of the area at risk is not occurring, this results in necrotic myocardial cell death and myocardial infarction (MI). When reperfusion takes place, either spontaneously or iatrogenic, the reperfused myocardium suffers from reperfusion damage. While reperfusion therapy, using thrombolytics, like tPA, is the standard treatment for patients suffering from acute myocardial ischemia, to date, treatments to reduce the anount reperfusion damage, using for instance anti-apoptotic substances or growth factors, are still in an experimental stage. The administration of growth factors like FGF-1 and $1 \mathrm{GF}-1 \mathrm{might}$ attenuate this reperfusion-induced myocardial cell damage, thereby preserving myocardial function. (Figure 1)

When reperfusion is not accomplished (in time), an acute myocardial infarction accurs. Scar tissue is formed when necrotic cardiomyocytes are degraded and the remote myocardium compensates for the loss of contractile tissue by hypertrophy of the viable cardiomyocyte population. In addition to growth factors, several other neurohumoral factors influence hypertrophy, like the

Sequence of events following a thrombotic coronary artery occlusion and possible ways to intervene, to prevent or reduce myocardial damage

Thrombotic coronary artery occlusion

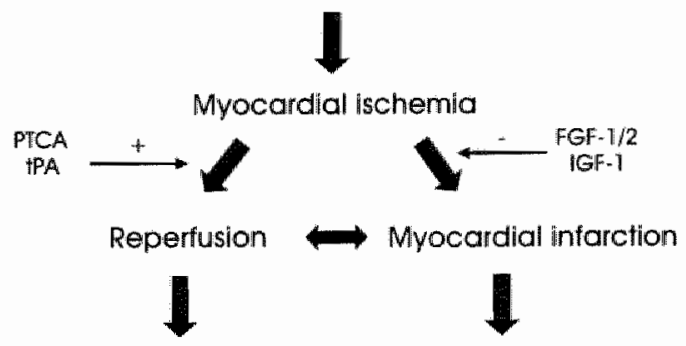

Reperfusion damage

Cardiac remodeling

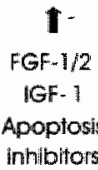

$$
\begin{gathered}
\text { 1+ } \\
\text { FGF-1/2 } \\
\text { IGF- } 7 \\
\text { VEGF } \\
\text { GMT-CSF } \\
\text { MICP-1 }
\end{gathered}
$$

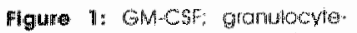

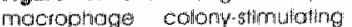

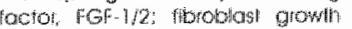

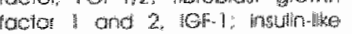
growh toctor-l, Mep-1: morocoyles

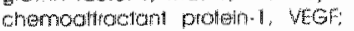

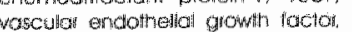
FTCA: perculanous ianshiming

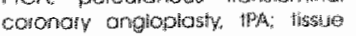
pilasminogen activator.

- mogative or firthiblory offect 4. posthe or sirnuldoty affect 
RAS system. While initially cardiomyocyte hypertrophy compensates for the loss of contractile tissue, eventually a pathological type of hypertrophy (inappropriate remodeling) occurs in response to the constitutively active RAS system, among other factors. This eventually results in ventricular dilatation and cardiac failure. Currently, therapy after $\mathrm{MI}$ is based on the reduction of oxygen demand by the myocardium (beta-adrenergic receptor blockade), or diminishing the hyperthrophic overdrive on cardiomyocytes by inhibiting the RAS system (ACE-inhibitors or AT- II antagonists). Growth factors, like IGF1. initiate a more physiological type of hypertrophy (appropriate remodeling) and could therefore be used as a therapy in patients suffering from myocardial infarction and cardiac failure.

In order to nurture these hypertrophying cardiomyocytes and to allow adequate scar formation in the infarcted tissue, new vessels are required (both arterioles [arteriogenesis] and capillaries [angiogenesis]]). Growth factors like FGF-1 and IGF-1 (among other factors like VEGF and MCP-1) play a pivotal role in these processes and stimulate an adequate remodeling response.(Figure 1) In this thesis, the role of FGF-I and [GF-I in acute myocardial ischemia and adaptation after chronic myocardial infarction (MI) is investigated. For this purpose, we used two models of myocardial ischemia. To investigate the effects of FGF-1 and IGF-1 during acute myocardial ischemia, we used an ex vivo model of ischemia and reperfusion. To study the effects of these growth factors on chronic Ml, we used a model of regional MI, induced by coronary artery ligation.

\section{FGF-1 and IGF-1 during chronic myocardial infarction}

In two transgenic mouse models, a model of heterozygous $I G F-1$ deficiency and a model of cardiac-specific FGF-1 overexpression, MI was induced by ligation of the left anterior descending coronary artery. One week after induction of MI, cardiac function was measured, using different techniques in each study (left ventricular pressure measurements in IGF-1 deficient mice and the (more sophisticated) cardiac output measurements, using an electromagnetic flow probe in FGF-1 transgenics). Subsequently, general architecture, infarct size and (cellular) composition of the myocardium was investigated using different (immuno-) histochemical staining techniques.

\section{The role of FGF-1 during myocardial infarction}

The infarcted FGF-I transgenic animals demonstrated a deterioration of cardiac function following $\mathrm{MI}$ and an altered cardiac remodeling response to induc- 
tion of MI. The main differences in cardiac architecture and composition were a decrease in collagen deposition in the scar tissue and an enhanced rate of apoptosis of non-myocytes in the infarcted tissues. In addition, an enhanced hypertrophic response of the interventricular septum. No differences were found in cellular proliferation, capillary density and infarct size.

The finding that FGF-l overexpression resulted in worse functional characteristics was unexpected, since several studies demonstrated a preservation of cardiac function, when either FGF-1 or FGF-2' was administered during the development of MI and the subsequent remodeling phase. These studies focused on the angio/arteriogenic properties of FGF-I and 2 and the positive results are mainly ascribed to the enhanced collateral flow, causing a reduction in infarct size. ${ }^{2.8}$ In some studies, this resulted in enhanced myocardial function after MI. ${ }^{1,5}$ It is known that, in the absence of ischemia FGF- 2 is negatively inotropic in vitro" and ex vivo. ${ }^{10}$ However, the SHAM-operated FGF-1 transgenic mice did not display an alteration in functional characteristics of the left ventricle. Therefore, we hypothesized that FGF-I unfavorably alters the architecture of the infarcted ventricle. Indeed, we found differences in the composition and architecture of the left ventricle.

The finding that cardiac-specific FGF-1 overexpression did not result in a decreased infarct size is in line with the recently published observations by Buehler et al." , who demonstrated in the same transgenic mouse line that FGF-1 postponed, rather than prevented infarct formation. At 75 minutes, infarct size was significantly smaller in FGF-I transgenic mice, compared to WT littermates. However, when the period of ischemia was extended to 90 minutes, infarct size was similar in both experimental groups.

Fernandez et all ${ }^{12}$ characterized this mouse strain and demonstrated arteriogenesis, an increase in epicardial vessels, rather than increased numbers of capillaries in this mouse strain. Apparently, this increased number of arterioles and the more pronounced branching pattern of these arterioles does not result in increased collateral flow in this mouse line. This is in agreement with our results, demonstrating no differences in capillary density between both genotypes and no reduction in infarct size between FGF-1 transgenic animals and wild-type (WT) controls.

Because infarct size was similar in both genotypes, the difference in cardiac function following MI in favor of the WT controls must be explained by other factors related to differences in cardiac architecture. Indeed, we found differences in several parameters of remodeling. FGF- I transgenic mice showed an enhanced hypertrophic response of the interventricular septum after MI. This is in agreement with studies in literature, reporting a pro-hypertrophic effect of FGFs on cardiomyocytes, both in vitro and in vivo. ${ }^{13.16}$ 
In addition, collagen deposition was decreased in the infarcted tissue of FGFI transgenic mice, while the number of fibroblasts producing collagen was similar in both genotypes. Therefore, the reduced amount of collagen might be explained by the FGF-I related induction of MMP's, degrading the collagen deposited in the infarcted area. ${ }^{17.19}$ The reduced amounts of collagen in the infarcted area could predispose to the phenomenon of "systolic stretch", in which the infarcted area shows paradoxical outward movement when the ventricle contracts. This unfavorably affects cardiac architecture and therefore the ventricular contraction pattern, resulting in a decreased maximal output, observed in the FGF-1 transgenic mice. However, the amount of diastolic dilation of the left ventricle was not increased in the infarcted FGF-l transgenic group.

Furthermore, we found increased apoptosis rates in the infarct area of the FGF-1 transgenics. At first sight, this is a surprising finding, since both FGF$\mathrm{I}^{20}$, and $\mathrm{FGF}-2^{21}$ have been shown to decrease apoptosis during acute myocardial ischemia. This phenomenon of increased apoptosis rates may, however, be explained by results of the study by Buehler et al." As FGF-I postpones infarct formation, it might also postpone the formation of scar tissue:

Therefore, at the time of measurement the formation of scar tissue might not have progressed to the same level as the WT controls, explaining the enhanced levels of apoptosis in the developing scar tissue. The relevance of this increased levels of apoptosis for cardiac function is unclear, and needs further investigation. Whether or not the enhanced hypertrophic response in FGF-1 transgenic mice could affect cardiac function also remains to be determined.

\section{The role of IGF-1 in chronic myocardial ischemia}

Heterozygous IGF-1 deficiency was associated with a proportional decrease in body and organ weight resulting in equal heart weight to body weight ratios. These observations underline the general growth promoting role of IGF- ${ }^{22.25}$ In literature, IGF-1. overexpression resulted in improvement of cardiac performance after induction of MI. ${ }^{26.29}$ In the heterozygous IGF-I deficient mice, no differences in cardiac function were observed between both genotypes. Induction of MI resulted in a similar decrease in cardiac performance. Apparently, a $40 \%$ reduction in IGF-1 plasma levels is not sufficient to cause significant differences in cardiac function. However, we found interesting structural differences between the infarcted heterozygous IGF-I deficient mice and the WT controls.

IGF-1 deficient mice showed increased rates of apoptosis in the infarcted myocardium. This is in agreement with results in literature demonstrating the 
protective effects of IGF-1 against apoptotic cell death ${ }^{22330.32}$ In addition, IGFI deficiency was associated with a blunted hypertrophic response of the interventricular septum. Also in literature, the pro-hypertrophic effects of IGF-I have been extensively described. ${ }^{28,29,33.35}$ However, Li et al. ${ }^{26}$ described that hypertrophy of the remote myocardium during $\mathrm{MI}$ is attenuated due to IGF-I overexpression, together with an attenuation of left ventricular dilatation. In literature, IGF-1 overexpression was associated with decreased fibrosis of the viable remote myocardium. ${ }^{36,37}$ In addition, IGF-1 is known to induce a more physiological type of cardiac hypertrophy devoid of patchy replacement fibrosis of the pathologically hypertrophying myocardium. ${ }^{36}$ In our study, we found that collagen deposition in the infarcted and the non-infarcted tissues was similar in both genotypes. Apparently, collagen deposition is not influenced by reduced circulating IGF-1 levels.

Infarct size was similar in IGF-1 deficient mice and WT littermates, indicating that reduced IGF-1 levels have no influence on collateral flow and does not influence infarct size.

\section{FGF-1 and IGF-1 in myocardial ischemia and reperfusion}

In order to study the effects of enhanced levels of FGF 1 and IGF-1 on cardiac functional recovery and cell death following ischemia and reperfusion, we used an isolated ejecting murine heart model of $\mathrm{I} / \mathrm{R}$. Both growth factors demonstrated a protective potential in this setting. To delineate the intracellular signaling pathways involved in this phenomenon, we pharmacologically blocked several intracellular signaling proteins that could play a role in $\mathrm{FGF}_{-1}$ and IGF-1 mediated protection against ischemia and reperfusion induced damage.

\section{Cardiac protection by IGF-1 during ischemia and reperfusion}

Reduced circulating IGF-I levels were not associated with changes in cardiac functional recovery following $I / R$. Therefore, we concluded that $40 \%$ reduction in IGF-1 plasma levels does not alter the hearts tolerance to ischemia. However, pre-ischemic administration of IGF-1 $(65 \mathrm{nM})$ resulted in enhanced cardiac functional recovery and reduced $\mathrm{I} / \mathrm{R}$ related cell death. In addition, we found that inhibition of Phosphatidyl-inositol-triphosphate-kinase (PI-3K) resulted in an abrogation of cardiac protection. Finally, we demonstrated that the inhibition of protein kinase C (PKC) could block the [GF-1 mediated protective effects (figure $2 \mathrm{a}$. and $\mathrm{Zb}$.). Therefore, we conclude that IGF- I mediated protection against ischemia and reperfusion induced damage is PI-3K and PKC dependent. The protective potential in this setting was described earlier 
|GF-I mediated cardioprotection

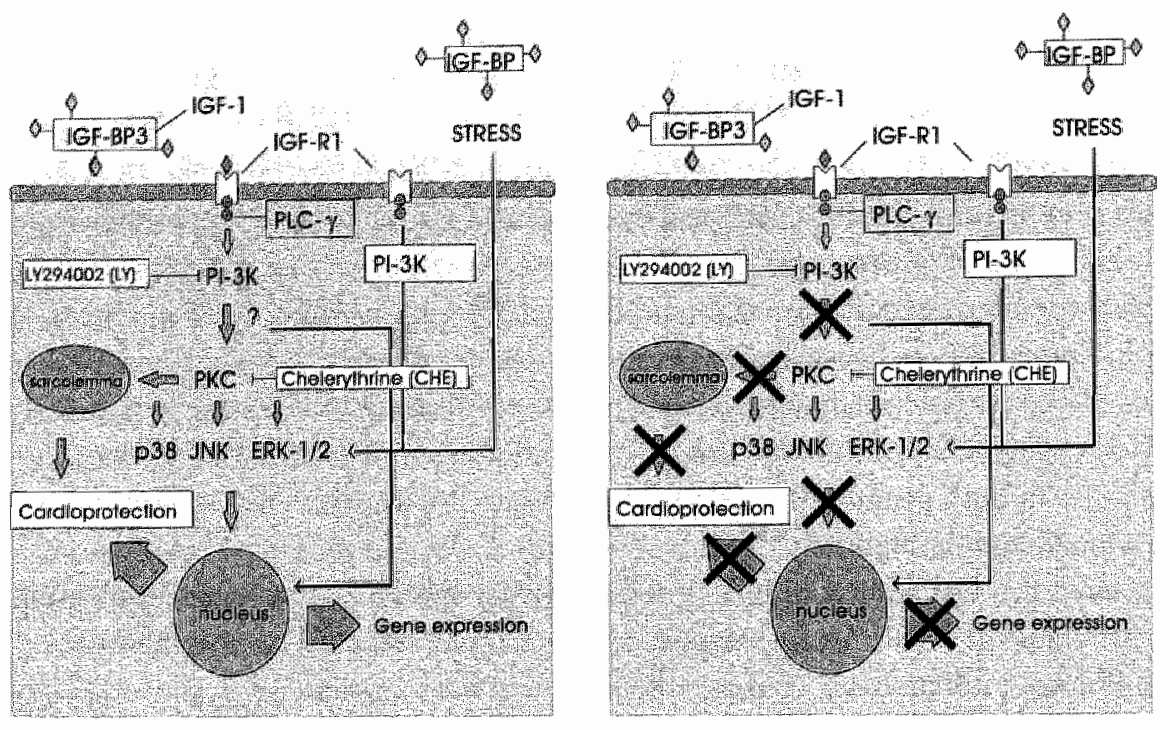

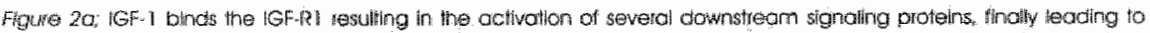

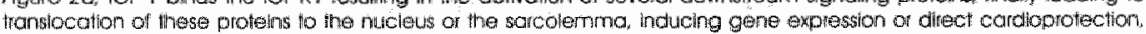
serpectively.

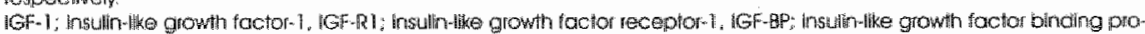

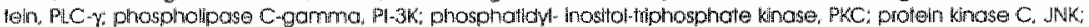

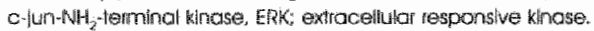

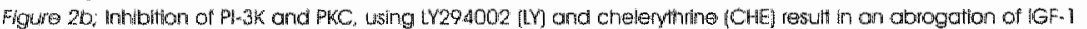
incluced condlioprotection:

in literature by Otani et al. ${ }^{38}$, who demonstrated in a rat model of $\mathrm{I} / \mathrm{R}$ that cardiac functional recovery was enhanced when $I G F-I$ was administered before the ischemic period was commenced. This was associated with a decrease in necrotic cell death, when compared to untreated controls. The protective effects of IGF-1 in this study could be completely abrogated by the addition of a PI-3K inhibitor. Apparently, PI-3K is required for IGF-I mediated protection. Similar protective effects of IGF-I were shown by Friehs et al. ${ }^{39}$ These are in line with our observations. Similar protective effects could be acqui$\mathrm{red} / \mathrm{accomplished}$ by using insulin, with the same degree of PI-3K dependence. However, these effects were shown not to be dependent on PKC. Because the protective effects of insulin could mask the effects of IGF-1 administration, we did not add insulin to the perfusion buffer.

\section{Cardiac protection by FGF-1 during ischemia and reperfusion}

We demonstrated a spectacular reproducible and consistent cardioprotective 
FGF-1 mediated cardioprotection
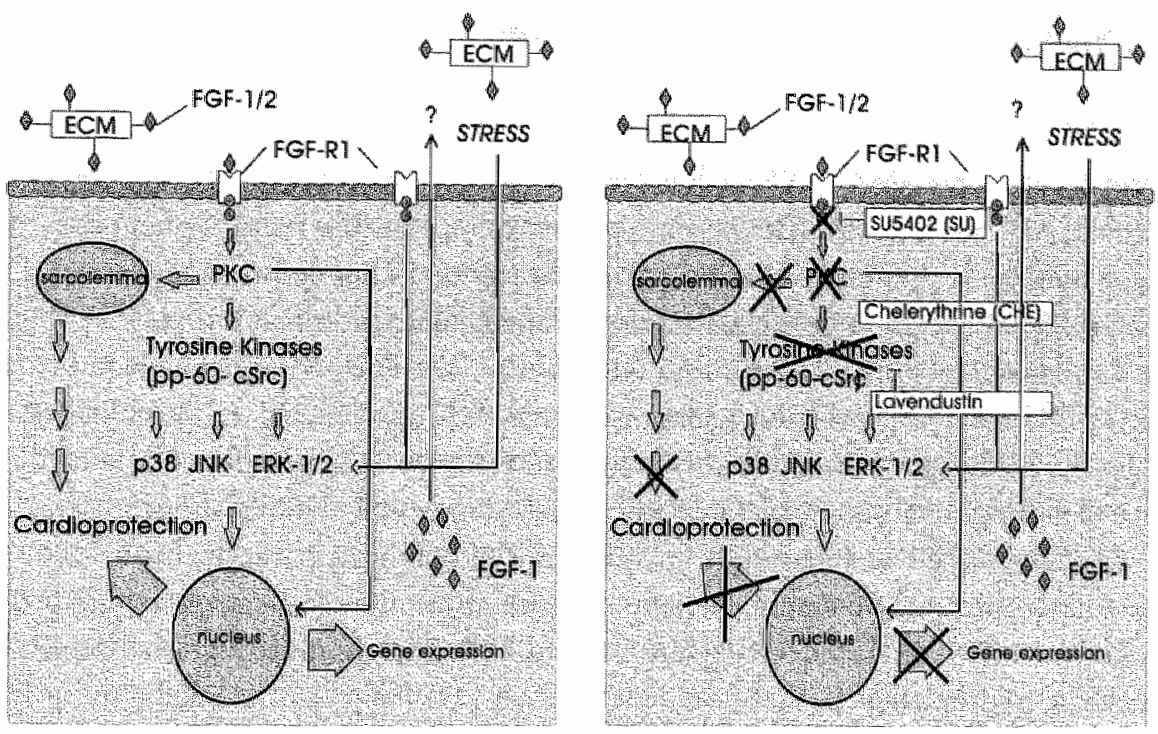

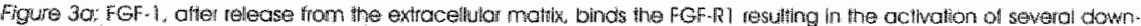

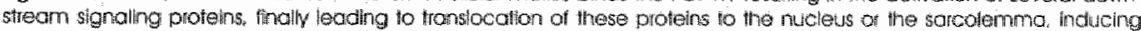
gere expression or dillect catcioprotectlon, yespectively:

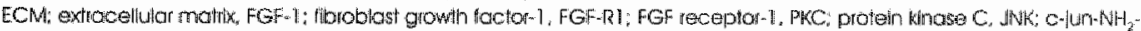
terminal kinose. ERk extracellullor sespomive kinose.

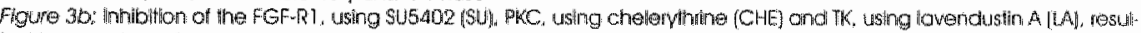

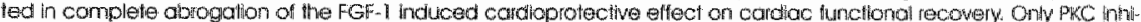

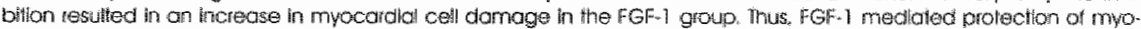

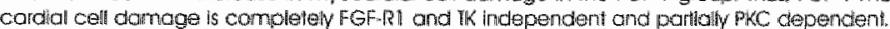

effect of FGF-1 overexpression in an isolated mouse heart model of $\mathrm{I} / \mathrm{R}$. Cardiac functional recovery was preserved and necrotic myocardial cell death was attenuated, through a FGF-receptor-1 (FGF-RI), PKC and tyrosine kinase (TK) dependent pathway.

In literature, several studies demonstrated the cardioprotective nature of several of the FGF family members. FGF-2 decreased apoptotic cell death both in wivo and in vitro. ${ }^{\text {a }}$ Administration of FGF-2 prior to $\mathrm{l} / \mathrm{R}$ in an isolated rat heart model reduced myocardial cell death through a PKC and T'K dependent pathway. ${ }^{10}$ In addition, administration of $F G F-2$ prior to a prolonged ischemic period could reduce infarct size in a canine model of myocardial ischemia and reperfusion. ${ }^{4,4.42}$ Furthermore, FGF-2 therapy reduced the reperfusion damage to the ischemic-reperfused myocardium, by reducing the neutrophil infiltration. $^{43}$

Also FGF-1 proved to be cardioprotective. FGF-1, like FGF-2 reduces apoptotic cell death of cardiomyocytes in vitro. ${ }^{20}$ Htun et al ${ }^{44}$ demonstrated in a porcine model of $\mathrm{I} / \mathrm{R}$ that FGF-I induced an ischemic preconditioning respon- 
se protecting the myocardium from subsequent ischemic damage.

Furthermore, Buehler et al. "recently demonstrated in a murine model of FGF-1 overexpression, that infarct development is delayed, but not prevented during ischemia and reperfusion, since with increasing the ischemic time, infarct size increased to $\mathrm{WT}$ values.

To unravel the intracellular signaling pathways responsible for this phenomenon, and with the notice that FGF-1 might mimic ischemic preconditioning, we selectively inhibited several intracellular signaling proteins that play a pivotal role in preconditioning. To find out whether the FGF-RI was involved in FGF-I mediated protection against ischemia and reperfusion, we also blocked the FGF-R1. All of the inhibitors completely blocked the protective effects on cardiac functional recovery. Only PKC inhibition could partially suppress the FGF-1 mediated attenuation of myocardial cell death. Apparently, FGF-1 mediated protection is only partially dependent on PKC and completely independent of FGF-R1 and TK (figure 3a. and 3b.). This finding might be explained by "redundancy".

\section{Clinical implications for future IGF-1 and FGF-1/2 growth factor therapy}

The ultimate goal of basic growth factor research is to bring these growth factors into clinical practice, using them as an alternative or adjuvant therapy to the conventional strategies to treat patients suffering from cardiovascular disease. As growth factor research concentrated on the basic scientific aspects in the past 20 years, recently, several multi-center clinical trials have been launched to investigate the possible benefit of growth factor therapy in patients suffering from MI and cardiac faillure.

Growth factor therapy to stimulate angiogenesis, and to improve remodeling and function in patients suffering from myocardial infarction and failure.

Most clinical trials have been initiated with the goal to induce angiogenesis or to improve the remodeling response, in order to favorably affect the cardiac contraction pattern, and therefore output. So far, several promising results have been described in case reports and small-scaled studies. However, randomized, placebo-controlled clinical trials with $I G F-1^{45}$ and FGF-2 $2^{46,47}$ have not been able to demonstrate significant effects (chapter 1).

Recently, large clinical trials have not been able to demonstrate favorable effects of IGF-I therapy in patients with cardiac disease. Although short-term 
improvement of cardiac function could be obtained ${ }^{48}$, the long-term clinical outcome has not been improved. Therefore, the general consensus is that IGF- 1 therapy to improve cardiac remodeling and function; has to be reevaluated.

Despite the efficacy of FGF therapy has been proven, caution should be paid when FGFs are used on a chronic basis to treat patients post-MI. FGF-2 overexpression resulted in abnormal bone growth in mice. ${ }^{49}$ Furthermore, it was demonstrated that FGF-1 promotes intimal hyperplasia and angiogenesis in arteries and artherosclerotic plaques in vivo. ${ }^{50}$ This might predispose to plaque rupture resulting in an acute (coronary) vascular event. Similarly, accelerated atherosclerosis in cardiac transplants is characterized by coronary intimal hyperplasia. FGFs, being potent mitogens for intimal smooth muscle cells, are constitutively expressed in cardiac allografts ${ }^{57}$ and might play a catalysing role in the development of neointima formation and accelerated atherosclerosis. ${ }^{52}$ In this thesis, we demonstrated that chronic elevation of FGF-1 in the setting of remodeling post-MI might not be favorable, as cardiac function was decreased in the FGF-1 overexpression group.

One of the explanations for the disappointing results of growth factor therapy to induce angiogenesis might be that the inappropriate patient category is included. Often growth factor therapy is applied to patients, who cannot be adequately revascularized. It is this patient group that has proven to be incapable of forming an adequate collateral circulation. Therefore, additional growth factor therapy may not be the solution for this specific patient group. Several considerations have to be taken into account to evaluate growth factor trials. Furthermore, several considerations will be mentioned for future growth factor research and therapy.

To prove the concept of growth factor therapy, proper placebo control groups should be enrolled. 45,53

Growth factor therapy should be used as a sole therapy, instead as an adjuvant therapy next to coronary artery revascularization, since the effects of therapy will always be clouded by the effects of conventional revascularization.

Additional clinical studies are required to assess the optimal dose and route of administration Future growth factor therapy might be most effective when a cocktail of different angiogenic and vasculogenic growth factors is administered. $^{54}$

A choice should be made between protein administration or gene delivery as the primary pro-angiogenic therapy. ${ }^{55}$

Growth factors and their receptors are expressed in large quantities in response to acute ischemia or other pathogenic stimuli. Currently, no information is present on growth factor production and growth factor receptor expression 
during chronic ischemia and the interindividual differences of expression in these patients. We hypothesized that during chronic myocardial ischemia, growth factor receptor expression might have been downregulated and additional growth factor administration to these patients may therefore not be effective, because the signal cannot be relayed into the target cells. This might be one of the explanations for the disappointing results in clinical trials, mainly aiming at enhancement of angiogenesis. in patients with chronic myocardial ischemia without further options for revascularization or PTCA. Therefore, growth facter and, more important, growth factor receptor expression should be investigated in patients suffering from chronic myocardial ischemia. Taking the above into account, it might be interesting to enhance the growth factor receptor population in the ischemic myocardium. This can be done by the creation of a dominant-positive growth factor receptor. This receptor is consitutively activating downstream signaling proteins, indepent of ligand binding to the extracellular domain of the receptor. This dominant-positive receptor protein could be expressed in the target cells using an adeno-viral construct ${ }^{56}$ or an adeno- associated viral construct, with or without ventricularspecific promotor.

It was demonstrated that several growth factors act synergistical during the induction of angiogenesis. ${ }^{2}$ To avoid administration of a cocktail of growth factors, it might be interesting to generate a fusion-protein. This protein should contain binding sites specific for the extracellular binding domain of several growth factor receptors. One of the problems that will be encountered in this concept is to create a three-dimensional protein structure that exposes all the growth factor receptor binding sites, without interfering with growth factor receptor interaction for each of the growth factors.

Taking into account the existing experimental data and the results from several small-scale clinical trials, the general consensus is that protein-based therapy seems to have some advantages over gene therapy at the present time. ${ }^{45}$ While direct intramyocardial injection of the angiogenic protein now seems the most effective way of protein delivery in combination with the lowest circulating levels of protein, continuous efforts should be made to increase the exposure time of the target area, in order to maximize angiogenesis and induction of adequate bridging collaterals to ischemic tissue (arteriogenesis). myocardial angiogenic gene transfer, using adenoviruses encoding a growth factor, intracoronary and intramuscular injections both proved to be effective in improving myocardial function in the setting of myocardial ischemia in animal models. ${ }^{53,57}$ Whether or not this is feasible for treatment of patients remains to be determined in placebo-controlled trials, which are currently in progress. 


\section{FGF-1/2 and IGF-1 therapy during acute myocardial ischemia}

So far, no clinical trials have been reported investigating the possible benefits of FGF-1/2 or [GF-] treatment during acute myocardial ischemia. This might be due to the fact that only recently the cardioprotective effects of these proteins came to notice. However, several basic scientific reports supporting this notion have been published.

Our results are in line with results presented by other groups, suggesting a cardioprotective potential for both growth factors in acute myocardial ischemia. The disadvantage of our approach is that the growth factor of interest was present or administered prior to the induction of myocardial ischemia, which does not resemble the clinical situation. Therefore, more research is required to evaluate whether or not these growth factors can also reduce the level of additional damage when administered during reperfusion of ischemic tissue.

If favorable effects can be demonstrated in these pre-clinical studies, clinical trials may be initiated. One of the study strategies could be intracoronary growth factor delivery (to reduce the systemic load and therefore diminish the hypotensive effects of the growth factor to be administered], for instance in concert with standard or intracoronary thrombolytic therapy. By adding the growth factor, additional damage due to reperfusion could be attenuated. This could further reduce infarct formation and diminish the loss of cardiomyocytes. This might therefore favorably affect cardiac functional recovery after MI. In addition, growth factors might be used as a protective agent during cardiac surgery, for instance when added to the standard cardioplegic solution, especially in patients with sub-optimal myocardial protection during surgery, for instance in patients with few collaterals, or when the time of artic crossdamping is expected to be long. In the routine, uncomplicated patient, undergoing valve replacement or $\mathrm{CABG}$, the damage to the myocardium is already minimalized. In patients with pre-existent diminished left ventricular function or in patients with a prolonged duration of cardioplegic arrest, it would be very interesting to investigate whether or not growth factors added to the cardioplegic solution could diminish myocardial stunning direct post-operatively, thereby facilitating the weaning process from cardio-pulmonary bypass and reducing the requirement of inotropic pharmaca. Before these hypotheses can be tested in patients, the results should be thoroughly validated and confirmed in animal models.

Recently, stem cell transplantation has been described as a novel therapeutic option in the treatment of ischemic heart disease. ${ }^{58.59}$ Currently, several research groups are optimizing the methods to induce differentiation of pluripo- 
tent stem cells into adult cardionyocytes, which could then be used for cardiomyocyte transplantation, called "cellular cardiomyoplasty". ${ }^{60}$ These transplanted cardiomyocytes could contribute to increased contractile function, passive improvement of the mechanics of the ventricle by improving the architecture of the ventricle ${ }^{\text {bil }}$, or the induction of neoangiogenesis. Autologous mesenchymal stem cell transplantation resulted in successful differentiation into cardiomyocytes and increased myocardial function in swine ${ }^{61}$ In mice, stem cells were able to repair the infarcted myocardium, generating a band of new myocardium, when injected adjacent to the site of the infarction. ${ }^{62,63}$ Both embryonic and adult stem cells have been used for transplantation. In another study, Orlic et al ${ }^{64}$ demonstrated that injection of these primitive bone-marrow cells adjacent to the infarcted myocardium in mice resulted in a decrease in infarct size, an augmentation of cardiac function and a decrease in mortality. Currently, clinical trials are planned to investigate whether this treatment could be useful for patients suffering from MI and failure. 


\section{References}

1. Harado $K_{\text {r }}$ Grossman $W$. Friedman $M$, et al.: Basic fibrablas growth foctor improves myocardial function in chronically ischemic porcine hearts. J Ciln Invest 1994:94:623-630.

2. Asahara $T$, Bauters $C$, Zheng $L P$, ef al.: Synergistic effect of vascular endothellal growth foctor and basic fibroblast growth factor on angiogenesis in vivo. Circulation 1995:92:365-371.

3. Yanaglisawa-Miwa $A$, Uchida $\mathrm{Y}$, Nakamura $\mathrm{F}_{s}$ ot al.: Salvage of infarcted myocardlum by anglogenic action of basic fibrobiast growth factor. Science 1992;257;1401-1403.

4. Horrigan MCG, Maclsaac Al, Nicolini FA, et al.: Reduction in myocardial infarct size by basic fibroblast growth factor after temporary coronary artery occlusion in a canine model. Circulation 1996;94:1927-1933.

5. Schumacher $B$, Pecher $P$, Specht von BU, et al:: Induction of neoangiogenesis in ischemic myacardlum by human growth factors. Circulation 1998;97:645-650.

6. Schumacher B, Specht von B-U, Haberstroh J, et al.: The stimulation of nea-anglogenesis in the ischemic heart by the human growth factor FGF. J Cardlovasc Surg 1998;39:445-453.

7. Doevendans PA, Hunter $\mathrm{JJ}_{f}$ Lembo $G$, et al.: Strategles for studying cardiovascular diseases in transgenic and gene-targeted mice, in Monastersky GM, Robl JM (eds): Strategies in Transgenic Animal Science. Washington DC, American Soclety for Mlcroblology. 1995, pp. 107-143.

8. Metais C, LI J, LU J, et al.: Effects of coronary artery disease on expression and microvascular response to VEGF. Am J Physiol 1998;275:H1411-H1418.

9. Ishibashl $Y$, Urabe $Y$, Tsutsul $H$, et al.: Negative inotrophic effect of basic fibroblast grawth factor on adult rat cardiac myocyte. Circulation 1997;96:2501-2504.

10. Padua RR, Merle P-L, Doble BW, et al.: FGF-2 induced negative inotropism and cardioprotection are inhibited by chelerythrine: involvement of sarcalemmal calcium-independent protein kinase C. J Mol Cell Cardiol 1998;30:2695-2709.

11. Buehler A, Matire A, Strohm C, et al.: Angiogenesis-independent cardloprotection in FGF-1 transgenic mice. Cardlovasc Res 2002;55:768-777.

12. Fernandez $B$, Buehler $A$, Wolfram $S$, et al.: Transgenic myocordial overexession of Fibroblast growth factor-1 increases coronary artery density and bronching. Circ Res 2000;87:207213.

13. Pellieux $C$, Folettl $A$, Peduto $G_{s}$ et al.: Dilated cardiomyopathy and impaired hepertrophic response to angiotensin-II In mice lacking FGF-2. J Clin Invest 2001;108:1843-1851.

14. Corda S, Mebozad A, Gandolfini M-P, et al.: Throphic effect of human pericardial fluld on adulf cardiomyocytes; differentilal role of fibroblast growth factor 2 and factors related to ventrilcular hypertrophy. Circ Res 1997:81:679-687.

15. Schultz JEL, Witt SA, Nieman ML, et al.: Fibroblast growth factor-2 mediates pressure-induced hypertrophic response. J Clin Inwest 1999; 104:709-719.

16. Tomito $Y$, Kusama $Y$, Seino $Y$, et al.: Increased accumulation of acidic fibroblast growth factor In left ventricular myocytes of patients with idiopathic dilated cardiomyopathy. Am Heart J 1997; 134:779-786.

17. Rifkin DB, Moscatell $\mathrm{D}$ : Recent dewelopments in the cell blology of basic flbroblast growth factor. J Cell Biol 1989; 109:1-6.

18. Tseng SC, Savion N, Stern R, et al.: Flbroblast growth factor modulates synthesis of colliagen in cultured endothelial cells. Eur $\mathrm{J}$ Blochem 1982;122:355-360.

19. Vlodavsky 1, Gospodarowicz D: Structural and functional alferations in the surface of vascular endothelial cells associlated with the formation of a confluent cell monolayer and with the withdrowal of fibroblast growth foctor. J Supramol Struct 1979:12:73-114. 
20. Cuevas $P$, Reimers $D$, Carceller $F$, ef al.: Fibroblast growth factor-1 prevents myocardial apoptosis triggered by ischemia reperfusion injury. Eur J Med Res 1997;2:465-468.

21. Iwal-Kanai $\mathrm{E}$, Hosegawa $\mathrm{K}$, Fuilta $M$, ef al., Basic fibroblast growth factor protects cardiac mycytes from iNOS-mediated apoptosis. $J$ Cell Physiol 2002;190:54-62.

22. Baker $J$, Liu J-P Robertson EJ, ef al. Role of insulin-like growth factors in embryonic and postnatal growth cell 1993:75:73-82.

23. Delatontaine P. Insulin-like growth factor 1 and its binding proteins in the cardiovascular system. Cardiovase Res 1995;30:825-834.

24. Froesch ER, Schmid $C$, schwonder $L$, of al: Actions of insulin-like growth factors. Ann Rev Physiol 1985:47:443-467.

25. Schneider MD, Parker TG: Cardiac growth factors. Prog Growth Fact Res 1991;3:1-26.

26. Li $Q$, LI B, Wang $X$, et al.: Overexpression of insulin-like growth factor- 1 in mice protects from myocyte death after infarction, attenuating ventricular dilatation, wall stress, and cardiac hypertrophy. J Clin Invest 1997;100:1991-1999.

27. Jin $\mathrm{H}_{4}$ Yang $\mathbf{R}$, Gillet $\mathrm{N}$, ef all.: Benifficiel effects of growth harmone and insulin-llike growth facior-1 in experimental heart failure in rats freated with chronic ACE inhibition. Cardlovasc Pharmacol 1995;26:420- 425

28. Duerr RL,. Huang S, Miraliakbar HR, et al.: Insulin-like growth factor-1 enhances ventricular hypertrophy and function during the onset of experimental cardiac fallure. J Clin Invest 11995,95:619-627.

29. Duerr RL, Mckiman MD, Gim RD, et al.: Cardiovascular effects of Insulin-like grawth factor-1 and growth hormone in chronic left ventricular fallure in the. Circulation 1996;93:21882196.

30. Chen $\mathrm{DB}_{\text {, Wang }} \mathrm{L}$, Wang $\mathrm{PH}$ : Insullin-like growth factor 1 retards apoptotic signaling induced by ethanol in cardiomyacytes. Life Sci 2000;67:1683-1693.

31. Leri A, Liu $Y$, Claudlo PP, et al.: Insulin-like growth factor-1 induces Mdm2 and down-regulatos p53, attenuating the myocyte renin-angiotensin sytem and stretch-mediated apoptosis. Am J Pathol 1999; 154:567-580.

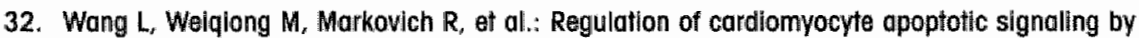
insulin-like growth factor 1. Circ Ras 1998;83:516-522.

33. L G. LI R-K, Mickle DAG, at al: Elevated Insulin-like growth factor-1 and Transforming growth factor-betal and their receptors in patients with idlopathic hypertrophic obstructive cardiomyopathy. Circulation 1998;98:144-150.

34. Redaelli G, Malhotra A, LI B, et al.: Effects of constifutive overexpression of insulin-like growth factor-1 on the mechanical characteristics and molecular properties of ventricular myocytes. Circ Res 1998;82:594-603.

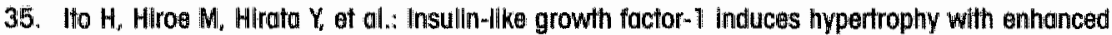
expression of muscle specific genes in cultured rat myocytes. Circulation 1993;87:1715-1721.

36. Clttadinl $A$, Str ${ }^{n}$ mer $H$, Katz SE, ef al.: Differential cardlac effects of growth hormone and Insulim-like growth factor-1 in the rat. Circulatton 1996;93:800-809.

37. Gittadini A, Grossman JD, Napoli R, ef al.: Growth hormone attenuates early left ventricular remodeling and improves cardiac function in rats with large myocardial intarction. J Am Coll Cardiol 1997;29:1109-1116.

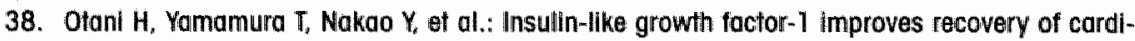
ac pertormance during reperfusion in isolated rat heart by a wortmannin-sensitive mechanism. J Cardiovasc Pharmacol 2000;35:275-281.

39. Friehs I, Stamm $\mathrm{C}_{\text {s }}$ Cao-Dahn $\mathrm{H}$, et al.: Insulin-like growth factor-1 improves postischemic recovery in hypentrophied hearts. Ann Thorac Surg 2001:72:1650-1656. 
40. Sheikh F, Sontag DP, Fandrich $R R_{\text {, }}$ et al.: Overexpresston of FGF-2 increases cardiac myocyte viability after infury in isolated mouse heart. Am J Physiol 2001,280:H1 039-41050:

41. Cuevas $\mathrm{P}$, Carceller $\mathrm{F}$, Lozano RM, et al:: Protection of ral myocardium by mitogenic and nonmitogenic fibroblost growth factor during post-ischemic reperfusion: Growth Factors 1997:15:29-40.

42. Padua $R R_{\text {, Sethi }}$, Dhalla NS, ef al.: Basic fibroblast growth factor is cardloprotective in ischemia- reperfusion Injury. Mol Cell Biochem 1995: $143: 129-135$.

43. Cuevas $P_{2}$ Carceller $F$, Cuevos $B_{x}$ et al.: A non-mitogenic form of acidic fibroblast growth foctor reduces neutrophill infiltration in rat ischemic reperfused heart. Eur J Med Res 1997;2:139. 143.

44. Htun $P$, to WD, Hoefer IE, et al.: Intramyocardial infusion of FGF-1 mimics ischemic preconditioning in pig myocardium. $J$ Mol Cell Cardiol 1998;30:867-877.

45. Osterzlel KJ, Strohm O, Schuler J, et al.: Randiomised, double-blind, placebo-controlled trlal of humon recombinant growth hormone in patients with chronic heart fallure due to dilafed cardiomyopathy. Lancet 1998;351:1233-1237.

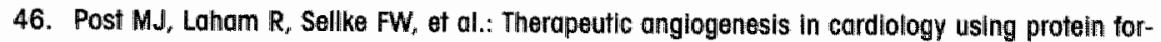
mulations. Cardiovasc Res 2001,49:522-531.

47. Simons $M$. Annex BH, Loham R.J, et al.: Pharmacological treatment of coronary artery disease with recombinant fibroblast growth factor-2; o double blind, randomized, controlled clinical trial. Circulation 2002; 105:788-793.

48. Osterziel KJ, Ranke MB, Strohm 0, ef al.: The somatotrophic system in patients with dilated cardiomyopathy: relation of insulin-like growth factor-1 and lis alterations during growth hormone therapy to cardiac function. Clin Endocrinol 2000;53:61-68.

49. Coffin JD, Florkiewicz RZ, Neumann $J$, et al.: Abnormal bone growth and selectlve transiational regulation in basic fibroblast growth factor (FGF-2) Iransgenic mice. Mol Biol Cell 1995;6:1861-1873.

50. Nabel EG, Yang $Z-Y$, Plautz $G$, et all: Recombinant fibroblast growth factor- 7 promotes intimal hyperplasia and anglogenesis in arteries in vivo. Nature 1993;362:844-846.

51. Zhoo X-M, Yeoh T-K, Frist WH, et al.: Induction of acidic fibroblast growth factor and fulllenght platelef- derived growth factor expression lin human cardlac allografts. Circulation 1994,90:677-685.

52. Zhoo X-M, Frist WH, Yeah T-K, at al.: Modification of alternative messenger RNA splicing of fibroblast growth factor receptors in human cardiac allogratts during rejection. J Clin Invest 1994:94:992-1003.

53. Hammond HK, McKiman MD: Anglogenic gene therapy for heart disease: a revlew of amimal studies and clinical trials. Cardiovasc Res 2001;49:561-567.

54. Folkman J: Anglogenic therapy of the human heart. Circulation 1998:97:628-629.

55. Simons $M$, Bonow RO, Chronos NA, et al.: Clinical trlais in coronary angiogenesis; Issues, problems, consensus; an expert pannel summary. Circulation 2000;102:E73-EB6.

56. Grines $\mathrm{CL}$, Watkins MW, Helmer G, et al.: Angiogenic gene therapy (AGENT) trlal in patients with stable angina pectoris. Circulation 2002;105:1291-1297.

57. Isner JM: Myocardial gene theropy. Nature 2002;415:234-239.

58. Boheler KR, Czyz $J$, Tweedie $D$, ell al.: Differentiation of pluripotent embryonic stem ceills into cardiomyocytes. Circ Res 2002;91:189-201.

59. Doevendans PA, Kubalak SW, An $\mathrm{RH}_{s}$ ef all:: Differentiation of cardiamyocytes in flooting embryaid bodies is comparable to fetal cardlomyocytes. J Mol Cell Cardiol 2000;32:839851. 
60. Toma $\mathrm{C}$, Pittenger MF, Cahil KS, al al.: Human mesenchymal stem cellis differentiate to al cardiamyocyte phenotype in the odult murine heart. Circulation 2002; 105:93-98.

61. Shoke JG, Gruber PJ, Baumgarther WA at al.: Mesenchymal stem cell implantation in a swine myocardial infarct model: engraftment and functional effects. Ann Thorac Surg 2002;73:1919-1925.

62. Orlic 0 , Kajstura 3 , Chimentil $S$, at al: Transplanted adult bone marrow cells repair myocardial infarets in mice. Ann NY Acad Scl 2001;938:229-230.

63. Orflic $\mathrm{D}$, Kajstura $\mathrm{J}$. Chimenti $\mathrm{S}_{*}$ ef al.: Bone marrow cells regenerate infarcted myocardium. Nature 2001:410:701-705.

64. Orlic D, Kajstura J, Chimenti $\mathrm{S}$, et al.: Mobilized bone marrow cells repair infarcted heart, improving function and survival. Proc Natl Acad Sel USA 2001;98:10344-10349. 


\section{Summary}

Cardiovascular diseases are the leading cause of mortality and morbidity in the Western society. With the advent of different reperfusion techniques (throm bolytic therapy, PTCA, rescue-CABG), damage due to thrombotic coronary artery occlusion can be attenuated. Therefore, mortality numbers decrease, but on the expense of morbidity.

Myocardial infarction results in necrosis of cardiomyocytes and scar formation in the tissue area at risk. To compensate for the loss of contractile units, the cardiomyocyte population has to increase in size (hypertrophy), to be able to live up to the bodily requirements. Because cardiomyocytes lost the ability to divide (hyperplasia) shortly after birth, they have to rely on growth (hypertrophy). In order to provide enough oxygen supply for these hypertrophied cardiomyocytes, the formation of new capillaries is required (angiogenesis). This is often associated with the formation of epicardial collaterals (arteriogenesis). If reperfusion is accomplished within several hours after thrombotic coronary artery occlusion, necrotic cell death and therefore infarct size can be diminished. However, the process of reperfusion can also be harmful for the myocardium. While ischemia mainly induces necrotic cell death, reperfusion results in apoptosis, or programmed cell death, of cardiomyocytes located in the area at risk.

Growth factors are peptides that play a pivotal role in development and growth of the organism as a whole, but also on the level of the individual organs. Several growth factor families (like IGF-1 and 2, and the VEGF and FGF family of growth factors) are indispensable for the formation of the cardiovascular system. Some growth factors are produced systemically. For instance IGF- 1 is produced in the liver in response to growth hormone $(\mathrm{GH})$ stimulation. In addition, growth factors are produced locally in the target tissues in response to certain (pathogenic) stimuli. In the myocardium, growth factors (like IGF-1, FGF-1 and 2 and several VEGF isoforms) are produced in response to increased workload or myocardial ischemia. These growth factors play a crucial role in de evolution of a myocardial infarction and response to ischemia. The processes that have been described above (cardiomyocyte hypertrophy, scar formation, angiogenesis and arteriogenesis) are largely controlled and modulated by a complex interplay of several growth factors. These growth factors display effects during both acute ischemia and reperfusion, and in chronic myocardial ischemia and infarction. In this thesis, attention is focused on FGF-1 and IGF-I and their role in acute and chronic myocardial ischemia and myocardial infarction. 
Chapter is an introduction and gives an elaborate overview of current literature, while chapter 2 reviews the role of growth factors in myocardial angiogenesis. The first part of the experimental work focuses on IGF-1 for Insulinlike growth factor-1). In chapter 3, we induced an experimental myocardial infarction by coronary artery ligation in heterozygous IGF-1 deficient mice, displaying $60 \%$ of the normal IGF-1 plasma levels. One week after induction of a myocardial infarction (MI), cardiac function was measured, using a left ventricular pressure catheter. Afterwards, the heart was excised for morphological and (immuno-) histochemical analysis. IGF-1 deficient mice had lower body and organs weights. Cardiomyocytes of IGF-I deficient mice were smaller, underlining the general growth promoting role of this growth factor. In addition, these mice had fewer capillaries per carcliomyocyte ( $\mathrm{C} / \mathrm{F}$ ratio was decreased), when compared to WT littermates. Induction of MI resulted in decreased cardiac function. However, no differences in cardiac function were found between IGF-1 deficient mice and WT littermates and infarct size was similar in both genotypes. When cellular composition and general ventricular architecture was investigated, several differences between both genotypes were found. IGF-1 deficiency was associated with increased apoptosis rates and diminished cellular division in the infarcted area of the myocardium. In addition, the hypertrophic response of the remote myocardium was blunted in IGF-I deficient mice. We conclucle that although IGF-1 deficiency is associated with altered remodelling of the infarcted ventricle, cardiac function was not altered when compared to infarcted WT animals.

To investigate the role of IGF-1 in acute myocardial ischemia and reperfusion, we mounted the hearts of IGF-I deficient mice and their WT littermates in an ex viwo murine heart model of ischemia and reperfusion (chapter 4). After a 20 minute period of ischemia, the hearts were reperfused for one hour. Throughout the complete duration of the experiment several parameters of cardiac function were measured. In addition, coronary effluent was sampled for determination of lactate and LDH, parameters for anaerobic metabolism and necrotic cell death, respectively. We found that partial (heterozygous) IGF-1 deficiency did not result in enhanced tolerance to ischemia, since cardiac functional recovery and cell death were similar in IGF-I deficient mice and their WT littermates. However, coronary flow was significantly lowered during reperfusion in IGF- 1 deficient mice, without functional consequences. Pre-ischemic administration of IGF-I resulted in augmentation of cardiac functional recovery during the complete reperfusion phase, in both IGF-1 deficient mice and WT littermates. Furthermore, in IGF-I deficient mice, IGF-I administration was associated with a normalisation of coronary flow to 
the level of (un)treated WT hearts. In addition, ischemia-induced necrotic cell death was decreased in both genotypes after pre-ischemic IGF-1 administration. To unravel the intracellular signalling pathways associated with IGF-I mediated cardioprotection, we selectively inhibited two intracellular signalling proteins, namely PKC (protein kinase C) and PI-3K (phosphatidyl-inositol-triphosphate kinase), using pharmacological inhibitors. Simultaneous $\mathrm{IGF}^{-1}$ administration in combination with selective inhibition of either PKC or PI-3K resulted in an attenuation of the IGF-1 mediated cardioprotective effects. Cardiac functional recovery and myocardial cell death were similar in non-treated hearts and hearts treated with the combination of $1 G F-1$ and an inhibitor of either PKC or PI-3K. We conclude that IGF-I enhances myocardial tolerance to ischemia, resulting in augmentation of cardiac functional recovery and attenuation of myocardial necrotic cell death following ischemia and reperfusion. IGF-1 mediated protection was proven to be PI-3K and partially PKC dependent.

In the second part of the experimental work, the attention switched to another cardiac growth factor, FGF-1 (Fibroblast growth factor-1). For these experiments, transgenic mice with a cardiac-specific $\mathrm{FGF}-1$ overexpression were used. By using a heart-specific promotor, (human) FGF-1 is produced, but only in the myocardium. One week after induction of a myocardial infarction, cardiac function was measured using a flow probe, positioned around the ascending aorta (chapter 5). After these function measurements had been completed, the heart was excised for morphological and immunohistochemic analysis. Despite the fact that these mice had more epicardial vessels (arteriogenesis), which could lead to enhanced collaterall flow, myocardial infarct size was similar in FGF-1 transgenic mice and their WT littermates. In addition, no difference was found in capillary to fiber ratios. However, induction of $\mathrm{MI}$ resulted in decreased collagen formation in the infarcted left ventricular free wall and enhanced apoptosis rates in this area, when compared to WT littermates. Surprisingly, cardiac function was decreased in $\mathrm{FGF}-1$ transgenic mice following myocardial infarction. We conlude that FGF-I overexpresssion leads to alterations in the cardiac remodelling response and attenuation of cardiac function, following myocardial infarction.

To study the role of FGF-1 during acute ischemia and reperfusion, we mounted FGF-1 transgenic hearts and WT hearts in the ex vivo, isolated mouseheart model of ischemia and reperfusion (chapter 6). Cardiac function and lactate/LDH release were continuously monitored throughout the experimental protocol. FGF-1 overexpression resulted in a spectacular augmentation of car- 
diac functional recovery following a $25 \mathrm{~min}$. period of ischemia, compared to WT littermates. In addition, ischemia and reperfusion-induced necrotic cell death was sigwificantly attenuated in FGF-1 transgenic hearts. To unravel the intracellular signalling pathways involved in FGF-1 mediated cardioprotection, we selectively inhibited several intracellular signalling molecules that were hypothesized to play a role in FGF-1 mediated protection. Inhibition of the ${ }^{2} \mathrm{CF}^{2}$ receptor-1 (FGF-R1), protein kinase $\mathrm{C}$ (PKC), and tyrosine kinases (TK)

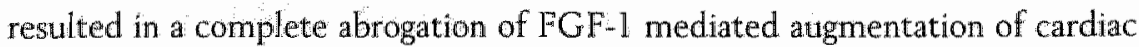
functional recovery. Recovery of cardiac function in inhibitor-treated FGF-1 transgenic hearts was similar when compared to non-treated WT hearts. However, the protective effects of FGF-I on necrotic cell death could not be abrogated by inhibiting FGF-R1 and TK and could only be partially abrogated by PKC inhibition. We conclude that FGF-1 overexpression enhances myocardial tolerance to ischemia and that these effects are FGF-Rl, PKC and TK mediated. FGF-1 mediated protection of myocardial mecrotic cell death is partially PKC dependent and completely FGF-RI and TK independent.

In the final chapter of this thesis (chapter 7), results from this experimental work are discussed in the light of current literature on this subject. Furthermore, the clinical implications of these results for future growth factor therapy are discussed. 


\section{Samenvatting}

Hart- en vaatziekten zijn verantwoordelijk voor een groot deel van de mortaliteit en morbiditeit in de westerse maatschappij. Sinds de opkomst wan verschillende reperfusie technieken (thrombolytica, PTCA, resque-CABG), kan de schade van een myocardinfarct vaak ten dele worden beperkt. Hierdoor neemt de mortaliteit van hart- en vaatziekten af, terwijl de morbiditeit stijgt. Indien een hartinfarct optreedt, gaat dit gepaard met het verlies van hartspiercellen (cardiomyocyten) en de vorming van littekenweefsel in het stroomgebied van de afgesloten coronair arterie. Om te compenseren voor het verlies van contractiel weefsel zal de rest van de hartspiercellen in omvang moeten toenemen om aan de zuurstof-behoeften wan het lichaam te kunnen voldoen. Omdat hartspiercellen het vermogen tot celdeling hebben verloren, nemen de hartspiercellen in cel-grootte toe (hypertrofie). Om deze hypertrofische cardiomyocyten van voldoende bloed te kunnen voorzien is het verder noodzakelijk dat het capillair netwerk zich proportioneel uitbreidt (angiogenese). Deze uitbreiding van het capillaire netwerk, gaat soms gepaard met de vorming van arteriolen (arteriogenese).

Indien reperfusie binnen enkele uren optreedt na thrombotische occlusie van een coronair arterie, al dan niet iatrogeen, kan de ischemische schade worden beperkt. Echter, reperfusie alleen heeft ook al schadelijke effecten (reperfusion damage). Terwijl ischaemie met name tot necrose van cardiomyocyten leidt, induceert reperfusie van de area at risk apoptose van cardiomyocten, ook wel geprogrammeerde celdood genoemd.

Groeifactoren zijn eiwitten die een belangrijke rol spelen in de groei en ontwikkeling, zowel op het niveau van het organisme, als ook op orgaanniveau. Zo hebben deze groeifactoren een belangrijke rol bij de ontwikkeling van het cardiovasculaire systeem. Sommige groeifactoren, zoals IGF-I, worden in de lever geproduceerd na stimulatie met groeihormoon $(\mathrm{GH})$. Daarnaast worden groeifactoren geproduceerd in de verschillende doelwit-organen (target tissues), na het optreden van verschillende (pathologische) stimuli. In het hart wordt de productie van groeifactoren (zoals IGF-1, FGF-1 en 2, en verschi]lende VEGF-isoformen) gestimuleerd door bijwoorbeeld een toename in "work-load" of myocardiale ischaemie. Deze groeifactoren spelen een cruciale rol bij de evolutie van een infarct. Bovengenoemde processen (cardiomyocythypertrofie, littekenvorming, angiogenese, arteriogenese, apoptose) worden in belangrijke mate gereguleerd door deze groeifactoren. Deze groeifactoren spelen een rol zowel bij acute ischaemie (en reperfusie), als tijdens de remodellering van de ventrikels (remodeling) na een doorgemaakt infarct. 
In dit proefschrift wordt de rol van twee van deze groeifactoren, FGF-I en $I G F-1$, in acute en chronische myocardischaemie en myocardinfarct belicht.

In dit proefschrift wordt het experimentele werk voorafgegaan door een uitgebreid overzicht van de bestaande literatuur (hoofdstuk 1), gevolgd door een review over de rol van groeifactoren in angiogenese (hoofdstuk 2). Het eerste gedeelte van het experimentele werk concentreert zich op IGF-I (of Insulinlike growth factor-1). In hoofdstuk 3 hebben we in myocardinfarct geinduceerd bij genetisch gemodificeerde muizen met en partiële (heterozygote) IGF-1 deficiëntie. Deze muizen hebben $60 \%$ van de normale plasmaspiegels van IGF-1. Na een week werd de hartspierfunctie gemeten met gebruikmaking van een druk-catheter in de linker ventrikel. Vervolgens werd het hart uitgenomen voor histologische en immunohistochemische analyse. IGF-I deficiẻnte muizen wogen minder dan hun WT soortgenoten en haddlen kleinere hartspiercellen, hetgeen de algemene groei-bevorderende eigenschappen van IGF-1 onderstreept. Daarnaast hadden deze muizen minder capillairen per hartspiercel. Na vergelijking met niet-transgene muizen (wild-type littermates) bleek dat de hartspierfunctie voor een na infarct niet beinvloed werd door IGF-1 deficiëntie. Daarnaast bleek de grootte van het infarct identiek bij de twee genotypen. De architectuur en celcompositie van het geïnfarceerde hart was echter duidelijk verschillend bij IGF-1 deficiënte muizen. IGF-1 deficiëntie was geassocieerd met een significante toename van apoptose en een afname van celdeling in het geïnfarceerde gebied. Daarnaast bleek de hypertrofe respons van het resterende levende myocard afgenomen in IGF-1 deficiënte muizen. Concluderend kunnen we dus stellen dat wel de structuur en celcompositie van het (geinfarceerde) hart verandert ten gevolge van IGF-I deficiëntie, maar dat dit niet leidt tot een verandering in hartspierfunctie.

Om de rol van IGF-I bij acute myocardiale ischaemie en reperfusie te kunnen bestuderen hebben we de harten van IGF-I deficiënte muizen en hun WT littermates in een ex vivo, geisoleerd muizenhart-perfusie opstelling geprepareerd (hoofdstuk 4). Na een periode van 20 minuten ischaemie werd gereperfundeerd gedurende een uur. Gedurende het gehele experiment werden verschillende parameters voor hartspierfunctie gemeten en werd het coronair perfusat gesampeled voor bepaling van LDH en lactaat, parameters voor necrotische celdood en anaeroob metabolisme, respectievelijk. Het bleek dat een partiëlle IGF-1 deficiëntie niet resulteerde in een afgenomen tolerantie voor nnyocardischaemie. Herstel van hartspierfunctie en celdood gedurende de reperfusie perioden waren niet wezenlijk verschillend, indien IGF-1 deficiënte muizen werden vergeleken met WT littermates. Wel bleek dat de coronaire flow na ischaemie lager was in IGF-1 deficiënte muizen, echter zonder functi- 
onele consequenties. Pre-ischemische toediening van IGF-1 leidde tot een verbetering van het herstel van hartspierfunctie gedurende de reperfusie fase, zowel in IGF-1 deficiënte muizen als in hun WT littermates. Ook de necrotische celdood ten gevolge van ischaemie en reperfusie $(1 / R)$ nam af ten gevolge van pre-ischaemische IGF-I toediening. Om nu te kunnen bepalen welke signaaltransductie eiwitten in het hart betrokken zijn bij deze IGF-1 gemedieerde inductie van tolerantie voor ischaemie, hebben we enkele van deze signaaltransductie moleculen farmacologisch geinhibeerd. Inhibitie van ofwel PI-3K. (phosphatidyl-inositol-triphosphate kinase), ofwel PKC (protein kinase C) samen met IGF-1 toediening resulteerde in een afname van de IGF-1 gemedieerde protectie. Zowel het herstel van hartspierfunctie als de hoeveelheid necrotische celdood was vergelijkbaar met de harten die geen IGF-I voorbehandeling ontvingen. Wij concluderen dat IGF-1 de tolerantie voor myocardischaemie verhoogt en resulteert in een verbetering van hartspierfunctie en een afname van (necrotische) celdood na ischaemie en reperfusie. Deze effecten blijken (partieel) afhankelijk te zijn van intracellulaire signaaltransductie eiwitten PI-3K en PKC.

In het tweede deel van het experimentele werk werd de aandacht verlegd naar een andere groeifactor, namelijk FGF-1 (Fibroblast Growth Factor-1). We gebruikten voor deze experimenten transgene muizen met een hart-specifieke overexpressie van FGF-1. Door deze hart-specifieke promotor, wordt in de muis humaan FGF-1 aangemaakt, echter alleen in het myocard. Wederom werd een myocardinfarct geïnduceerd, na een week gevolgd door functiemetingen (hoofdstuk 5). Hiertoe werd een flow-probe aangebracht on de aorta ascendens. Vervolgens werd het hart uitgenomen voor morphologische en (immuno-] histochemische analyse. Ondanks een toename van epicardiale arteriolen (arteriogenese), hetgeen zou kunnen leiden tot een toegenomen collaterale flow, hadden deze muizen geen afname van infarctgrootte, indien vergeleken met WT littermates. Ook was er geen verschil in het aantal capillairen per hartspiercel ( $\mathrm{C} / \mathrm{F}$ ratio). Echter, inductie van een myocardinfarct in $\mathrm{FGF}$ 1 transgene muizen leidde tot een afname van de hoeveelheid collageen in het geinfarceerde myocardium, gepaard gaande met een toename van apoptosis, vergeleken met WT muizen. Verrassend genoeg was de hartspierfunctie na infarct verslechterd ten gevolge van chronische FGF-1 overexpressie. Wij concluderen dat FGF-I overexpressie leidt tot een verandering in remodeling na een infarct en gepaard gaat met een afname van hartspierfunctie.

Om de rol van $\mathrm{FGF}-$ ] overexpressie bij ischaemie en reperfusie te onderzoeken, werden harten van FGF-I transgene muizen en hun WT littermates 
geprepareerd in het ex vivo, geisoleerd muizenhart-model voor ischaemie en reperfusie (hoofdstuk 6). Ook hier werd continu hartspierfunctie gemeten en coronair effluent opgevangen voor biochemische bepalingen. FGF-1 overexpressie induceerde een spectaculaire verbetering in het herstel van hartspierfunctie tijden reperfusie na een ischaemische periode ( 25 minuten). Ook was ischaemie-geinduceerde necrotische celdood sterk gereduceerd ten gevolge van FGF-1 overexpressie. Om het intracellulaire mechanisme van FGF-1 gerelateerde cardioprotectie te kunnen determineren, werden wederom enkele signaaltransductie eiwitten selectief farmacologisch geïnhibeerd. Inhibitie van de FGF-receptor (FGF-R1), PKC en tyrosine kinases (TK) resulteerde in een complete verdwijning van de FGF-1 gemedieerde protectie. Het herstel van hartspierfunctie na ischaemie van inhibitor-behandelde FGF-1 transgene muizen was vergelijkbaar met (on)behandelde WT littermates. Echter, alleen inhibitie van PKC kon het protectieve effect van FGF-1 op necrotische celdood gedeeltelijk ongedaan maken. Concluderend kunnen wij stellen dat FGF-1 de tolerantie voor schadelijke effecten van ischaemie op hartspierfunctie verhoogt, en dat deze bescherming gemedieerd wordt via de FGF-receptor, PKC en tyrosine kinases. FGF-1 gemedieerde bescherming tegen $1 / R$ geinduceerde celdood is gedeeltelijk afhankelijk van PKC, echter FGF-RI en TK-onafhankelijk.

In het laatste hoofdstuk van dit proefschrift (hoofdstuk 7) worden de resultaten van het experimentele werk in het licht geplaatst van de hedendaagse literatuur $_{f}$ en worden de klinische implicaties van deze resultaten voor toekomstige groefactor therapie bediscussieerd. 


\section{Dankwoord}

Eind 1997 kreeg ik de kans om wetenschappelijk onderzoek te gaan doen bij CARIM. Na enige aarzeling ben ik aan deze kruistocht begonnen, en nu, bijna 5 jaar later hebben deze inspanningen geleid tot de verdediging van dit proefschrift. Op de weg van student Geneeskunde naar gepromoveerd arts ben ik veel mensen tegengekomen die ervoor gezorgd hebben dat dit pad wat malkkelijker te bewandelen viel. Deze mensen wilde ik hier bedanken;

Allereerst mijn promotoren; prof. dr. M.J. Daemen. Beste Mat, toen ik enkele jaren groen als het spreekwoordelijke gras bij jou binnen stapte, heb jij mij meteen wegwijs gemaakt in de wereld die onderzoek heet. Niet alleen door zo nu en dan sturend op te treden, maar ook door mij zelf de zaken uit te laten zoeken, met ideeën te laten komen om de zich voordoende problemen op te kunnen lossen. De maandagochtend besprekingen waren behalve erg vroeg, ook iedere keer zowel leerzaam, stimulerend als confronterend. Vij hebt altijd geloofd in mijn kunnen, en mij in de moeilijke perioden die ellke AlO wel eens doormakkt weten te overtuigen om door te zetten. Jij hebt mij altijd weten te stimuleren en motiveren en had niet alleen oog voor mijn wetenschappelijke prestaties, maar had ook belangstelling voor mijn studie resultaten en andere zaken op het persoonlijke vlak. Samen met Pieter Doevendans waren jullie een geweldig team. Ik ben je enorm dankbaar voor deze fijne tijd en ik hoop dat we in de toekomst nog veel samen zullen werken.

Prof. Dr. H.J.J. Wellens; Ik wilde $u$ hartelijk danken voor de stimulerende discussies over mijn proefschrift. $U$ bent altijd geïnteresseerd geweest in mijn wetenschappelijke prestaties en de presentaties op de AHA werden vooraf zorgvuldig door u beoordeeld en zo nodig bijgeschaafd. Hartelijk dank hiervoor.

Dr. P.A. Doevendans (co-promotor); Beste Pieter; Als lid van het promotieteam Doevendans/Daemen was jij de motor achter mijn wetenschappelijke werk. Door jouw nooit aflatende enthousiasme en ideeën-stroom wist jij mij als geen ander te stimuleren en te prikkelen om verder te ontdekken en dieper te graven. Jouw werklust en energie hebben mij dan ook altijd sterk geinspireerd. Ook jij nam ondanks je bezigheden in de kliniek altijd de tijd om mijn wetenschappelijke voortgang te bespreken, maar ook om een luisterend oor te bieden voor andere problemen, waar je als jonge arts/onderzoeker tegenaan (!) loopt. Ik vind het jammer dat je Maastricht ondertussen hebt verlaten, maar ben ervan overtuigd dat je in Utrecht een mooie carriere als hoogleraar mole- 
culaire cardiologie tegemoet gaat. Ik hoop dat wij elkaar nog vaak zullen tegenkomen, zowel op klinisch wlak als bij verdere onderzoeksactiviteiten. Beste Pieter, hartelijk dank voor alle steun en hulp die je mij al die jaren hebt geboden. Zonder jou was dit alles niet gelukt.

Geachte leden van de beoordelings-commissie; Prof. Dr. B. Mochtar, beste Bas, ik zie er naar uit om onder uw leiding te werken binnen de afdeling cardio-thoracale chirurgie als cardiothoracaal chirurg in opleiding. Dank voor voor beoordeling van dit proefschrift. Ook de andere leden van de beoordelingscommissie wilde ik danken voor het kritisch doorlezen van mijn proefschrift; Prof. Dr. A. van der Laarse, Prof Dr. M. Borgers, Prof. Dr. M. Post and Prof. Dr. W. Schaper, hartelijk dank voor uw bijdrage aan mijn promotie.

Mijn paranimfen: Luc Palmen en Ward Vanagt;

Luc, als neef(je) ben je altijd een van mijn beste vrienden geweest. We hebben zowat onze gehele jeugd samen doorgebracht en ik denk nog met veel plezier terug aan alle "avonturen" die we samen beleefd hebben. Jij bent door de jaren altijd mijn maatje geweest en daarom wilde ik jou hier als paranimf aan mijn zijde hebben.

Beste Ward; wij hebben elkaar ontmoet in ons eerste jaar en zijn in de loop van de jaren goede vrienden geworden, met als een van de hoogtepunten onze survival-tocht in de Schotse hooglanden. De fotos spreken voor zich. Een lift versieren met gitaar en zang en slapen in schapenstallen... Ik bewonder je levensinstelling, je aandacht voor anderen en je "joie de vivre". We zullen nog veel samen reizen als het aan mij ligt. Veel succes met promoveren en met je opleiding tot kinderarts (kinder-cardioloog misschien?)

Dr. J.G. Maessen; beste Jos, ik ben als eerstejaars Geneeskunde student naar je toe gekomen met de wens een hartoperatie bij te kunnen wonen. Vanaf dat moment ben ik gefascineerd geraakt door dit vak. I $\mathrm{k}$ wilde cardio-thoracaal chirurg worden. In de hierop volgende jaren ben je altijd op de achtergrond aanwezig geweest en heb je mij geholpen om in mijn carriere de juiste stappen te zetten om dit doel te bereiken, door mij te stimuleren en mij soms paradoxaal genoeg, een beetje af te remmen. Ik wilde je bedanken voor deze hulp en hoop in de toekomst veel van je te kunnen leren, zowel op klinisch vlak, als op het gebied van onderzoek.

Mijn eerste stappen in het onderzoek heb ik gezet bij de groep van Dr. Ir. Erik van der Veen, alwaar ik met veel plezier enkele jaren als student-assistent heb gewerkt. Het was een geweldige en ook leerzame tijd. Een beetje knutselen 
hier en daar, en af en toe achter een op hol geslagen varken aanjagen. En altijd in een ongedwongen sfeer. De anderen die hieraan hebben bijgedragen zijn Theo van der Nagel, Jo Habets, Jet, en Ruud Kruger. Ook de periode als student-assistent onder leiding van dr. Frits Prinzen heb ik als zeer leerzaam ervaren. Hartelijk dank voor deze leerzame en leuke tijd.

En dan zijn er natuurlijk alle collegas op de verschillende vakgroepen, waarmee $\mathrm{ik}$ in de loop van de jaren in aanraking ben gekomen. Enkele van hen wilde ik met naam noemen;

Pathologie: Esther Lutgens, mijn partner in de queeste nar de doctorstitel (samen met Jeroen Kloover). Jij bent in de loop der jaren uitgegroeid tot een fantastische onderzoekster en daarnaast konden we af en toe goed onze frustraties met elkaar bespreken. Mijn kamer-genoten en mede-onderzoekers Birgit (Birrie the Best), Esther Creemers (the Hip), Cherida (de zwarte parel van de pathologie), Sylvia (western-blot queen), Robert-Jan (partner in het kwaad), Kitty Cleutjens, Ann-Pascale, Suzanne, Linda, Kitty, Natacha en de analysten Monique, Anique, Petra en Wendy wilde ik bedanken voor de gezellige tijd en de noodzakelijke hulp bij vele experimenten. Ook Jack Cleutjens, Cor Beek en Elly van Essen hebben een belangrijk steentje bijgedragen tot de totstandkoming van dit proefschrift.

Fysiologie: De koning van de geisoleerde muizenhart-perfusies, Jodil Willems, heeft mij met de nodige humor de kneepjes van het vak bijgebracht en mij geholpen bij het ontwerp van de kaft (kapje kaffie) van dit proefschrift. Dr. Marc van Bilsen en Peter Willemsen wilde ik danken woor de hulp bij de "ex vivo" experimenten.

Moleculaire cardiologie: Dr. Leon de Windt, naast je deskundige hulp bij het "moleculaire werk" was het met jou ook uitstekend toeven op congressen, zoals in Salt Lake City, alwar we danig gefrustreerd met beide benen op de grond werden gezet door al het wetenschappelijk geweld aldaar. Eva, Vanessa, Fawzi, Els, Reinier, Sigmund, Xander en Daan, bedankt voor de gezellige tijd en nu zijn jullie aan de beurt om de "s" weg te poetsen. Zonder de hulp van Chiel de Theye, Alexandra Buehler en Ronald Bronsaer was dit proefschrift niet zo snel tot stand gekomen, hartelijk dank hiervoor. De statistische kennis en kunde werd verstrekt door Dr. W Dassen (page-number Pim). Beste Pim, New Orleans is een geweldige stad en dat de AHA meeting daar ook toevallig plaatsvond, was mooi meegenomen. Ook de secretaresses van de cardiologie, 
(en met name Nicole) verdienen een woord van dank voor het regelen van 1001 zaken.

Farmacologie: Prof, Dr. Jos Smits; hartelijk dank voor alle hulp en voor de mogelijkheid om op jouw lab mijn infarct-studies te mogen doen en voor de vaak verhelderende discussies over miln werk. Peter, Jacques en Nicole, bedankt woor de lessen in de muizen-hartchirurgie en voor het verrichten van de vele (!) functiemetingen.

AV dienst: Beste Geertjan en alle anderen, hartelijk dank voor de (vaak) snelle service als ik weer eens met een "spoedgeval" bif jullie kwam aankloppen. GJ, ook bedankt voor de vakkundige lay-out van dit proefschrift.

CPV: Ik wilde dr. Ton van den Boogaard, Peter, en met name Paulien bedanken voor het verzorgen van mijn muizen.

En dan zijn er natuurlijk nog mijn vrienden; Eilen, we hebben elkaar in ons derde jaar ontmoet en sindsdien hebben we een geweldige vriendschap ontwikkeld. Veel succes met je opleiding tot Internist. Nadine, onze vriendschap is onbetaalbaar. Mijn volleybal-maatjes; Tim (Tim-Slushy alias caesar, de ontdekkingsreiziger onder de evenaar), Martin (Hoorne, de man van de gortdroge humor op de meest onverwachte momenten) Rob en Nina, Rob (Boemboem Bouman] en Corinne, Dennis, Bart en Fenna, Carla, Marieke, Anke, Andrea + Bas, Loek (mentor], Bas B. Bedankt voor de geweldige tijd en jullie begrip als ik weer eens moest werken. Tamir, our friendship goes beyond boundaries and religion. I wish you all the best in life. Verder zijn er nog mijn collegas bij de CTC die het werk aldaar een stuk gezelliger maken. Zonder anderen tekort te doen wilde ik graag de volgende mensen bedanken; Gijs, Ted, Kees, Paul, Jindra, Vincent, Jeroen Jeurissen (Jezeker, het dynamisch duo op de afdeling), Jan Nijs, Cecile, Barry, Jérôme, Colette, Nancy, Ria, Marion, Nicol, Andrea, Theo, Jo, Marielle, en alle andere collega's op D4.

En als laatste natuurlijk mijn familie; lieve pap en mam, zonder jullie had ik hier niet gestaan, en was ik ook niet geworden tot de persoon die ik nu ben. Jullie stimulans, advies en levenservaring zijn nog steeds van onschatbare waarde voor mij. Bedankt voor alles dat jullie mij gegeven hebben. Beste Pim. (en Manon) (we staan er weer met zijn tweeën... niet alleen een fantastische broer, maar ook mijn beste vriend) en Ward (ons muzikale wonder), jullie zijn geweldige broertjes, die altijd voor mij klaar staan op mooie en minder mooie momenten. 


\section{Curriculum Vitae}

Meindert Palmen werd op 25 juni 1976 geboren te Heerlen. Na het behalen van het VWO diploma op het Eijckhagen college te Landgraaf (1988-1994) volgde hij de studie Geneeskunde aan de Universiteit Maastricht (Propaedeuse 1995). Tijdens de doctoraalfase Geneeskunde (1994-1998) (cum laude), werkte hij enkele jaren als student assistent bij Dr. Ir. van der Veen (afd. Cardio-thoracale chirurgie) en voor Dr. F. Prinzen (Fysiologie). Eind 1997 begon hij het onderzoek als student-AlO onder leiding van Dr. P.A. Doevendans (Cardiologie) en Prof. Dr. M.J. Daemen, waaruit dit proefschrift tot stand is gekomen. Tijdens de studie geneeskunde deed hij een stage hartchirurgie te Haifa (Israel) onder leiding van Prof. Dr. G. Uiretzky en Dr. G. Bolotin, en een stage kinder-hartchirurgie aan het Thorax Center Rotterdam, onder leiding van Prof. Dr. A.J.J. Bogers. Na het behalen van het Art-examen Geneeskunde in 2001 (cum laude) werkte hij gedurende een jaar als AGNIO op de afdeling Cardiothoracale chirurgie in het AZM. Hij zal begin 2003 onder leiding van Prof Dr. B. Mochtar en Dr. J.G. Maessen beginnen aan zijn opleiding tot cardiothoracaal chirurg bij de afdeling cardiothoracale chirurgie, AZM 


\section{Articles}

1. M.Pulmen, R van der Zee, M.J.A.P.Daemen, E.D.de Muinck, A.J.N.Lucassen, P.A.F.M.Doevendons: Cardac anglogenesis and growth factors. Cardiologie 1998;5:406-413.

2. M.Pelmen. M.J.A.P.Daemen, R.Bronsaer, W.R.M. Dassen, H.R. Zandbergen, M.Kackx, J.F.M.Smits, R. wan der Zee, P.A.F.M. Doevendans (2001): Cardiac remodeling after myacardial infarction is impaired in IGF- i deficlent mice. Cardiovasc. Res.; 50: 516-524.

3. M.Palmen, S.C. Bekkers. (2001): Scientific conference on therapeutic anglogenesis and laser revascularization, Neth. Heart. J,; 9:256-261.

4. A. Buenler, A. Martire, C. Strohm, S. Woltram, B. Fernandez, M. Palmen, X. Wehrens, P. Doevendans, W. Franz, W. Schaper, R. Zimmermann (2002): Anglogenesis-independent cardioprotection in FGF-1 transgenic mice. Cardiovasc. Res " $55: 768-777$.

5. M.Palmen, M.J.A.P.Daemen, A Buehler, R.J Bronscaer, D. Lips, R. Zimmermann, E.D. de Muinck, M. van Eickels, M.A. Kockx, J.F.M. Smits, P.A.F.M. Doevendans: Cardiac-specific FGF1 overexpression of hFGF-1 deteriorates cardiac function and alters cardiac remodeling following chronic myocardial infarction. (submitted)

6. M. Palmen, M.J. Daemen, J. Willems, R.J. Bronsaer, P. Willemse, S. Heeneman, M. Vertuyten, W.R. Dassen, M. van BIlsen, PA. Doevendans : FGF-1 Improves cardiac functional recovery and enhances cell survival following ischemia and reperfusian; a FGF-R1, PKC and tyrosine kinase dependent mechanism. (submilted)

7. M.Palmen, M.J. Daemen, J.Willems, R.Willemse, W.R.Dassen, M.van Bilsen, P.A.Doevendans: IGF-1 Improves cardlac functional recovery and enhances cell survival during ischemila and reperfusion: A PI-3K and PKC mediated mechanism. (submitted) 


\section{Abstracts}

1. Histologic and electrocardiographic alterations in the chronically paced dog heortPalmen M.. Vanagt W.Y.R, Oosterhout M.F.M van, Prinzen FW. Dep. of Physiology Maastricht University, CARIM. (MMSRC, march 1997).

2. Preservation of cardiac function despite reduced capiliarization offer myacardial inforction in [GF-1 deficient mice. M.Paimen, M.J.A.P.Doemen, R.Bronscer, J.Debets, P.Leenders, J.F.M.Smits, P.A.F.M. Doevendans. Dept. Cardiology, Pathology and Pharmacology CARIM, Magstricht. JACC val 33, 344A, March 1999.

3. Impaired cardiac remodeling of IGF-1 deficient mice after myocardial infarction. M.Palmen, Bronsaer RJP, Smits JFM, Daemen MJAP, Doevendans PAFM. Dept. of Cordiology, Pharmacology and Pathology, CARIM, Maastricht University, The Netherlands. JMCC vol 31 No.6 june 1999.

4. Preserved cardiac function despite impaired cardiac remodeling following myocardlal intarction in IGF-1 deficient mice. Piefer A. Doevendans1, Meindert Palmen 1, Ronald Bronsaer1, Jos F. Smits2, Mat J. Daemen3. Dept. Cardiology1, Pharmacalogy2 and Pathology3, CARIM. Scientific Conference on Molecular, Celliular, and Integrated Physlological Approaches to the Falling Heart. Salt Lake Clty, Utah, August 18-22 1999.

5. Cordiac-specific FGF-1 overexpression results in deterioration of cardiac function and altered remodeling after experimental myocardial infarction. M.Palmen, M.J.Daemen, A.Buehler, R.Bronsoer, R.Zimmermann, J.F.Smits, P.A.Doevendans. GARIM, The Metherlands. Scientiflc Conference on Molecular, Cellular and Integrated Physialogicalapproaches to the Falling Heart, Salt Lake Clity, Utah, August 18-22 1999. (Winner AHA New Investigators award.

6. Cardiac-speclfic FGF-1 overexpression results in deteriorotion of cardiac function and altered remodelingafter myocardial infarction. M. Palmen, Mat J. Daemen, Alexandra Buehler, Ronald Bronsaer, Rene Zimmermann, Jos F. Smits, Pleter A Doevendans. CARIM, Maastricht, the Netherlands. NVVC 1999.

7. Cardiac function and remodeling following MH in FGF-1 transgenic mice. Transgeneur meeting oktober 1999. Edinburgh.

8. Impaired cardiac remodeling and function after myocardial infarction in FGF-1 transgenic mice. Meindert Palmen, Mat J.Doemen, Alexandra Buehier1, Ronald J. Bronsaer, Rene Zimmermann1, Jos F.M. Smits, Pieter A. Doevendans. CARIM, Madastricht, the Netherlands, Max Planck Institute T, Bad Natheim, Germany. Circulation vol. 100 (78) 1999 (Suppl I) (Oral presentation at the American Heart Meeting, Atlanta 8 now. 1999)

9. FGF-1 protects the myocardium during ischemia and reperfusion through a tyrosine kinase and protein kinase $C$ dependent pattiway. Meindert Palmen, Mat $\downarrow$ J. Daemen, P. Willemse, Ronald J. Bronsaer, Jodll Willems, Rene Zimmermann1, Marc van Bilsen, P.A. Doevendans, CARIM Maostricht, the Netherlands, Max Pionck Instifute 1, Bod Nauheim, Germany. Circulation vol. 102 (18) 2000 (suppl il) (Oral presentation at the American Heart Association meeting, New Orleans, 14 nov. 2000)

10. FGF-1 protects the myocardlum during ischemia and reperfusion. M. Palmen, M.J. Daemen, J. Willems, P. Willemse, Ch. De Theije, R. Bronsaer, S. Heenemon, M.van Blisen, P. Doevendans. Presented at the AHA scientific conference on therapeutic anglogenesis and myocardial leser revascularization, Jan 24-27, 2001, Santa Fe, New Mexico.

11. Fibrablast growth factor-1 protects the myocardium during ischemia and reperfusion. $M$. Palmen, P.A. Doevendans, M.J. Doemen, M. Van Bilsen, B. Mochtar, J.G. Maesisen. CARIM Maastricht. (gepresenteerd op de NVTC, 26 aprli 2002). Neth. Heart. J.; 10:suppl. 1 pp 25. 


\section{Abbreviations use in this thesis}

\begin{tabular}{|c|c|}
\hline $\mathrm{aFF}$ & adidic Fibroblast Growth Factor (FGF-1) \\
\hline$A N \mathbb{F}$ & atrial natriuretic factor \\
\hline ATP & adenosine-triphosphate \\
\hline bFGF & basic Fibroblast Growth Factor (FGF-2) \\
\hline $\mathrm{CABG}$ & coronary artery bypass grafting \\
\hline $\mathrm{CHE}$ & chelerythrine (PKC inhibitor) \\
\hline $\mathrm{DAG}$ & diacylglycerol \\
\hline $\mathrm{ECM}$ & extracellular matrix \\
\hline ERK & extracellular responsive kinase \\
\hline PGF $-\mathrm{R}$ & fibroblast growth factor receptor \\
\hline $\mathrm{GH}$ & growth hormone \\
\hline HSP & heat-shock protein \\
\hline HSPG & heparan sulfate-containing proteoglycans \\
\hline $\mathrm{IGF}$ & insulin-like growth factor \\
\hline $\mathrm{IGF}-\mathrm{BP}^{\mathrm{B}}$ & insulin-like growth factor binding protein \\
\hline IGF-R & insulin-like growth factor receptor \\
\hline IP & ischemic preconditioning \\
\hline IRS & insulin-like growth factor receptor substrate \\
\hline $\mathbb{I} / \mathbb{R}$ & ischemia and reperfusion \\
\hline JNK & c-Jun $\mathrm{NH}_{2}$-terminal kinase \\
\hline KATPchannel & ATP-dependent potassium-channel \\
\hline $\mathrm{KO}$ & knock-out \\
\hline LA & lavendustin- $A(T K$ mbibitor $)$ \\
\hline MAPK & mitogen activated protein kinase \\
\hline $\mathrm{M} \|$ & myocardial infarction \\
\hline MMP & matrix metallo proteases \\
\hline MRI & magnetic resonance imaging \\
\hline$N F=\mathbb{K B}$ & nuclear factor kappa-B \\
\hline NO & nitric oxide \\
\hline NOS & nitric oxide synthase \\
\hline NYHA & New York Heart Association \\
\hline PDGF & platelet-derived growth factor \\
\hline pERK & phosphorylated ERK \\
\hline pJNK & phosphorylated JNK \\
\hline PI-3K & phosphatidy]-inositol-triphosphate kinase \\
\hline PLCY & phospholipase- $\mathrm{C} \gamma$ \\
\hline $\mathrm{PKC}$ & protein kinase $C$ \\
\hline PMA & Phorbol-12-myristate-13-acetate \\
\hline
\end{tabular}


PTCA

RACK

RAS

$\mathrm{SH}-2$

SU

TGF

TK

VEGF

WT percutanous transluminal coronary angioplasty receptor for activated kinases

renin-angiotensin(-aldosteron) system rhrecombinant human Src homology 2

SU5402 (FGF-RI inhibitor)

transforming growth factor

tyrosine kinases

vascular endothelial growth factor

wild-type ( $=$ non-transgenic control animal) 